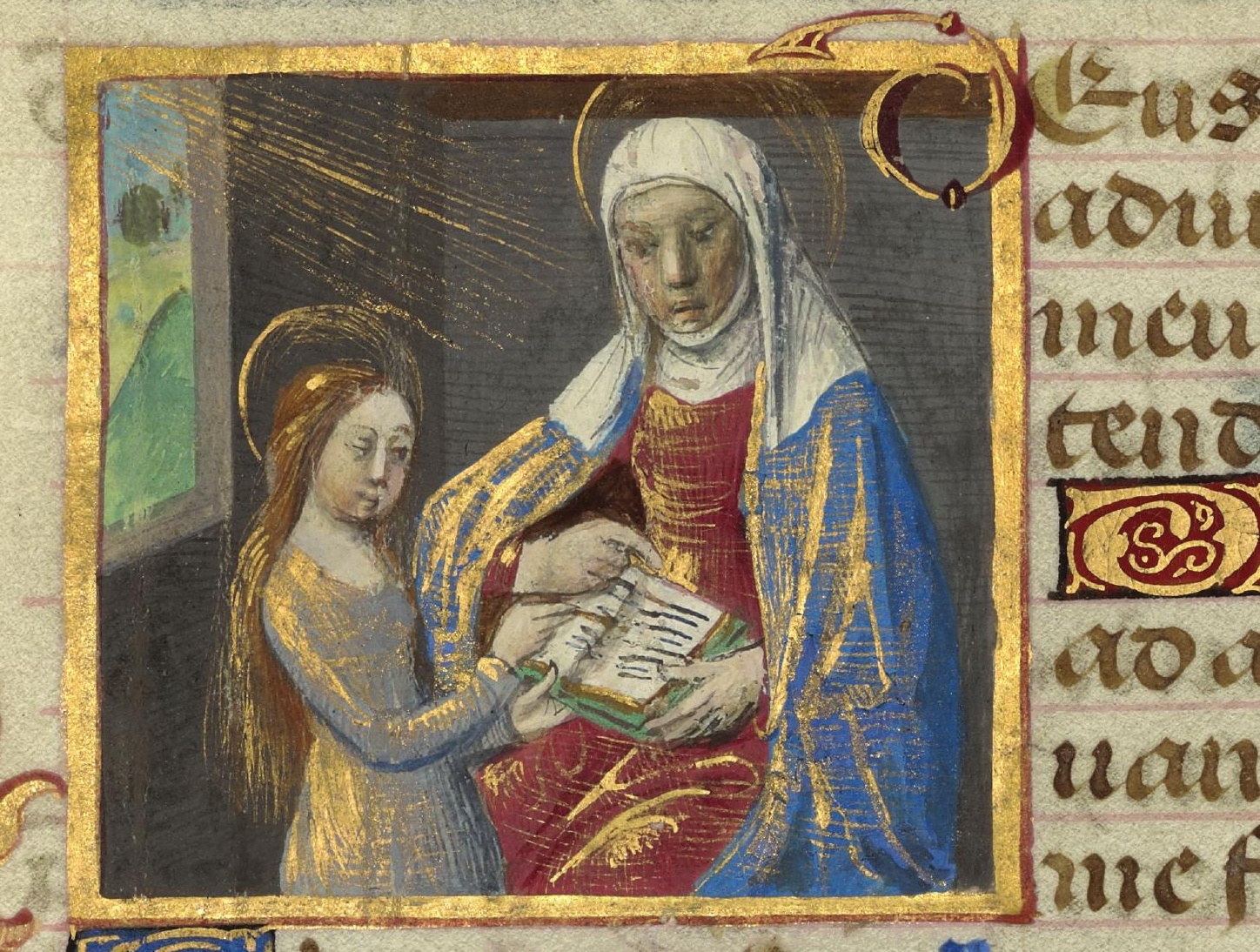
$2 \sqrt{6.5102 t a}$ patat. $72 m m$

\title{
Participatory reading in late-medieval
} England

HEATHER BLATT 


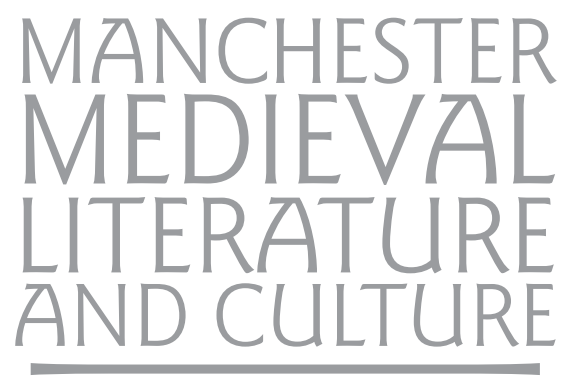

PARTICIPATORY READING IN LATE-MEDIEVAL ENGLAND

\section{MANCHESTER 1824}

Manchester University Press 
Series editors: Anke Bernau, David Matthews and James Paz

Series founded by: J. J. Anderson and Gail Ashton

Advisory board: Ruth Evans, Nicola McDonald, Andrew James Johnston, Sarah Salih, Larry Scanlon and Stephanie Trigg

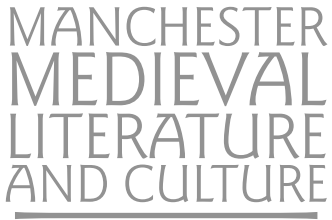

Manchester Medieval Literature and Culture publishes monographs and essay collections comprising new research informed by current critical methodologies on the literary cultures of the Middle Ages. We are interested in all periods, from the early Middle Ages through to the late, and we include post-medieval engagements with and representations of the medieval period (or 'medievalism'). 'Literature' is taken in a broad sense, to include the many different medieval genres: imaginative, historical, political, scientific, religious. While we welcome contributions on the diverse cultures of medieval Britain and are happy to receive submissions on Anglo-Norman, Anglo-Latin and Celtic writings, we are also open to work on the Middle Ages in Europe more widely, and beyond.

\section{Titles Available in the Series}

6. A knight's legacy: Mandeville and Mandevillian lore in early modern England Ladan Niayesh (ed.)

7. Rethinking the South English Legendaries Heather Blurton and Jocelyn Wogan-Browne (eds)

8. Between earth and heaven: Liminality and the Ascension of Christ in Anglo-Saxon literature Johanna Kramer

9. Transporting Chaucer

Helen Barr

10. Sanctity as literature in late medieval Britain

Eva von Contzen and Anke Bernau (eds)

11. Reading Robin Hood: Content, form and reception in the outlaw myth Stephen Knight

12. Annotated Chaucer bibliography: 1997-2010

Mark Allen and Stephanie Amsel

13. Roadworks: Medieval Britain, medieval roads Valerie Allen and Ruth Evans (eds)

14. Love, history and emotion in Chaucer and Shakespeare: Troilus and Criseyde and Troilus and Cressida

Andrew James Johnston, Russell West-Pavlov and Elisabeth Kempf (eds)

15. The Scottish Legendary: Towards a poetics of hagiographic narration Eva von Contzen

16. Nonhuman voices in Anglo-Saxon literature and material culture James Paz

17. The church as sacred space in Middle English literature and culture Laura Varnam

18. Aspects of knowledge: Preserving and reinventing traditions of learning in the Middle Ages

Marilina Cesario and Hugh Magennis (eds)

19. Visions and ruins: Cultural memory and the untimely Middle Ages Joshua Davies 


\section{Participatory reading in late-medieval England}

HEATHER BLATT

Manchester University Press 


\section{Copyright (C) Heather Blatt 2018}

The right of Heather Blatt to be identified as the author of this work has been asserted by her in accordance with the Copyright, Designs and Patents Act 1988.

Published by Manchester University Press

Altrincham Street, Manchester M1 7JA

www.manchesteruniversitypress.co.uk

British Library Cataloguing-in-Publication Data

A catalogue record for this book is available from the British Library

ISBN 9781526117991 hardback

ISBN 9781526118004 open access

First published 2018

This electronic version has been made freely available under a Creative Commons (CC-BY-NC-ND) licence. Details of the licence can be viewed at https://creative commons.org/licenses/by-nc-nd/3.0/

The publisher has no responsibility for the persistence or accuracy of URLs for any external or third-party internet websites referred to in this book, and does not guarantee that any content on such websites is, or will remain, accurate or appropriate.

Typeset by

Servis Filmsetting Ltd, Stockport, Cheshire 


\section{Contents}

Introduction: Reading practices and participation in digital and medieval media

\section{Part I: Participatory discourse}

1 Corrective reading: Geoffrey Chaucer's Troilus and Criseyde and John Lydgate's Troy Book

2 Nonlinear reading: the Orcherd of Syon, Titus and Vespasian, and Lydgate's Siege of Thebes

\section{Part II: Evoking participation}

3 Reading materially: John Lydgate's 'Soteltes for the coronation banquet of Henry VI'

4 Reading architecturally: the wall texts of a Percy family manuscript and the Poulys Daunce of St Paul's Cathedral 128

5 Reading temporally: Thomas of Erceldoune's prophecy, Eleanor Hull's Commentary on the penitential Psalms, and Thomas Norton's Ordinal of alchemy

Conclusion: Nonreading in late-medieval England

Appendices

Bibliography $\quad 235$

Index 


\section{Acknowledgements}

As will surprise no readers of a work focused on participation, its production involved the support and contributions of many members of my family, friends, and communities of colleagues. I would like to thank them for their aid and contributions, great and small.

To Mary Erler, Martin Chase, Mary Bly, and Jocelyn WoganBrown, who read and commented on the nascent version of this book when it began life as a dissertation, most sincere thanks. My grateful appreciation goes to James Sutton, Nathaniel Cadle, Jason Pearl of the Department of English at Florida International University for welcoming me when I arrived, and supporting me in the years that have followed as I laboured to bring this book to fruition. Jason and Nathaniel, to you, Nandini Dhar, Martha Schoolman, Wanda Raiford, and Vanessa Sohan, I offer my heartfelt thanks for wise counsel, helpful feedback, and timely prodding. I would also like to thank Tovah Bender for critical insights on the framing of this book, and Mary Flannery and Carrie Griffin for their suggestions on a chapter, and the encouragement their interest provided to my work on the whole. To other colleagues and friends, Janice McCoy, Erika Harlitz Kern, Rhona Trauvitch, Allison Adair, Mary Kate Hurley, and Sarah Noonan, thank you for wading through drafts early and late, and offering the insights and suggestions that improved it immeasurably. My appreciation to Elizaveta Strakhov for her enthusiasm over my naming of 'extracodexical texts', which inspired me to engage in the timely and necessary revision needed to incorporate it here. To Lois Swales, who worked with me on a project that became the seed that led me to study medieval reading practices, thank you. Maija Birenbaum assisted me with some tricky bits of the French of England, for which I'm very appreciative. For brief, but influential comments at conferences that encouraged me to continue work at pivotal 
moments, I thank Robert Yeager, Michael Sargent, Holly Crocker, Martin Foys, Julia Boffey, and Christopher Baswell.

My appreciation extends to the staff members who assisted me at the Morgan Library \& Museum, the Newberry Library, the British Library, the Bodleian Library, and the Special Collections department at the University of Chicago. Finally, to the editors and anonymous readers at Manchester University Press, my thanks for your feedback, which helped to make this a better book.

An early version of Chapter 4 appeared in Spaces for reading in later medieval England, ed. Mary C. Flannery and Carrie Griffin (London: Palgrave MacMillan, 2016), as 'Mapping the Readable Household'. 
Heather Blatt - 9781526118004 Downloaded from manchesterhive.com at 04/26/2023 ๑6:39: ๑०AM 


\section{Introduction: \\ Reading practices and participation in digital and medieval media}

'Where is the moralizynge?' So asked a friend of the early fifteenthcentury clerk and writer Thomas Hoccleve when shown a copy of Hoccleve's newly translated poem 'Jereslaus' Wife'. Hoccleve describes this exchange in his long poem Dialogue, in which he explains that he had 'endid' the tale a 'wike or two' before his friend visited. Taking up the work, the friend read the poem eagerly, but objected to its ending. After storming home for his copy of Hoccleve's source, the friend returned, book in hand, to regale Hoccleve with the moral. In response, Hoccleve adds it following the end of his poem. ${ }^{1}$

The interaction Hoccleve describes represents one of the underreported ways in which medieval readers could participate in the development of texts. Hoccleve clearly views his work in translating and composing the tale as finished and complete before his friend confronts him with an alternative view of the work that prompts Hoccleve to add the interlude and the moralizing. He then identifies the moral as an addition for which his friendly reader holds responsibility. His friend's participation alters both the text itself, through the provision of an explicit moral, and Hoccleve's own nascent role as author. This alteration enacted through participation responds to the reader's casual assumption that he possesses authority sufficient to counter Hoccleve's own authority. Neither he nor Hoccleve view the writer as the sole determinant of the work. Instead, his friend asserts authority as a reader to contribute to Hoccleve's work, and the friend's suggestions lead to its modification.

This relationship Hoccleve depicts between a writer who accepts and responds to the authority of a reader occurs at a critical moment in the history of medieval English literature. From the late fourteenth to the early sixteenth centuries, expanding literacy among the upwardly mobile mercantile and professional classes 
of England created new audiences desirous of vernacular reading material. At the same time, writers approached composition in Middle English with increasing interest and vigour, exploring the shifting boundaries of their role in the transition from the medieval writer - subordinate to the creativity and influence of the authorities of antiquity - to the modern notion of the author as the sole creator of unique works.

To the culture of late-medieval England that witnessed the rising prominence of poetry, and the growing facility of the English vernacular, both writers and readers contributed in fundamental ways, among which can be included the shaping of their own roles. Although the transition of the medieval writer into the modern author, with a modern author's understanding of authority and creative ownership of a text, has been well studied, the reader plays an often overlooked, albeit central role. For, among the topics to which late-medieval English writers repeatedly turn when considering both their authority and that of their texts, the issue of what readers, not just writers, should do develops as a central concern. This both recognizes the identity of an English reading public, as Katharine Breen has discussed, while building on that recognition to consider what the lay vernacular reader could and might do. ${ }^{2}$ Hoccleve's friend did not volunteer this response to Hoccleve's work without context or precedent: Writers in latemedieval England imagine readers as possessing the authority to change the text, turn a page, or move away from a work, all modes of participation, and they established a discourse that emphasized these and other modes of readers' participation. Along with recognizing readers' capabilities, writers also recognize both the potential and the threat offered by this participation to support or undermine writers' own authority. In other words, the attention paid to writerly authority is incomplete without attending to its complement, readerly authority; one cannot understand medieval writers without understanding also medieval readers, their relations to each other, and the profound role played by readers - both through the ways writers anticipated their participation, and as readers effected it. It is this subject of participation that provides the basis for this study, and offers a needed corrective to a view of medieval literature dominated by the role of writers. How was the participation of readers elicited by writers and texts? What readers were invited to participate? And what did their participation achieve for themselves or others? 
The context: reading, participation, and agency

The central subject of this project thus focuses on participation, a concept for which I am indebted to digital media studies. Perhaps because of the autobiographical self-interest of a writer raised in a print-centric culture but currently inhabiting a culture impacted by a new technology of writing and reading technology, I find great interest in studying a culture on the cusp of a parallel, earlier change. Yet beyond the bounds of self-interest, digital media can offer much to those studying media studies, literary culture, and book history in the late Middle Ages. In digital media, participation relates to interaction, which together have been used to emphasize the ground-breaking nature of the digital, initially perceived as setting 'new' media aside from 'old' media. While that divisive view has since diminished in the current approaches of digital media studies, which recognize greater continuity among historical forms of media, the attention given to participation still proves beneficial for current work. Henry Jenkins, who coined the term 'participatory culture', offers a useful distinction between participation and interaction, which might otherwise seem synonymous. Interaction is mediated by tools; clicking a link that takes one from one web page to another constitutes interaction. Participation, in contrast, develops through social relations, casting light upon not simply the technology, but also the culture it shapes and by which it is shaped. ${ }^{3}$ To use participation as a concept through which one can scrutinize a literary culture requires evaluating the processes and procedures that condition relations between, for example, medieval readers and writers, who interact through the technology of the manuscript or printed text. Participation thus creates the grounds for studying interactions among the different facets that contribute to medieval literary culture in general: writer-reader relations, the materiality of medieval manuscripts, reading practices, and the book as a technology.

In late-medieval England, developing participatory reading practices often centres around eliciting and guiding readers' choices. Consequently, the participatory reading practices I focus on can be described as 'proleptic' reading, which is determined in advance of the moment of reading. ${ }^{4}$ Writers recommend or use their texts to model a variety of practices that seek to elicit, shape, and frame the choices readers might make as they apprehend texts. Focusing on participation as a determining condition of medieval literary expression and interpretation enables a reframing of the 
traditional approaches to studying relationships between writers and readers and texts in medieval literary culture, in which the work and aims of writers occupy the centre frame, and readers are considered secondarily for the evidence they provide supporting assessments of those writers. In attending to participatory reading, it is readers who occupy the central role, and the work of writers supplies the evidence needed to understand perceptions about and constructions of readers' roles and capabilities in late-medieval literary culture.

Attending to the choices medieval readers were encouraged to make - and the choices they then chose to make - thus necessitates considering how writers anticipated that readers might express agency. ${ }^{5}$ Agency itself has generated much enthusiasm among critics of digital media. Such critics have viewed digitally mediated interaction and participation as anticipating and instantiating poststructuralist, postmodern theories of the open text. Representing the first wave of new media criticism, George Landow argued that hypertext, for example, 'provides an infinitely recenterable system whose provisional point of focus depends upon the reader, who becomes a truly active reader' by choosing the order in which to link together sections of a hypermedia work. ${ }^{6}$ In contrast, the experience of reading a novel or other traditional print text was perceived as supporting 'passive' reading, which conveyed readers from beginning to end of a work without necessitating their input. ${ }^{7}$ Criticism that partook of this and similar views thus often supported anxieties about the book, and even touted its demise. ${ }^{8}$

Yet such discourse has not gone unchallenged. Scholars of digital media have since resisted the liberatory and excessively democratizing rhetoric of earlier criticism to argue that digital media in many cases perpetuates, if not increases, restrictions on interactors. ${ }^{9}$ Considering such, Henning Ziegler highlights how digital media creates these restrictions through the very mechanism that had previously been lauded as the hallmark of digital media's liberation from the passivity and fixity of print: the hyperlink. Ziegler explains that 'The link necessarily partakes in a hegemonic framework that actually highlights the limits of choice rather than its possibilities.' 10 Ziegler emphasizes that, by creating coded links within a work of hypermedia, writers and designers restrict the ability of readers to determine extra- or intertextual connections for themselves. In consequence, the choices readers can easily effect are limited to the links presented to them. Ziegler's assessment does not stand alone. 
Critics now argue that digital media can disempower users and provide mechanisms for their restraint. For example, as one critic has observed, '[A] uthors may actually have more control over the work than in conventional fiction, where readers are free to read the end of the story first if they wish'. ${ }^{11}$ In the field of popular media, journalist Nicolas Carr turns to print history, and even the culture of medieval manuscripts, to argue that today's digital media negatively affect intelligence and attentiveness. ${ }^{12}$ As these and similar comments suggest, examining how participation functions in a particular work or media context can raise awareness of how its accompanying instructions or design can facilitate or restrict agency. These critiques, however, all too often elide use and the discourse and evidence of subsequent use, focusing instead on the technology in acts of technological determinism - suggesting that technology itself controls behaviour.

In contrast, I do not focus exclusively on the manuscript as the technology through which participation emerges. Rather, I examine how the social mediation of participation manifests through late-medieval English reading practices, which may rely on or function independently of manuscript technology. Indeed, many of the practices studied here continue well into the early age of print, and other practices rely on media other than the manuscript, giving rise to what I call - and discuss further in Chapter 3 as - 'extracodexical' texts. What takes centre stage in place of the manuscript and alternative media are the choices enjoined upon and elicited from readers through the activity of reading. I therefore offer an overarching argument about how the modes of participatory reading examined here represent practices elicited for and applied to socially contextualized purposes. As each of the chapters examines a particular practice, whether as modelled in a text, elicited from readers through the guidance of writers, or necessitated by the interpretive demands of texts themselves, I demonstrate how the medieval work of reading is viewed and enacted through readers' participatory work. In other words, I use connections between digital and medieval media to illuminate constructions of readers and reading practices; in so doing, I explore their contributory role in shaping late-medieval literary culture.

\section{Medieval media, digital media, and book history}

Tracing the affinities between participation in digital and medieval literary cultures situates the medieval as participating in the long 
history of media forms and practices. This project is not the only to have broken ground in exploring the relevance of the digital to the medieval; engaging with digital media criticism and theory has gained standing in recent years as scholars identify productive ways to initiate these cross-temporal studies. Martin Foys's Virtually Anglo-Saxon represents an early, influential pathbreaker that demonstrated how digital media might contrast usefully with medieval media in ways that demonstrated the historical specificity of each period's media. Focusing on one particular genre of digital and print media, the multi-threaded narrative, Andrew Higl explored how this genre might illuminate readers' ludic engagement with early manuscripts of the Canterbury Tales. With a similarly tight focus, Seeta Chaganti analysed virtuality in the medieval danse macabre. Chaganti argues that dance provided a metaphor for interpretation that evokes virtual reality in response to a single poem. These and Participatory reading in late-medieval England demonstrate that perspectives offered by interdisciplinary engagement with digital media studies continue to offer medieval studies productive ways of rethinking our assumptions about medieval literature and culture.

In particular, examining participation in late-medieval literary culture through the perspectives offered by digital media criticism and theory facilitates identification and evaluation of the processes and procedures that shaped how readers engaged with works, interpreted texts, thought of authors, and practised reading. Indeed, focusing on participation in late-medieval English literary culture reveals how commonly writers turn to participation as a mode of reading in order to envision possibilities for interaction among themselves, their texts, and their readers, and both facilitate as well as constrain those possibilities in order to try achieving ones viewed as desirable. This historical moment illuminates a period that categorically differs from that of previous periods in which vernacular, lay readers' participation is an occasional act, not a sustained focus of attention. Furthermore, how writers treat readers from the fourteenth to early sixteenth centuries anticipates and relates to many similar concerns in later literature, particularly in the current digital era. Consequently, the way that late-medieval writers anticipate, depict, model, and shape reader participation demonstrates a developing understanding of readers as participants, and a growing reliance upon and expectation of their participation - in other words, a literary culture focused on ways to make readers work. 
Analysing the role of reader participation in late-medieval English literary culture consequently provides an opportunity to inform the history of books and reading with the approaches of contemporary digital media theory and criticism. As the critic Thomas Pettitt has suggested when arguing for the idea of a 'Gutenberg Parenthesis', in which pre- and post-print media share more in common with each other than either does with print media, medieval literature and modern digital culture intersect in a variety of ways. As I trace these historical intersections of medieval and digital media studies through participatory practices, I show how experiences now perceived as characteristic of digital media, such as open emendation, nonlinear apprehension, and immersion, offer parallels to practices that emerge in the context of medieval reading.

To help provide a framework through which to identify and assess these practices, I thus turn to digital media criticism, in which studies of the 'new literacies' required by digital media have flourished. Reading has come under scrutiny in digital media studies partly because the remediation of texts into digital formats, along with the new possibilities for design and artistry in digital media, have led to questioning the nature of the reading experiences such works prompt. For example, in the iPad work Pry, whose creators identify it as both a novella and a 'book without borders', how much does the experience of apprehending it resemble reading when the work required involves not only comprehension of text, image, and video, but also manipulation of the screen via using one's fingers to 'pry' open the eyes of the paralysed main character? ${ }^{13}$ To help distinguish how digital media constitute and facilitate reading, one model of reading applied to digital media proposes distinguishing among three different, but overlapping acts: manipulation (the processes of handling a text), comprehension (understanding a work), and interpretation (the relationship between the text and the context, such as other texts, the reader applies to its explanation). ${ }^{14}$ As the term 'manipulation' suggests, critics view this reading act in relation to physical engagement with a text, whether in digital or print form; such an approach needs modification for the literacy conditions of the late Middle Ages, in which reading might not require physically engaging with a text. I refer to this task more generally as apprehension, which involves processes that can include but are not restricted to manipulation.

This methodology thus positions Participatory reading in latemedieval England as drawing on three disciplinary modes of 
investigation and analysis: book and reading history, manuscript studies, and digital media studies, to offer an argument situated within the inquiries of cultural studies. The consequences of my methodology have further bearing on how readers and critics of medieval and media culture can engage with connections between historically distant moments and works. As Eileen Joy and Myra Seaman say of studies that read the past through the present, such approaches 'reveal mentalities and social customs that persist over long durations of time, as well as certain sensual particularities unique to their respective times of production and reception' ${ }^{15}$ The digital and the medieval may here be separated by more than five hundred years, but the uniqueness of one period can help identify and extend our understanding of the uniqueness of another. Examining these persistent analogues is not to treat them as simple parallels surprisingly shared by two cultures. Instead, these resonances between media practices today and in the late Middle Ages become points of departure for exploring participatory reading practices within a specific historical environment: that of England from the late fourteenth to the early sixteenth centuries, during which period writers from Chaucer to Caxton and beyond consider what it means to be a reader in ways that centre around eliciting participation, guiding it, and discouraging it. Furthermore, my approach casts light on how the reading practices that shaped late-medieval literary culture are not isolated, even as it emphasizes that the uniqueness of digital media does not rely on its newness. Here, practices in use before the 'Gutenberg Parenthesis' not only chip away at the opening parenthesis, but reappear after its closure - their guises changed, their meanings and applications specific to their own moments, but nevertheless in and inviting dialogue. Assessing medieval reading practices through the language and criticism of digital media accomplishes more than shedding light on medieval writer-reader relations; it also suggests that the print period that defines so much about our views on writers and readers is in many ways an anomaly, and that the medieval and the digital share an interest in exploring texts in a literary culture not guided by property relationships, but by community and knowledge.

\section{Participatory reading in late-medieval England}

In this context of the relationship between reading and changes in media culture, participation not only offers a discourse and procedures to shape relations between writers, readers, and texts, 
but also becomes a framework used by writers to explore the developing authority of themselves and their texts, and the limits of this authority when contrasted to that of readers, thus casting light upon the literary culture of late-medieval England. Such concerns were vital in the context of the rapid expansion of lay literacy that characterizes England from the late fourteenth through early sixteenth centuries. As has become a critical commonplace to note, assessment of literacy proves a slippery issue, in part because literate practice in the Middle Ages involved skills that did not necessarily require an individual ability to read. Rebecca Krug thus advocates for the term 'literate practice', which acknowledges how literacy among vernacular readers in late-medieval England could encompass a range of skills. ${ }^{16}$ Offering a useful way to frame the various skills that could be involved in literate practice, Paul Saenger distinguishes between 'phonetic literacy' and 'comprehension literacy', where phonetic literacy marks a reader able to sound out words and pronounce them orally, whether in English or through that mainstay of the popular medieval book trade, the Latin book of hours. Comprehension literacy involves gazing upon a written text and apprehending it silently and fully. ${ }^{17}$ Estimates of literacy consequently vary. Conservative estimates suggest perhaps as little as 5 per cent of the overall population could read, but in urban locations perhaps as much as 50 per cent of the male population could read English. This expansion was concentrated among the mercantile, gentry, and noble classes for whom literacy and literary engagement marked opportunities for developing social prestige. Late-medieval England represents a period and place characterized by developments in literate skills that are concentrated in urban locales and expand down the social scale. ${ }^{18}$

In consequence of these changes, the growing audience of vernacular readers in this period evidences eagerness for new works, and eagerness for instruction, while not sharing in the formal training and sophisticated Latinate practices writers themselves possessed. At the same time, writers were becoming increasingly aware of and interested in their own authority and ownership of their literary work. This increased interest in writers' authority marks the transition from the early medieval notion of a writer who copies and reworks the ideas of ancient authorities to the modern notion of an author who bears the authority and responsibility of original, creative production. ${ }^{19}$ Yet writers did not define themselves solely in contrast to ancient authorities and other writers. Readers, too, played a vital role. They could support or upset a writer's plans for 
his text and, by extension, his reputation; readers could also read in ways that supported beneficial interpretations of a text, or not read in such a productive way. Thus readers were, in their actions and in their potential, figures whose status provoked the ongoing interest and concern of writers. Readers presented the potential for productive partnership with writers through their participatory engagement with texts even as they simultaneously proffered the possibility of disruptive work. By distinguishing themselves from readers, and by exerting control over them, writers both emphasized their own authority and promoted a particular ideology of readerly identity and readerly work as complementary to that of writers, but separate and subordinate. Accordingly, writers in late-medieval England, in order to maintain and develop their own status and engage readers in their projects, focus on how readers can help and hinder through participatory reading practices. What becomes particularly clear in assessing reader participation in England from the late fourteenth to the early sixteenth centuries is that the changing status of writers is accompanied by developments in the role of readers in vernacular literary culture.

Reading practices thus emerge as crucial to the definitional strategies of readers, writers, and their relationships. While the reading practices discussed herein are seldom new to Latin-literate writers, and are often drawn from Latinate scholastic traditions, they are frequently presented to readers treated as unaware of them and in need of education in sophisticated reading practice. These readers occupy a variety of categories, among which approaches to the assessment of reading practices in medieval studies have long focused on distinguishing. Such distinctions have helped draw attention to overlooked communities, such as those of women readers, or have addressed the differences in skill levels between scribes, considered to be professional readers, and the general untrained layperson, considered to be an amateur reader. ${ }^{20}$ Other approaches have attended to evidence for the occurrence of reading, as, for example, through marginal annotations or in the layout of a manuscript. ${ }^{21}$ Some of the most specific work on reading practices emerges in studies of devotional reading. ${ }^{22}$ These latter studies tend to address the experience of reading in particular genres, examining reading for its devotional affect or performative qualities. $^{23}$ Yet space remains in which to push consideration of reading further by examining the specific reading processes through which writers urged readers to make meaning of their works and, in the process, shed light on the role made for readers in 
late-medieval vernacular culture. Further assessment of reading in these directions is needful particularly because studies of medieval reading often focus on the goal of the reading experience, or the literary genre that forms reading matter; the former can result in mistaking the goal for the process, and the latter can overlook how the same reading practice can be applied or elicited across genres. Focusing on reading through the practice of participation helps illuminate the variety of processes that supported apprehension, as participation itself requires making readers work. Attending to the participatory practices of reading apprehension in late-medieval England also helps distinguish the different modes of reading that contributed in the period to intensive reading, which historians of reading view as characteristic of reading work before the end of the eighteenth century. ${ }^{24}$

In order to both sketch the outlines of the discourse and practices of participatory reading, I focus on a wide, eclectic range of texts that often circulated independently of each other, and whose authors were seldom responding to one another. While in some cases a writer's response to an earlier writer's treatment of a participatory reading practice comes into focus, in most the writers and texts studied herein circulated among different audiences whose common, defining characteristic is their choice of vernacular reading material. In this way, I show how the practices identified and studied herein were not the purview of a small group of writers or their coterie readers, but instead develop, contribute to, and reflect a widespread engagement with participatory reading practices.

The first section of the book, 'Participatory discourse', examines two reading practices writers used explicitly to invite readers' participation, and details the characteristics and work of readers as constructed through these reading practices. These practices were used by influential writers including Chaucer and Langland, although neither established the practices, which are employed by writers across a variety of genres, secular and religious. Highlighting this widespread use of such practices facilitates recognition of how participatory reading became a prevalent, systematic practice. In this way, participatory reading practices shaped readers' identities and their relations with writers and texts. The second section of the book, 'Evoking participation', reviews texts that elicited particular participatory reading practices not reliant upon explicit descriptions or invitations. Examining the strategies for eliciting participation demonstrates how participatory reading became so 
ingrained and expected in late-medieval literary culture that it need not be addressed explicitly, but could nevertheless structure readers' behaviour and textual interpretations.

Through exploring the shift from invited to elicited participation, two themes emerge throughout Participatory reading in late-medieval England: one focused on materiality and the other focused on the body of the reader. Materiality emerges through corrective and nonlinear reading practices, which in different ways involve interaction with the book as material object. Material engagement becomes a way of framing the experience of immersive reading, which also relies on the materiality not simply of objects, but also on the materiality of the reader's body. In addressing how participatory practices engage the material body of the reader, I show how participatory reading practices evidence a late-medieval awareness of the significance of bodily experience to the work of reading. In other words, studying the participatory work of reading involves assessing how reading was understood as a bodily, embodied activity. Embodiment becomes manifest in reading practice through the mobility of readers in architectural space, through the practice of immersion that led readers to situate themselves as if physically embodied in narratives, and to other reading experiences that rely upon bodily experience and perception. This approach thus expands the understanding of not only the range of medieval participatory reading experiences, but also the roles of medieval multimedia texts.

In Chapter 1, 'Corrective reading', I focus on invitations issued to readers by writers who describe a reading practice focused on the process of emendation. Emendation invitations emerge in conjunction with a popular topos of humility, in which the writer expresses insecurity regarding the text. Writers in late-medieval England often add an additional, overlooked feature to the topos: they invite readers to correct the text as they read. This practice of corrective reading relies on a characteristic shared by medieval manuscripts as well as much digital media: that of accessibility to correction. A reader able to write and in possession of a pen and ink might effect changes with almost as much ease as that of a modern reader who can, with only a few clicks of a mouse, add to, edit, or remove passages in a Wikipedia article. In digital media studies, this accessibility to reader intervention is termed 'openness'. Medieval writers, in their recommendation of corrective reading, reflect a similar awareness of the openness of the material form of manuscripts. Whereas readers' marginal contributions have 
conventionally been studied as individual actions following the act of reading within a specific manuscript, this chapter demonstrates that writers were deeply engaged in shaping the practice of readers' corrections, seeking to guide how and to what readers responded before readers ever set pen to parchment.

In tracing the boundaries of emendation invitations, Chapter 1 tightens focus on one of the much-studied moments of Chaucer's Troilus and Criseyde that arrive near the poem's final lines, when Chaucer dedicates the text to his colleagues Gower and Strode, granting them the authority, where 'ther need is, to correcte' the text. ${ }^{25}$ Chaucer presents a model that, viewed through the perspective of today's digital media approaches to crowd-sourced editing, is defined as closed-access, for he restricts permission to change a text only to a select few. Chaucer's most prolific and ardent follower, John Lydgate, develops a dramatically different approach in his response to Troilus and Criseyde, the Troy book. There, Lydgate creates an open-access model of editing when he invites 'alle pat schal it rede or se' to correct his work. ${ }^{26}$ More than five hundred years ago, Lydgate recognizes the potential seen today in developing open-access relationships with readers through digital media, and turns to this potential to engage with his readers, shape his reputation, and contribute to the transmission of his text.

In effect, Chaucer articulates a closed-access mode of emendation, while Lydgate emphasizes an open-access model characterized by invited correction. Through their disparate attitudes towards error, Chaucer and Lydgate demonstrate their perceptions about the role of readers as participants in textual correction after the release and dissemination of their texts, and use corrective reading practice as a means by which to shape the responses of the readers that they anticipated would engage with their texts. In these ways, addressing corrective reading becomes a dominant method for guiding readers' interaction with and contribution to English literary culture. The resistance to such participatory reading displayed by writers like Chaucer also points to the tension developing in response to the increasing ability of readers to exert their own authority over a text. Consequently, corrective reading becomes a practice inflected by contemporary concerns about readers' authority, the gender of readers, censorship, and the developing technology of print in ways that reveal reading as a contested practice.

Chapter 2 attends to the practice of nonlinear reading, which has long been viewed as a defining feature of digital media. Through 
the use of links and the juxtaposition of disparate forms of media on the same page, hypertext and hypermedia works have been celebrated for enabling and making widespread a reading practice defined as selective, discontinuous, nonlinear. Through this way of mediating text, readers choose where to begin and end their reading. This selective approach to reading is facilitated by links that enable readers to read nonlinearly among other pages or nodes of text in whatever order they choose. They are not simply bound to read linearly from start to finish. Depicting a similar interest in nonlinear reading practice, Middle English devotional texts written in the fourteenth and fifteenth centuries often explicitly recommend this practice to their audiences. Yet, although most commonly articulated in devotional works, evidence for nonlinear reading and nonlinear narrative structures can be identified in secular works as well. Strikingly different, however, are the purposes critics treat as served by nonlinearity in digital media when compared to the purposes medieval writers viewed as facilitated by nonlinear reading: today's nonlinearity is viewed as facilitating a speedy, 'hyper' practice of shallow engagement, while medieval nonlinear reading was recommended as a way to encourage deeper, more intense focus on a work or a passage. Contrasting these two perspectives on nonlinear reading points to the culturally determined consequences of reading.

To explore how writers engaged with or promoted nonlinear reading, Chapter 2 examines three texts that represent different modes of nonlinear reading: the Orcherd of Syon invites female readers to determine their own nonlinear reading pathways that they might customize their devotional experience, introducing the issue of how reading can facilitate or control readers' agency; in doing so, the translator of the Orcherd draws on metaphors of mobility, the body, and time that become central to the subsequent participatory reading practices described in the following chapters. In contrast to the Orcherd stand Titus and Vespasian and the Siege of Thebes. The former models nonlinear reading for its audience through the assemblage of a poetic text from diverse sources, demonstrating how a writer might seek to recreate the experience of nonlinear reading for an audience apprehending a linear text; and John Lydgate's sequel to the Canterbury Tales, the Siege of Thebes, invites a hybridized approach to nonlinear reading, both guiding readers and eliciting readers' own choices, much as does the Canterbury Tales. These texts reveal how medieval writers viewed nonlinear reading as a practice crucial to facilitating partici- 
pation in literary culture across the divide of secular and devotional works. In addition, considering manuscripts of Titus and Vespasian and the Siege of Thebes reveals the complex material politics of nonlinearity, in which writers' aims could be supported or undermined by scribal choices of layout beyond the writers' control.

Even as increasing scholarly attention has been devoted to the significance of the material nature of medieval manuscripts, attention has only begun to focus on how the materiality of a text affects readers' apprehension of it. John Lydgate's 'Soteltes for the coronation banquet of Henry VI' represents one of these texts that gestures to one of the alternative material contexts favoured by late-medieval writers, for the 'Soteltes' text, extant in multiple surviving manuscript copies, offers a series of stanzas that accompanied, described, and spoke on behalf of figurative dishes presented at the 1429 coronation feast. Movement, initially discussed in Chapter 2 as a metaphor for nonlinear textual navigation, returns here in Chapter 3 with a difference: in the case of the 'Soteltes', it is the physical mobility of the text that contributes to one mode of its apprehension, alongside the visual, aural, textual, gestural, and performative. This chapter thus shows interaction among multiple participatory reading practices, a subject that returns again in subsequent chapters. Through their reliance upon movement and, in anticipation of Chapter 4, space, texts like the 'Soteltes' demonstrate how different aspects of materiality affect and give rise to distinct participatory reading practices. Furthermore, in the identity of the 'Soteltes' as banqueting texts, they can be situated along with texts represented on wall hangings, vases, plates, and decorative boxes. These represent a little-studied category of medieval textual media that I refer to as 'extracodexical'. Extracodexical texts present a challenge to literary critics and manuscript scholars, for they gesture to the commingling of different modes of apprehension predicated upon the material conditions of a text. These materialities could incorporate elements of the visual, physical, aural, and gestural. Such multiple modes of apprehension point to the role of performative materiality, an approach that has been applied to how digital media manifest meaning through participation. In the case of the 'Soteltes', as the audience at the coronation banquet witnessed the performance of the 'Soteltes' from their seats, the figurative dishes themselves were ceremoniously ushered into the hall and moved into the sight of all. Space, place, movement, image, and text work with and through readers to shape recognition of the new king's authority. In such cases, 
then, reading can be understood as an act that requires not simply participation through the apprehension of a textual message either visually or aurally - the most basic understanding of medieval literacy - but as an act that requires familiarity with other, material modes of meaning-making, all deliberately selected, as well.

Reading was not only an experience that could occur as audiences sat reading a text, or metaphorically navigated a text described as a garden. Participatory reading could also be enacted through the efforts of a reader who negotiated architectural spaces. Exploration of the moving body in medieval textuality, then, invites consideration of what happens to that body as it negotiates architectural space to engage in specific reading experiences. In Chapter 4, I examine how texts painted onto walls in the Percy family's principal estates of Leconfield and Wressle, preserved in the British Library manuscript Royal 18 D.ii, and in the mural of the danse macabre installed in a cloister at medieval St Paul's Cathedral in London, invite consideration of the relationship between architecture, text, and image within and without the manuscript space. By turning to digital media theorists focusing on space, particularly those addressing architecture and embodied space, I argue in this chapter that the wall texts in their architectural frames elicit participation from readers whose bodies become the framers of knowledge as they move through and read the different estate spaces provided with wall texts. This chapter further argues that, by describing the original locations of the texts, the Percy family manuscript Royal 18 D.ii, and John Stow's manuscript containing Lydgate's text of the daunce macabre, Trinity College, Cambridge R.3.21, create opportunities for the virtual tourism of a fabricated space. In this way, Chapter 4 shows how the presentation of the wall texts evokes virtual space that the reader can then negotiate. In addition, the two wall texts in their manuscript and architectural contexts produce a tension between lived and virtual space that invites readers to engage in types of mental pilgrimage. Finally, forging a link between the manuscript as enabling virtual travel and the body of the reader who negotiates that space shows how mobility as part of reading experiences alters and extends the reach of the human body, a turn to the medieval posthuman. ${ }^{27}$

Given that the 'best-seller of the Middle Ages' was the book of hours, a devotional text whose reading was determined by calendars, clocks, and church hours, it is a striking oversight that little attention has been paid by medievalists to the relationship between time and reading, even as late antique and medieval thinkers like 
Augustine have themselves considered the subject. Books of hours were not alone in situating reading within a temporal frame: medieval writers advocating nonlinear reading also refer to the relationship between time and reading. For these writers, temporal choices made by readers determined interpretation. Returning to digital media criticism about the relationship between time and agency in video games, and developing further the metaphorical relationship between reading and time first introduced in Chapter 2 as it becomes reading practice, Chapter 5 explores the significance of time to reading experiences. Time and temporal participation develop markedly in three fifteenth-century texts that encourage readers to make temporal choices as part of their reading experiences: Thomas of Erceldoune's prophecy, a prophetic text focused on the relationship between Thomas Rhymer and the Queen of Faerie; Dame Eleanor Hull's Commentary on the penitential Psalms; and Thomas Norton's Ordinal of alchemy. In the way these writers and texts invite readers to make temporal choices and interpretations through the reading process, they encourage readers to perform reading shaped by temporality. Such temporal performativity includes inviting readers to rethink relationships created by the chronology of history by moving nonlinearly through time. Indeed, Thomas of Erceldoune's prophecy provokes readers to reorganize chronologies, with the effect that readers craft individual narratives of past and future. Hull and Norton focus on modes of temporal manipulation, engaging readers in choices that affect their temporalized experiences of reading. These texts encourage readers to shape their understanding of personal history, political history, and the future of the political or spiritual self through temporally mediated reading. In this way, specific perceptual views of time emerge from individual acts of reading. Reading becomes an experience shaped by temporalities, and the mode in which one reads evokes a particular performative relationship to time.

The conclusion of Participatory reading in late-medieval England introduces the topic of resistance to reading and the relationship between the refusal to read and the participatory reading practices discussed in previous chapters. As writers struggled to both solicit and guide readers' exercise of agency through reading practices, they also reflect ongoing concerns that what readers could do might easily escape the boundaries writers sought to establish. One practice that reflects how readers might act in ways that not only countered writers' attempts to guide reception and interpretation of texts is through what Leah Price calls 'nonreading'. When the 
Wife of Bath in Chaucer's Canterbury Tales takes up a book of wicked wives with which to beat her husband Jankyn over the head, her use of the manuscript illustrates a moment in which, instead of turning to the book for its designed role, the Wife repurposes it into a weapon. In the Wife's moment of nonreading, the book has become 'more valuable for some other purpose', ${ }^{28}$ and that new value places it into a fresh network of social relations. Other examples of nonreading that attend to the material nature of texts include readers' signatures and doodles, where the book becomes useful in ways that have little to do with their textual contents. Considering the role of nonreading through the lens of digitally inspired object-oriented theory that focuses on assemblages and relations within networks, this chapter argues that, when letters or books are more valuable for nonreading, their meanings, and the ways in which readers participate with them, change. This change affects books even in moments of reading, for it highlights their ever-present potential to act and be used in ways contrary to how writers might want them to work. Analysing the role of nonreading through its literary instantiations in scenes like that from the Wife of Bath's Prologue, and in manuscripts where readers draw or inscribe their names, extends the argument of Participatory reading in late-medieval England to encompass acts of participation that resist and critique modes of participatory reading like those studied in previous chapters. In this way, I demonstrate how nonreading could shift books into alternative networks, and highlights how medieval readers could take charge and make books and reading work for themselves.

In arguing for recognition of the emergence and dissemination of a wide range of participatory, vernacular reading practices throughout Participatory reading in late-medieval England, I also show how these participatory reading practices enhanced tension between writers and readers. Such tension reveals an overlooked aspect to late-medieval literary culture of which I trace the importance: just as tensions surface in the developing notion of authorship, so too do they emerge around the practice of participatory reading. Reading involves culturally constructed practices; in a changing literary culture, what reading entails undergoes change and changed meaning. The growing tension between writers and readers thus requires revising accepted perceptions of the roles of the writer and reader, along with reading practices. I thus argue that the writer was not perceived as an unchallenged authority, nor were the readers' contributions limited to marginal additions. 
Instead, I show that the boundary between writing and reading is less stable, that writers explored what readers might be to them by anticipating readers' enthusiasm for textual participation, and viewed readers as possessing a growing authority to contribute in sophisticated ways to late-medieval English literary culture. I thus cast new light on the literary practices of a period pre- and postprint to demonstrate how participatory reading vitally contributed to and shaped these negotiations of fragile authority. Finally, I end by revealing how readers resisted and critiqued participatory reading practices in ways that allowed readers, not writers, to set the agenda for their reading experiences.

\section{Notes}

1 For the full interlude, see 'Jereslaus's wife' in the Dialogue, from Hoccleve's works: the minor poems, ed. Frederick Furnivall and I. Gollancz. Early English Text Society Extra Series Nos. 61 and 73. Revised by Jerome Mitchell and A. I. Doyle (London and New York: Oxford University Press, 1970), 174-8.

2 Katherine Breen, Imagining an English reading public, 1150-1400 (Cambridge: Cambridge University Press, 2010).

3 Jenkins's work has profoundly influenced the study of the social cultures and uses of digital media; see Henry Jenkins, Convergence culture (New York: New York University Press, 2008); Joshua Green and Henry Jenkins, 'The moral economy of Web 2.0: Audience research and convergence culture'. Media industries: history, theory, and method, ed. Jennifer Holt and Alisa Perren (Malden, MA: WileyBlackwell, 2009), 213-25; Henry Jenkins, 'What happened before YouTube'. YouTube, ed. Jean Burgess and Joshua Green (Cambridge: Polity Press, 2009), 109-25; Henry Jenkins, Sam Ford, and Joshua Green, Spreadable media: creating value and meaning in a networked culture (New York: New York University Press, 2013).

4 Daniel Wakelin, 'Instructing readers in fifteenth-century manuscripts.' Huntington Library Quarterly 73:3 (September 2010), 453-52, at 433-4.

5 In the seminal and still-influential discussion of agency offered in Hamlet on the holodeck: the future of narrative in cyberspace (New York: Free Press, 1997), Janet Murray defines agency through participation as 'the satisfying power to take meaningful actions and see the results of our decisions and choices' (126). This view of agency represents it partly as an aesthetic experience (it can be 'satisfying') and as linked to meaning, in which a person's intentional decisions and choices determine their relationship to, and understanding of, a work. 
6 George Landow, Hypertext 3.0: critical theory and new media in an era of globalization (Baltimore: Johns Hopkins University Press, 2006), 56.

7 Some scholars have even taken the increase in annotations appearing in early modern print books as encouraging passive readers, though William Sherman cautions against this view: Used books: marking readers in renaissance England (Philadelphia: University of Pennsylvania Press, 2007), xi, 5, 45.

8 See Robert Coover, 'The end of books', in The New York Times book review (June 21, 1992), 11, 23-5; Astrid Ensslin and Alice Bell, 'New perspectives on digital literature: criticism and analysis', dichtungdigital no. 37 (2007) at www.brown.edu/Research/dichtung-digital/ editorial/2007.htm; Ray Kurzweil, 'The future of libraries, part 2: the end of books', Library journal (February 15, 1992), 140-1; and Priscilla Coit Murphy, 'Books are dead, long live books', in Rethinking media change, ed. David Thorburn and Henry Jenkins (Cambridge, MA: MIT Press, 2004), 81-94.

9 For an introductory discussion to the use of interactivity to exert control over readers, see Andrew Dewdney and Peter Ride, The digital media handbook. 2nd ed. (New York: Routledge, 2014), 263-76.

10 Henning Ziegler, 'When hypertext became uncool: notes on power, politics, and the interface', dichtung-digital, no. 27 (2003) at www. brown.edu/Research/dichtung-digital/2003/issue/1/ziegler/index.htm.

11 Jill Walker Rettberg, 'Feral hypertext: when hypertext literature escapes control', The international handbook of internet research, ed. by Jeremy Hunsinger, Lisbeth Klastrup, and Matthew Allen (Dordrecht and London: Springer Verlag, 2010), 477-93, at 487.

12 Nicholas Carr, The shallows: what the internet is doing to our brains (New York: W. W. Norton, 2011).

13 For an introduction to Pry, including demo videos, review http:// prynovella.com.

14 See Ray Siemens et al., 'Human-computer interface/interaction and the book: a consultation-derived perspective on foundational e-book research', in Collaborative research in the digital humanities, ed. Marilyn Deegan and Willard McCarty (Farnham, Surrey: Ashgate, 2012), 163-90; Bertrand Gervais, 'Is there a text on this screen? reading in an era of hypertextuality', A companion to digital literary studies, ed. Susan Schreibman and Ray Siemens (Oxford: Blackwell, 2013), 183-202. This conceptualization of reading activities builds on the work of Gilles Thérien, Sémiologies (Montreal: Université du Québec à Montréal, 1985).

15 Eileen A. Joy and Myra J. Seaman, 'Through a glass, darkly: medieval cultural studies at the end of history', in Cultural studies of the modern Middle Ages, ed. Eileen A. Joy, Myra J. Seaman, Kimberly K. Bell, and Mary K. Ramsey (New York: Palgrave, 2007), 1-22. Relatedly, 
see also Truth and tales: cultural mobility and medieval media, ed. Fiona Somerset and Nicholas Watson (Columbus, OH: Ohio State University Press, 2015).

16 Rebecca Krug, Reading families: women's literate practice in late medieval England (Ithaca: Cornell University Press, 2006), 7; and Sharon D. Michalove, 'The education of aristocratic women in fifteenth-century England', Estrangement, enterprise and education in fifteenth-century England, ed. Sharon D. Michalove and A. Compton Reeves (Stroud: Sutton, 1998), 117-39, who notes that elite women did not need to learn how to write because they had access to scribes who could write for them.

17 Paul Saenger, 'Books of Hours and the reading habits of the later Middle Ages', The culture of print: power and the uses of print in early modern Europe (Princeton: Princeton University Press, 1989), 141-73.

18 For particular discussions and summaries of the work on literacy rates in late-medieval England, see Susan Crane, 'The writing lesson of 1381', Chaucer's England: literature in historical context, ed. Barbara A. Hanawalt (Minneapolis: University of Minnesota Press, 1992), 201-23, at 202; Judy Ann Ford, Fohn Mirk's Festial: Orthodoxy, Lollardy and the common people in fourteenth-century England (Cambridge: D.S. Brewer, 2006), 26-8.

19 Alastair Minnis remains the authority on this subject; see Medieval theory of authorship: scholastic literary attitudes in the later Middle Ages. 2nd ed. (Philadelphia: University of Pennsylvania Press, 2010). For related studies on the rise of the vernacular in late-medieval England, see Jocelyn Wogan-Browne et al., Idea of the vernacular: an anthology of Middle English literary theory, 1280-1520 (Philadelphia: University of Pennsylvania Press, 1999), as an accessible overview; see also the essay collections edited by Fiona Somerset and Nicholas Watson, The vulgar tongue: medieval and postmedieval vernacularity (University Park: Pennsylvania State University Press, 2003), and Elisabeth Salter and Helen Wicker, Vernacularity in England and Wales, c. 1300-1500 (Turnhout, Belgium: Brepols, 2011).

20 Studies particularly influential in these ways include Krug, Reading families; Kathryn Kerby-Fulton and Denise L. Despres, Iconography and the professional reader: The politics of book production in the Douce Piers Plowman (Minneapolis: University of Minnesota Press, 1999).

21 For exemplary studies of this nature, see Kerby-Fulton and Despres, ibid.; Jane Griffiths, Diverting authorities: experimental glossing in manuscript and print (Oxford: Oxford University Press, 2014); C. David Benson and Barry A. Windeatt, 'The manuscript glosses to Chaucer's Troilus and Criseyde', Chaucer Review 25.1 (1990), 33-53; Julia Boffey, 'Annotation in some manuscripts of Troilus and Criseyde', English Manuscript Studies 5 (1995), 1-17; Ralph Hanna III and A.S.G. Edwards, 'Rotheley, the De Vere Circle, and the Ellesmere Chaucer', in Reading from the margins, ed. Seth Lerer (San Marino: Huntington 
Library, 1996), 11-35; and Ryan Perry, “"some sprytuall matter of gostly edyfycacion”: Readers and readings of Nicholas Love's “Mirror of the Blessed Life of Jesus Christ"', in The Pseudo-Bonaventuran lives of Christ, ed. Ian Johnson and Allan F. Westphall (Turnhout: Brepols, 2013), 79-126.

22 Jessica Brantley, Reading in the wilderness: private devotion and public performance in late medieval England (Chicago and London: University of Chicago Press, 2007); Jennifer Bryan, Looking inward: devotional reading and the private self in late medieval England (Philadelphia: University of Pennsylvania Press, 2008).

23 See Brantley, Reading in the wilderness, and Robert L. A. Clark and Pamela Sheingorn, 'Performative reading: experiencing through the poet's body in Guillaume de Digulleville's Pelerinage de Jhesucrist', in Cultural performances in medieval France: essays in honor of Nancy Freeman Regalado, ed. Eglal Doss-Quinby, Roberta L. Krueger, and E. Jane Burns (Rochester: Brewer, 2007), 135-51; also Robert L. A. Clark and Pamela Sheingorn, 'Performative reading: The illustrated manuscripts of Arnoul Greban's Mystere de la Passion', European medieval drama 6 (2002), 129-54; and Robert L. A. Clark and Pamela Sheingorn, "“Visible words": gesture and performance in the miniatures of BNF, MS FR. 819-20', in Parisian confraternity drama of the fourteenth century: the Miracles de Nostre Dame par personages, ed. Donald Maddox and Sara Sturm-Maddox, Medieval texts and cultures of Northern Europe 22 (Turnhout: Brepols, 2008), 193-217.

24 The distinction between intensive and extensive reading, which is characterized by frequent and wide-ranging access to a great number of books, as opposed to focused concentration applied to a small number, was developed by a seminal historian of the book, Rolf Engelsing, and is best summarized in his influential article, 'Die Perioden der Lesergeschicte in der Neuzeit' (The phases of reading in the modern age), in Zur Sozialgeschicte deutscher Mittel-und Untershicten (Gottingen: Vandenhoeck und Ruprecht, 1973), 112-54. David Hall has shown a similar difference in kinds of reading at play in early modern New England; see 'The uses of literacy in New England, 1600-1850', in David Hall, Cultures of print: essays in the history of the book (Amherst: University of Massachusetts Press, 1996), 36-78. Scholars have critiqued Engelsing's work, however, on several grounds.

25 Quoted from The Riverside Chaucer, 3rd ed. Ed. Larry D. Benson (Boston: Houghton Mifflin, 1987).

26 Cited from line 379ff. of Troy book, ed. by Henry Bergen, EETS e.s. 97, 103, 106, 126 (London: Kegan Paul, Trench and Trübner \& Co., 1906-35).

27 For a key work on posthumanism, see Andy Clark, Natural-born cyborgs: minds, technologies, and the future of human intelligence (New 
York: Oxford University Press, 2003), at 138-9. Other influential contributions to the exploration of the posthuman include N. Katherine Hayles's How we became posthuman: virtual bodies in cybernetics, literature, and informatics (Chicago and London: University of Chicago Press, 1999); and Donna Haraway, 'A cyborg manifesto: science, technology, and socialist-feminism in the late twentieth century', Simians, cyborgs, and women: the reinvention of nature (New York: Routledge, 1991), 149-81. In medieval studies, see particularly the inaugural issue of the journal postmedieval (New York and London: Palgrave Macmillan, 2010), When did we become post/human?, edited by Eileen Joy and Craig Dionne. In a related argument, Cohen in Medieval identity machines (Minneapolis: University of Minnesota Press, 2003) argues for understanding Margery Kempe's position as posthuman through her use of language. To this I would add that, in Cohen's terms, reading practices themselves function as identity machines.

28 Leah Price, How to do things with books in Victorian Britain (New Haven: Princeton University Press, 2012), 8. 
Heather Blatt - 9781526118004 Downloaded from manchesterhive.com at 04/26/2023 ๑6:39: ๑०AM 


\section{Part I}

\section{Participatory discourse}


Heather Blatt - 9781526118004 Downloaded from manchesterhive.com at 04/26/2023 ๑6:39: ๑०AM 


\section{Corrective reading: Geoffrey Chaucer's Troilus and Criseyde and John Lydgate's Troy Book}

This chapter focuses on a trope, one so common in medieval English literature that its critical work in the construction of latemedieval reading practices has gone unnoticed. This rhetorical device, often simply referred to as the humility topos, flourishes in Middle English during the fifteenth century, although it has its roots in fourteenth-century French of England and was common in Latin hagiographies before that. ${ }^{1}$ In the humility topos, a writer draws attention to the spectre of his or his work's flaws in order to elicit a kinder reception by readers. ${ }^{2}$ It is a trope used by two of the three most influential poets of late-medieval England, Geoffrey Chaucer and his successor John Lydgate, and is turned to repeatedly by the merchant and translator who first introduced the printing press to England, William Caxton. In the hands of all three, and in its use by scores of other writers from the late fourteenth to the early sixteenth centuries, the topos accomplishes work that extends beyond the performance of humility and its consonant structuring of writerly authority. It does so through an additional feature in which writers anticipate readers' responses to the flaws of a work and, most significantly, request that readers correct them. For example, as the fifteenth-century poet John Lydgate writes in The Fall of princes, he 'requeyr[es] of humbles / That all thoo which shal this makyng rede, / For to correcte wher-as they se nede', that is, he humbly requires all those who read his poem to correct it wherever they see need. ${ }^{3}$ I call this feature of the humility topos the 'emendation invitation', and it serves to promote - or discourage, in the variations of the discourse it establishes - 'corrective reading'. For its expansive late-medieval deployment by writers, corrective reading elicited through emendation invitations deserves closer scrutiny. In particular, its reliance on participation positions emendation as crucial to understanding how late-medieval writers explored what the growing audience of vernacular readers might 
be capable of achieving, for good or ill. In other words, through the vehicle of the humility topos, emendation occupies a central position contributing to a discourse of participatory reading that exemplifies how late-medieval writers articulated, anticipated, and responded to the participatory work of readers.

An early emendation invitation can be found in the AngloNorman Roman de toute chevalrie, a version of the Alexander legend composed by Thomas of Kent around 1175. This and other texts that followed attest to use of the invitation written in the French of England and the Continent. ${ }^{4}$ The emendation invitation thus possess long-standing status among the vernaculars of medieval Europe. It is not until the late fourteenth and fifteenth centuries, however, and in Middle English, that the emendation invitation reaches the pinnacle of its utility, versatility, and popularity. Over the course of the century, variations emerge in its use. These variations demonstrate a systemic reliance upon the emendation invitation that reveals it as foundational to a discourse of participatory reading, one well established enough that variant expressions and uses of it become possible. Such variations also proliferate widely in late-medieval English literature, to the extent that patterns can be identified in the deployment of variations on the emendation invitation, and these variations distinguish among groups of readers to encourage some and discourage others, and similarly encourage or discourage types of corrections.

The emendation invitation thus depicts participatory reading expressed through correction, and it emerges in numerous contexts that touch upon defining features of England's late-medieval literary scene, such as writerly authority, censorship, gendered audiences, vernacular reading practices, and the technological shift from manuscript to print. In its emergence, it most commonly demonstrates varying attitudes towards readers' corrective reading that seek either to encourage or restrict its practice. These attitudes strongly resemble those adopted towards open- and closed-access participation possible today in digital media, suggesting a longer, premodern history of practices today considered characteristic of digital media, such as crowd-sourced editing.

\section{Open and closed-access invitations}

What follows will delve more deeply into an example of each of these variations on the emendation invitation, selected from among the many writers who use the invitation partly for clarity of expres- 
sion and partly because all three examples come from writers associated with Chaucer: Chaucer himself, Lydgate, Chaucer's most influential follower, and Thomas Norton, a late fifteenth-century Chaucerian. Chaucer's contributions to the development of a modern understanding of the writer as author, possessing authority and creative originality, has long been explored by critics. ${ }^{5}$ Yet constructing authorship also implicitly constructs readership as well. Thus, even though emendation invitations predate Chaucer, his adoption of the emendation invitation signals both recognition of its influential work in constructing readership through a participatory reading practice, and promotes to other writers its utility in constructing relations among writers, texts, and readers - a promotion traceable through how Lydgate and Norton, and many other authors influenced by Chaucer, adopt the emendation invitation even as they use variations of it. That these examples, and many others, emerge across a variety of genres from courtly romance to history to alchemical treatises testify as well to its systematic use in late-medieval literary culture.

As Lydgate, referenced above, depicts an open example of the emendation invitation through inviting all readers to correct the text, Chaucer occupies a middle ground in his offer of an early example of the emendation invitation in Middle English at the end of Troilus and Criseyde following the 'Go, little book' address of the Envoy. There, Chaucer famously expresses concern about the stability involved in the transmission of his text, and envisions a compensation for this instability. In doing so, he relies on the discourse of participation exemplified through the emendation invitation. Yet, rather than inviting any readers to contribute, Chaucer restricts participation only to a named few:

And for ther is so gret diversite

In Englissh and in writing of oure tonge,

So prey I God that non miswrite the,

Ne the mysmetre for defaute of tonge;

And red wherso thow be, or elles songe,

That thow be understonde, God I biseche!

O moral Gower, this book I directe

To the and to the, philosophical Strode,

To vouchen sauf, ther need is, to correcte,

Of youre benignites and zeles goode. ${ }^{6}$

Commonly assessed for what it might indicate about Chaucer's literary circle, critics most often refer to this passage as a dedication 
and commentary on the capabilities of English as a literary language, expressed through the focus on the writer's incapability, so familiar in humility topoi. ${ }^{7}$ However, Chaucer moves beyond the expression of authorial humility through his evocation of emendation. Chaucer charges two specific people, Strode and Gower, to intervene in the work of manuscript transmission by acting as editors and preservers of Chaucer's text.

Chaucer's use of the emendation invitation demonstrates an emendation invitation restricted to only two people, specified by name; it is neither fully open, nor is it entirely closed, forbidding correction by any and all readers. In representing himself as possessing both the authority to secure the future of his work and its treatment at the hands of readers, Chaucer employs the emendation invitation to contribute to his writerly authority, interest in and control over textual transmission, and his interest in and limitation of readers' participation. Considering how writers use the emendation invitation to shape relations with readers and the text provides opportunity to resist (in the words of Gilles Deleuze and Felix Guattari) 'cut[ting] the book off from its relations with the outside'. ${ }^{8}$ In other words, viewing Chaucer's dedication of the book as merely an example of the humility topos overlooks how writers sought to use the trope to imagine and guide relations with readers. Instead, in its use by Chaucer, the passage depicts how Chaucer both assessed the roles of his readers and envisioned his relationship to his audience. He deploys his authority as creator of the text in order to influence who should care for the work after it leaves his hands and control, even as he anticipates who will not care - like the scribes who would copy his text. Accordingly, Chaucer's emendation invitation can be situated in conversation with his later short lyric, 'Chaucer's Wordes unto Adam, His Owne Scriveyn', in which Chaucer chides - perhaps playfully, perhaps seriously - his scribe for the many infelicities that Adam has introduced into Chaucer's works, which Chaucer must then correct. Intimately familiar with the problems a scribe can create for his texts, Chaucer seeks to forestall those problems by placing Gower and Strode in charge of overseeing the correction of Troilus and Criseyde. That 'Adam Scriveyn' was composed after Troilus and Criseyde indicates that Chaucer was, perhaps, aware that seeking to encourage a restricted audience of correctors to oversee and emend his text had little impact.

In crafting his authority to limit emendation to specific readers, Chaucer draws on terms commonly found in humility topoi: 
the terms of correction and emendation. Gower and Strode are 'to correcte' the text where they determine that need exists. In asking them to 'vouchen sauf', Chaucer requests that they guide and also that they permit such correction, consequently placing Gower and Strode in charge of determining the emendation the text undergoes. Furthermore, in doing so, he suggests that they form a particular class of reader, that of the professional reader whose experience and education situate them as learned and familiar with sophisticated literature and its transmission. Chaucer thus turns to the emendation invitation to provide language and practice through which to guide engagement with the text. Such examples of the emendation invitation as Chaucer's perform key work in establishing a discourse of participation focused on soliciting specific readers' contributions to the text's correction and transmission.

The emendation invitation both informs us about writers' expectations regarding what work readers should or should not perform, and it highlights the diverse strategies writers employed in anticipating and shaping participation with their audiences. It also, and quite explicitly, provides instructions for readers regarding how they should participate with and respond to the text or author. Recognizing this also highlights how the emendation invitation makes reading a visible activity, and articulates sophisticated subject positions for readers, whom the topoi represents in the role of overseeing the text after its copying and dissemination.

These instructions consequently act as guidance that attempts to shape a subsequent reading experience. One of the challenges of studying medieval reading is that its performance, at the cognitive level, leaves no material traces, and what usually offers itself for study is the retrospective evidence of reading, such as that presented by manuscript marginalia. Examining the variety of means by which writers chose to phrase their invitations to emend, or discouraged readers from doing so, provides access to a critical backdrop against which to situate specific medieval readers' manuscript marginalia. In this context, the invitation to emend crafts expectations regarding readers' participation in manuscript transmission and treatment: it maps out the details of reading in advance - proleptically, rather than retrospectively. ${ }^{9}$ Considering the invitation emendation in this way thus invites us to situate studies of individual manuscripts' marginalia against this context, when evaluating what manuscript marginalia contribute to the picture of late-medieval English readers and reading practices. 
The discourse of participation figured through emendation invitations also invites researchers to consider how specific texts and their readers participate in that discourse. In its simplest form, this assessment might begin by considering whether the text in a specific manuscript includes an emendation invitation. Such assessment would refine understanding of the marginalia of that manuscript by further characterizing its readers as responding to, resisting, or ignoring such invitations.

An example of an emendation invitation that strikingly contrasts with and almost certainly responds to Chaucer's invitation to Gower and Strode at the end of Troilus and Criseyde is that provided by John Lydgate in his response to Troilus and Criseyde, the Troy book, in which Lydgate extends and refines his invitation to emend the text no fewer than six times. Rather than strictly modelling his use of the invitation after that of Chaucer, which might be expected given how strongly and frequently Lydgate affiliates his work as a writer with Chaucer's, Lydgate employs an alternative approach. Whereas Chaucer envisions restricted, limited participation in the work of emendation guided by Gower and Strode, Lydgate, at the end of the Troy book prologue, invites correction of his work in expansive terms:

Preynge to alle pat schal it rede or se,

Wher as I erre for to amenden me,

Of humble herte and lowe entencioun

Commyttyng al to her correccioun,

And ther-of thanke; my wille is bat pei wynne,

For thoruz her support pus I wil begynne. ${ }^{10}$

Lydgate invites all readers - not simply a learned subset of the author's contacts, or the audience of scribes as professional readers - to participate in the work of textual correction. In his expansive conception of a broad audience eligible, fit, and likely to correct the text, Lydgate's use of the emendation invitation exemplifies the open type of emendation invitation, one that sees value in encouraging corrective reading. For Lydgate, adopting a model of openness facilitates the kinds of participation with readers that leads to the improvement of his text in the face of the inevitable vagaries of manuscript transmission. Lydgate's openaccess model of emendation relies on the technological qualities of a manuscript as a writing surface accessible to modification by readers. Corrective reading is thus a process both interactive and participatory; the interactive participation possible through 
corrective reading encourages the development of a collaborative relationship between writer, text, and readers. For Lydgate, corrective reading is a form of social reading with benefits accruing to writer, text, and readers alike.

As with Chaucer, Lydgate relies on his role as writer to provide the grounds for instructing readers and constructing the basis of their work as such. Reading should be an act embarked upon not simply to benefit the reader by gaining an understanding of the matters a text expresses, but also performed with a critical eye for where the text might need correction, benefitting the reputation of the writer and the reliability of the text. To facilitate this corrective reading, Lydgate also specifies the types of emendations he desires when he restates his emendation invitation at the end of book five. Expecting similar types of scribal alterations as Chaucer seems to have unhappily anticipated at the end of Troilus and Criseyde, Lydgate beseeches 'al pat shal pis noble story rede' to correct 'falsely metrid' lines and emend lines where they observe that 'any word [is] myssit'.11 ('Myssit' here describes words that can be absent, unbecoming, or unsuitable.) He then links this collaborative work of review and editorial correction to moral and intellectual improvement - his own and his readers': not to emend a passage in need of correction 'is no worshippe to hym pat is wys', as Lydgate explains. ${ }^{12}$ This form of participatory reading thus, as Lydgate sees it, conveys benefits to the reader, the writer's reputation, and the stability and truth of the text.

Lydgate's encouragement of reader emendation also speaks to one of his poem's central projects, the provision and preservation of truth. His use of the emendation invitation promotes corrective reading, which he views as conveying moral benefits to his readers. In correcting the text as Lydgate invites, participatory audiences would put the moral instruction the text offers to practical use by assisting in correcting it and Lydgate. The work of such readers would thus contribute to the preservation of textual and personal truth, preventing Lydgate's translations and elaborations from 'hyd[ing] trouthe falsely under cloude' (265) as had been done in other literary retellings of the Trojan War. Readers protect the truth of Troy book by correcting its errors and winnowing false from true as they read. Furthermore, the connotations of 'amenden' and 'correccioun' that evoke practices of textual emendation enhance the moral valence of readers' corrective work, for 'amenden' and 'correccioun' are also common terms in the discourse of moral improvement. ${ }^{13}$ In effect, Lydgate positions 
corrective reading as enabling readers to participate in the work both materially and morally. How readers participate, what they change, why they change it, and what the results are - all is initially left to their discretion. Yet, by yoking reader participation to moral correction, Troy book does not simply instruct its readers in virtues; instead, Troy book directs readers to a practice that enables them to perform virtue through emendation. Corrective reading transforms Troy book into a dynamic, moral learning space for its readers.

One of the fundamental effects of emendation invitations is their emphasis on the development of readerly agency, for the invitations suggest that readers can and should make choices about how they participate in response to a text. In addition, the invitations suggest that the decisions readers make carry significance for themselves, the writer, and the text. In the way that they emphasize agency, the emendation invitations both create a discourse of reader participation, and further normalize an identity of readers as participants whose work matters. This carries significance because, in the inclusivity of invitations addressed to 'alle' of the readers of a work, these emendation invitations speak not to the audience of professional readers alone, but to the audience of amateur readers as well. Such treatment conveys legitimacy upon their efforts, encouraging them. It also distils from the sophisticated interpretive and textual practices of professional readers basic building blocks - paying attention to the metre, to word choice, or other errors - that provide guidance to amateur readers desirous of education in more formal modes of reading. Finally, it facilitates and directs their investment in literary culture, much as openaccess editing today does, by encouraging audiences to read a text seriously. ${ }^{14}$ Given that some of the invitations occur at the end of the text, ${ }^{15}$ rather than the start, they could also have been a spur to reread with another focus in mind than readers might have had in their initial engagement with the work.

While Lydgate's attempts to encourage amateur readers to participate in emendation express optimism that their contributions can be useful for a text, and value the prospect of reader participation, other writers explicitly and comprehensively condemn reader participation in the creation of a text's meaning, or limit participation to specific people, as Chaucer does in Troilus and Criseyde, and as other writers do in suggesting that corrections be managed by the patron who commissioned their texts. Such attempts to close access to emendation indicate concern regarding 
the negative repercussions of reader participation, and lead to attempts to control the participation of readers by encouraging readers to receive passively the text as transmitted by its author. One writer interested in maintaining authorial control over the text was Thomas Norton. ${ }^{16}$ The Ordinal of alchemy, a text the author began composing in 1477 to introduce the science of alchemy to a lay vernacular audience, offers a dissenting view on the work of readers that sharply contrasts with the more inclusive invitations of Lydgate and other writers who openly invite reader emendation. ${ }^{17}$ It is a contrast that emphasizes anxieties about readers' abilities and enables the assemblage of a more detailed picture of expectations for, and about, readers. These anxieties seem to cluster around texts whose topics or genres were viewed as weighty or dangerous: alchemy, and also religious writing.

Norton cites Chaucer's 'Canon's Yeoman's Tale' when discussing the Philosopher's Stone and thus situates himself within a tradition of English poetic works on alchemy, even as he also situates himself within the Chaucerian tradition, thus making his work a particularly fitting example of an approach that contrasts with the Chaucerian Lydgate and Chaucer himself. The diversity of responses among these three writers indicates that, while attentiveness to readers and their relations to a text is certainly an aspect Chaucer draws attention to, his example does not become a template adopted by his followers. In contrast to Lydgate's open invitation to all readers, Norton does align himself more closely to Chaucer's model of restricted access to corrective reading - but does so to an extreme, by forbidding emendation altogether. Accordingly, Norton's approach exemplifies a highly restrictive model that also allows Chaucer's version to be identified as a hybrid example of the emendation invitation, partly open (to Gower and Strode), and also closed (to all others). Norton, in contrast, closes access to all readers: the only person eligible to change the text is the author himself. Yet Norton also demonstrates awareness of the work of readers and presumes them inclined towards corrective reading, even if he does not view the consequences of this reading practice in a positive light. Indeed, unlike Lydgate and other authors interested in open-access emendation, Norton views readers' emendations as an especially undesirable outcome, potentially dangerous in the hands of the 'rude peple' he aims to educate. ${ }^{18}$ In the Ordinal of alchemy's prologue, he explicitly and bluntly seeks to dissuade readers from participating materially with his text: 
And that no man for better ne for wors

Change my writing, for drede of Goddis curs;

For where quyck sentence shal seme not to be,

There may wise men fynd selcouth privyte;

And changing of som oone sillable

May make this boke unprofitable. (170-5)

Fear, first of the curse of God - a rote phrase describing excommunication - and then for the integrity of author-developed meaning, becomes the tool Norton initially uses to forestall reader engagement with textual emendation and transmission. Norton seeks to evoke doubt in his readers regarding their fitness to engage with the text, however insignificant they perceive their emendations to be. Even changing 'oone sillable' may obscure meaning and render the book of little use. Perhaps motivated by the genre of his work as a treatise in the scientific mode, Norton views readers' attempts to correct seemingly obvious errors as opening the floodgates to textual corruption. He, as does Chaucer in 'Adam Scriveyn', views readers' and scribal modifications as corruptive, a view shared by modern editors for much of the nineteenth and twentieth centuries.

Not only does Norton engage to forestall readers' drive to correct what might be perceived as minor orthographical errors, however, he also attempts to circumvent reader contributions based on what he anticipates will be mistaken acts of interpretation. Even when an initial reading leaves a reader struggling to identify the 'quyck sentence', Norton asserts that meaning exists, available to closer rereadings. 'Trust not to oon reading or twine', he further declares, 'But xx. tymes' (176-7). Neither one nor two readings will suffice; only rereading twenty times will do. This advice responds to his concern that readers will alter his work to draw out or correct places where the meaning seems obscure, a practice he emphatically condemns. He views readers who are interested in participating through corrective reading as engaged in a shallow mode of apprehension. In this way, Norton finds emendation lacking in substance and benefit. ${ }^{19}$ He turns away from corrective reading to promote another reading practice instead, one defined by disciplined rereading.

Norton's efforts to control reader participation reflect his desire to preserve his treatise as a fixed work, and he expresses concern about the ease with which an emendation made in ignorance by a reader could disturb his system of concealed messages, such as his use of acrostics to identify himself as the author of the text. ${ }^{20}$ 
Consequently, Norton advocates textual stability as authorially determined. He ends at the last by developing another form of control: intellectual. In order to maintain textual stability and the primacy of authorial meaning, Norton encourages the development of the omnivorous reader, who will 'rede many bokis' but not emend them. Accordingly, Norton adopts a stance that favours readers whose consumption of the text focuses exclusively on interpretive reception, and further promotes recognition of authorial autonomy. His adoption of this stance further indicates that 'intensive' reading viewed as characteristic of pre-eighteenth century reading practices, which focuses on the close study of a small number of books, is countered here by Norton's advice to read not intensively alone, but also 'extensively', consulting and consuming a high number of books. ${ }^{21}$

Like all the Middle English writers who articulate a policy of closed or open access, Norton conveys his concern for the afterlives of his work, and envisions readers' immediate response to a text as likely to pursue corrective reading. Whereas Lydgate and Chaucer, to varying degrees, promote the participation of corrective reading and imply it as unlikely to occur without prompting, Norton tries to forbid participation altogether. They may also be responding in different ways to practices they already perceived as common and likely to be undertaken by their readers, and thus seek to shape particular effects of such anticipated engagement. Their differing stances, articulated over the course of nearly a hundred years, reveal the degree to which participatory reading through emendation had pervaded fifteenth-century vernacular literary discourse. Emendation invitations, and the corrective reading strategy they shape, not only intersect with expectations about readers' capabilities, but also demonstrate how corrective reading might be perceived as harmful, and therefore in need of efforts to control or even prohibit. In response to these concerns, Norton encourages a mode of reading that produces immaterial work from his audience: he focuses on the interpretive work of reading, rather than the kind of close reading encouraged by Lydgate's recommendation that his participatory readers pay attention to matters of syntax, spelling, and metre. Norton's choice may have reflected the higher stakes for him as a writer producing an alchemical poem that also critiqued the king; in such a context, he may have felt more cautious regarding what his readers might do with his work than Lydgate, who in focusing on history pursued a less fraught path. 


\section{Medieval emendation, modern crowd-sourcing, and collaboration}

The treatment of the emendation invitation in these examples by Chaucer, Lydgate, and Norton exemplifies the three major types of emendation invitations: the open invitation, the closed invitation, and the hybrid invitation. The language used to describe these three types of the emendation - open and closed highlights a parallel between medieval and contemporary media practices. In particular, it draws on the discourse of open access that has developed in response to the technological, economical, and social conditions that shape and are shaped by the internet and digital media. ${ }^{22}$ That is, the shift from analogue and print to digital media, and the subsequent development of digital media, emphasized interaction - interaction not simply in accessing or sharing media, but in contributing to it. This interest in enhancing participation, insofar as it connects with emendation and participatory reading, can be best exemplified by three developments that linked a media platform to reader participation. The first of these is Wikipedia, whose culture of open-access, crowd-sourced editing is fuelled by readers who become contributors to the site; by blogging software that facilitated the development of communities of commentators that writers could encourage to participate in specific ways, as did Noah Wardrip-Fruin when he invited readers of his blog Grand text auto to submit questions, suggestions, and corrections to drafts of his then in-progress book; and the adoption of crowd-sourced editing applied to open peer review within academic journal publishing, initially explored by Shakespeare quarterly in their special issue on 'Shakespeare and New Media'. ${ }^{23}$ That these developments became possible can be attributed partly to the emphasis on participation that emerged as a hallmark of what is referred to as 'Web 2.0', that is, secondgeneration internet culture, but also because this nascent culture emphasized an approach to digital media defined not by the mainstream capitalism-driven consumer economy, but by sharing and open access. ${ }^{24}$

The sharing economy of second-gen digital media development countered traditional hierarchies that limited interaction between creators and consumers by enabling consumers to participate in media creation and development. The digital sharing economy also challenged the long-standing capitalism-driven framework that has developed around authorship, which constructs writing and editing as forms of labour recognized through copyright and consonant 
financial remuneration, and reading as a form of entertainment with no labour value, and therefore no financial value. Through digital sharing economies, writers, texts, and readers can interact freely. This sense of 'free' connotes both freedom of access and freedom from the constraints of institutionalized financial valuation of writing and the lack thereof for reading. That these qualities can also apply to descriptions of late-medieval literary culture is neither coincidental nor irrelevant to how, in both cultures pre- and post-print, an interest in reader participation flourishes. In these literary cultures, value is expressed socially through reputation and influence, which readers can contribute to or hinder through their own efforts. In this context, the late-medieval emendation invitation, which identifies audiences of readers who are guided in accessing and contributing to a work, can be firmly situated within this long history of media access discourse.

The strikingly different approaches toward corrective reading that Chaucer, Lydgate, and Norton demonstrate also represent how late-medieval English authors grappled with models of review, correction, and reception. Their uses of corrective reading - whether encouraging or discouraging it - highlight issues including the authority of writers and readers, writer participation with audiences, and preservation the integrity of works whose every manuscript transmission invited fresh changes. Many of these are issues that have also emerged in contemporary debates about the state of academic publishing in the context of new approaches made possible by social media platforms, and have invited evaluation of the challenging economies of publishing, perceptions of collaboration, and opportunities to alter writer-reader participation. In this context, Chaucer's act of committing the text to the attentions of Gower and Strode, for example, evokes the academic peer-review process, for Chaucer authorizes the review of his work by an educated audience of his peers. Their learned review and emendation will help ensure the integrity of the text and, thereby, the writer's and text's reputation. Similarly, Lydgate also seeks to ensure the integrity of his text and its reputation along with his own, but he instead turns to his broad community of non-professional readers. Situating Chaucer, Lydgate, and Norton within the discourse of open and closed access asserts connection between the preand post-print media cultures. The analogues between medieval emendation invitations and modern editorial practices provide an alternative way to consider associational, rather than chronological, narratives of book history. 
Considering Chaucer's, Lydgate's, and Norton's emendation invitations through the lens of closed/open access and crowdsourcing also sheds more insight on the role of corrective reading as a practice advocated by Lydgate and other fifteenth-century writers. As noted by Kathleen Fitzpatrick, open-access practices, in particular, represent a form of interaction. Fitzpatrick uses the term, as do many, as a synonym for participation. In this light, she observes that '[T] he key issue is interaction. The author is not operating - and has never operated - in a vacuum, but has always been a participant'. ${ }^{25}$ When the author participates or envisions participation through the invitation to emend the text, engagement with a reader becomes the focus. Furthermore, this participation depicts a collaborative relationship - or, in a closed-access invitation, resists collaboration - among writer, text, and reader. Corrective reading, articulated through the emendation invitation, can consequently be positioned as a nexus of social reading practices. Although the dominant narrative of reading in the later Middle Ages explores the rise of silent reading that made solitary reading a possibility, and a contrast with public reading practices, the emendation invitation points to a narrative of reading as a social act. Even if performed silently, emendation invitations structure social relations between writers and readers through promoting a model of readership that figures textual correction as a participatory activity furthering writer-reader relationships.

This focus on the social aspects of reading were furthered through the way some writers, in their emendation invitations, addressed their audience. Lydgate and most other writers address invitations to those who 'rede or se' the text, with William Caxton preferring to address those who 'see or here' the text. ${ }^{26}$ Together, the 'see and here' and the 'rede and se' constructions gesture to the encompassing nature of medieval literacy and reading practices, where both those who see or hear the text engage in the work of reading. ${ }^{27}$ Even the person who reads the text through aural apprehension can identify where the metre of a line has gone astray, and see to its correction. This construction first points toward the multivalent understanding of medieval literacy practices: hearing the text, as well as apprehending it with the eye, are both modes of reading. It does mean, however, that members of Lydgate's anticipated audience may not have possessed the writing skills that enabled them to follow through with the provision of corrections. Corrections may then have been enacted more by the most 
sophisticated and learned of readers, such as scribes, instead. Yet the 'see or here' construction, in particular, emphasizes corrective reading as a social practice, in which participation furthers relations among readers in dialogue with each other as they speak of needed emendations to a text. Although readers invited to participate in corrective reading may only effect changes to a single manuscript (although corrections could proliferate through its descendant copies), Lydgate, Caxton, and other writers figured corrective reading as a social activity that provides immediate benefit to its participating practitioners.

In the assumption that readers can correct texts, writers employing the emendation invitation recognize a hallmark of crowdsourced editing today that makes such contributions possible: that is, the accessibility of the medium to non-professional, amateur contributions. The reader who makes corrections to Wikipedia can do so because of its accessible design; in the fluidity and accessibility of manuscript culture, corrective readers simply needed access to a pen and ink in order to register their changes - and only to a knife to scrape away ink in order to rewrite a passage altogether. Fluidity, participation, and interaction mark the convergence among the technologies, practice, and study of open-access editing today and the materials, reading practices, and textual culture of late-medieval England. Both point to how late-medieval English writers, through the invitation to emend their texts, situate readers as participants in the creation of meaning through not reception alone, but also through production. Reading is thus represented as an activity that can include writing; readers and writers exist in a collaborative partnership of mutual benefit.

Lydgate clearly recognizes the possibilities of reader collaboration through emendation, and the value of including readers in the literate community presupposed by his texts. In Troy book, for example, Lydgate employs the humility aspect of the invitation to emend the text in order to engage more directly and equally with his readers: he refers in the prologue not to the text alone, but also to himself as the recipient of his readers' corrective work. At one point, he also enhances this sense of community participation between himself and his readers by addressing them as ' $3 \mathrm{e}^{\prime}$ : ' 3 et in pe story ze may fynde plesaunce / Touching substaunce of pat myn auctour wryt. / And pou ze so be pat any word myssit, / Amendith it, with chere debonaire' (V.3492-5). The plurality of this pronoun figures readers as participants both in a relationship with Lydgate and as participants in a literary community of all those who 'rede 
or se' the text, where membership is gained through the work of participatory reading.

Even for those readers approaching the text alone or in isolation, emendation invitations remind them that others also participate in similar ways, and each reader contributes to the continuing circulation of copies of the work that are ever improved. In this way, Lydgate envisions how reading with an eye turned to emendation becomes a means for participating in a shared literary endeavour. Furthermore, participation carries personal consequences for both text and writer, in addition to the gateway it provides for participation in literary culture of fifteenth-century England. Through his open invitation to emend the text of Troy book, Lydgate presents participation in literary culture as an attainment accessible to all possessing a basic degree of literacy. He does not require the ability to visually apprehend a text, but enough ability to understand metre and sense, so as to identify when a word has been left out or written in such a way that the formal qualities of the verse have been affected. For Lydgate, basic literacy involves familiarity with literary and artistic modes of expression. As participatory reading establishes a sense of community figured around beneficial contributions to a text, Troy book and texts that similarly invite open access to emendation offer a counter to the 'hostility to writing' that had erupted in the late fourteenth century, particularly during the Uprising of $1381 .{ }^{28}$ Rather than figuring texts as a locus of divisiveness between the literate and illiterate, emendation invitations frequently gesture to the inclusivity and accessibility of reading and writing to the author's primary audiences, and to the possibility of furthering relations between writers and their readers.

How emendation invitations charge participatory reading with a sense of community participation invites another association to today's media culture, in the latter's emphasis on the relationship between participation and community. Indeed, scholars of digital media often credit participation with enhancing the social relationship of writers and readers by simulating presence and the give-and-take of conversation, thus providing the grounds for development of trust and familiarity. ${ }^{29}$ In digital media openaccess editing projects, with their feedback loops that facilitate interaction, a sense of community among author, text, and user can be sustained and developed. ${ }^{30}$ In this way, when Noah WardripFruin asked for readers of his blog to offer corrections to his thenforthcoming monograph Grand text auto, he anticipated being 
able to discuss suggestions with his readers through the comment features on his blog interface. ${ }^{31}$ The situation clearly differs in manuscript and print cultures, where exchange is limited to the physical text and its reader, with the writer's presence simulated but not actualized. A change to a reader's copy of a manuscript or print edition does not automatically update a copy to which the writer has access. Yet, by relying on the use of first- and secondperson forms of address as exemplified in Lydgate's emendation invitations, writers in medieval manuscript culture relied on participation through emendation 'to facilitate interactions similar to interpersonal communication'. ${ }^{32}$ In other words, corrective reading offered medieval writers and readers a simulation of interpersonal interaction and education, an evocation of community participation in literary culture that views readers' textual participation as enabling desirable, essential, and beneficial contributions on behalf of a writer, not a text alone. Furthermore, the reliance by Lydgate and other writers on corrective reading, predicated as it is on accepting and developing the accessibility of the manuscript text to readers' contributions, emphasizes how medieval notions of literary community contrast with the idea of the solitary writer that developed over the course of the print era. Corrective readers, today and in the fifteenth century, are social readers. As social readers, they participate in relationships both with the text and the writer as the objects of their correction.

\section{Changing attitudes towards emendation}

One of the fascinating developments in the use of emendation invitations that emerges over the course of the fifteenth century occurs through the wide range of variance in attitudes towards open- or closed-access emendation by readers. These attitudes are not static, but change over time. Although many readers today might expect attitudes towards emendation to change in the wake of the advent of the printing press, seeing it as stabilizing and fixing the form of the text, neither Caxton nor his immediate successors treat print as fixed in ways that prevent the transmission of reader emendations. This expectation regarding the transformative nature of print owes much to the work of Elizabeth Eisenstein's influential work on the introduction of the printing press. ${ }^{33}$ More recent studies, however, attest to how printers and readers, even two centuries after the advent of the printing press in Europe, viewed it as adding little to textual stability, and, in some cases, worsening the reliability 
of the text. ${ }^{34}$ This recognition of the fallibility, malleability, and motility of the printed work may explain much about Caxton's continued reliance on the emendation invitation. Developments in the treatment of emendation invitations appear, instead, to correspond to the genre of the texts offering invitations to emend, the gender of the texts' intended audience, and the professional affiliations of a text's audiences. Surveying emendation invitations written between 1385 and 1499, during which more than thirty authors deploy emendation invitations, reveals trends that can better situate emendation invitations within the literary discourse of late-medieval England.

In general, the ratios of open to closed to hybrid change in significant ways over the course of the fifteenth century. Between 1380 and 1399 , the ratio of open to closed to hybrid is $1: 1: 2$, representing parity between open to closed and a preference for hybrid invitations. ${ }^{35}$ By the end the fifteenth century, that ratio has flipped in dramatic favour of open invitations. Between 1480 and 1499 , the ratio is $5.5: 1: 2 .{ }^{36}$ There are more than five times the number of open invitations for every closed invitation extended to readers. ${ }^{37}$ The general trends suggested by changing ratios of types of emendation invitations reveals, from 1380 to 1430 , a preference for hybrid review that closes participation except to specific groups of participants, particularly among writers of devotional works. The situation then changes markedly. From 1431 to 1495 , the preference is for open invitations. This increase in the solicitation of open-access emendation by readers is facilitated by Caxton, who contributes a significant portion of them, but the rise in numbers predates Caxton and his press largely due to Lydgate's preference for open-access emendation, particularly in poems written in the latter years of his career.

In other words, the technology of the printing press facilitated the change in the ratios towards open-access invitations to emend texts, but did not create that change. Nevertheless, print contributed significantly. Contrasting the ratios of emendation invitation types found in print with those in manuscript from 1475 to 1499 indicates that texts in print trend in favour of open emendation and, with it, corrective reading, 14:1:4. Texts that circulate in manuscript, in contrast, prefer closed invitations, 0:2:1. These ratios reflect changing behaviours and attitudes towards emendation and readers' access across genres and technologies of text. While Lotte Hellinga said of Caxton that his early choice to print short books that might be collected into a volume, followed 
by his publication of Chaucer's Canterbury tales, reflected a way that he had 'made readers', 38 the use and treatment of emendation invitations additionally reflect how writers from the late fourteenth to the early sixteenth centuries represent their investment in the project of making readers. Making readers, and making them work, involves considering how to encourage, direct, or limit corrective reading practices. These considerations were further emphasized by Caxton and his own followers in the early years of the printing press' contributions to English book culture, suggesting that early printers saw the press as providing an opportunity to enhance and further build upon the changing attitude toward readers displayed by other late-medieval writers. ${ }^{39}$ Furthermore, in focusing on participation expressed through the practice of corrective reading, writers locate readers within a constructive, participatory, frequently collaborative understanding of England's literary culture.

These changing attitudes toward emendation and access suggest further developments in behaviour towards and understanding of non-professional readers. Whereas Chaucer emphasizes his authority over that of his readers, and restricts participation to a select few, writers over the course of the fifteenth century appear vigorous in seeking ways to engage readers' direct participation in literary culture. Readers become viewed as capable of contributing to a text in sophisticated ways. The emendation invitations in Lydgate's Troy book to all his readers depict them as capable of doing for his text what only Gower and Strode were represented as capable of doing for Chaucer's. Accordingly, the discourse differentiating the 'learned' from the 'lewid' diminishes and readers gain prominence as collaborative communities whose assistance and participation writers increasingly chose to value and solicit. In this way, Chaucer, Lydgate, and their fellows are evaluating not only their goals for the dissemination, reception, and futures of their works, but they are also considering how engaging the interest and participation of readers in different ways can contribute to the outcomes they seek.

Tracking reader responses to these invitations suggests that they worked with mixed success, either in encouraging or discouraging participation. The majority of changes to Chaucer's Troilus and Criseyde, for example, come from the hands of professional readers, the scribes who recopied Chaucer's work. Analysing scribal variants in Troilus and Criseyde, Barry Windeatt describes how scribes regularly altered Chaucer's more obscure or non-standard diction as they attempted to simplify or literalize the figurative complexity 
of his verse, and demonstrates that these alterations frequently changed the syllabic content of Chaucer's lines. ${ }^{40}$ His analysis has been extended by Daniel Wakelin's broad assessment of scribal correction in late-medieval England, which reveals scribes to have pursued the alterations they made with thoughtful deliberation. ${ }^{41}$ In this light, Chaucer's commendation of his text to Gower and Strode seems as prescient as it was futile: professional readers did as they wished regardless of Chaucer's discouragement. As the majority of marginal comments and glosses appear to be scribal in origin, this suggests that Chaucer's discouragement of generalized corrective reading enjoyed limited success among amateur readers, who more often than not left the text clean of marginalia and, when providing it, did not offer the kinds of corrections other writers sought to elicit.

Perhaps aware of this treatment of Chaucer's texts, Lydgate's opposing invitations to emend Fall of princes, following the pattern established by the invitations of Troy book, also seem to have enjoyed mixed success. Of twenty-nine manuscripts of Fall of princes, twenty-six contain marginalia from readers other than the text's scribes. Of these twenty-six, only two contain the kinds of reader corrections Lydgate specifically elicits, University of Chicago Library MS 565 and British Library Harley 1766 - and in the latter, the changes seem to have been motivated not by a desire to improve the text, but to erase references to the papacy. By and large, scribes effected more corrections to texts in the act of copying them than did amateur readers, whose desire to participate in texts seems to have pursued other imperatives than textual emendation, such as that of noting passages of personal and moral significance.

This seeming disregard by readers of invitations to engage in corrective reading evokes a parallel with the current treatment of crowd-sourced editing. Aside from the highly publicized examples of crowd-sourced editing, such as that employed by Noah Wardrip-Fruin and Shakespeare quarterly, the practice of crowdsourced, open-access peer reviewed editing has subsided since 2011, and attention has shifted to developing tools that facilitate open access to published work, rather than work pre-publication. While diagnosing the challenges facing such a complex practice that extends across disciplines and fields of study is beyond the scope of this book, let alone this chapter, and while noting that implementation of crowd-sourced peer review today differs in scope and aims than the medieval writer inviting his original audience to correct the text, one issue both rely on is the social aspect 
of corrective reading. This social aspect, however, is largely fictive: medieval writers and readers can only enact participation with the text, not with each other; modern crowd-sourcing attempts like that developed by Shakespeare quarterly rely on novelty to draw attention and participation. Situating crowd-sourced editing projects within pre-existing communities has been attempted only by Wardrip-Fruin, who then found himself too overwhelmed to attend to the feedback. It could be, then, that audience take-up of corrective reading in medieval and digital media foundered in part because of how communities that foster investment in the writer-reader relations promoted by crowd-sourced approaches such as corrective reading struggle to coalesce around the texts. Its lack of success may - to inch out further on the limb of speculation - centre around the core of its activity: making readers work. Readers, as will be discussed further in the final chapter, may be resistant to the forms of labour enjoined upon or elicited from them through participatory reading practices, choosing instead to apply their efforts elsewhere.

The absence of widespread engagement in corrective reading in late-medieval England thus speaks to how the invitations to emend have contributed to literary culture in other ways than textual correction, primarily by creating recognition of the agency and ability of readers to participate in literary culture through their reading practices, by creating a discourse focused on that participation, and by the various ways these invitations legitimize the participation of certain groups in contrast to that of others. One of the important consequences of the promotion of open, corrective reading by late-medieval writers is that it positions the community as validating a work and the standards it represents. This is an issue cogent today in ongoing debates about open access, which suggest both promise and threat in the way they offer to shift the responsibility of validation away from closed-access models and institutionalized authority. The transition away from validation of a work by the learned, Latinate elite to the lay, vernacular commons suggests that late-medieval writers, even as they desired to develop and defend their own growing authority, viewed readers - if properly educated about how to read effectively in ways that subordinated their work to the aims of writers - as powerful partners in the development of literary culture. That the interest in corrective reading emerges around and continues to develop and flourish even after the introduction of print suggests that writers and printers, too, saw in it a valuable tool for developing literary community. 
The positions taken by Lydgate in Troy Book and Chaucer in Troilus and Criseyde, as well as that of Norton in the Ordinal of alchemy, and other writers who invited readers to emend their texts, are marked by encouraging emendation by all readers, by some under specified limitations, or discouraging it altogether. In the hybrid invitations mentioned previously, writers qualify open access to emendation in significant ways. A common element of these restrictions on open access includes the gender of their readers. Between 1385 and 1495, for example, 20/23 texts cite gender as a primary or secondary issue in promoting hybrid, not open, access to corrective reading. Furthermore, 11/23 of these texts can be classified as religious in focus, suggesting concerns that perhaps respond to the restrictions of Arundel's Constitutions. Published in 1409, the Constitutions are often credited with creating a perilous climate for writers, translators, and readers of devotional material, because of concerns about being affiliated with Wycliffitism. ${ }^{42}$ While critical discussion in recent years has nuanced long-standing perceptions about the repressive influence of the Constitutions, certainly the discourse focused on restricting open access to corrective reading that emerges in the intersection of religious texts and audiences of women indicates that writers attended to how emendation invitations and the reading practice they promoted might affect or respond to such topical concerns.

A prominent example of this awareness of the topical implications of corrective reading can be identified through the emendation invitation provided in the prologue to the Mirror of our lady. This commentary on and partial translation of the Bridgettine Office used by the nuns at Syon was composed between 1420 and 1450 . The writer of the prologue establishes a partially open, partially closed hybrid invitation to emend the text when he states, '[L]owely I submyt me and all oure wrytynges, and other werkes to the correccyon of oure mother holy chyrche, $\&$ of the prelates and fathers therof, and of all that are wyser and can fele better'. The text conveys some openness to emendation, in that the writer directs the invitation to unspecified male religious, while at the same time discouraging participation from the audience to whom the text is directed, nuns of Syon. To them, he immediately turns and says instead that he, 'Besech[es] you all way mooste dere and deuoute systres to praye that bothe thys, and all other dedes be euer rewlyd to oure lordes worship'. ${ }^{43}$ That is, the work of correction should be left in the hands of men. For the male, clerical audience, 
emendation is an open possibility; in contrast, the writer encourages women readers to pray.

This attempt to limit performance of corrective reading to a subset of the text's audience creates an equivalency between emendation and prayer. Emendation and prayer are opposing, but equivalent responses. This gesture also seeks to control readers' participation by gendering a particular type of reading activity, textual correction, as masculine work. Emendation is men's work; prayer, women's. Accordingly, the practice of corrective reading, which can be leveraged to establish a discourse of control over readers even as it authorizes readers' agency, thus contributes to a gendered discourse of late-medieval censorship. By restricting women's responses to prayer rather than emendation, the text seeks to curtail women's scholarly activities. This gendered treatment of corrective reading additionally represents women's participation as ephemeral, eschewing material textual legacies.

Similarly, concerns that readers or media consumers might go too far, do too much to the media with which they participate, drive much legislation aimed at controlling or even supporting digital media today. For example, the non-profit organization Creative Commons provides text for licenses that help rights owners negotiate the permissions given to others for the use of their works. Licenses address permitted forms of audience participation, interaction, and transformation of works, attempting to mediate among the agency, authority, and rights of users and those of a work's creators. These and other efforts address contemporary concerns regarding the sometimes-threatening ability of media consumers to become creators of modified and re-envisioned material. As participatory media have increased in popularity and ease of access, a 'backlash' has developed 'of new technologies, softwares, and legal methods that actively seek to prevent alteration and re-distribution of texts'. ${ }^{44}$ Such concerns form a modern practice in comparison to which we can consider late-medieval attempts to control the creative, participatory abilities of readers, who may, at any moment, assert their own control over a text.

In views that express concern regarding how readers' changes could threaten the integrity of their works, medieval writers' comments can consequently be seen to reflect a developing awareness of their works as the product of their own creative effort. This presages a developing recognition of creative literary production as intellectual property that goes hand-in-hand with the developing notion of authorship as discussed by Alastair Minnis. ${ }^{45}$ That is, 
as writers explored strategies to define and secure their status as authors, not merely copyists collecting or adding to the work of ancient authorities, writers saw readers as possessing the ability to affect that status. The developing authority of writers could be threatened by corrective readers running amok. These concerns regarding the agency of readers are part of the landscape of latemedieval England, for reader authority intersected with concerns about heresy, particularly in the wake of Arundel's Constitutions. As has been discussed by Katherine Kerby-Fulton, however, modes of literary censorship antedate and postdate the Constitutions, and an attitude of tolerance existed even in the climate from which the Constitutions arose. ${ }^{46}$ In consequence, recognizing the role of participation as articulated through the discourse of corrective reading in late-medieval English literature provides insight on premodern ideas of textual ownership. Yet, as in today's culture, reader participation could be as problematic as it was desirable. Participatory reading practices, even as they offered a means for instructing readers in how they should behave towards texts, motivating them, and engaging them in a literary community, could be - for some writers - too accessible, too extensive, and too empowering.

Although the roles of women in restrictions imposed upon corrective reading are especially telling for how medieval writers distinguished among their potential audiences and the abilities or potential of those audiences, women were not the only readers subject to restrictions placed upon corrective reading. Some writers also articulate separate approaches to Latinate readers and vernacular audiences, whom they view as differently able to engage with the text through corrective reading, and whose participatory reading is, consequently, differently valued. This attitude towards the participatory reading of diverse audiences is articulated in the Pricke of conscience around 1400 and in a Wycliffite glossed Gospel of Matthew written in the first half of the fifteenth century. Both restrict corrective reading to the learned, inviting emendation only from 'any man pat es clerk' and any 'lerid man in holy writ'. ${ }^{47}$ John Capgrave, in his Life of St Norbert, tells the 'noble men' who wish to 'race / Or rende my leuys' - a rather violent means of interacting with the text - that he leaves the work in their hands to do so if they wish. In Stans puer ad mensam, Lydgate's verse instructions about etiquette for children, he simply claims responsibility for errors without encouraging youthful readers to correct them or offering to emend them himself. Lastly, John Russell, who wrote his Boke of Nurture on the life of royal household service in the middle of 
the century, invites corrections from the 'yonge gentilmen' for whom he has written. ${ }^{48}$ These attitudes suggest that, even as many writers viewed 'all who rede or se' a text as able to engage in corrective reading, they nevertheless distinguished some audiences as better fit for it, and better able to offer productive responses.

\section{Conclusion}

The comments about corrective reading described in the texts cited here, from Chaucer to Caxton and beyond, manifest how the participatory practice of corrective reading, as noted today in conversations about open-access editing, enables conferment of 'group identity', and facilitates 'the textualization of social relations'. ${ }^{49}$ 'Through emendation invitations, late-medieval English texts become bodies through which not only changing ideas about readership, authorship, and participation in literary culture become worked out, but that also reflect the complex networks of social relations in an increasingly socially mobile culture. Emendation invitations depict how writers distinguished their work's reception among various audiences, and categorized these audiences according to networks of patronage, political hierarchy, gender, education, and professional relations. These varying attitudes towards corrective reading further attest to how - as Deleuze and Guattari have observed of the book more generally - late-medieval invitations to emend texts were understood to 'fix territories and genealogies'. ${ }^{50}$ In other words, some texts offered territories open to the emendation of many categories of potential readers, whereas others closed these territories to a select few; through opening or closing the territory of the text, writers sought to shepherd and guide the transmission of their works across generations of copies.

Corrective reading functions as a participatory, interactive reading practice responsive to the materiality of the manuscript as a writing technology. Medieval manuscript culture was predisposed to participatory practices, given the number of 'nontrivial efforts' required 'to traverse the text', 51 for instance, the work required to expand abbreviations. That corrective reading continues to be deployed as a strategy for relating to readers in printed texts attests to the slowness of recognition that print represented a technology that functions in ways other than how manuscripts function. The use of corrective reading invitations in print books for decades after their introduction also attests to the ongoing influence of the idea of the participatory reader who contributes productively to 
the transmission of a text. Furthermore, in a practice to which I will return in later chapters, materiality becomes significant for the way it shapes the possibilities of participatory reading practices. Corrective reading can be made possible and recommended to readers because the material body of the manuscript is accessible to readers' interventions. In advocating for its use, medieval writers give careful thought to the different ways material conditions impact and facilitate reading experiences. Finally, the invitational strategies that focus on emendation have not been recognized as contributing to late-medieval constructions of readers, yet manifestly they fashion the reader in important ways. They also affect the reception of medieval texts. Scholars now recognize that such contributions - emendations, modified prefaces, added passages - create texts worth study, not texts viewed as ravaged by the errant interventions of wayward readers. Beyond the reconsideration of the value of reader emendation stands the participatory reader, whose figure gave focus to writers' expectations about their audiences.

References to reader participation, rare in Middle English or Anglo-Norman works before the late fourteenth century, flourish in the fifteenth. This rise in the articulation of a discourse of participation provides insight on developing expectations for lay vernacular readers, as the increase in literacy intersected with the growing popularity of the English vernacular and the heightened production of books. Participation facilitates transformative reading practices: in the late Middle Ages as now, the spread of access to materials and technologies created both controversy and acclaim, those who wanted to support and those who wanted to control. ${ }^{52}$ The presence of participation gestures toward textual practices and a concept of the reader that we have only recently begun to access, a reader whose deep engagement with texts could create as well as receive, and traces a more communal relationship between writer and reader that was later lost as the authority of print became fixed.

Texts inviting or discouraging participation, such as Troy Book and the Ordinal of alchemy, illustrate tensions among author, text, and readers that were occasioned by participation. They also demonstrate that such participation, as useful as it could be, was not always desirable. The empowered reader could at times be a threat as much as an ideal, and the tensions raised by participation could occasion 'a struggle for control over the authorial "purity" or "authenticity" of the text'. ${ }^{53}$ Such struggles encompass a variety 
of participatory practices. These struggles also reflect ongoing negotiations about emergent ideas of authorial control, textual integrity, and reader control. Lydgate, Caxton, and other writers position themselves as writers willing to collaborate with readers who are eager to engage deeply and constructively with their works - a position that does much to inform readers of the attitude with which they were expected to receive texts. Encouraging or discouraging corrective reading thus became a means of educating readers regarding how they were to read, and the behaviours appropriate reading entailed. Corrective reading and participatory reading practices more generally, in effect, contributed to a discourse of reading etiquette. Accordingly, the study of participation in medieval texts enables us to understand previously overlooked details of the reading process. Corrective reading practice, as elicited or discouraged in these works, including Lydgate's and the dozens of others that explicitly invite it, also demonstrates medieval recognition of the fluidity of texts within the register of reading practices.

By seeking out evidence for participatory reading practices, and recognizing how corrective reading offers a practice for textual participation, we can also turn to studies of other readers, such as the professional readers of the Douce Piers Plowman or Guillaume Machaut's Voir Dit, and re-evaluate such responses. ${ }^{54}$ The professional readers who modify, alter, or otherwise leave their traces through the text of these works respond to them within what is clearly becoming a participatory tradition focused upon the practice of corrective reading. We may, then, also look for how other readers might resist or alternatively interpret the discourse of corrective reading, as exemplified by Norton, who discourages corrective reading only to promote, instead, an alternative of disciplined, temporally contextualized rereading.

In considering who participated in response to emendation invitations, I have here and above distinguished in some contexts between the category of all readers and that of scribes as professional readers. Doing so follows recent critical trends that examine how scribes acted as the first readers of texts. ${ }^{55}$ Yet this is a point worth re-evaluating in the light of emendation invitations and the corrective reading they promoted, particularly with reference to writers' own sense of authority. That is, by themselves treating scribes as part of the community of their readers, late-medieval writers distinguished more emphatically between their roles and their authority and that of scribes. Given that St Bonaventure's long-standing definition of a writer included scribes in their role 
as copyists, the choice of late-medieval writers to treat scribes not as fellow-writers, but as readers, signals how these writers sought to use emendation invitations to further authorize themselves. In other words, emendation invitations offered a rhetorical, persuasive discourse by which to distinguish authorial from scribal work. This makes a distinction between creative effort, textual reproduction, and emendation: in these writers' eyes, they are not only different types of work, but they belong to different literary identities. One type of work is that of the author. The others are situated as enjoying a lesser status that provides the ground for reclassifying scribes not as writers, but as readers. That writers nevertheless occasionally sought to distinguish scribal work as somewhat other than that of the general reader also testifies to how uneasily scribes fit into the category of readers. Consequently, the emendation invitation crafts a writer-text-reader triumvirate that strategically elides how scribes moved between the roles of writer and reader. In this way, variations in the discourse of corrective reading attest not only to the tension that surrounded the identity of the writer and the identity of the reader, but also to how the definition of who belonged in the category of 'reader' played a crucial role relative to the changing definition of 'writer'.

These are conversations pursued today in discussion of academic publishing trends. That they arise in a moment that, in parallel to the situation of late-medieval England, is characterized by increasingly diverse modes of literacy and accompanied by technological developments that increase ease of access to both books and writers, is not coincidental. Such conditions clearly impact how boundaries between writers and readers are both distinguished and deterritorialized; they also influence participation and its development as a culture of practice. Accordingly, it may be worth consideration, today, how Lydgate, Caxton, Chaucer, Norton, and other writers viewed the possibilities of accessible emendation and its potential to shape communities. Rather than pursuing the model of the text that eventually develops in the long history of print, that of the fixed text to whom the readers' contributions materially and socially remain constrained and marginalized, it could benefit to think of alternatives. The open-access style of emendation invitation situates the manuscript text and its iterations, as its copied and recopied, as a nexus for social interaction between writers and readers; it contributes to the development of a social economy of writer-reader relations that has not yet become dependent upon economic exchange. Instead, the social economy facilitated by 
corrective reading figures participation as central to responding to a defining characteristic of manuscript culture: the possibility for textual flexibility. The work, even after its dissemination to the public, is never fixed. In its lack of fixity opportunity arises for ongoing social exchange, mediated through the pages of the text. Given the as-yet inability of crowd-sourced editing to affect in substantial ways the institutional editing practices of academic publishing that might, as I have suggested above, struggle in part because of the absent social culture around sites for disseminating work pre-publication, what culture might flourish within the realm of academic publishing today if digitally distributed essays and monographs were viewed as sites for ongoing conversation and exchange between writers and readers?

Finally, the practice of corrective reading, demonstrated through the emendation invitations that solicit it, continues into the first centuries of print culture. As David McKitterick discusses in his detailed account of reading practices and book history, 'From the sixteenth to the eighteenth centuries, readers were requested by authors, stationers and printers alike to amend with the pen what had been set and printed in type'. ${ }^{56}$ Writers did not cease to invite readers to participate and contribute materially to their texts with the introduction of print; such invitations continued to be a commonality of the possible ways in which readers could participate with those responsible for textual production and dissemination. Reliance upon modes of participatory reading, even well after the development of print culture, continued and flourished. Yet in how these invitations to emend identify the person to receive corrections, emendation invitations also reflect growing awareness of the particular material considerations of print. Readers, no longer able to effect changes to texts themselves in ways that would be transmitted to successive copies of a work, were invited to submit suggested corrections not only to authors, but to printers and publishers as well. The identification of alternatives to authors for receiving corrections gestures to the role played by printers both as gatekeepers to publication and as professionals concerned about, and interested in increasing, the fixity and reliability of printed texts. Thus, although Caxton represents the continuation of medieval practice in how he invites readers to engage in effecting corrections themselves, subsequent reliance of the emendation invitation, by the late sixteenth century, reflects how technological change affected not the act of corrective reading itself, but the material realities of changing modes of textual tradition. The continuance 
of emendation invitations also suggests that, even though the fixity of the printed text limited the transmission of readers' corrections to subsequent copies of the work, corrective reading continued to play a valued role in shaping relations among writers, readers, and printers, and the texts that interested them all.

\section{Notes}

1 Representative comments about the humility topos describe it as no more than the passing offer of 'a hackneyed humility' (Margaret Connolly, in Fohn Shirley: book production in the noble household in fifteenth-century England [Aldershot, UK and Brookfield, VT: Ashgate, 1998], 45) or the merely 'topical expression of (usually false) modesty' (John Dagenais, The ethics of reading in manuscript culture: glossing the Libro de Buen Amor [Princeton: Princeton University Press, 1994], 24).

2 For examinations of the humility topos and its classical tradition, see Ernst Robert Curtius, European literature and the Latin Middle Ages, transl. Willard R. Trask (Princeton: Princeton University Press, 1990), 407-13; see also Barbara Newman, who examines its use in relation to women in Sister of wisdom: St. Hildegarde's theology of the feminine (Berkeley: University of California Press, 1987), 2-3, 35, 114-15, 182, 248, and 254-7. For examples of its use in Middle English, see Wogan-Browne et al., Idea of the vernacular.

3 From Fall of princes, ed. Henry Bergen. Early English Text Society extra series 121-4 (London: Oxford University Press, 1924-27), at lines 3378-9.

4 The Anglo-Norman 'Alexander' ('Le Roman de Toute Chevalerie') by Thomas of Kent, ed. Brian Foster, with the assistance of Ian Short, 2 vols. Anglo-Norman Text Society 29-33 (London: Anglo-Norman Text Society, 1976-7), lines 6655-6.

5 See in particular Seth Lerer, Chaucer and his readers: imagining the author in late-medieval England (Princeton: Princeton University Press, 1993), and Stephanie Trigg, Congenial souls: reading Chaucer from medieval to postmodern (Minneapolis: University of Minnesota Press, 2002).

6 Quotes from Chaucer's works come from the Riverside Chaucer. 3rd ed., ed. Larry D. Benson (Boston: Houghton Mifflin Co., 1987). Here, the lines cited are from V.1793-8 and 1856-9 in Troilus and Criseyde.

7 See, for example, Paul Strohm, 'Chaucer's fifteenth-century audience and the narrowing of the "Chaucer tradition"', in Writing after Chaucer: essential readings in Chaucer and the fifteenth century, ed. Daniel J. Pinti (New York and London: Garland Publishing, 1998), 107-8, and Anita Obermeier, The history and anatomy of auctorial 
self-criticism in the European Middle Ages (Amsterdam: Rodopi, 1999), 191-2.

8 Gilles Deleuze and Felix Guattari, A thousand plateaus: capitalism and schizophrenia. Trans. Brian Massumi (Minneapolis and London: University of Minnesota, 1987), at 127.

9 The terms 'proleptic' and 'retrospective' are discussed more fully by Wakelin in 'Instructing Readers in Fifteenth-Century Manuscripts', at 433-4.

10 Quotations here and following are from the Troy Book, lines P.379-84. See Appendix A for other examples of emendation invitations.

11 Ibid., V.3476, 3484, and 3494. Shortly after this passage, Lydgate echoes Chaucer's words in his poem to Adam Scriveyn when he writes that he wonders if there might be anyone capable of following in Chaucer's traces, and if there is anyone, Lydgate is, 'Besechyng hem, with her prude loke, / To race \& skrape boruz-oute al my boke, / Voide $\&$ adde wher hem semeth nede' (V.3537-9). In addition to his earlier open call for emendation, here Lydgate makes a Chaucerian, learned request for editorial intervention from a colleague.

12 Ibid., V.3498.

13 See, for example, Thomas Hoccleve's Regiment of princes, in which Hoccleve explains: 'For whan a man y-falle in-to errour is, / His brother ought hym counseille \& rede / To correcte \& amende his wikked dede; / And yf he be vexed with maladie, / Mynystre hym helpe, his greef to remedie' (lines 2488-92, in the edition ed. by F. J. Furnivall, EETS extra series [hereafter e. s.] 72 [London: K. Paul, Trench, Trübner \& Co., 1897]).

14 See Dan Cohen, 'The social contract of scholarly publishing', an influential blog post, originally published in 2010, that shaped the debate surrounding modes of access to publishing and editing. Reprinted in Debates in the digital humanities, ed. Matthew K. Gold (Minneapolis and London: University of Minnesota Press, 2012), 319-21.

15 See, for example, John Lydgate's Troy Book, where one of the invitations (discussed earlier in this chapter) occurs in book five of the poem.

16 Norton has been little-studied even in the wake of the publication of a critical edition of the Ordinal, which circulated in more than two dozen manuscript copies. In what is perhaps the most substantial article devoted to the study of Norton since the publication of the critical edition in 1975, Cynthea Masson argues that Norton approaches his audience with a 'pedagogical agenda' ('Poetry and pedagogy in Norton's Ordinal of alchemy', in Florilegium 17 [2000], 45-58, at 46). For the critical edition, see John Reidy, ed., Ordinal of alchemy, Early English Text Society o. s. 272 (London: Oxford University Press, 1975), from which all quotations are drawn.

17 See Appendix A for examples of other writers employing open-access corrective reading invitations. 
18 Norton explains that the text is 'sett owte in englishe blonte \& rude, / For this is so made to teche a multitude / Of rude peple' (lines 3089-91).

19 Norton and Lydgate both write from the perspective of authors utilizing manuscript for the transmission of their works, but the sentiments they express change little with the introduction of print. Many of Caxton's prologues may be viewed almost as quotations of Lydgate (see Appendix A), and the expectation that readers may alter the texts they view in error flourishes over the course of the sixteenth century. For example, see Percy Simpson's Proof-reading in the sixteenth, seventeenth, and eighteenth centuries (Oxford: Oxford University Press, 1970), 25-31. Simpson's offers the most extended analysis of the continuing use of what I call emendation invitations in early modern print culture.

20 The first word of the preface and first two or three letters of the first words in each subsequent chapter spell out, 'liber Thomas Norton of Bristol. A perfect master ye may him trowe'. Jonathan Hughes views use of the acrostic as Norton's attempt to conceal his identity because he critiques Edward IV in the Ordinal. See 'Politics and the occult at the court of Edward IV', in Princes and princely culture: 1450-1650, vol. 2. Ed. Martin Grosman, Alasdair MacDonald, and Arie Vanderjagt (Leiden: Brill, 2005), 97-128, at 125.

21 Cf. Engelsing, 'Die Perioden der Lesergeschicte in der Neuzeit'.

22 For entries into the discussion about open and closed access, see Peter Suber, Open access (Cambridge, MA: MIT Press, 2012); Martin Paul Eve, Open access and the humanities: contexts, controversies, and the future (Cambridge: Cambridge University Press, 2014).

23 For posts by Wardrip-Fruin with readers' comments, and for WardripFruin's evaluation of the process, see https://grandtextauto.soe.ucsc. edu/category/expressive-processing/. For the Shakespeare Quarterly crowd-sourced editing issue (61:3, Fall 2010), see its introduction by Katherine Rowe, guest editor, at http://mediacommons.futureofthebook.org/mcpress/ShakespeareQuarterly_NewMedia/.

24 On the development and identification of this generation of internet culture as a sharing economy, see Nicholas A. John, 'Sharing and Web 2.0: The emergence of a keyword'. New Media and Society 15:2 (2012), $167-82$.

25 Kathleen Fitzpatrick, Planned obsolescence: publishing, technology, and the future of the academy (New York: NYU Press, 2011), at 56. For an assessment of how this might affect publishing in medieval studies, see Holly Crocker's introduction to the postmedieval forum discussion on the status of academic review, 'Introduction: how open, or, can vulnerability go digital?’ Online at https:/postmedieval-forum.com/ forums/forum-ii-states-of-review/introduction/ along with the other essay distributed in this forum. 
26 See Appendix A for other examples of invitations to emend; that quoted from William Caxton can be found in his publication of the Golden Legend, excerpted in The prologues and epilogues of William Caxton, EETS 176, ed. W. J. B. Crotch (London: Oxford University Press, 1928), at 73.

27 This point also applies to the expansiveness of medieval media practices, an issue addressed further in subsequent chapters.

28 See Crane, 'The writing lesson of 1381', 204.

29 Rodney H. Jones and Christoph A. Hafner, Understanding digital literacies: a practical introduction (London and New York: Routledge, 2012), at 43; Marohang Limbu, 'Digital and global literacies in networked communities: epistemic shifts and communications in the cloud era', Digital rhetoric and global literacies: communication modes and digital practices in the networked world, ed. Gustav Verhulsdonck and Marohang Limbu (Hershey, PA: IGI Global, 2014), 131-153, at 141.

30 Although not to any great degree - no work of interactive fiction of which I am aware positions the writer at the keyboard, able to respond in person to each interaction of readers with her text. Rather, the modifiability of hypertext fiction produces an illusion of readers and writers engaged in dialogue through the text and the technological means of displaying it. This point further illustrates what Wendy Chun refers to as the fantasy of freedom (here, the freedom to converse beyond the physical boundaries of immediate presence) developed in digital media discourse (Control and freedom: power and paranoia in the age of fiber optics [Cambridge, MA: The M.I.T. Press, 2006]).

31 It is worth noting that Wardrip-Fruin discovered this expectation to be a fantasy: he did not have time to address the comments he received. See 'Blog-based peer review: four surprises', http://grandtextauto. org/2009/05/12/blog-based-peer-review-four-surprises/ at paragraph 21 and following. This suggests, as will be discussed below in its medieval application, crowd-sourced, open-access approaches did not produce a sustainable practice for writers or readers.

32 Spiro Kiousis, 'Interactivity: a concept explication', in New media and society 4.3 (2002), 355-83, at 356.

33 Elizabeth Eisenstein, The Printing press as an agent of change: communications and cultural transformations in early-modern Europe. 2 vols. (Cambridge: Cambridge University Press, 1979).

34 For a magisterial response to Eisenstein's argument, along with a detailed counter depicting seventeenth-century attitudes towards the instability of printed texts, see Adrian Johns, The nature of the book: print and knowledge in the making (Chicago: University of Chicago Press, 1998).

35 In this and all the ratios following, the first number represents the portion of open invitations; the second, closed invitations; and the 
third, hybrid invitations. For this first ratio, the raw totals of open, closed, and hybrid invitations are: 1, 1, 2 .

36 For 1480-99 the raw numbers of invitations total 11, 2, 4.

37 See Appendix A for quotations from texts providing invitations to emend.

38 Lotte Hellinga, Caxton in focus: the beginning of printing in England (London: British Library, 1982), 101-2, at 102.

39 On the role of the printing press in this period, see Julia Boffey, 'From manuscript to print: continuity and change', in $A$ companion to the early printed book in Britain, 1476-1558, ed. Vincent Gillespie and Susan Powell (Woodbridge, UK, and Rochester: Boydell and Brewer, 2014), 13-26.

40 Barry Windeatt, 'The scribes as Chaucer's early critics', Writing after Chaucer: essential readings in Chaucer and the fifteenth century, ed. Daniel Pinti (New York: Routledge, 1998), 27-44. Ralph Hanna discusses even more significant textual differences in the stemmatic affiliations of Troilus manuscripts in Pursuing history: Middle English manuscripts and their texts (Stanford: Stanford University Press, 1996), in chapter seven, 'The manuscripts and transmission of Chaucer's Troilus', 115-29.

41 As Daniel Wakelin argues in Scribal correction and literary craft: English manuscripts 1375-1510 (Cambridge: Cambridge University Press, 2014), however, emendation is one of the ways scribes commonly adjusted and interacted with the texts they copied.

42 Subsequent scholarship has complicated the argument that the Constitutions generated a climate of censorship and can be partly held responsible for the 'dullness' of fifteenth-century literature, but for the most influential voice supporting this analysis of the Constitutions as exerting a repressive effect on vernacular religious literary composition, see Nicholas Watson, 'Censorship and cultural change: vernacular theology, the Oxford translation debate, and Arundel's Constitutions of 1407'. Speculum 70:4 (1995), 822-64. For an overview of responses to Watson's argument, see the special issue of English Language Notes 44:1 (2006), 'Vernacular theology and medieval studies: literary history and the religious turn', ed. Bruce Holsinger and Elizabeth Robertson, dedicated to this topic.

43 From The myroure of oure ladye, EETS e. s. 19. Ed. John Henry Blunt (London: N. Trübner \& Co., 1873, repr. 1998), 8-9.

44 Rob Cover, 'Audience inter/active: interactive media, narrative control and reconceiving audience history', in New Media $\Xi^{\circ}$ Society 8.1 (2006), 139-58, at 140 .

45 See Minnis, Medieval theory of authorship.

46 See Katherine Kerby-Fulton, Books under suspicion: censorship and tolerance of revelatory writing in late medieval England (Notre Dame, IN: Notre Dame University Press, 2006). 
47 The Pricke of Conscience quote comes from The pricke of conscience (stimulus conscientiae): a Northumbrian poem by Richard Rolle de Hampole, ed. Richard Morris (Berlin: A. Asher, 1863), line 9587; the Wycliffite gloss is transcribed in Margaret Deansely, The Lollard Bible and other medieval biblical versions (Cambridge: Cambridge University Press, 1920), at 457. Excerpts from both texts are available in Appendix A.

48 All the texts referenced above are excerpted in Appendix A. The Capgrave quote comes from The life of St. Norbert by $\mathcal{F}$ ohn Capgrave, ed. by Cyril Lawrence Smetana (Toronto: Pontifical Institute of Mediavel Studies, 1977), lines 19-28. John Lydgate's Stans puer ad mensam and John Russell's Boke of nurture are available in Early English meals and manners, ed. F. J. Furnivall. E.E.T.S. o. s. 32 (London: N. Trübner, 1931); the relevant lines of Stans puer are 92-9 and, of the Boke of nurture, 1235-8.

49 Sande Cohen, 'Publication, knowledge, merit: on some politics of editing'. Cultural critique 75 (Spring 2010), 114-47, at 126.

50 Deleuze and Guattari, A thousand plateaus, 127.

51 Espin Aarseth, Cybertext: perspectives on ergodic literature (Baltimore: Johns Hopkins University Press, 1997), 1.

52 For the most influential discussion of books and manuscripts as technologies, see Jeffrey Masten, Peter Stallybrass, and Nancy Vickers, 'Introduction: language machines', in Language machines: technologies of literary and cultural production, ed. Jeffrey Masten, Peter Stallybrass, and Nancy J. Vickers. (London and New York: Routledge, 1997), 1-16, esp. 3-5.

53 Cover, 'Audience inter/active', 140.

54 Kerby-Fulton and Despres, Iconography and the professional reader, and Deborah McGrady, Controlling readers: Guillaume de Machaut and his late medieval audience (Toronto: University of Toronto Press, 2006).

55 See, for example, Wakelin, Scribal correction and literary craft and the essay collection Author, reader, book: medieval authorship in theory and practice, ed. Stephen Partridge and Erik Kwakkel (Toronto: University of Toronto Press, 2012), and Matthew Fisher, Scribal authorship and the writing of history in medieval England (Columbus, OH: Ohio State University Press, 2012).

56 David McKitterick, Print, manuscript and the search for order, 1450 1830 (Cambridge: Cambridge University Press, 2003), 183. 


\section{Nonlinear reading: the Orcherd of Syon, Titus and Vespasian, and Lydgate's Siege of Thebes}

Published in 1549, The book of common prayer for the first time presented the reformed services for worship as reconceived in the wake of English separation from the Church of Rome. In considering medieval reading practices, a passage from its preface deserves particular attention. The preface targets for condemnation the consequences of what it considers flawed Catholic practices of textual organization, stating that the Bible 'hath be so altered, broken and neglected by plaintyng in uncerteyne stories, Legendes, Responds, Verses, vaine repetitions, Commemorations and Sinodalles', and asserts that such additions 'breake the continual course of the reading of the scripture' $\left(\mathrm{Aii}^{\mathrm{r}}-\mathrm{iii}{ }^{\mathrm{r}}\right)$. The book of common prayer thus targets practices of textual organization that can be considered collative, relying on the collation of multiple external texts or excerpts drawn together into a single work. ${ }^{1}$ Perhaps the most commonplace example of such a work is one that dominated literary and devotional culture in the later Middle Ages, the book of hours. How books of hours compiled texts together, drawn from the Bible and liturgical books, leads directly to the condemnation issued in The book of common prayer. As addressed in the preface, this type of textual organization also prompts a particular reading practice.

This reading practice is known as 'nonlinear', 'nonsequential', or 'selective' reading, and it is most conventionally performed when apprehending a text organized into sections, called 'nodes' or 'lexia' in digital media. ${ }^{2}$ The number of terms to describe the concept refers to an inherent contradiction: nonlinear, discontinuous, nonsequential reading can still be said to occur linearly, continuously, or sequentially, as a reader follows the order of words in grammatical sequence or creates a sequence even out of image and text located in separate regions of the page. I have followed the usage of digital media critics in my preference for the term 'nonlinear', in part because it also relates to terms used 
to describe both structural and narrative organization, as will be discussed below. In nonlinear reading, readers select their own paths of navigation among lexia, as, for example, when someone clicks from one link to another to move between pages of a website. In its discussion of textual organization and reading, The book of common prayer represents texts designed to facilitate nonlinear reading as characteristic of outmoded, misleading ideology. In their stead, The book of common prayer encourages religious reform by promoting changes to reading practices, focused in particular on a linear approach to reading scripture. ${ }^{3}$

The passage from The book of common prayer demonstrates several points relevant to the study of medieval reading practices. It indicates that the form of the codex was not viewed as inherently linear, for the way that texts were included and arranged could invite readers to navigate its pages in nonlinear ways. It also shows how, by the mid-sixteenth century, textual organization and reading practices could be linked together to such a degree that the kinds of 'broken' or 'continual' reading that modes of textual organization prompt scarcely need explanation. In effect, The book of common prayer demonstrates that writers understood how their organization of texts bore consequences for the ways people apprehended them. For example, arranging a work to be uninterrupted by the 'plaintyng' of other lexia prompts a 'continual course' of reading. In other words, at its most basic, linear textual organization prompts linear reading, and nonlinear organization prompts nonlinear reading. ${ }^{4}$ Building on these points, in this chapter I contend that medieval writers produced texts shaped by norms of textual organization to influence the results of reading practices, in terms of both apprehension and interpretation.

Although nonlinear reading invitations flourish in late-medieval English literature, they do not originate in this period any more than nonlinear reading originates in the era of digital media. Rather, as with emendation invitations, they trace their roots to a long tradition of sophisticated Latinate reading practices stretching back for centuries. Martin Foys argues that Anselm's use of nonlinear reading - particularly through the hypertextual organization of his Orationes sive meditationes (Prayers and meditations) into sections accessible nonlinearly and dynamically - 'erases [the] interface' of the physical text's material manuscript instantiation in order to 'rende[r] the act of reading transparent' (46). ${ }^{5}$ In contrast, consider how Walter of Chatillon, writing in the 1170s, references nonlinear reading in The Alexandreis: at the end of the prologue, he 
writes, 'Nunc autem quod instat agamus, et ut facilis que quesierit quis possit inuenire, totum opus per capitula distinguamus', that is: 'Now let us undertake what is at hand and mark out the whole work with chapter headings, so that the reader can more easily find what he seeks' ${ }^{6}$ (11. 40-3). Walter's explanation of the division of his work into chapters conveys his recognition that his Latin-literate, learned readers already know how to read nonlinearly, and will read nonlinearly regardless of the organization of the text. He indicates that he only hopes to make that practice easier for them through his provision of markers to identify textual divisions.

Late-medieval English writers' attempts to introduce these practices to their audiences of the fourteenth and fifteenth centuries testify to how they used these Latinate reading practices to teach their readers. These readers did not resemble the writers themselves, learned in Latin, nor did the writers even closely resemble those of previous centuries. In their turn to practices like nonlinear reading, such writers, as Vincent Gillespie notes, were 'prompted by the increasing range of vernacular materials available to compilers and collectors and by the increasing sophistication of readers and of the demands they were likely to make on books'. Yet, in their approach to nonlinear reading, late-medieval writers also move beyond the demands of readers by transforming it, for writers recommending its use to their readers turn to nonlinear practice to teach their readers not only how to read in a sophisticated way, but also to reflect writers' growing understanding of themselves as authorities on their texts and creators of a relationship with their readers that relies on their readers' participation with them and their texts. This use of a reading practice to represent writers' and readers' authority again, as with emendation, testifies to a developing discourse of participatory reading that also reflects increased understanding of what reading by unlearned audiences could entail, and shows how writers conceived of the ways they might participate through their texts with readers. It also describes what work readers could be expected to accomplish.

\section{Nonlinearity in the Orcherd of Syon}

One of the expressions of nonlinearity in late-medieval English literature most familiar to today's audiences of medieval literature appears in the Orcherd of Syon, a fifteenth-century translation of the dialogues of Catherine of Siena. The instructions given to readers in the prologue by the translator deploys language common 
to other explicit descriptions of late-medieval nonlinear reading. Consequently, it represents an exemplary norm by which to assess nonlinear reading. The translator writes:

Therefore, religiouse sustren, in pis goostli orcherd at resonable tyme ordeyned, I wole bat ze disporte $30 u$ and walke aboute where 3e wolen wip zoure mynde \& resoun, in what aleye zou lyke, [and] namely pere ze savouren best as ze ben disposid. 3e mowe chese if 3e wole of xxxv aleyes where ze wolen walke, bat is to seye of $x x x v$ chapitres, o tyme in oon, anopir tyme in anopir. ${ }^{8}$

Comparing the text to an orchard and its chapters to the paths within it, the translator encourages readers to 'savour' the chapters in the order that suits them best. This recommendation immediately links the mode of apprehension, nonlinearity, to interpretation. Apprehending the text nonlinearly promotes its interpretation as desirably consumable in an intense, lingering way. This is a feature shared among the instructions to read nonlinearly in the Orcherd and other fifteenth-century Middle English works, and it depicts a practice that supports the kind of intensive reading predominant in book culture in the Middle Ages and early modern periods. In the Orcherd and texts like it, apprehension is frequently and explicitly connected to interpretation, specifically in the way nonlinear apprehension promotes affective interpretation. ${ }^{9}$

In contrast to Walter of Chatillon, who represents his readers as employing nonlinear reading in order to seek out particular passages already known in advance, and therefore already familiar with its practice and simply in need of navigational aids, the Orcherd translator takes an approach that implies that his readers, an audience of nuns, will not initially understand how to take advantage of the division of the work into chapters unless he explains to them how they should access this division of the text through nonlinear reading, and describes the advantages nonlinear reading offers to interpretation. As with emendation, the treatment of participatory reading differs in its application to different genders. The majority of explicit invitations to read nonlinearly emerge in texts aimed at audiences of women, whom writers assume need the basic instruction in nonlinear reading - even as most women readers learned to read via the book of hours, inherently a nonlinear text. In contrast to Anselm's use of nonlinearity, the author of the Orcherd's prologue emphasizes the textual organization not to make it transparent, but to explain it to readers that they become mindful of how they read and how the organization of the text can 
further their experiences with it in ways that help them develop as more sophisticated readers.

Another prominent feature shared among the Orcherd and other invitations to read nonlinearly emerges through how nonlinear reading works relationally by allowing readers to juxtapose sections or chapters of a text. The reader, at her own discretion, determines the sequence in which she proceeds through the text. It is a nonlinear sequence in which, as another fifteenth-century translator explains, 'is not nede to begynne at the begynnyng, but where it plesith hym best': the reader begins and concludes reading in whatever passage of the text she prefers. ${ }^{10}$ Any text can be apprehended in this way, although the Orcherd and a few other texts that advocate nonlinear reading explicitly turn to textual division to explain how it might be accomplished.

In addition to its explicit promotion of nonlinear reading as a reading practice requiring participation among reader, text, and writer, the Orcherd of Syon prologue uses the metaphorical language of participation that in later chapters will be explored as literal aspects of reading praxis. These metaphors focus on place and mobility, consumption, and time. Use of this metaphorical language of participatory reading in this fifteenth-century English text demonstrates how deeply participation as a mode of reading experience functions in late-medieval literary culture, and how it conveyed meaning that also shapes perception of its literal practice.

First, the translator recommends readers treat the text as a physical space, an orchard, which is laced through with many divergent paths. This speaks to the nonlinear work of reading, but also contextualizes it in a location remediated by human hands, characterizing Catherine of Siena's Dialogue concerning divine providence dialogue as both cultivated and organic in nature: in other words, blending divine creation through the filter of humanity. This metaphor, of course, evokes the conventional medieval understanding of nature as reflecting divine teachings, and humanity's role as engaging with nature in order to learn moral and theological lessons. ${ }^{11}$ The orchard metaphor, in its reliance upon a cultivated place, encourages readers to think about nature in subordination to both the will of God and the will of humans. Yet this metaphor gains refinement in how it positions the translator as the gardener, cultivating the place for his readers, whom he invites to walk along the paths criss-crossing the orchard, itself a place conventionally feminized through its long association with the virgin Mary, often depicted as reading in a hortus conclusus, an enclosed garden. The 
human will to which the garden is most directly subordinate, then, is that of the translator, who presents himself as possessing the authority to shape and control, and invite readers in at his will. The metaphor thus enables the translator to represent his own writerly authority and present readers as subordinate to it: they walk along paths he has created through the textual divisions he recommends they attend to, even as he encourages them to apply their own agency to the pace of reading - lingering to savour - and the paths along which they start or end their reading. Furthermore, readers, acting in accordance with the metaphor, are invited to think about reading as a cultivated activity, one requiring a writer's guiding hand, but also their discerning engagement. The garden metaphor thus carries the additional weight of negotiating participation between writer and reader played out through the organization of the text and how readers use it.

The text as ground for expression of readers' agency introduces the second aspect of the metaphorical language of the Orcherd, that of mobility. Readers of the Orcherd can express their agency through movement within the text, marked by following the paths laid out by the translator as indicated by the division of the text. Movement thus becomes a metaphor describing how the work of interpretation takes place: as readers move through the text, pursuing what paths they choose from among those made available by the translator's textual organization, they can draw meaning forth from the text, and with that meaning, shape their affective response. The translator so explains in an additional passage from the prologue expanding on the metaphor of the orchard:

In bis orcherd, whanne ze wolen be comforted, ze mowe walke and se bope fruyt and herbis. And albeit bat sum fruyt or herbis seeme to summe scharpe, hard, or bitter, 3 it to purgynge of be soule pei ben ful speedful and profitable, whanne pei ben discreetly take and resceyued by counceil. (1)

Reading as an act of walking enables orderly reading that facilitates encounters with material that might be appealing or unappealing, but productive either way. Thus readers know that even their difficulties arise from planned encounters shaped by the text and the translator who organized it for their access. Yet by emphasizing mobility, the translator proleptically frames his audience's reading experience in a way that draws attention to the agentive work of readers who have to thoughtfully select their paths, choose their textual encounters, and work through the savoury or bitter 
consumption of the text in order to interpret it effectively and to evaluate its relevance to themselves. Walking thus offers a metaphorical frame for conceiving of the participatory work of reading in a way that emphasizes the authority of the reader, even when that authority is conceived of as a subordinated authority ('resceyued by counceil'). Furthermore, reading as walking represents mobility as an active work of development, moving the reader from one state to another. Mobility becomes progression, progression both spatialized through the garden metaphor and also conceptualized as intellectual and spiritual growth. Mobile reading, in this metaphorical usage of walking through the garden of the text, gestures to how reading affects the identity of the reader.

The relationship between participatory reading effected through nonlinear apprehension attains additional prominence through the third use of metaphorical language that suffuses the prologue, the language of consumption. The translator has designed the Orcherd to promote the savouring of its text, as he states, and uses the language of taste ('bitter', 'sharp', and 'hard') to represent the affective experience of its interpretation. He returns again to this metaphor in the conclusion of the Orcherd, in which he writes, 'I sey to zou azein, seekip pis goostly mete wip bisye \& ofte redyng' (421). The text is as meat, food for the soul. Consumption and taste function as a metaphorical language of participation representing how the text can be internalized by its readers, signifying their acquisition of knowledge and spiritual improvement through the visceral medium of the body that consumes words as food. Reading becomes a means for gaining sustenance; knowledge becomes written on the body through its metaphorical internalization. Readers thus participate through consumption in the medium of their bodies.

The notion of sustenance implied in the way the Orcherd represents reading as consumption introduces the fourth metaphorical category employed in the prologue, that of time. For the translator, reading as consumption can produce 'speedful' effects, an adjective that means the effects of this reading are both beneficial and also swift. The translator evokes time again in the prologue when he states that reading can be performed 'at a reasonable tyme ordeyned', and recommends readers select among the alleychapters of the text to spend 'o tyme in oon, anopir tyme in anopir' (1), and again in the conclusion when referring to 'ofte' reading, reading frequently (421). These references indicate a variety of engagements with time, from the scheduling of reading (presum- 
ably according to the affordances for reading incorporated into the daily schedule enjoined upon the nuns by the rules of Syon), to the sequence of reading, to the frequency of reading and rereading, and to the time within which one might expect to experience the effects of reading. In these various treatments of time, the translator of the Orcherd shows himself sensitive to the myriad ways temporality enters into the reading experience, and represents these diverse temporalities as subject to the control of readers. For nonlinear readers, time becomes an additional element of this reading practice through which readers might express their agency and control over their reading experiences.

Altogether, these metaphorical representations of nonlinear reading experiences can be adduced, along with the language of emendation discussed in the previous chapter, as contributing to a discourse of participatory reading that pervades late Middle English literary culture. The language draws on many facets of readers' daily experiences, from the medium of the body as walking and consuming, to the organization of inked words on the page, to the landscapes that surrounded the places they lived and visited. Emerging in the vernacular with vigour corresponding to the increasing audience of vernacular readers, the discourse of participatory reading demonstrates how writers sought to address the challenge these unlearned but eager readers posed to writers, who sought to introduce their readers to reading practices that shape textual interpretation, while at the same time trying to figure out where the limits of their increasing agency ended and that of readers began.

As implied by the prologue to the Orcherd of Syon and similar instructions on nonlinear reading, writers by the late fourteenth and fifteenth centuries assumed that readers - particularly women readers - defaulted to a linear reading practice, and needed encouragement or instruction to effect the practice of nonlinear reading. As, however, evidenced by the overwhelming popularity of books of hours, vernacular audiences - including women and other audiences characterized as non-elite - already understood and frequently, commonly performed the practice of nonlinear reading. Consequently, instructions in the practice of nonlinear reading like those attested in the Orcherd demonstrate the assumptions writers bore regarding their less-educated audiences. Indeed, explicit instructions addressing any reading practice will demonstrate stereotypes that writers harbour regarding their audiences. In the case of corrective reading discussed in the previous chapter, writers 
clearly assumed readers would either fail to read productively if not prompted to correct, or they would alter the text, but not in productive ways; these assumptions were further inflected by the gender of audience and genre of texts. Here, in the case of nonlinear reading, gender also plays a role in the writers' assumptions that an audience of women will not understand the purpose of textual organization, nor how to use it for reading, unless explained. The instructions thus speak less to readers' capabilities than they do to the writer's expectations about his prospective readers.

Yet instructions about nonlinear reading serve more purposes than documenting the application of conventional medieval gender stereotypes to the practice of reading. The instructions in the Orcherd emphasize that writers relied on textual organization to make their works accessible to particular practices of reading, whether nonlinear or linear. These writers' expectations regarding how readers would apprehend their texts also suggest that nonlinearity played an influential role in late-medieval English literary culture. Nonlinear invitations like the Orcherd's were not there simply to teach readers how to read, but how to read in particularly sophisticated ways their writers judged them capable of achieving only with some guidance. Understanding nonlinear practice in this way speaks to the pressures surrounding the work of readers. It also attests to the tension between readers and writers who attempted to use nonlinear reading to shape their works' reception and interpretation. For the Orcherd, being able to place disparate chapters in conversation with each other and the readers' needs enhances the reading experience and readers' affective interpretation. In the eyes of Protestant Tudor audiences and writers, struggling to forge a new religious identity and practice, the way nonlinear reading enables the juxtaposition - and even collection - of texts threatens the integrity of the Bible, and becomes associated with Catholicism as a reading practice characteristic of it.

Hallmarks of nonlinear reading are, nevertheless, not exclusive to devotional works like the $O$ rcherd. As nonlinear reading responds to textual organization, and as textual organization can intersect with narrative organization, the organization of any text invites scrutiny of the kinds of reading practice it promotes. Indeed, Chaucer suggests the applicability of nonlinear reading to the Canterbury Tales when he suggests that readers who dislike one story may 'Turne over the leef and chese another tale'. ${ }^{12}$ Examining evidence for nonlinear reading across a number of texts further demonstrates different approaches to nonlinear reading. Three modes that 
emerge most prominently can be described as elicited nonlinearity, as invited in the prologue of the Orcherd of Syon; modelled, performed nonlinearity, as evidenced by the late-fourteenth-century poem Titus and Vespasian, about the fall of Jerusalem; and hybrid nonlinearity, which combines elicited and performed modes of nonlinearity, as found in John Lydgate's fifteenth-century sequel to the Canterbury Tales, the Siege of Thebes.

Assessing the modes of nonlinearity demonstrated in these works, and how nonlinearity becomes a practice facilitating relations with readers, reveals how three late-medieval writers composing both devotional and secular texts leveraged nonlinear practices. The different approaches to nonlinearity adopted by these three writers, particularly marked for the attention of readers in these three texts, demonstrate that the use of nonlinearity as a participatory reading practice was not exclusive to religious works, but instead employed by writers both to organize texts and also to guide reading practice across a range of literary genres, from the devotional to the historiographical. The independence of these texts from one another and the range of genres in which nonlinearity emerges thus testifies to its widespread influence in late-medieval literary culture and reading practice. In addition, these treatments of nonlinearity indicate that writers relied upon the choices that readers could make in ways that could affect not only interpretation, but also literary reputation. Far from viewing readers as passive recipients of instructional work, the writers of these texts figure their audiences as involved participants in the construction of meaning and authority. Consequently, how these texts address and use nonlinearity discloses much about their shaping of readers' agency and the writers' own authority in late-medieval England. The study of nonlinear reading practices thus provides an essential contribution to our understanding of medieval reading history and the conditions that determined readers' literary experiences in the late Middle Ages, even as its frame in the theories of digital media demonstrates an approach for evaluating 'old media' practices.

\section{Elicited nonlinearity and guiding readers in the Orcherd of Syon}

As stated above, the explicit invitation found in the prologue to the Orcherd of Syon seeks to encourage readers to engage in nonlinear apprehension, thus situating it as an explicit example of elicited nonlinearity. Its reliance upon nonlinearity reading to influence 
interpretation based on how readers devote their emotional labour to negotiating and understanding the text emphasizes the agency of readers to determine meaning. Such meaning emerges interstitially, as interpretation takes place through the convergence of the explicit message of the text and the message of the text as readers comprehend its relevancy to their own personal situation. In the context of digital media, nonlinearity elicited in this way is considered a valuable support to motivating readers' interest in a work, for determining the connection between the text and the reader, and which section of text to negotiate to after reading the current section - these offer a way of making the work personally relevant to readers. ${ }^{13}$ As will become clear, medieval writers saw similar possibilities for how their readers might benefit from nonlinear apprehension.

This nonlinear reading practice emerges from what has, in hypertext media, been termed the 'promiscuous possibilities' enabled by the comparisons and associations between lexia. The juxtapositions of nonlinear, associative reading (termed hyperreading) can provoke critical thinking. ${ }^{14}$ By eliciting nonlinear reading, the translator of the Orcherd urges his audience to adopt an interpretive strategy that enables them to take charge of their spiritual development. The Orcherd thus anticipates an audience of readers able to determine thematic connections between chapters, and between their spiritual state and the subjects of each chapter. In this way, the prologue exemplifies the ahierarchical possibilities of nonlinear textual negotiation and underscores the importance of reader participation and choice.

Yet, even as the Orcherd emphasizes the centrality of readers' choices, the reading paths - the 'xxxv aleyes' identified by the translator - are nonetheless predetermined through the organization of the work into chapters and paragraphs. While readers might make any juxtaposition that occurs to them, textual organization facilitates only a specified range of choices, which it makes available through a 'pre-programmed' system presented to readers, a situation that evokes the control exerted by the hypertext link. That is, while the hyperlink enables readers to apprehend a text or move between texts in nonlinear ways, the existence of the link itself facilitates a single, predetermined connection between a text and its subsection or another text. In ways similar to the controlling function of the link, the division of texts into chapters imposes structure on nonlinear reading practice that has been determined by someone other than the reader, whether author or scribe. 
In the Orcherd, the text has not been designed to facilitate connections between nodes smaller than each alley-chapter. Freedom is thus encouraged for readers along certain confines or, more precisely, along emphasized connections. Such gestures as walking among the Orcherd's alleys lead nonlinear readers to be 'positioned in particular pathways'. ${ }^{15}$ As another scholar puts it, the Orcherd enables the 'strategic but controlled empowerment of the text's reader or recipient'. ${ }^{16}$ In this way, the alleys of the Orcherd prologue cast into relief the tension between freedom and control in reading the work, even as they also highlight how readers' ability to effect choices about what they read and in what order they read it was viewed as essential to understanding the text. According to the Orcherd, reading is most meaningful when it emerges from readers' exercise of controlled agency, and the translator designed the structure of the text to elicit, guide, and limit that agency in order to direct his readers' attention towards the goal of spiritual development.

One consequence of such nonlinear reading in both medieval and digital media is its emphasis on individualized experiences. The choices readers pursue while navigating a work allow them to 'make sense' of their nonlinear experience with the text, but in order to make sense of it, 'the reader must produce a narrative version of it'. ${ }^{17}$ Every individual act of nonlinear reading can create, in a sense, a variant based upon the paths taken and texts and portions of text juxtaposed by each reader. The digital media approach to nonlinearity thus draws attention to how a text reflects an act of narrative creation as the reader assembles it. This narrative may differ in its arrangement from the text as presented on a printed page, depicted via the computer, or written in a manuscript.

The individual path negotiated by a reader of the Orcherd of Syon, for example, becomes that reader's narrative experience of the Orcherd: a devotional narrative, so to speak. Yet that path is also shaped by the materiality of the manuscript and its practices of textual organization. In the Orcherd, and emphasized by the layout of its manuscripts, the 'kalender' following the prologue promotes such individualization when it describes several chapters as containing 'a repeticioun of summe wordis seid bifore' or 'a profitable repeticioun of manye pinges, whiche ben seid'. ${ }^{18}$ Such summaries can suggest to a reader that these chapters might offer ideal introductory points for beginning reading, or provide chapters that one might read without or before having to read the foregoing chapters. In some of the surviving manuscripts, the 
textual organization, its ordinatio, is strikingly complex, belying the simplicity of the translator's description in the preface that the work has simply been divided into chapters for the ease of nonlinear practice. ${ }^{19}$ For example, British Library Harley 3423, which dates to the early fifteenth century and represents one of the earliest surviving manuscripts of the text, has an organization that is quite complex. Not only are several folios given elaborate, four-sided borders, but chapter summaries are also noted in red ink, as are the abbreviation of chapter numbers in the text. Each folio is provided with a running title above the text, identifying the book and chapter, and marginal, rubricated glosses are also provided. Consequently, the organizational apparatus of the text and its layout on the page, its mise-en-page, serves inexorably to catch the reader's eye, demanding attention be paid to the ways the text supports nonlinear access. ${ }^{20}$

In these ways, the Orcherd yokes proleptic instruction for the reader to organization and layout of text and manuscript in order to facilitate nonlinear reading focused on crafting affective interpretation of the text. In so doing, it exposes the tension between freedom and control that underlies the relationship between late-medieval writers and readers engaged in participatory reading practices. Nonlinear reading relies on readers' agency even as its treatment by these writers exposes concerns about the consequences of agentive readers for writers and the texts they increasingly saw as theirs. As nonlinear reading relied on readers to draw meaning from the text in ways that put them in the centre of literary activity as the source of interpretive meaning, potentially displacing writers' authority and even that of the text, how could writers ensure that readers engaged in responsible nonlinear reading and, consequently, interpretation?

\section{Modelled nonlinearity in Titus and Vespasian}

One particular response to promote effective nonlinear reading required writers to model such reading for their own audiences. Exemplifying performed nonlinearity, the late fourteenth-century poem Titus and Vespasian presents a work that models the writer's own collative, nonlinear reading process. While its presentation of that collative narrative invites linear apprehension, it nevertheless demonstrates the effects of nonlinear reading. In particular, the writer explicitly comments on shifts between narrative episodes. Through performed nonlinearity, the writer of Titus and Vespasian 
both demonstrates how nonlinear reading can enable readers productively to juxtapose episodes and passages in ways that promote effective interpretation and, in consequence, highlights how nonlinear reading creates space for readers' interpretive participation.

Although focusing its narrative on the subject of the fall of Jerusalem, the writer's frequent and repeated emphasis on the foundational tenets and events of Christianity suggests that Titus and Vespasian offers a homiletic text aimed at a lay audience desirous of religious and historical education in the vernacular. The writer treats the narrative of Jerusalem's fall as an occasion for affective devotion, focused in particular on the theme of vengeance. Critical assessment of the poem has primarily focused on its relationship to the Siege of Ferusalem, with which it shares anti-Semitic sentiment. Discussion of the poem has largely focused on this element in the context of medieval Christian romance and pious discourse, suggesting that it worked affectively to discourage its audience from sympathizing with Jews. ${ }^{21}$ This research has been critical for understanding how these poems functioned culturally for their medieval readers. Yet in comparison to the Siege of Ferusalem, Titus and Vespasian has been singled out for critical dismissal, which may also respond to the organization of the poem and the reading practice it prompts, as I will discuss. In an unusual move that has occasioned comment from critics, it begins not with a focus on Jerusalem or Titus and Vespasian, but with a lengthy account of Christ's life and miracles.

Over the course of its more than five thousand lines, Titus and Vespasian provides its audiences with a poem organized for linear reading. Yet it is notably episodic in its structure, and comments on this nonlinear organization, which consequently enables the poem to model the results of nonlinear reading based on the author's collation of passages drawn from a variety of sources. ${ }^{22}$ Its organization thus serves to depict the writer's work as a nonlinear reader, for it presents a text assembled from the juxtaposition of lexia. Modelling nonlinear reading begins in the poem with its incorporation of several other lives and episodes into its account of Jerusalem's fall, which adapt and expand on a variety of sources identified from the outset, for such incorporation relies upon negotiation among, and selecting from, diverse resources. The poet explains how he has composed the poem through nonlinear associations when he describes how he has relied upon 'The Gospelles ... [a]nd the passioun of Nicodeme ... [and] the geestes of emperoures'. ${ }^{23}$ Later in the poem, when supplementing the 
narrative from a new source, he adds after a description of Pilate's death that 'The Sept Sages pus doth us telle' (4391). By identifying his sources as ones from which he has extracted material to incorporate into the work, the writer thus relies upon and embeds within the text his own nonlinear reading experience, his performance of developing a narrative drawn from multiple narrative sources. For example, the writer's performance of nonlinear reading is staged not only through the identification of sources, but also through extensive, frequent insertions of additional narratives into the story of Jerusalem's fall in a way that highlight the episodic nature of the poem. This is made more transparent in a description of the poem's sequencing of a particular collection of episodes: lines 1169-1226 address Vespasian's illnesses (leprosy and a distressing plague of wasps in his nose), but it is not until more than a thousand lines and several scenes later - after the poem has related the life of Pilate, the story of St Veronica, her encounter with St Clement, his conversion, Clement's sermon to Vespasian about the Christian faith, and a few other events - that Vespasian is cured. Drawing attention to the moments where he joins episodes together, the poet announces, 'Agayn to be story wil we wende' (1630), and, after explaining the signs that betoken the destruction of Jerusalem and extending the discussion to include St Helen's discovery of the true cross, the poet declares, 'Lete we now be Jewes dwelle. Here gynneth her wrech for to telle' (1163-4). This episodic structure has been the subject of much of the critical dismissal aimed at the poem, which often focus on its lack of narrative unity. ${ }^{24}$ Rather than treating these references as providing evidence of inferior poetic craft, however, it is worth considering that different aesthetic preferences may be at play among both medieval audiences and modern critics, for whom literary culture has long been dominated by the linear form of the novel. Indeed, twelve manuscripts of the poem survive, attesting to its steady popularity. ${ }^{25}$ Survivals of a single poem in more than ten copies is noteworthy, and, although not approaching the numbers of surviving manuscripts of outliers such as the Canterbury Tales, which survives in more than sixty-five manuscripts, speaks to medieval audiences' enjoyment of Titus and Vespasian. This generous number of surviving witnesses suggests that, despite modern critics' aesthetic dissatisfaction with it, medieval readers of Titus and Vespasian certainly did appreciate the poem and responded to its marked engagement with nonlinearity.

Through emphasizing the diverse sources brought together to assemble the poem, Titus and Vespasian re-creates for its 
audience the experience of nonlinear reading and the collation and assemblage of multiple sources in order to develop narrative meaning. Thus, even as readers apprehend in a linear sequence a poem initially designed for linear apprehension, they experience a performance of nonlinear reading laid out through the organization of the text and the stylistic aspects that identify the work of assembling and linking narrative lexia. Furthermore, the writer's repeated emphasis on his performance of nonlinear reading also reinforces the poem's and writer's authority as to guiding readers among various events. Its modelling of nonlinear reading and writing indicates to readers that the events it relates come from richly complex historical moments that would be a challenge to the general reader to negotiate in order to identify which ones bear particular importance and relevance to the subject. By flagging for readers' attention how he has collected these sources into a single narrative, the writer emphasizes that this work has already been accomplished for the reader through provision of the poem. In this way, the writer of Titus and Vespasian turns to nonlinearity as a means for exerting control over readers: the writer is the judge of relevancy and intersecting historical events, and guides readers' apprehension to how these events can be juxtaposed. Consequently, the writer also guides readers to practice how such juxtapositions enable them to discern what actions or themes connect episodes and events.

Comparing Titus and Vespasian's use of nonlinearity to that of the Orcherd of Syon emphasizes how diversely medieval texts present nonlinearity to their audiences, inviting them to make it a feature of their reading practice. The Orcherd requires nonlinear reading be performed by readers and Titus and Vespasian performs nonlinearity for readers. In order to facilitate the performance of nonlinear reading, the Orcherd urges readers to decide the order in which they negotiate among its chapters and thereby determine the rationale that forges connections to or among chapters. In contrast, Titus and Vespasian recreates the experience of nonlinear reading for its audience by emphasizing the text's creation from and continued juxtaposition of varied sources, events, and lives. In elicited nonlinearity, as in the Orcherd, readers create a sequence of texts or textual segments for themselves as they navigate a work. In performed nonlinearity, as in Titus and Vespasian, the text provides readers with a sequence of textual segments linked together not by temporality but by thematic parallels. Whereas the translator of the Orcherd expects readers to determine how the chapters apply to 
their own lives, and through this personal application develop the connecting, thematic, devotional tissue that will link their experience of the text's chapters, the writer of Titus and Vespasian has already determined the themes that connect its events, and invites readers to determine what these are. A text can also mix these forms of nonlinearity, offering readers both performed and elicited nonlinearity within the same text, as will be demonstrated below in John Lydgate's Siege of Thebes.

Performed nonlinearity enables Titus and Vespasian to make available to readers the various texts needed to emphasize the lessons that can be derived from the siege of Jerusalem, including thematic connections among the lives of people who do not meet directly and are brought together only through their presence in Jerusalem. This use of nonlinearity in Titus and Vespasian emphasizes the writer's devotional aims, which emerge most intensely when he concludes the account of Jerusalem's destruction by juxtaposing it with Pilate's suicide and the life and suicide of Judas Iscariot. These comparisons emphasize the fates of those who - whether they be people or cities - betray Christ through deed or by harbouring those who injure him. As Maija Birenbaum mentions in her discussion of the juxtaposition of these episodes, layering events linked by shared themes allows the poet to urge readers towards a particular experience. '[T]he episodes of miracles of healing and conversion interspersed throughout Titus and Vespasian', Birenbaum asserts, 'supplement and enrich the reader's affective devotional experience'. ${ }^{26}$ Such devotional engagement arises through nonlinearity, which guides readers to recognize the instructive relevance of apparently unrelated episodes and to understand the consequences to those who refuse Christ's message. Used in a devotional context, this reading practice could underscore particular hermeneutic goals by encouraging readers to interpret the concepts, themes, experiences, or ideas that connect episodes. Performed nonlinearity, because it does not require readers to seek out connections between lexia according to their own associations, can be used as a technique for instructing readers in a predetermined manner. It thus closes down some of the interpretive agency made possible by readers in texts such as the Orcherd of Syon, which allows readers to choose which lexia to assemble and compare, and thus exercise their own interpretive agency in a highly personalized manner, by predetermining the lexia for comparison, and thus limiting the types of interpretations readers might effect. 
Strikingly, however, Titus and Vespasian does not directly identify or explicate the thematic connections among its juxtaposed lives and events: that work still remains left to the reader (and, of course, the modern critic). For example, the conclusion of Pilate's life moves with only the most minimal of interpretive glosses to the story of Judas's death. Pilate has committed suicide, his body tossed in a barrel thrown to sea; like the Wandering Jew, he will never find rest:

He nas not worthy, I understande,

To have noo rest in water ny londe,

He pat demede Jhesu to be spylt

To shamefull deth withouten gylt.

Now wil I tellen of a aventure

Of Judas, Goddes treytoure. (4483-88)

Pilate is found unworthy of rest in death, whether on land or sea, because of his condemnation of Jesus and resistance to acknowledging his guilt for that act. In essence, he becomes subject to God's vengeance for refusing to acknowledge the significance of Jesus' status. In a poem that repeatedly emphasizes Jesus' salvific grace and the several conversions that he inspires - Vespasian's, Titus's, Veronica's, Clement's - Pilate and the Jews destroyed in Jerusalem's fall are marked as those who continually reject him. Similarly, the description of Judas' end concludes with the brief comment that 'Pus cam Judas to the ende, / To dampnacion withouten ende. / Lete we Pilate and Judas dwelle; / Of pe Emperour I wil zou telle' (4883-6). Instead of explicating the connections between these lives and the fall of Jerusalem, however, the author of Titus and Vespasian relies upon readers to identify the thematic, devotional rationale behind his juxtaposition of the death of the city, Pilate, and Judas. Consequently, in its use of performed nonlinearity unaccompanied by extensive explanation, Titus and Vespasian provides evidence for the poet's assessment of his vernacular audience. The poet clearly anticipates readers capable of identifying for themselves themes used to link the events, lives, and stories related in the poem.

In consequence, although inviting reader participation through identification of themes and subjects that arise from its connection of episodes, Titus and Vespasian also structures its engagement with nonlinearity in such a way as to limit the choices of readers. These readers are expected to negotiate the text linearly in a way that has them recreating the writer's nonlinear experience. They 
should not associate just any episode with any other, but instead follow the juxtaposition of specific episodes that evoke didactic, thematic connections. The work thus exemplifies the controlled use of performed nonlinearity to enhance readers' devotional experience and understanding. Furthermore, drawing on the discourse of the previous chapter, it presents nonlinear reading within a closed network. By collating the relevant sources into a single poem, the writer of Titus and Vespasian makes it unnecessary for readers to turn elsewhere for instruction. Other texts that gesture to nonlinearity may, however, grant more license to readers, a license afforded, for instance, in Chaucer's sly comment that readers who would dislike the ribaldry of the Miller's Tale may 'Turne over the leef and chese another tale'. ${ }^{27}$

\section{Hybridized nonlinearity in the Siege of Thebes}

A work that grants greater license to nonlinear readers is John Lydgate's so-called sequel to the Canterbury Tales, the Siege of Thebes. The first generations of Chaucer's readers viewed the Canterbury Tales as needing completion, since Chaucer's pilgrims never arrived at Canterbury or returned to London to finish their story-telling game as promised in the General Prologue. Among these fifteenth-century responses that sought to complete the work by adding links to the frame or extending the frame narrative, Lydgate's Siege of Thebes circulated most widely in manuscript and, today, has been assessed by critics as crucial to how Lydgate authorizes himself and his work in the wake of Chaucer's influence and his desire to develop himself as a poet in Chaucer's mould. ${ }^{28}$ In the poem's prologue, Lydgate relates the arrival of Chaucer's pilgrims in Canterbury. Lydgate thus depicts the reading practice of immersion - most familiar to readers today by its deployment as the primary participatory practice operative in video games that function through the selection and play of user-chosen, userdesigned avatars - by inserting himself into the frame narrative of the Canterbury Tales. From Lydgate's pen then flows the story of how he joins the pilgrims on their return to London and shares with them a story about the destruction of Thebes. The destruction of Thebes offers a further connection to the Canterbury Tales, for it is an event that takes place before the events addressed in the Knight's Tale. Lydgate's prologue thus follows the sequence of the frame narrative of the Canterbury Tales, while the story he relates sequentially precedes Chaucer's first tale. This juxtaposi- 
tion of multiple sequential relations to the Canterbury Tales makes reading practice central to the poem in ways that extend beyond how it might represent Lydgate's presentation of his own reading practice. In specific terms, the poem's chronological and structural relationships to the Canterbury Tales and Lydgate's own relationship to Chaucer relate directly to the practice of nonlinearity.

Lydgate first elicits nonlinear reading from his audience by crafting a seeming contradiction into the structure of the Siege of Thebes: its frame narrative follows the events of the Canterbury Tales chronologically by situating its initial action in Canterbury, where Chaucer's pilgrims encounter the monk John Lydgate at their inn. In contrast, the story told by John Lydgate after joining their company relates events that chronologically precede the actions in the Knight's Tale. The Siege of Thebes can thus be associated with the Canterbury Tales in two ways, either linked after it by following the chronology of the frame narrative, or before it by following the chronology of the story of 'Thebes' destruction. This juxtaposition that Lydgate presents his readers with is clearly one of textual organization. The multiple organizational possibilities Lydgate crafts position the Siege of Thebes as a challenge to reading sequence. Consequently, Lydgate's use of nonlinearity contrasts with its use in the Orcherd of Syon and Titus and Vespasian. Whereas the Orcherd relies upon elicited nonlinearity and Titus and Vespasian models nonlinear reading, the Siege of Thebes exemplifies hybridized nonlinearity. It models nonlinear reading in the way Lydgate juxtaposes and associates his work with the Canterbury Tales. It also elicits nonlinear reading, for the dual chronological relationship between the works, that of sequel and prequel, invites readers to choose how to associate and sequence the two. Furthermore, readers' associations have interpretive consequences for Lydgate's relationship to and with Chaucer, which Lydgate seeks to further guide in the poem.

The structural relationship of the Siege to the Canterbury Tales has gained the attention of scholars writing on the poem for the place it holds among Lydgate's many self-authorization strategies and what it indicates about Lydgate's aspiration to fame. Lydgate's decision to compose a work that incorporates such a layered chronological relationship to the Canterbury Tales has often been viewed by critics as an aggressive, anxious work of selffashioning, particularly when set beside Lydgate's decision not to omit Chaucer from the company of Canterbury pilgrims in the frame narrative of the Siege. ${ }^{29}$ Specifically addressing the structure 
of the Siege's relationship to the Canterbury Tales, James Simpson describes the Siege as a poem constructed 'praeposterously', that is, in a back-to-front order in which 'events that are recounted later in the fictional time of the newly enlarged Canterbury Tales happen earlier in history'. ${ }^{30}$ Another critic describes the relationship between the two poems as 'circular', for ' $[\mathrm{t}]$ he end is made to join with the beginning'. This circularity reflects Lydgate's 'vision of a historical past in which heroes and their civilizations constantly re-enact the ritual of rise and fall upon Fortune's wheel'. ${ }^{31}$ Yet more than a parallel to Lydgate's view of history emerges from how readers could negotiate between the Siege and the Canterbury Tales. While these views treat the relationship between the poems as complex but fixed, in fact that fixity is not a given. A consequence of the organizational relationship between the two texts is that the very multiplicity Lydgate effects creates a space for the exertion of readers' agency.

The possibility of choice is embedded even in the terms used by modern critics to describe the texts' relationship: sequel or prequel. These terms reflect a decision Lydgate thus invites readers to make. How should the two texts be linked? What conditions should influence that choice? Here, Lydgate's careful use of textual organization to prompt choice also turns to guidance, as made evident by considering more fully the work of linking lexia. In digital media, links are crucial tools in staging the expression of readers' agency, for they request the performance of agency even as they forge predetermined connections. In effect, a hypertext link limits readers' choices even as it makes possible the appearance and expression of choice through the exercise of nonlinear apprehension. The link goes from one location to one location; a reader can choose to traverse it bidirectionally, but its end points are fixed. As Paul Delany observes of this practice in literary contexts, nonlinearity 'weakens the boundaries of the text', and this weakening of boundaries can 'be thought of as either correcting the artificial isolation of the text from its contexts or as violating one of the chief qualities of the book'. ${ }^{32}$ Lydgate weakens the boundaries between his text and the Canterbury Tales in order to open a space for reconsidering the texts' relationships. In the parlance of the previous chapter, applied here to the organization of the text, Lydgate crafts an open network that connects his work to another. In opening the network of the text in this way, and by further relying on nonlinear reading practice, he urges readers to perform comparative interpretation 
of his work in relation to Chaucer's. He also capitalizes on the limitation of choice enabled through the links his chronologies create with the Canterbury Tales to enforce a decision focused on sequence. Which view of the text dominates, sequel or prequel, is decided by the choices readers make. 'The stakes of readers' choices, however, are not limited to the chronological relationship between the texts.

Lydgate relies on nonlinear practice in writing and reading to, in effect, re-found the Knight's Tale as part of a Theban tradition which begins with himself, whom Chaucer, though the earlier writer, follows in precedence. In order to achieve this re-foundation, Lydgate must elicit from his readers a reading of the Canterbury Tales that does not follow the linear trajectory of literary history. Whereas elicited nonlinearity in a devotional context might respond to the explicit initiation urging readers to make decisions about thematic or spiritual connections between passages, Lydgate elicits nonlinearity in a way that invites readers to determine his literary reputation. By relating the Siege of Thebes to the Canterbury Tales in a way that provokes readers to determine how to associate the two texts, Lydgate invites them to determine whether he is Chaucer's follower and successor, or - despite the temporal relationship imposed upon them by chronological history - whether he is someone capable of superseding Chaucer. Lydgate thus treats the choice readers make in associating the Siege with the Canterbury Tales, whether viewing and reading it secondarily as a sequel, or reading it first as a prelude to Chaucer's work, as carrying interpretive weight for their view of Lydgate's reputation. Consequently, nonlinear practice supports Lydgate's self-authorization strategies. It reflects his perception of readers as able to effect choices regarding textual organization that carry consequences for the presentation and interpretation of the writer's authority and reputation. This view of the relationship between writer and reader was arguably a fresh development in the latemedieval literary scene. As Deborah McGrady describes this changing relationship between late-medieval writers and readers, writers granted readers authority through a variety of reading strategies in order to promote closer study of their texts, a shift that forged deeper connections between texts and readers. In such a way, 'the concept of the individual reader promised for [vernacular writers] and their works an aura of authority'. ${ }^{33}$ Lydgate similarly turns to his readers as a source for granting both his work and himself greater authority. 
Having presented his readers with a choice, Lydgate does not rely on them to effect their choice without guidance, however. He thus turns repeatedly to nonlinearity throughout the Siege of Thebes to organize, thematize, and comment on workings of chronological history. In doing so, he emphasizes repeatedly that what makes history meaningful is the interpretation people draw from events they associate as meaningful when juxtaposed. That is, history offers a narrative the interpretation of which can be determined by how people - how readers and writers - organize and associate events. Linearity becomes notional, and nonlinearity a practice for shaping historical narrative.

Lydgate furthers this model of history as assembled by readers after the prologue, in the first of the three parts into which he divides the story of the Theban siege, where he moves from relying upon elicited nonlinearity to performing nonlinear reading for his audience. In the first part of the poem, Lydgate relates 'Thebes' foundation narratives before moving on to the story of Laius and Eddipus. Part I concludes by detailing Eddipus' incestuous marriage and his death. Part II shifts focus to Eddipus' sons, Polymyte and Ethiocles, whose disagreement over the Theban crown leads to strife and Polymyte's exile. Part III relates the battle between these brothers, their deaths, and Theseus' arrival and subsequent destruction of Thebes. As becomes evident throughout the Siege of Thebes, nonlinearity is at the heart of Lydgate's view of history. His oft-dismissed didactic moralizations on the events he relates transform them from exemplifications of sinfulness and Theban deceit into passages that provide Lydgate with the occasion for diverting from the narrative of Theban events in order to explore political strengths and weaknesses. These moralizing moments also provide the opportunity for Lydgate to comment on the organization of history. One of the conventional medieval views of history focused on its cyclicality, which operates to repeat, but also to emphasize the linear sequence of events (this happens, then this happens; a man grows in greed, commits sins, falls, and then the sequence repeats with a different person as focus). Lydgate, however, examines how this linear cyclicality can be broken. For example, when Oedipus' son Eteocles, under the burden of his promise to cede the crown to his brother at the end of a year, rethinks his oath, Lydgate uses the moment as an opportunity to exhort kings to hold to truth and avoid falsity (11. 1721-5). Lydgate suggests, when he informs his readers that Thebes 'Distroied was ... / For doublenesse of Ethiocles' (1777-8), that his readers, and kings in particular, are 
not bound to repeat this fate but, keeping truth, may avoid it. That is, history is not, in its effects, inevitably circular. Its cycle can be broken, allowing history to advance in a new direction. In fact, what has become history does not have to become the future. What makes the inevitable cyclicality of the future neither inevitable nor cyclical is determined by the choices individuals, like kings and even his readers, can make.

This transformation that Lydgate seeks to effect in the Theban narrative also extends to his and Chaucer's relationship as poets. Again, as in the structure of the Siege, Lydgate relies upon the authority of his readers to determine his reception and reputation. The ability to upend history by making fresh choices effects a change that readers can also apply to how they view his relationship to Chaucer. In order to make this possibility more apparent to his readers, Lydgate turns again to the modelling of nonlinear strategies when discussing the foundation narratives of Thebes. His most pointed modelling of a nonlinear approach to historical chronology emerges when he describes the first foundation of Thebes by Cadmus after Lydgate has already described its second foundation by Amphion. The order of Lydgate's telling is itself a significant feature. But rather than following Lydgate's sequence, let us first address the first foundation. For it, Lydgate turns to older authorities as his source:

\section{Some expositours,}

Groundyng hem / vpon olde auctours,

Seyn that Cadmvs / the famous olde man,

Ful longe afor / this Cite first began ...

With thong out-korve / of a boolys hyde ...

To get Inne londe / a ful large space

Wher-vp-on to byld / a dwellyng place (I.293-6, 299, 301-2).

Thus Lydgate summarizes the myth of Thebes' Cadmean founding, in which Cadmus, in search of his sister Europa, was advised by the Delphic oracle to give up the search and instead follow another cow and found a city upon the place it first rested. Cadmus sowed dragon's teeth in this ground, and from them warriors sprang up and began attacking each other. It was there, with the help of the fittest survivors, that Cadmus built his city.

Of course, the history of Thebes does not end with its Cadmean foundation. 'But Cadmus ther hath longe not sojourned', Lydgate notes before he returns to the story of the exemplary King Amphion. This second foundation, for Lydgate, seems more 
meaningful. After the exile of Cadmus led to the ruin of the city's first foundation, Amphion rebuilt the city 'With the swetnesse / and melodious soun / And armonye / of his swete song' (I.202-3). The arts, expressed through Amphion's playing and song, figure centrally in this second foundation. A few lines later, Lydgate returns to this theme with an extended comparison of the pen versus the sword. The arts, he concludes, provide a stronger foundation for a city than does military might. As Lois Ebin and Lee Patterson remark, this second foundation demonstrates the triumph of Mercury over Mars, words and song over war. ${ }^{34}$ For Lydgate, the first poet to refer to rhetoric as artistic 'illumination', the second foundation of Thebes is infinitely preferable to the first.

Yet Lydgate is concerned not only with the foundation of Thebes, but also, as the Siege prologue has demonstrated, with the foundation of the English literary scene and his own place in it. In the context of the relationship between the Siege and the Canterbury Tales, the foundational position of arts resonates strongly, while it simultaneously raises the question of whose arts hold precedence. Lydgate's retelling of the two foundational narratives of Thebes strikingly orders the two events so as to relate Amphion's later foundation first (lines 200-43) and offer a moralization upon the example Amphion sets for rulers. He then turns to Cadmus (lines 293-315), who loses his crown and gains exile in its stead. Last, Lydgate returns to the example of Amphion (lines 325-8), from whom descends a line of kings including Laius and his infamous son Oedipus. As the audience of the Siege reads these foundation narratives, they learn first of Amphion, then of Cadmus, and then Amphion again. This sequence represents Lydgate's most prominent use of performed nonlinearity. Lydgate juxtaposes these foundation narratives for his readers in a way that emphasizes how the arts help a kingdom flourish, and how a second foundation can improve upon the first. This juxtaposition also evokes one choice that nonlinear readers could make: beginning to read with Chaucer, turning to Lydgate, then returning to Chaucer. Chaucer, as a sweet singer, might well fit the role of Amphion, and this would be consonant with Lydgate's respectful treatment of him. Such an interpretation, however, makes no place for Lydgate himself.

Instead, a chronological account offers a stronger parallel for Lydgate's and Chaucer's relationship vis-à-vis Cadmus and Amphion: Chaucer, like Cadmus, was a founder and originator - in Chaucer's case, a founder of the English literary scene. As Cadmus 
was credited with introducing the alphabet, so was Chaucer assigned the foundational English literary role. ${ }^{35}$ Indeed, Lydgate treats Chaucer thus in the Siege, acknowledging his fundamental indebtedness even as he simultaneously builds upon and elides Chaucer's work. In this way, it is Lydgate who, Amphion-like, expands on the initial foundation with a newer, successful foundation of his own. The sequencing of the two narratives emphasizes the prominence of the second foundation. The Cadmean narrative, which has the potential to unseat Lydgate's preferred narrative through the authority of greater antiquity, historical precedence, and 'olde auctors', becomes subordinated to the second foundation in a way that mirrors the work and the choice presented by the Siege as a whole. Chaucer himself is one such 'expositour' and a 'famous olde man' who may give way to Lydgate even as Cadmus gives way to Amphion.

Notably, even after he introduces the Cadmean narrative, Lydgate continues to insist on the primacy of Amphion's foundational story. In the broader context of nonlinearity as elicited by the relationship between the Siege prologue and the Canterbury Tales, this approach of Lydgate's invites a closer reading of his own relationship to Chaucer. At the same time, by acknowledging the Cadmean narrative and moving directly from the second discussion of Amphion to Laius, Oedipus' father, Lydgate attempts to close the narrative of 'Theban foundation so as to prevent his own work from being superseded and replaced. In this way, Lydgate shares something with the writer of Titus and Vespasian, who also relies upon performed nonlinearity in order to provoke particular readerly interpretations. Lydgate here provides readers with an example of performed nonlinearity in order to make a point about how they can narrate the story of his and Chaucer's relationship.

Readers who respond to this suggestion that historical chronology does not have to determine the truth of precedence, that the trajectory of history does not have to be everlastingly subject to linear sequence, suggest a medieval pre-history to Espin Aarseth's term for digital media nonlinear readers: 'agents of the text'. ${ }^{36}$ Lydgate invites his readers not only to reconcile the Siege with the Canterbury Tales, but also to become his proxies, his agents, in the struggle to develop and assert his own literary reputation. Through his readers, and through their use of nonlinear practice, Lydgate seeks to re-found the Knight's Tale as part of a Theban tradition that begins with himself, whom Chaucer, though the earlier writer, follows in precedence. That Lydgate does so through reorganizing 
the foundation narratives, inviting readers to apply a familiar mode of reading, and, by means of that application, agree with Lydgate in shaping his literary reputation, must be acknowledged. The description of Lydgate as a derivative imitator struggling vainly to match or even exceed his literary forefather - still a common perception of the poet even in the wake of recent revisionist scholarship - gains new significance if the Siege is read before the Canterbury Tales. Lydgate seeks to strategize his way to becoming a literary luminary whose work sheds new light upon familiar texts. Chaucer's greatness supports Lydgate's own exceptional status as a poet. In such a light, Lydgate assumes precedence over Chaucer, and Chaucer's works become interpreted through the lens of Lydgate's didactic morality. Readers engaged in following Lydgate's suggestions to read not simply his text, but history in a nonlinear way become powerful agents for redefinition of his own authority. Nonlinear reading thus relies on readers' agency and interpretive authority, even as that agency and authority are crafted in such a way that they become subject to - Lydgate clearly hopes - the writer's guidance. As with open- and closed-access emendation, nonlinear reading becomes a site for exploring the developing relations between writers who see both themselves and their readers as sources of authority.

\section{Manuscripts and Nonlinearity}

Evidence attesting to readers' performance of nonlinear reading can be difficult to identify, as nonlinearity prompts a reading experience primarily experienced ephemerally through readers' intellectual associations among texts and selections from texts. Indeed, as the discussion in the previous chapter of how gender intersected with restrictions placed upon corrective reading has shown, that ephemerality may have provided a degree of its attraction to writers of devotional works. For translators like that of the Orcherd of Syon, the ephemerality of nonlinear reading provides another way that audiences of women readers could participate with texts and writers, yet leave the work of writing itself in the hands of learned writers, a body predominantly male in its composition.

Yet manuscript evidence can further our understanding of how readers and scribes both understood the nonlinearity of these texts. Such evidence indicates that providing support to nonlinear reading through provision and marking out of textual divisions formed an interest of the scribes copying Titus and Vespasian, and 
that Lydgate's extensive efforts to reformulate his audience's perception of his reputation and legacy relative to Chaucer achieved only limited, mixed results. Clearly, however, the evidence indicates that audiences responded to the prompt to participate with texts through nonlinear reading in thoughtful ways, though not necessarily with the results the writers tried to elicit.

That readers may have appreciated the nonlinearity of Titus and Vespasian, but also found it taxing, perhaps especially for the effort required to determine its connections among the legendary and miracle narratives, is suggested by both manuscripts of Titus and Vespasian and The prose siege of Ferusalem, a fifteenth-century redaction of Titus and Vespasian that excises much of the legendary material surrounding the attack on Jerusalem. ${ }^{37}$ The life of Christ, with which Titus and Vespasian begins, and the death of Judas, with which it ends, are the two most prominent excisions. In this way, the manuscript provides a streamlined narrative with fewer of the episodic juxtapositions that would have made readers work to identify the thematic connections among them. The active work of interpretation required to understand the connections between Titus and Vespasian's episodes here finds a response allowing for more passive, less effortful reader engagement.

Taking a different approach, the scribe of one Titus and Vespasian manuscript, Morgan Library MS M.898, provides chapter summaries at the beginnings of episodes. These summaries suggest that the scribe anticipated that readers would find the summaries useful and less laborious than identifying the pertinent developments in plot and themes themselves. Furthermore, the use of summaries indicates that readers might, despite how the writer of Titus and Vespasian crafted the work to be read in a linear sequence, be interested in accessing only certain portions of the text at certain times. This approach builds on the writer's documentation of his own use of nonlinear reading, while at the same time making it easier for readers to approach the episodic elements of the narrative in their own determination of sequence, rather than that provided by the writer. That is, scribes who imposed textual division on the narrative indicate their anticipation that readers might prefer to access the work nonlinearly, and rework the poem by creating an organizational structure to facilitate nonlinear access.

Such reorganization of the text might take different pathways according to how the scribes, in their role of professional readers, interpreted the text. These attitudes towards the work also seem to 
have altered over time. For example, the scribes of British Library MS Add. 10036 and Add. 36523, two of the earliest manuscripts of Titus and Vespasian, provide no distinctions between episodes, designing textual layouts that consequently facilitate linear reading in accordance with the writer's organization of the text. Later manuscripts, perhaps responding to fifteenth-century preferences for texts with marked divisions, supply summaries and chapter divisions like those seen in M.898. ${ }^{38}$ Such mixed responses to the work's nonlinearity attests to how the creation of linear narrative from nonlinear reading experiences works rather experimentally in Titus and Vespasian. While some scribes recognized the writer's attempts to represent his nonlinear experience in a linear narrative, others could and did override this by dividing the text in ways that responded to their own perceptions that it should be read nonlinearly, thus facilitating subsequent readers' nonlinear access to various narrative episodes. In other words, perceptions of a text's accessibility to linear or nonlinear reading could vary among audiences, and could be shaped and reshaped not only by writers' efforts and readers' decisions, but also by the decisions of scribes.

In the case of the Siege of Thebes, perhaps the most vivid illustration of the success of Lydgate's nonlinear reading strategy can be identified in a manuscript that collects it along with selections from the Canterbury Tales: Longleat, Warminster, Marquis of Bath MS 257. This manuscript contains the Knight's Tale, the Clerk's Tale, and the Siege of Thebes, copied in a single hand. ${ }^{39}$ Strikingly, the Knight's Tale and the Clerk's Tale have been stripped of the prologues that position them within the pilgrimage frame of the Canterbury Tales. Only the Siege of Thebes retains its prologue, and in Longleat 257, the Siege of Thebes comes - strikingly and pointedly - first. This manuscript anthology, which dates to 1457-69, gives evidence for reading choices that privilege the Siege of Thebes, attending to the chronology of the Theban narratives rather than the pilgrimage frames. The alternative reading pathway that Lydgate made available to readers through the nonlinear relationship he developed structurally between the Siege and the Canterbury Tales gains material force in this manuscript. ${ }^{40}$ Chaucer has, literally in the arrangement of the texts in this manuscript, become Lydgate's follower, and the Knight's Tale and the Clerk's Tale become incorporated into Lydgate's own poetic creation and aspirations. Lydgate, a skilled and professional reader who elsewhere shows himself interested in accommodating and instructing his readers in the various ways in which they might 
read and interpret his works, in the Siege deftly develops a tale that capitalizes on a common reading skill of his readers and, in so doing, accommodates those who came to him first, or in preference, as a means by which he can extend his reputation and authority.

Longleat both demonstrates the existence of one reading path that Lydgate made available to his nonlinear readers, and also demonstrates the agency of readers to arrange such readings according to how they interpreted what they read, whether these are readers such as the scribe responsible for the creation of the manuscript, or the patron who commissioned its development and determined its contents. The Longleat manuscript gives their readings material force through textual collection - for collections not only facilitate nonlinear reading but can, in their creation, derive from nonlinear reading as well. The common perception of the Siege, one that dominated in the late Middle Ages as now, is that of a work written as a sequel to the Canterbury Tales. Alongside this interpretation of the Siege emerge others cast into relief by the text's reliance upon performed and elicited nonlinearity. Nonlinearity provides readers with the agency and authority to grant primacy to Lydgate's provision of the foundational Theban narrative that the Knight's Tale then concludes.

When readers approached the Siege in this manner, then the relationship between the Siege and the Canterbury Tales developed by Lydgate suggests less about failure than it does about success. For these readers, the Siege of Thebes and Lydgate pave the way for the more frivolous Canterbury Tales, pre-emptively casting Chaucer's text within a didactic framework that begins with Lydgate's moral interpretation of the matter of Thebes and ends with the Parson's sermon. In reflecting this reading order, manuscripts of the Siege like Longleat 257, and manuscripts of Titus and Vespasian that emphasize or obscure the episodic narrative in ways that promote nonlinear or linear reading make visible not only the variety of ways the texts were used by their original readers, but also contribute to our understanding of the writers' goals for shaping their perceptions of their readers, the possibilities of their readers' interpretive strategies, and their own understanding of their authority to make their readers work in these ways.

Assessing the manuscript evidence of nonlinearity further reveals how contingent could be the categorization of scribes. For example, in the context of corrective reading practice, writers' references to their audiences situate scribes as belonging firmly to the category of readers who need to be encouraged to pay attention 
to the details of the text and correct it. In the context of nonlinear reading, scribes move between categories of reader and writer even as they resist categorization. That is, in Lydgate's case, scribes once again become implicated among his diffuse conception of a broad reading public. In other cases such as that of the Orcherd of Syon, which is directed specifically to an audience of nuns, or in that of Titus and Vespasian whose scribes impose dramatically distinct modes of organization upon the text, scribes adopt a more interventionist role in shaping reception of the text. In fact, how scribes of Titus and Vespasian impose organizational schema upon the text in ways that facilitate readers' nonlinear engagement with the work suggests that these scribes adopted a much more authorial role in guiding and shaping the audiences' reading experiences. Consequently, assessing nonlinear practice provides further ways by which the work and status of scribes may be evaluated.

\section{Conclusion}

Studying the use of nonlinearity in the Orcherd of Syon, the Siege of Thebes, and Titus and Vespasian enables examination of how a culture grappling with strategies for negotiating the sequence of texts in manuscripts gave rise to works that reflected, anticipated, shaped, and promoted the choices of their writers and readers. The Orcherd showcases the agency of readers, who are anticipated as able to effect meaningful choices about the text and its relationship to their spiritual state. The Siege of Thebes provides a fascinating study of one author's expectations about his vernacular audience's ability to determine relationships between texts and what that ability signifies for his developing reputation as a writer. Titus and Vespasian offers a compelling glimpse into how a single writer, reflecting his own nonlinear reading practices, developed a text that models that reading practice in order to enhance the work's devotional interpretations.

The Siege of Thebes and Titus and Vespasian represent works for which the authority of readers is both crucial and yet also constrained, exemplifying tension between freedom and control that scholarship on contemporary nonlinear media helps distinguish. In these and other works, readers' choices are often presented as conditional, limited to the options authorized by a text. The Orcherd, for example, focuses on the choices readers could make as they negotiate within the text, yoking those choices to specific goals and attitudes and, additionally, excluding from its attention 
how readers might also bring external texts to bear. In Elizabeth Schirmer's observation, this facilitation and restriction of readers' choices creates a tension 'between empowering ... readers and containing and controlling their readerly agency'. ${ }^{41}$ Such a tension can be seen in Titus and Vespasian as well, which manages readers' authority by juxtaposing lives and events in order to provoke devotional interpretation of the text and consequently enhancing its own authority. Yet, as Lydgate's treatment of nonlinearity in the Siege of Thebes vividly demonstrates, such sophisticated reading practices were not restricted to religious texts and audiences alone. Pursuing the secular audience interested in Chaucer's Canterbury Tales, the Siege capitalizes on a growing thirst for participation amongst readers and uses readers' authority to shape a writer's authority. Lydgate relies on elicited nonlinearity to provide readers with a choice about how to relate his text to Chaucer's, then performs a nonlinear reading of history to suggest how that decision could be resolved in a way that heightens his own authority and reputation.

These texts' reliance upon and development of a discourse of participatory reading focused on nonlinear reading practices furthermore recalls John Dagenais's comment that 'Reading, not writing, was the dominant literary mode in the Middle Ages'. ${ }^{42}$ The possibilities of nonlinear reading shape the structural and thematic concerns of all three works. The translator of the Orcherd frames the dialogues of Catherine of Siena with a metaphor of the reading process designed to elicit a particular mode of interpreting and negotiating among sections of the text that generates affective responses. By turning to nonlinearity, the writer of Titus and Vespasian imposes a familiar mode of devotional, affective interpretation upon his readers to elicit their participation through thematic analysis. ${ }^{43}$ Through such applications, the uses of nonlinearity in the Orcherd and Titus and Vespasian provide evidence for what has been described as a 'steadily growing level of confidence and sophistication in the composition, production, circulation, and consumption' of vernacular religious texts. ${ }^{44}$

As Lydgate's Siege of Thebes demonstrates, however, reliance upon this sophisticated reading practice for the composition, circulation, and consumption of texts cannot be restricted to the devotional alone. In the Siege, Lydgate makes use of nonlinearity by applying it to the construction of his literary reputation, in a manner that also intersects with traditions for assembling manuscript anthologies and miscellanea. In this way, Lydgate also 
anticipates the print-era role of editors as collaborators in developing and publicizing texts as he relies on nonlinearity to encourage readers to become his literary agents. Nonlinear reading, for Lydgate, becomes a mode of self-promotion.

While Lydgate's strategy differs from that of the translator of the Orcherd and the writer of Titus and Vespasian, all of the writers deploy nonlinearity to achieve specific goals for their texts through a tensely negotiated, limited reliance upon readers' agency. Yet, even as Elizabeth Schirmer attributes this tension to the 'textual culture of Syon Abbey' and 'a moment of crisis in Middle English textual culture, sparked by the controversy over the Lollard heresy', ${ }^{45}$ the shared presence of nonlinear practices in Titus and Vespasian and the Siege of Thebes, works neither associated with Syon Abbey nor exclusively religious in their audiences, points to the broader reach and influence of nonlinearity, even as it also suggests a deeper understanding of the practices and pressures shaping English textual culture. In this light, these three texts can be seen as pointing to late Middle English writers' recognition of the potential vernacular readers possessed for understanding, practising, and becoming skilful with sophisticated reading practices. Furthermore, the reliance these writers placed on their late-medieval readers, particularly in ways that disregard the work of scribes, shows how such readers' authority and agency became framed as crucial to the success of the writers' goals.

In addition, how the translator of the Orcherd, Lydgate, and the poet of Titus and Vespasian negotiated between granting readers' agency and controlling the extent of that agency, evidences the historical contingency that attends medieval uses of nonlinearity. At the same time, however, medieval uses of nonlinearity provide a bridge for understanding its emergence in media today. As developed here, the subcategories of nonlinearity, performed and elicited, could be applied to forms of digital media in order to distinguish better how nonlinearity today continues to be a powerful mechanism for controlling readers. They can also refine our understanding of the applications, aesthetics, and strategies that applied to medieval uses of nonlinearity. Such aesthetics point to how writers used reading practices not only in the formation of their own writing, but to create connections with other works, which they could then present in their own works in ways that raised or lowered the boundaries between texts. Such efforts reflect the establishment of literary networks, within and between works. At the same time, readers could ignore these boundaries, reorgan- 
ize the relations of texts in a network, and even establish their own networks through associations they recognize between the present text and prior reading. Reflecting on the slipperiness of nonlinear practice in this way highlights the queerness of readers through the heterogeneity of their practices, the ease of their resistance to the imposition of organizational norms, and even the way that scribes and writers tensely negotiate or complicate those norms. In such a context, reading evokes a queer potential. The attempt to discredit and condemn nonlinear reading in the 1549 Book of common prayer highlights the contentious, dangerous nature of what queer reading can do to the body of the book; through nonlinear practice, the book and reading practice both become perceived as 'broken'. Yet that potential for disruption also provided medieval writers with ways to mend relations between readers and texts, crafting a practice that facilitated the savoury consumption of texts.

As we attend to the 'medieval literacy industry', ${ }^{46}$ the insights of digital media criticism offer a framework useful for reconsidering the medieval pre-history of today's digital media practices, particularly the function of nonlinear reading in the late Middle Ages. Attending not only to the manuscripts that provide material evidence for medieval reading, but also to the literary works that provide their own evidence for reading practices, and to the broader cultural practices that reflect and influence the same, helps pave the way for a more nuanced, informed understanding of medieval literary culture, the forces that shaped the texts we still read today, and the tools available to writers and readers alike.

\section{Notes}

1 On the early modern work of collative composition and reading, see Matthew P. Brown, 'Undisciplined reading', Common-Place 8:1 (2007), n. pag., web, and further contextualized historically in The pilgrim and the bee: reading rituals and book culture in early New England (Philadelphia: University of Pennsylvania Press, 2007).

2 Landow, Hypertext 3.0, 53-5.

3 Despite this early rejection of discontinuous reading, Matthew Brown notes that devotional works in early modern England continued to rely upon and advocate nonlinear reading to their audiences ('The thick style: steady sellers, textual aesthetics, and early modern devotional reading', PMLA 121:1 [2006], 67-86). For a religion that relies upon continued assessment of the New versus Old Testaments, and whose central redemptive narrative is repeated across four Gospels, habitual linear reading provides a continual challenge. 
4 Scholars of nineteenth-century literature connect these issues particularly to the novel. For example, J. Hills Miller writes that 'The linearity of the written or printed book is a puissant support of logocentrism. The writer ... sits at a desk and spins out on the page a long thread or filament of ink. Word follows word from the beginning to the end. The manuscript is set for printing in the same way, whether letter by letter, by linotype, or from tape by computer. The reader follows, or is supposed to follow, the text in the same way, reading word by word and line by line from beginning to the end', in Ariadne's thread: story lines (New Haven and London: Yale University Press, 1992), 5. Miller suggests that, just as writing a novel produces a linear narrative, and the materiality of the work is linear, so too reading follows linearly. Yet, while this may be true for some novels, these are not ontological truths of the codex as a media form, as I discuss here. These qualities are instead influenced by the organization of a particular literary form. Similarly, Jeffrey Knight argues that textual composition is related to the materiality of printing only through the choices made by writers to respond to the material form of printing, in Bound to read: compilations, collections, and the making of Renaissance literature (Philadelphia: University of Pennsylvania Press, 2013).

5 See Martin Foys, Virtually Anglo-Saxon: old media, new media, and early medieval studies in the late age of print (Gainesville: University Press of Florida, 2007), particularly the chapter on 'Anselm's hypertext', 38-78.

6 Walter of Chatillon, The Alexandreis, translated by David Townsend (Toronto: Broadview Editions, 2007), 11. 40-3.

7 Vincent Gillespie, 'Vernacular books of religion', in Book production and publishing in Britain 1375-1475, edited by Jeremy Griffiths and Derek Pearsall (Cambridge: Cambridge University Press, 1989), $317-44$, at 328 .

8 Phyllis Hodgson and Gabriel M. Liegey, eds, The Orcherd of Syon, Early English Text Society original series 258 (London: Oxford University Press, 1966), at 1 . Subsequent quotations will be from this edition. In modern English, this passage might be translated as, 'Therefore, religious sisters, I encourage you to disport yourselves in this spiritual orchard at reasonably set times, and walk about with your mind and reason where you wish, in what alley you like. Specifically, savour there as best you be disposed. You must choose as you like where you will walk among thirty-five alleys - that is to say, thirty-five chapters - one time in one, another time in another'. The Orcherd has received much scholarly attention in recent decades for its importance in representing women's devotional and reading practices in the community of nuns at Syon. For discussions of the Orcherd and its readers, see Denise Despres's 'Ecstatic reading and missionary mysticism: The Orcherd of Syon', in Prophets abroad: the reception of continental holy 
women in late-medieval England, ed. Rosalynn Voaden (Cambridge: D. S. Brewer, 1996), 141-60; several essays by C. Annette Grise, but specifically, “In the blessed vyne[y] erd of oure holy saueour”: female religious readers and textual reception in the Myroure of oure ladye and the Orcherd of Syon', in The medieval mystical tradition: England, Ireland, and Wales, ed. Marion Glasscoe (Cambridge: D. S. Brewer, 1999), 193-211 and 'Prayer, meditation, and women readers in late medieval England: teaching and sharing through books'. Texts and traditions of medieval pastoral care: essays in honour of Bella Millet, ed. Cate Gunn and Catherine Innes-Parker (Woodbridge, UK: York Medieval Press, 2009), 178-92; Vincent Gillespie, 'Anonymous devotional writings', in A companion to Middle English prose, ed. A. S. G. Edwards (Cambridge: D. S. Brewer, 2004), 127-49; Elizabeth Schirmer, 'Reading lessons at Syon Abbey: the Myroure of oure ladye and the mandates of vernacular theology', in Voices in dialogue: reading women in the Middle Ages, ed. Linda Olson and Katherine Kerby-Fulton (South Bend, IN: University of Notre Dame Press, 2005), 345-76.

9 See Appendix B for examples of other instructions on nonlinear reading. For discussions on how nonlinearity is used to promote affective interpretation, see Sarah Noonan, "'Bycause the redyng shold not turne hem to enoye": reading, selectivity, and pietatis affectum in late medieval England', New Medieval Literatures 15 (2013), 225-54; and, more generally, Mark Amsler, 'Affective literacy: gestures of reading in the later Middle Ages', Essays in medieval studies 18 (2001), 83-110, and Affective literacies: writing and multilingualism in the late Middle Ages (Turnhout: Brepols, 2011).

10 From the Pseudo-Augustinian Soliloquies, provided in John C. Hirsch, The revelations of Margery Kempe: paramystical practices in late medieval England (Leiden: E. J. Brill, 1989), 62.

11 For details on medieval approaches to the environment, see Ellen F. Arnold's Negotiating the landscape: environment and monastic identity in the medieval Ardennes (Philadelphia: University of Pennsylvania Press, 2011).

12 Riverside Chaucer, I.3177.

13 Ziming Liu, Paper to digital: documents in the Information Age (Westport, CT: Greenwood Publishing, 2008), 60; Byeong-Young Cho and Lindsay Woodward, 'New demands of reading in the mobile internet Age', in Mobile pedagogy and perspectives on teaching and learning, ed. Douglas McConatha et al. (Hershey, PA: IGI Global, 2014), 191.

14 See Robert Payne, The promiscuity of network culture: queer theory and digital media (New York: Routledge, 2015); Stuart Moulthrop, 'You say you want a revolution? Hypertext and the laws of media', The new media reader (Cambridge, MA: MIT Press, 2003), 691-704, at 699; and Davida Charney, 'The effect of hypertext on processes of reading 
and writing', in Literacy and computers: the complications of teaching and learning with technology, ed. Cynthia L. Selfe and Susan Hilligoss (New York: Modern Language Association of America, 1994), 238-63, at 259 .

15 Martin Lister et al., eds, Digital media: a critical introduction (New York: Routledge, 2003), 29.

16 Gillespie, 'Anonymous devotional writings', 127.

17 Aarseth, Cybertext, 79, 95.

18 Hodgson and Liegey, eds, The Orcherd of Syon, 3, 9.

19 Richard H. Rouse and Mary A. Rouse address the issue of ordinatio in their seminal works, 'Statim invenire: schools, preachers and new attitudes to the page', in Renaissance and renewal in the twelfth century, ed. by Robert L. Benson and Giles Constable (Cambridge, MA: Harvard University Press, 1982), 191-335 and Authentic witnesses: approaches to medieval texts and manuscripts (South Bend, IN: University of Notre Dame Press, 1991). Cf. the equally influential essay by Malcom Parkes, 'The influence of the concepts of ordinatio and compilatio on the development of the book', in Scribes, scripts and readers (London: Hambledon Press, 1991); and Paul Saenger, Space between words: the origins of silent reading (Stanford: Stanford University Press, 1997). Saenger connects the rise of silent reading to accommodations for dividing and organizing texts, because such accommodations facilitated individual readers' use of and access to texts.

20 As Jessica Brantley notes, such considerations of page layout and design support nonlinear reading of the page itself, as the eye moves not from first word to last in linear sequence, but from heading to text to gloss and decorative capital (Reading in the wilderness, 94). Particular sequences can be encouraged by the relative size of different visual elements on the page, as well as the colours used, but the performance of nonlinearity still remains up to the reader.

21 Maija Birenbaum, 'Affective vengeance in Titus and Vespasian', Chaucer Review 43:3 (2009), 330-44.

22 On the subject of collative reading, see Brown, 'Undisciplined reading'. Another parallel might be drawn to the works of Marie de France, who refers to her work of composition using the term 'assembler', to assemble, in the prologue to the Lais. As such, the text does not require the interpretive effort of assemblage in the way that the Orcherd does, this labour having been accomplished already by the writer.

23 J. A. Herbert, ed., Titus and Vespasian or, the destruction of Ferusalem (London: Roxburghe Club, 1905), lines 7-11. Subsequent quotes are also drawn from this edition.

24 For instance, in her chapter comparing The Siege of Ferusalem with Titus and Vespasian in The Siege of Ferusalem in its physical, literary, and historical contexts (Dublin and Portland, OR: Four Courts Press, 2000), Bonnie Millar dismisses Titus and Vespasian as incoherent 
because of its narrative additions and divagations (124-5), and even the poem's editor declares that 'For the sake of brevity I have frequently alluded to the present metrical composition as a poem, but the justice of Dr. Brandl's description of it as "void of artistic composition" cannot be gainsaid' (Herbert, Titus, xliv).

25 As catalogued by the Digital index of Middle English verse, http://www. dimev.net. See also Carl F. Bühler, 'The new Morgan manuscript of Titus and Vespasian'. PMLA 76:1 (1961), 20-24, at 20.

26 Birenbaum, 'Affective vengeance', 340.

27 Riverside Chaucer, I.3177. Implicit in this suggestion that readers turn the leaf to avoid the tale is the expectation that - without such prompting - readers will negotiate the work linearly, and certainly the number of spurious links and additional tales added to fifteenth- and sixteenth-century manuscripts and printed texts of the Canterbury Tales suggest a desire, not simply for a completed work, but one that could be read linearly, without fragmentation or breaks between beginning and end.

28 Daniel T. Kline, 'Father Chaucer and the Siege of Thebes: literary paternity, aggressive defense, and the prologue to Lydgate's Oedipal Canterbury Tale', The Chaucer Review 34 (1999), 217-35; and Mary C. Flannery, Fohn Lydgate and the poetics of fame (Cambridge: Cambridge University Press, 2012).

29 On Lydgate's strategies for authorization and self-fashioning, see John Meyer-Lee, Poets and power from Chaucer to Wyatt (Cambridge: Cambridge University Press, 2007); John M. Bowers, Chaucer and Langland: the antagonizing tradition (South Bend, IN: University of Notre Dame Press, 2007), especially at 18; Thomas Augustine Prendergast, Chaucer's dead body: from corpse to corpus (New York: Routledge, 2004). As Meyer-Lee puts it, Lydgate enters the Siege of Thebes 'to bestow upon it the authority he possesses outside of it. The agon with Chaucer that he states throughout his imitation of the Canterbury Tales ... aims not so much to depict himself as an authentic disciple and heir as to transform Chaucer into a flesh-and-blood laureate who retroactively defines the role that Lydgate implicitly claims to occupy' (39-40). See Meyer-Lee, 'Lydgate's laureate pose', in Fohn Lydgate: poetry, culture, and Lancastrian England, ed. Larry Scanlon and James Simpson (South Bend, IN: University of Notre Dame Press, 2006), 36-60.

30 “"Dysemol daies and fatal houres": Lydgate's Destruction of Thebes and Chaucer's Knight's Tale', in The long fifteenth century, ed. Douglas Gray, Helen Cooper, and Sally Mapstone (Oxford: Clarendon Press, 1997), 15-34, at 22.

31 John Bowers 'The Tale of Beryn and The Siege of Thebes: alternative ideas of The Canterbury Tales', in Writing after Chaucer, 201-25, at 215 and 216. 
32 Paul Delany, 'Hypertext, hypermedia and literary studies: the state of the art', in Hypermedia and literary studies, ed. Paul Delany and George P. Landow (Cambridge, MA: MIT Press, 1991 [repr. 1994]), at 12 .

33 McGrady, Controlling readers, at 6.

34 Lois Ebin, Fohn Lydgate (Boston: Twayne, 1985), at 53; Lee Patterson, 'Making identities in fifteenth-century England: Henry V and John Lydgate', in Jeffrey N. Cox and Larry J. Reynolds, eds, New historical literary study: essays on reproducing texts (Princeton: Princeton University Press, 1993), 69-107, at 75.

35 For references to Cadmus as developer of the alphabet, see John Gower's Confessio Amantis, 4.2401; Godfrey of Viterbo's Pantheon 6, col. 157; and Isidore of Seville's Etymologiae 1.3.5-6, which was also adapted by Hugh of St Victor in Didascalion 3.2.

36 Espin Aarseth, 'Nonlinearity and literary theory', in George Landow, ed., Hyper/text/theory (Baltimore: Johns Hopkins University Press, 1994), 51-86, at 66. Aarseth's work on ergodic literature, within which he includes nonlinear texts, continues to be influential in the field: also see Cybertext.

37 Such a treatment seems to anticipate the fate of hypertext fiction today, as the taxing effort required to read and assemble narrative has been one of the reasons attributed to the genre's failure to gain wide readership. See, for example, Benjamin Paloff, 'Digital Orpheus: the hypertext poem in time', Fournal of electronic publishing 14:2 (Fall 2011), http://dx.doi.org/10.3998/3336451.0014.211; Paul LaFarge, 'Why the book's future never happened', Salon.com (October 4, 2011), www.salon.com/2011/10/04/return_of_hypertext/ singleton/; Stuart Moulthrop, 'For thee: a response to Alice Bell', in the Electronic book review (January 21, 2011), www.electronicbookreview.com/thread/electropoetics/networked; and Roy Rosenzwieg and Steve Brier, 'Historians and hypertext: is it more than hype?' in Clio wired: the future of the past in the Digital Age (New York: Columbia University Press, 2011), 85-91. In a similar vein, Robert Coover updated his prediction of the 'End of books' in 'Literary hypertext: the passing of the golden age', a keynote address given October 29, 1999 at the Digital Arts and Culture conference (http://nickm.com/ vox/golden_age.html). For a discussion of contemporary readers' discouraged responses to hypertext fiction, see James Pope, 'A future for hypertext fiction', in Convergence: the international journal of research into digital media technologies 12:4 (2006), 447-65.

38 On the preference for layout divisions in late-medieval English manuscripts, see Stephen Partridge, 'Designing the Page', The production of books in England 1350-1500, ed. Alexandra Gillespie and Daniel Wakelin (Cambridge: Cambridge University Press, 2011), 79-103. Daniel Wakelin addresses how scribes responded to the form 
of a poem in guiding layout and organization in Scribal correction, $217-45$.

39 For a detailed description of this manuscript, see Jordi Sánchez Martí, 'Longleat House MS 257: a description', in Atlantis 27:1 (June 2005), 79-89. Sánchez Martí offers compelling evidence that narrows the previously determined estimates of the manuscript's date.

40 Longleat 257 may not have been the only manuscript to evidence such a reading pathway. Daniel W. Mosser argues for the placement of Siege of Thebes before the Canterbury Tales in Austin, University of Texas Library MS 143 (olim Cardigan). For a description of this earlier configuration of the manuscript, see his 'The two scribes of the Cardigan Manuscript and the "evidence" of scribal supervision and shop production', Studies in bibliography 39 (1986), 112-25, at 123.

41 Schirmer, 'Reading lessons at Syon Abbey', at 347.

42 Dagenais, Ethics of reading, 24.

43 For further assessment of the role of affective reading, see Sarah McNamer, who addresses the role of affective meditation practice in late-medieval spirituality in Affective meditation and the invention of medieval compassion (Philadelphia: University of Pennsylvania Press, 2009). Jennifer Bryan counters the accepted belief that meditation was predominantly practised by women, arguing that devotional literature in general was not 'the special province of women readers', in Looking inward, 20. Similarly, see Vincent Gillespie, 'Lukynge in haly bukes: lectio in some late medieval spiritual miscellanies', Spätmittelalterliche Geistliche Literature in der Nationalsprache, Band 2, Analecta Cartusiana 106, ed. James Hogg (Salzburg: Institut für Anglistik und Amerikanistik, 1984), 1-27, at 4 and 17.

44 Vincent Gillespie, 'The haunted text: reflections in A Mirror to Devout People', in The text in the community: essays on medieval works, manuscripts, authors, and readers, ed. Jill Mann and Maura Nolan (South Bend, IN: University of Notre Dame Press, 2006), 129-72, at 131.

45 Schirmer, 'Reading lessons at Syon Abbey', 347.

46 Kerby-Fulton and Despres, Iconography and the professional reader, 2. 
Heather Blatt - 9781526118004 Downloaded from manchesterhive.com at 04/26/2023 ๑6:39: ๑०AM 


\section{Part II}

\section{Evoking participation}


Heather Blatt - 9781526118004 Downloaded from manchesterhive.com at 04/26/2023 ๑6:39: ๑०AM 


\title{
Reading materially: John Lydgate's 'Soteltes for the coronation banquet of Henry $\mathrm{Vl}$ '
}

\author{
Allone as I went vp and doun, \\ I ane abbay wes fair to se, \\ Thinkand quhat consolatioun \\ Wes best in to aduersitie, \\ On cais I kest on syd myne e \\ And saw this writtin vpoun a wall: \\ 'Off quhat estait, man, that thow be, \\ Obey and thank thi God off all'.
}

Robert Henryson, 'Abbey Walk'1

Like other texts addressed in these chapters, the short lyric poem 'Abbey Walk', by the late fifteenth-century Scots poet Robert Henryson, engages the work of reading in ways that facilitate and even necessitate reader participation. A poem concerned with man's awareness of God's mercy, 'Abbey Walk' introduces a simple refrain at the end of each of its stanzas: 'Obey and thank thi God off all'. The poem gains its modern title from its first few lines, in which Henryson describes an occasion when, solitary and struggling to address life's adversities, the narrator of the poem goes out walking and unexpectedly sees a hymn written upon a wall. This positioning suggests an external origin for the hymn: rather than simply a composition of Henryson's, it can be viewed as a lesson the narrator must learn from an external source, one that surmounts his own troubled state. The source of the hymn as located on the abbey wall is repeatedly referenced by the narrator throughout the remainder of the poem. Provided by the stones in a place desolate of any human presence but the reader's, addressing humanity's transitory possession of royalty, goods, and gold, the hymn offers a text illustrative of the natural order of the world, one that connects that natural order to reading by the transmission of the hymn by means of natural objects, the stones of the wall. 
'Abbey Walk' thus represents reading that emerges from the representation of an overlooked category of medieval textual media that I call 'extracodexical'. An extracodexical text is a written work that circulates outside the boundaries of the familiar codex, whether manuscript or print book. Heraldry, dishes, walls, tapestries, and embroidered or woven textiles and other objects are common surfaces for medieval extracodexical texts, which can also take the form of various charms and talismans. These and other examples invite scrutiny about how participatory reading practices emerge from interactions with such extracodexical texts. In addition to emendation and nonlinear apprehension, two primary and widespread modes of participatory reading reliant upon the written codex format, what modes of apprehension might be identified in participation with texts outside the codex? What experiences might contribute to shaping participatory reading in circumstances where texts are inscribed on objects people wear, dine from, walk around, or consume?

This chapter explores how extracodexical texts can illuminate participatory reading practices that emerge from works in and outside of manuscript contexts. In doing so it paves the way for subsequent analysis of other examples of extracodexical texts and their impact on participatory reading practice in the following chapter. Considering texts outside the boundaries of manuscripts as belonging to a shared category invites evaluation both of their parallels with each other, and also evaluation of how they differ from works in manuscript contexts. It is not simply that books mattered in the later Middle Ages: it is that texts mattered, and mattered in and across a variety of media. In other words, attending to extracodexical texts enables a de-centring of the book format in manuscript and print, and facilitates attention to and engagement with the variety of forms that medieval literary texts could assume. Furthermore, some texts can evoke extracodexicality by, in a manuscript context, relating or describing or otherwise circulating texts that were, in their original context, extracodexical. The movement of extracodexical texts into (and out of) manuscript contexts thus invites further evaluation of what is gained and what is transformed or obscured or multiplied by the changing medium of transmission. In these ways, assessing the roles played by extracodexical texts enables the effects of a particular medium - whether manuscript or other - to be explored with greater nuance.

Critical to extracodexical texts is the role played by their materiality, for it is the material difference of medium that defines them 
as a group. In 'Abbey Walk', the hymn engages the reader through several communicative modes predicated upon its materiality, its stone vehicle. The stone does not have pages that can be turned; it does not have rubrication or drawn margins or drawn lineation, typical hallmarks of books that shaped readers' literate practices. It cannot be apprehended nonlinearly, nor can it be emended with any degree of casualness. Nor can it easily be manipulated; the reader must concede to its location and permanency and approach it. Its extracodexical form requires or disallows certain behaviours and practices by readers. Yet the stone, durable and natural as it might seem, nevertheless requires the presence of a reader to engage it and make its meaning manifest. Without the presence of the narrator as reader before the wall, a presence that that allows him to apprehend the poem, it would not exist as a hymn to be represented by the poet. Without the wall, the narrator as reader would have to learn the lesson offered by the abbey wall text in a less visceral way. Crucially, the encounter between the narratorreader and the poem on the wall - preserved in a manuscript text - serves to illuminate how reading shaped and was shaped by the materiality of the extracodexical text.

\section{Materiality and extracodexical texts}

Accordingly, this chapter focuses on participatory reading as understood through the critical framework of materiality. Materiality has flourished in medieval studies in recent decades, influenced by new materialisms and especially object-oriented ontology, which provides a framework for understanding the independent agency of things. Object-oriented ontology and speculative realism provide the means to approach medieval historicity outside and around the perspective of the human, and have usefully intersected with ecocritical studies to generate ecomaterialist analyses that consider the agency of, for example, water or fire. ${ }^{2}$ Yet the materiality of objects that evoked or necessitated human participation can be assessed in ways that extend beyond the ontological focus. In particular, recent developments in the study of materiality in digital contexts offer approaches of use to the study of premodern, medieval materiality. Joanna Drucker, N. Katherine Hayles, and Matthew Kirschenbaum have been the leading voices discussing how to assess the materiality of digital media. In their approaches, they expand upon the understanding of materiality developed through the work of phenomenologists 
and gender theorists such as Maurice Merleau-Ponty and Judith Butler. The approaches of digital materiality studies also help to illuminate ways of thinking about medieval textual experience beyond that of the pages of a manuscript, which has dominated critical perspectives of literary materiality particularly in the wake of heightened consideration of the 'manuscript matrix', which 'involves cognitive perception as two kinds of literacy: reading text and interpreting visual signs'. ${ }^{3}$ In counterpoint, Michael Camille asserts that attending to the manuscript involves more than confronting medieval reliance upon both word and image; it also requires assessing the sensory experiences manifested through the tactility of parchment. ${ }^{4}$ Yet, as critics studying the materiality of digital media have shown, details like these that represent the 'forensic materiality' of works are only one among a number of ways that materiality constitutes meaning.

Forensic materiality contrasts with 'formal' materialities in assessing digital media, according to Matthew Kirschenbaum. Forensic materialities are those physical properties of a media's form, familiar to medieval studies as the 'manuscript matrix' to which New Philology directed such attention, and the sensation of the parchment page that Camille discusses. In contrast, formal materiality emphasizes the 'imposition' of multiple states on an object, which Kirschenbaum applies in particular to data or digital objects. ${ }^{5}$ For example, the use of a text editor to delete symbols on the page of a digital document represents a formal materiality of deletion. Ensuring that the data is also deleted from the hard drive engages in forensic materiality. In a manuscript context, the erasure of a word or page can be an act of formal materiality; it is not necessarily also an act of forensic erasure, as contemporary technologies such as those applied to palimpsests can be used to recover traces of the original writing. Just as one example of how this might relate to studies of medieval manuscripts, even current materialist focuses tend to miss the layer of the forensic when attending to their materiality: such analyses see the 'words and not the ink with which they were written', as Tim Ingold asserts. ${ }^{6}$ Against a 'poetics of parchment' and its corresponding material investigations, medievalists might also wish to investigate the 'poetics of ink'. Certainly, medieval writers distinguish between the qualities of red and black ink, for instance, which they respectively treat as representing the blood of Christ and the nails that pinned him to the cross. This association between nails and black ink might be extended further still if referring to ink written 
evocatively with the highly acid ink made from oak galls, bitter and biting in its nature.

Such distinctions between forensic and formal materiality can also be represented in the literary imaginary. For Henryson's abbey wall, the forensic materiality would be that of stone, whereas the formal emerges in the relation between the materiality of the text and the apprehension of the narrator-reader as discussed above. Similarly interested in what Kirshenbaum would term the forensic materialities of a work, N. Katherine Hayles evaluates how the material instantiation of a work, particularly in digital media, represents the convergence of communicative modes once viewed as medium-specific, such as moving images united with audio and text. ${ }^{7}$

This convergence of communicative modes evoked through encounters with materiality resonates strongly with medieval media, both in manuscript and outside it, where orality, imagery, text, and other modes may intersect and mutually affect each other, even as the emphasis on forensic materiality also invites consideration of the effects and types of formal materiality. It is these that engage Joanna Drucker, who offers the concept of 'performative materialities' to consider how 'the cognitive capacities of the reader make the work through an encounter' that 'is always situated within historical and cultural circumstances and expresses ideology at every level of production, consumption, implementation, and design'. For Drucker, works cue readers' engagement and the performance of materiality, and such materiality is always historically and culturally dependent. Materiality is not inherent in the form, but emerges through participation with readers as acts of interpretation. ${ }^{8}$ The materiality of Henryson's hymn on the abbey wall develops not through any essential properties consistently conveyed by the stone wall, but through the narrator-reader's apprehension of and participation with the stone-transmitted hymn.

In examining how materiality evokes participatory reading, this chapter marks a further turning point in relation to the studies of previous chapters. Whereas assessing corrective and nonlinear reading focused initially on the articulation of these practices by writers, in this and subsequent chapters the reading practices attended to are not the focus of instruction provided by medieval writers. Instead, particularly in the practice of material reading, participation manifests through the interpretive work initiated by how the texts function to create meaning. ${ }^{9}$ Accordingly, further consideration of how materiality shapes reading through its 
production in participation with the reader becomes a necessity, as evidenced by how the stones of Henryson's 'Abbey Walk' required the participation - even the performance - of a reader to make their hymn manifest.

Performativity in the context of medieval literature has gained increasing attention in the work of Robert Clark and Pamela Sheingorn, and through Jessica Brantley's work on British Library manuscript Additional 37049, a Carthusian miscellany. Brantley situates her analysis particularly in the context of and response to the effects of the texts and images that stimulate performative devotional reading of the manuscript's diverse collection of texts. ${ }^{10}$ Performative reading is not produced by the text alone, as Brantley observes; it can be evoked by a wide range of literary genres, such as plays to paternosters. Yet the alignment of reading with performance, while it effectively highlights how reading and performing in the later Middle Ages could often overlap, can potentially overlook aspects of a work not traditionally considered performative, but which can certainly be a practice of participation and interaction - such as walking and even sitting, both practices discussed below. Focusing on the role of materiality in the context of participatory reading in manuscript also invites, as mentioned above, consideration of how different types of materialities shape participatory reading. Exploring how participatory reading can be elicited particularly through materiality, in a way that explores materiality's engagement with extracodexical texts, is the project of this chapter.

Consequently, this chapter facilitates the study of extracodexical texts, arguing that considering the materiality of texts emphasizes how medieval reading functions as embodied practice. That is, reading materially involves bodily, materially mediated modes of experience. These modes of experience not only include word and image and touch, but also sound, place, movement, gesture, and the material properties of texts often neglected as under- or unliterary. One such under-literary, materially dependent text is that of the 'Soteltes for the coronation banquet of Henry VI', composed for the 1432 coronation banquet by John Lydgate; this work will be the focus of the present chapter. Lydgate's work has been the subject of reinvigorated assessment of materiality in medieval literary culture. ${ }^{11}$ Such materiality is central to the 'Soteltes', as the verses accompanied possibly edible, decorative dishes that concluded each course of the coronation banquet. Examining the verses and the materially dependent, embodied reading experiences 
they occasion will illuminate the role of participatory materiality in the work of reading and pave the way for the tighter focuses on movement, architecture, and time in the following chapters.

\section{Lydgate's 'Soteltes' as materially situated extracodexical texts}

The verses of Lydgate's 'Soteltes' poem take their name from their original material context. Subtleties were decorative or sometimes edible tableaux presented as the culmination of a course or as the high point of an entire feast. ${ }^{12}$ While the shape, subject matter, and scale of subtleties could vary, they aspired to grand display and often evoked symbolism pertinent to the occasion of the feast at which they were served. For example, when the Holy Roman Emperor Sigismund visited Henry V just after the feast of St George in 1416 and was inducted into the Order of the Garter, three subtleties were served at the celebratory feast that followed. These works depicted a lady arming St George, St George fighting a dragon, and a castle with St George and the king's daughter leading a lamb: fitting images for such an occasion. ${ }^{13}$ The subject matter of the subtleties evoked the patron of the order and of England itself, and reflected chivalric values important to the order, such as martial prowess and courtly behaviour, that Henry $\mathrm{V}$ sought to have the order embody. Whereas these tableaux focused on their imagery for meaning, Lydgate's 'Soteltes' exemplify a work that, in its manuscript survival, points to its materially conditioned original state. Accordingly, the kind of participatory materiality that shaped the reading of the 'Soteltes' at the coronation banquet provides a case study through which the role of materially contextualized reading can be assessed. Doing so shows how reading the 'Soteltes' could produce a particularly affective reading experience that relies on the readers' bodies to fashion and emphasize display of the new king's power and authority.

While the text in its manuscript survivals could be considered only as possessing the formal materiality of the manuscript matrix - its paper or parchment, its ink, and so forth - the representation of the 'Soteltes' in several of the manuscripts nevertheless includes details evocative of the work's prior materiality. ${ }^{14}$ First should be considered the textuality of the 'Soteltes' that make them readable, rather than wholly theatrical performances as discussed by Sponsler. In the manuscript context provided to the verses in London, British Library MS Cotton Julius B.i, each object constituting the subtleties is described as 'with this scripture suying', or 
'with this resoun', and 'with this reason folowyng'. This emphasizes the provision of verses in writing, as scripture, and through reasons, as mottoes, sentences, or verses. ${ }^{15}$ These descriptions attest to how the 'Soteltes' almost certainly offered their verses in a textual format. ${ }^{16}$ The textuality of subtleties accompanied by words is made even more explicit in records of the coronation feast of Henry VI's mother, Catherine of Valois. Her coronation in the same place as Henry VI's preceded it by the slim margin of ten years. Following each course of her coronation banquet subtleties were served, displaying motifs of St Katherine of Alexandria. The first subtlety consists of two tableaux, one with a pelican and other birds, and the other of Saint Katherine holding a wheel in one hand. A 'Reason [is] in hir [other] hande, Madame le Roigne', explains a London chronicle. To this the pelican responds, 'Cest enseigne' and the birds, 'Est du roy pur tenir joie. A tout gent il met sentient'. ('This is a sign / It is for the king to take joy / For all the people he makes [it] known'.) Here, the reason accompanying the subtlety is clearly provided as written text. ${ }^{17}$

The banqueting context proves significant to the manuscript witnesses as well, which reflect a continued interest in the original banqueting context of the verses, such as exemplified by the introduction to Lydgate's first verse for these coronation subtleties in London, British Library Cotton Julius B.i.:

This was the first cours at his coronacion, that is to say, first, ffurmentie with venyson. Viande Royal plantid with losenges of golde. Borehedes in castelles of earmed with golde. Beef. Moton. Signet. Capon stued. Heron. Grete pike. A redde lech with lions corven theryn of white. Custade Rooial with a leparde of golde sittyng theryn. Fritour like a sonne with a flour de lice therynne. A sotelte, Seint Edward and Seint Lowes armed in cote armours bryngyng yn bitwene hem the Kyng in his cote armour. (623)

Immediately following this introduction is given the verse of the first subtlety, introduced by explaining that it is provided 'with this scripture suying'. By situating the verses within the order and provision of food in a banquet, the subtleties become contextualized by the spectacle and consumption of the banquet itself. Roger Epstein, in writing on the textual nature of the subtleties, refers to their presentation of the text in a public banqueting event as effecting 'spectacular textuality'. ${ }^{18}$ The manuscript witnesses emphasize the combination of the subtleties' textual as well as visual elements, couching both in the framework of the banqueting display. As 
the hymn in 'Abbey Walk' functioned as an extracodexical text with which the reader-narrator interacted, the subtleties can be recognized as extracodexical texts integrated into the banquet, demonstrating the grounds of a reading practice dependent upon both forensic and formal materiality.

\section{Formal materiality and the 'Soteltes'}

Although the forensic materiality of Lydgate's subtleties is unknown, late-medieval subtleties could be fashioned from consumable items, such as bread or sugar, or from non-consumable items that might require the labours of craftspeople, including painters, carpenters, and metalworkers, to devise. ${ }^{19}$ Despite the insufficiency of current evidence to indicate the formal materiality of Lydgate's subtleties, the material possibilities would nevertheless have evoked different interpretations for the original audience. They thus deserve brief address in that context, for their forensic materiality shaped how the subtleties' formal materiality conveyed meaning to readers. Subtleties could encompass a range of forms and materials; the less sculptural ones might be made from as simple a material as ground meat. An example of this style of subtlety is provided in descriptions of the coronation feast of Catherine of Valois, Henry VI's mother. At her banquet, the subtlety for the third course was made from a 'mete in paste with iiij aungels in fourme of Sent Katerine whele in the myddes with a Reason'. ${ }^{20}$ 'The meat has simply been moulded into the shape of a Catherine wheel, either supported or being broken by angels; such a subtlety was clearly designed for consumption as well as admiration and reading. Lydgate's subtleties, along with the subtleties for the first two courses of the coronation of Queen Catherine, are more sculptural and thus required materials more suited for the purpose. Bread is a possibility, as is sugar, as are non-consumable materials. Given the details of Lydgate's subtleties, the likelihood of non-consumable materials having provided the support for the subtleties is strong. The probability of the use of some if not entirely non-consumable items may also be suggested by details of the subtleties' descriptions, such as the note that Edward and Louis are 'armed in cote armours', Emperor Sigismund and Henry $\mathrm{V}$ are 'armed' and both wear 'mantelles of the garters', suggesting that the heraldic armour and mantels may have been separate items, the armour perhaps even crafted by metalworkers. Yet if made of consumable items, the cultural background and figurative 
connotations of the foodstuffs would affect interpretation: if made from sugar, for example, the expense and foreign origin of sugar would have - as the banqueting dishes did themselves - attested further to the king's might and wealth. ${ }^{21}$ Bread could have been viewed as attesting to the king's ability to support and nourish his people. The forensic materiality would, consequently, have added to the formal materiality of the subtleties, based on the participants' understanding of the figurative implications of the subtleties' material supports. Yet in the manuscript witnesses' silence on the details of the subtleties' material, the one aspect of formal materiality that we can point to is the presence of the textual 'scripture', even as we can only speculate about the specific details of its formal materiality (was it written with edible vegetable inks? On an edible or nonedible vehicle?).

The description of the subtleties in the manuscript witnesses, in their absent commentary on the subtleties' formal materiality beyond the presence of the textual 'scriptures', asserts the primacy instead of formal materiality. The manuscript witnesses' descriptions demonstrate how - perhaps regardless of the subtleties' formal materialities - the material context of the subtleties nevertheless shaped their formal materiality. First, the convergence of the subtlety with the feast dishes indicates that each subtlety and its verse function as figurative consumables, their messages internalized in the bodies of the banquet audience. ${ }^{22}$ Understanding the text in this way demonstrates how cuisine functions as a materiality affecting the work's apprehension. The verses become works to be savoured virtually, if not also literally, and in that savouring their ideology is taken in by the reader through the vehicle of consumption, a bodily practice. Participatory materiality thus shapes a reading of the 'Soteltes' that is both affective and visceral. Second, linkage of the 'Soteltes' to food also evokes the medieval practice of meditatio in the reception of the subtleties. Through meditatio, 'reading is memorized and changed into personal experience', a practice that Mary Carruthers notes that Jerome links to consumption. Jerome argues that 'Consumption of the book is the foundation of reading and the basis of history. When ... we store away the book of the Lord in our memorial treasury, our belly is filled spiritually and our guts are satisfied'. ${ }^{23}$ Reading functions as an act of consumption that alters the formal materiality of the reader's own body. By imbricating consumption with the 'Soteltes' objects and verses, the subtleties themselves become works that readers internalize, forming the sacral yet secular foundation of the 
new history brought forth by the coronation of a new king. Third, beliefs about medieval food practice connected consumption to changes worked upon the body of the person eating. Even virtual consumption of the subtleties thus construct the bodies of readers as supporters of the Lancastrian ideology promoted by the subtleties. In this way, the formal materiality of cuisine contributes to the reading of the subtleties through the process of figurative and possibly even literal consumption.

As an aspect of the subtleties' formal materiality, the physical conditions of the Great Hall at Westminster as the place of the banquet also invite consideration for how they could shape participatory reading of the 'Soteltes'. As the manuscript matrix provides a textual and material context for texts transmitted in codices, extracodexical texts enjoy as their 'matrix' not only the materiality of their own physical form, but the context in which they can be situated, through which they act, or in which they were transmitted through readers. For the 'Soteltes', their matrix extends to the Great Hall at Westminster as a socially significant place in which they were presented and read. While the relationship between architecture and readers will be explored at greater length in the following chapter, it is key here to address how the physical, material surroundings of an extracodexical text could impact its reading. Spaces are not only physical settings, but also become - through the human valuation and articulation of space - transformed into culturally constructed places that convey meaning and shape identity. ${ }^{24}$ Space influences reading in physical ways, and place contributes to the meaning and practice of reading within a space.

The Great Hall of Westminster Palace, rebuilt only three decades prior at the instigation of Richard II, provided the traditional space for coronation banquets. As not just a space but also a place, it drew on religious traditions as well as spatial status to establish its social meaning. At the time of Henry VI's coronation, it was the largest hall of its size in Europe. Borrowing extensively from sacral architecture, the hall measured an immense 240 by 68 feet, and was able to host thousands for coronation feasts. ${ }^{25}$ Merchant stalls and shops typically lined the Great Hall during legal term-times, but for Henry VI's coronation event, these additions were swept away and the bare masonry was covered with decorative hangings, perhaps some of the Flemish tapestries collected by Richard II or, for a more unified look, decorative woollen hangings similar to those used for the coronation of Edward III in 1327. 
The hall thus functioned as a grand, imposing, and extensive place that emphasized the authority of the king. The arrangement of furniture for the feast stressed this point still further, for Henry VI sat behind the centre of a table on a raised dais located before the south wall, opposite the main ceremonial entrance to the north. Polychrome stone statues of England's kings occupied niches flanking the lofty south window above the dais, reinforcing the assertion of power and grandeur offered to Henry VI in his central, elevated seat. ${ }^{26}$ To either side of Henry sat some of the more illustrious members of the nobility. Perpendicular to this table, along the length of the Great Hall, were arrayed other tables in two long rows.

The scope of the hall materially influenced the subtleties themselves, and attendees' participatory reading of the subtleties. Few objects could be large enough that all those assembled at the coronation could read them. The issue of size relative to the physical space of the hall consequently indicates that those seated by the king, along with the king himself, to whom the subtleties would have been served, would have been their most intimate readers. In contrast, the rest of the court, clergy, and prominent London citizenry seated at the tables, and even the common citizenry assembled to watch from galleries, most probably heard the verses as they were read aloud, perhaps as the subtleties were processed into the hall. That reading aloud of the subtleties adds a vocal aspect to their materiality, one that could intersect with the acoustics of the hall. In these ways, the materiality of the Great Hall at Westminster affects the material process of engaging with the subtleties by creating contexts for reading the subtleties in ways differently affected by place and the arrangement of the people within it. Some of the readers could engage, through proximity to the objects, in intimate acts of reading where they apprehend the subtleties directly. For others, whose reading of the subtleties relies on aural apprehension of the verses, distance shapes their interpretation of the subtleties in various ways, giving greater emphasis to the visual cues of the subtleties and the performance of the verses, and making their reading more public in its effects.

In their presentation at the coronation banquet and in the way the verses were likely recited for aural apprehension by the audience at the banquet, the verses of the subtleties deserve recognition for how they participate in the realm of the public theatrical spectacle, as Claire Sponsler addresses. ${ }^{27}$ While many of the aspects of the subtleties can be viewed as performative - particularly their 
consumption and spectacular, public display - performance can also obscure the participatory role of the text itself as described above. Considering the subtleties within the framework of performance can emphasize their reception as the performative effort, with the subtleties providing the script provoking performance by the audience. In contrast, participation offers the framework for considering agency on the sides of both reader and text: the text can be an agent that interacts with readers, their mutual, coconstitutive participation constituting acts of reading.

In addition, medieval concepts of reading, as discussed in previous chapters, acknowledge that reading experiences could engage both the single reader directly apprehending the text for himself as well as audiences apprehending the text by hearing it read aloud by others. Both modes of apprehension represent acts of reading. Such aural apprehension contributes to the participatory work of reading. It also serves as a reminder to audiences today of how the medieval boundaries that distinguished between the status of a reader and that of an audience were much more diffuse and interchangeable in late-medieval England. It is in this light that the subtleties are considered here as readable, extracodexical literary works. Considering their function as readable works further underscores the necessity of adopting a framework for assessing the participatory materiality of reading, as participation can encompass the shifting interchanges between audiences and readers. Considering the evidence offered in the manuscripts for the subtleties' original context provides details that allow extrapolation of the forensic materiality of the verses as extracodexical works presented at the banquet. This materiality, together with the textuality of the verses, converges to engage the reader in the subtleties' participatory materiality. Yet the participatory materiality of the subtleties is not conditioned by these aspects alone. The specifics of the coronation location, the person reciting the verses aloud, the audience who reads these verses through aural apprehension, and the king who is positioned to read the verses directly, show how the verses invite participation as a mode of reading through interaction between many distinct circumstances shaped or defined by materiality. In this way, material reading becomes an embodied, participatory practice. The participatory materiality of the subtleties enfolds the interacting bodies of readers and texts into the work of reading. 


\section{Participatory materiality and mobility}

Having addressed the issues of textuality, cuisine, and place, it still falls to address other aspects of the participatory materiality of the subtleties. Related to place is the issue of mobility. Almost exclusively studied in the context of medieval cycle plays and their movement through civic space, mobility conveys material force through its performance in space, through its affects in space and on bodies, and through the meaning and significance of place. ${ }^{28}$ The subtleties were moved into the hall and processed under the eyes of all to the king's table, as was customary with subtleties and feast dishes more generally. ${ }^{29}$ Where the subtleties entered from also deserves note. The dishes for the feast were conveyed into the Hall from the Great Kitchen and temporary, improvised kitchens, all buildings outside the Hall. While the entrance to the Great Hall nearest the Great Kitchen was located midway along the western length of the hall between its main entrance on the north end and the king's seat at the south end, it is more probable that the feast dishes - and the subtleties - were brought through the main entrance at the north end of the Great Hall. Indeed, contemporary chronicles and coronation records indicate that the main north entrance was chosen for other major entries during the coronation feast, and it therefore seems most likely that this entrance was also chosen for the feast dishes and subtleties. ${ }^{30}$ Use of the main entrance would have allowed these officials to process the dishes up the length of the Hall, passing between the long tables, at right angles to the king's, that seated the attending nobility, clergy, and prominent citizens of the city; the subtleties would have processed to the king's table beneath these gazes. Accordingly, the entrance of subtleties into the hall took part in the carefully orchestrated display that surrounded grand feasts in general and Henry VI's coronation in particular.

How the subtleties participated in this orchestrated display must be understood as again engaged with participatory materiality: Subtleties moved as household officers carried them into the feast hall and presented them to those dining at table. As the subtleties entered, guests witnessed their movement from their own seats at tables in the Great Hall. Especially apparent in the chronicle description of the subtleties, their textual and imagistic focus on their own movement erases the movement of the officers bearing them into the Great Hall. This emphasis is made apparent through how the chronicle depictions focus only on the subtleties' move- 
ments. The first subtlety, for example, is described as 'A sotelte, Seint Edward and Seint Lowes armed in cote armours bryngyng yn bitwene hem the Kyng in his cote armour'. Edward and Louis are recognized as the agents moving the king through space in an ideologically evocative manner. This omission of the means by which the subtleties entered the hall thus elides the movement of their bearers. Such erasure transfers the agency of movement to the subtleties themselves.

Accordingly, mobility of the subtleties offers an additional participatory materiality conditioned by the subtleties as extracodexical texts, one that relies upon the bodies of the readers to enact. For the audience of the coronation feast, the movement of the 'Soteltes' into the Great Hall, their procession amidst the tables toward the king's dais, and the public reading of their texts, enjoin stillness upon their audience, who are called upon to listen, heed, and learn the lessons imparted by the subtleties' mobility and their own immobility. Emphasizing the mobility of the subtleties and the consequent stillness of their readers suits the political and performative needs of Henry VI's coronation event, where readerviewers and even king are the focal points of political messages designed for public reception. Showcasing the mobility of the subtleties thus contrasts with immobility of the readers, fashioning their seated performance as one of attentive listening that marks them as receptive to the instructional message of the subtleties. Such a move rhetorically positions the audience as the recipient, not the origination, of meaning - even as that meaning could not be enacted without the audience's participation. This relationship between the meaning of the subtleties and the audience who both help create that meaning through their participation and are also the objects of that meaning complicates the conventional understanding of participatory materiality, which recognizes both the human and the object participants as interacting subjects in the evocation of meaning. ${ }^{31}$ The message of the subtleties, however, is designed to shape and even constrain the subjectivity of the audience, as it simultaneously also relies on their participation in the creation of meaning, in order to represent that audience as ideologically compliant subjects of the king. Movement becomes an aspect of reading practice that is simultaneously material and political.

The last trio of participatory materialities intersect through the mode of the visual: the imagery of the subtleties, the gestures made by the figures represented in them (in the object and the verses), and the heraldic language of their appearances that make them 
easily recognizable as specific individuals. These details converge in both the description of a subtlety and its verses. Lydgate provides each subtlety with an accompanying verse, provided in the manuscript witnesses after description of the subtlety imagery. The scripture that accompanied the subtlety following the first course reads:

Loo here twoo kynges righte perfit and right good, Holy Seint Edwarde and Seint Lowes:

And see the braunch borne of here blessid blode;

Live, among Cristen moost souereigne of price,

Enheretour of the floure de lice!

God graunte he may thurgh help of Christ Ihesu

This sixt Henry to reigne and be as wise

And hem resemble in kyghthod and virtue. (1-8)

Gestures are prominent here in the imagery of the subtlety object and its verse, giving a bodily force to the message that is designed to be recognized by those assembled in the hall at Westminster. In this way, bodily work gains material function: even those unable to read the verses can recognize the body language of its message: The two sainted kings of England and France, Edward and Louis, support between them a figure of Henry VI himself. The verse elaborates on and makes this message of support clear, couching that support temporally in the hopes Lydgate offers for the potential excellence of the king. Politically, the dual support of the kings also reminds the audience of Henry VI's claim to the thrones of two countries. The emphasis on gesture is evident in the way Edward and Louis are 'bryngyng yn bitwene hem' the figure of the king. Their figurative support is conveyed through their material, embodied gestures, their action of carrying their heir who embodies England's hopes, reinforced by the easily identifiable heraldic imagery with which their armour is depicted. This prominence of an imagistic, gestural mode of the subtlety tableau enhances the force of its political message: the choice to usher Henry VI forward is one that has been made by Edward and Louis. In this context, their gestures in support of Henry VI perform an endorsement of the new reign.

The gestures also serve another function in that, although they are physically immobile in the object of the subtlety, the language used to depict them in the description of the subtlety and in the verses emphasizes the animated nature of the gestures. In the description of the first subtlety, Saints Edward and Louis are 
'bryngyng yn bitwene hem the Kyng'; in the second subtlety, the king is 'knelyng before' Henry $\mathrm{V}$; in the third, the Virgin Mary is 'holding in hir hand a crowne', while Saints George and Denis are 'knelyng' beside her, 'presenting the Kyng, knelyng' (623-4). In this way, the subtleties viewed by the audience at the coronation represent a convergence of movement with fixed image. This convergence of movement and imagery is subsequently reiterated to the audience of the verses in their manuscript contexts. This intersection of movement and imagery describing the formal materiality of the subtleties presents a shifting of meanings that construct a performance of animated materiality. Animated materiality attributes agency to the objects so moved. ${ }^{32}$ This contrasts with the traditional view of objects, in which their status as objects defines them ontologically as lacking in agency. Yet by simulating movement in the language of the verses, the subtleties nonetheless represent the objects as agentive subjects, carrying, sitting, holding, and kneeling. The subtleties thus simultaneously resist oversimplification into the status of static objects and images, even as they fall short of self-motivated movement. Their animation comes through performance, enhanced by hidden human agency of those carrying the subtleties into the Great Hall. This performance grants additional force to the ideology of the subtleties.

Such additional force is further reliant upon the bodily participation of viewers, evidencing an effect that reinforces the role of what digital media critics refer to as 'haptic visuality', in which the eyes facilitate touch. ${ }^{33}$ Medieval optical theories resonate strongly with the concept of haptic visuality, for medieval theories on sight presuppose exchange between objects and viewers. In particular contiguity can be drawn between the medieval theory of extramission, in which the viewer's eyes send forth a beam that perceives the object upon which one gazes, and haptic visuality, which considers how the work of the eyes function in ways analogous to touch, for in haptic visuality sight is thought of as 'reaching out' to apprehend the object of a gaze. The way the performance of animated materiality engages haptic visuality means that the audience of the subtleties works to constitute the image. As Susanne Akbari explains, 'for the subject to know the object, the two must come into contact; the object must come to be, in some way, inside the subject'. ${ }^{34}$ 'That inside-ness converges further with the materiality of cuisine that characterizes the subtleties as subtleties. But what haptic visuality makes explicit in ways overlooked in discussions of medieval optical theory is the reliance of visuality upon the body. 
The act of an image's constitution, made possible through the reaching out of the gaze represents a mutual exchange and a reliance upon the body of the viewer, without whom no gaze would be possible. Considering the subtleties in this way further illuminates the processes involved in participatory materiality. Consequently, the participatory materiality of the subtleties provides multiple modes for internalizing the message of the work.

Examining the subtleties through the framework of participatory materiality highlights the labour involved in making readers work, for it emphasizes the processes by which the meaning of materiality becomes manifest in the extracodexical text, even in its manuscript preservation. Accordingly, it offers a useful nuance to ontological approaches to materiality, in which meaning can be seen as a property of the material form. In addition, considering participatory materiality of multiple works, such as the 'Abbey Walk' poem by Henryson that is referenced at the start of this chapter, as well as that of Lydgate's subtleties, reveals how these works foreground materiality in common ways that require the participation and work of readers in interaction with the material text. Like the 'Soteltes', 'Abbey Walk' focuses on a material context in which is situated an extracodexical text, and this material context supports the message of the text. Both emphasize the imagery through which the text's message is both constituted and extended. Space and place further add to the meaning of the work, as does the movement either of the object or the reader. Accordingly, the two poems evoke shared categories of meaning: text, imagery, space and place, movement, and even the spoken quality of the words all become meaningful aspects of the works. These aspects are figured through their materiality. Furthermore, these shared modes of materiality require a reader, one who does not simply recognize these modes of the text, but whose engagement with them makes these materialities and their significance interpretable.

It is not until the narrator of 'Abbey Walk' approaches the wall that he then sees the text. Reading it, he understands how the stones offer a message that solves the matter he has been contemplating. Its solitude mirrors the poet's own as he walks alone; its formal materiality, the stone wall, testifies both to how the message came into being - through human agency - even as the durability of stone suggests the durability of the message, a counterpoint to the theme of the abbey wall text that suggests all human works fall into decay. Similarly, it is not until the audience 
at the coronation read the subtleties that the significance of their materiality becomes effected. 'The subtleties' mobility contrasts with the audience's presence and stillness, the readers' degrees of proximity and intimacy with the subtleties, the visual imagery and the textual message: all these constitute processes of participatory apprehension that support interpretation. Reading materially also engages in virtual enactment, for an object provokes its materiality, and an object's significance is not inherently in its forensic qualities, but constituted through culturally situated meaning and social ideology that is enacted by the reader. Materiality can thus effect an encounter with the virtual. ${ }^{35}$ Consequently, to assess medieval materiality in the context of reading practice requires understanding that it does not make meaning ontologically, but through potentialities in action. It must be understood by what it does, not what it is.

Finally, participatory materiality represents a reading practice tied to making readers work. This work is occasioned through an encounter with a text, and interpretation of the text is provoked by various aspects of a work's materiality. As Joanna Drucker asserts, reading becomes a 'constitutive interpretation of act' deeply affected by the materiality of a work in a particular historical context. ${ }^{36}$ Assessing the relationship between readers and materiality in Lydgate's 'Soteltes' and Henryson's 'Abbey Walk' shows how materiality cannot be identified simply and solely through the embedded properties of an object - its forensic materialities. Materiality is also conveyed and constituted through reception of its formal materialities, which are culturally produced. Accordingly, for medieval audiences, reading materially is a practice embedded in the moment, in the space, place, and other material conditions that shape the act of reading. In addition, how these qualities - and in particular the qualities of space, place, and movement - constitute a reading practice points not only to how reading functions as a materially bound practice, but also to how reading functions as a practice reliant upon a person's bodily presence, senses, and physicality. This suggests that a related reading practice is embodied reading, which contributes to the subject of the next chapter. 


\section{Notes}

1 Denton Fox, ed., The poems of Robert Henryson (Oxford: Clarendon Press, 1981), lines 1-8.

2 In an influential work contributing to medievalists' recent discussion of materialism, 'Medieval materialism: a manifesto', Kellie Robertson emphasizes how medieval definitions of matter can contribute to historicization of medieval materialities (Exemplaria 22:2 [Summer 2010], 99-118). Carolyn Walker Bynum, in Christian materiality: an essay on religion in late medieval Europe (New York: Zone Books, 2011), has contributed an invigorating study of the intersections between medieval materiality and religious and devotional practices. For examples of materialist studies inflected by object-oriented ontology, see the special issue of postmedieval edited by Jeffrey Cohen and Lowell Duckert, postmedieval 4:1 (Spring 2013), Ecomaterialism; and Jeffrey Jerome Cohen, Stone: an ecology of the inhuman (Minneapolis: University of Minnesota Press, 2015).

3 Stephen G. Nichols, 'Introduction: philology in a manuscript culture', Speculum 65:1 (Jan. 1990), 1-10, at 8. The essays collected in Imaginary worlds in medieval books: exploring the manuscript matrix, ed. Martha Rust (New York: Palgrave, 2007), offer thoughtful explorations attending to the manuscript matrix.

4 Michael Camille, 'Sensations of the page: imaging technologies and medieval illuminated manuscripts'. The iconic page in manuscript, print, and digital culture, ed. George Bornstein and Theresa Tinkle (Ann Arbor: University of Michigan Press, 1998), 33-53.

5 Matthew Kirschenbaum, Mechanisms: new media and the forensic imagination (Cambridge, MA: MIT University Press, 2008), 13.

6 Tim Ingold, 'Materials against materiality', Archaeological Dialogues 14:1 (2007), 1-16.

7 N. Katherine Hayles, Writing machines (Cambridge, MA: MIT Press, 2002).

8 Joanna Drucker, 'Performative materiality and theoretical approaches to interface'. Digital Humanities Quarterly 7:1 (2013), www.digitalhumanities.org/dhq/vol/7/1/000143/000143.html, paragraph 23.

9 For discussion on how texts work in ways that seek to engage readers' responses, emotional and intellectual, see Paul Alpers, 'Mode in narrative poetry', in To tell a story: narrative theory and practice, ed. Robert M. Adams (Los Angeles: William Andrews Clark Library, 1973), 25-56.

10 See Clark and Sheingorn, 'Performative reading' and 'Visible words'; for Brantley, see Reading in the wilderness. Brantley sees the manuscript as collecting together a wide range of texts marked by their reliance upon modes of performative reading.

11 See, for example, the essays collected in Lydgate matters: poetry and 
material culture in the fifteenth century, ed. Lisa H. Cooper and Andrea Denny-Brown (New York and London: Palgrave, 2008) and Claire Sponsler, The queen's dumbshows: Fohn Lydgate and the making of early theater (Philadelphia: University of Pennsylvania Press, 2014), 160-5.

12 In France during this period, the conclusion of a course ushered in the entremet, a much more dramatic spectacle than that accompanying subtleties in England (see Bridget Henisch, Fast and feast: food in medieval society [University Park: Pennsylvania State University Press, 1976], 229).

13 Critical consensus has not determined whether these subtleties were purely decorative or edible in nature; evidence suggests that some were both decorative and edible, while others only decorative. See, for instance, Anne Lancashire (London civic theatre: city drama and pageantry from Roman times to 1558 [Cambridge: Cambridge University Press, 2002], 125).

14 The text of the 'Soteltes' survives in nine manuscripts, most of which situated it amidst the passages of London chronicles; two manuscripts present it in miscellanies focused on literary collections. For an assessment of these manuscripts and their relationships, see Sponsler, The queen's dumbshows.

15 Henry MacCracken, The minor poems of Fohn Lydgate: part ii, secular poems, Early English Text Society (EETS) o.s. 192 (London: Oxford University Press, 1934), 623-4. All quotations from the text are drawn from this edition.

16 Walter Schirmer suggests that Lydgate's 'Soteltes' verses were displayed on a tablet or scroll; see Fohn Lydgate: a study in the culture of the xvth century (London: Methuen, 1961), 132.

17 A description of the coronation feast and subtleties are printed in $A$ chronicle of London: from 1089 to 1483, ed. Nicholas Harris Nicolas and Edward Tyrrell (London: Longman, Rees, Orme, Brown, and Green, 1827), 162-5, at 164.

18 Robert Epstein, 'Eating their words: food and text in the coronation banquet of Henry VI', Fournal of medieval and early modern studies 36:2 (Spring 2006), 355-77, at 371.

19 Melitta Weiss Adamson, Food in medieval times (Westport, CT: Greenwood Press, 2004), 75.

20 Nicolas and Tyrrell, A chronicle, 164. The materials for the subtleties concluding the first two banquets are not specified.

21 Sidney Mintz, discussing fourteenth-century European marzipan subtleties involving sugar, suggests that they could have similarly demonstrated wealth and power; see 'Color, taste, and purity: some speculations on the meanings of marzipan'. Etnofoor 4:1 (1991), 103-8; and in more recent work discussing the figurative implications of marzipan and other sweets in nunneries, see the chapter on 'Sweet traditions and the martyrdom of Saint Agatha', in Cristina Mazzoni’s 
The women in God's kitchen: cooking, eating, and spiritual writing (New York and London: Continuum, 2005), 77-8.

22 For an extended discussion of how the banquet's foods function as consumable signs, see Epstein, 'Eating their words'.

23 Quoted in Mary Carruthers, The book of memory: memory in medieval culture. 2nd ed. (Cambridge: Cambridge University Press, 2008), at 53.

24 The 'spatial turn' in literary and cultural studies, as well as in social sciences, from which the distinction between space and place described here has been drawn, has flourished in recent decades. Some of the major theorists and critics contributing to how we understand space and place include Henri Lefebvre, Michel de Certeau, Judith Butler, Gilles Deleuze, Michel Foucault, and others. For a general introduction, see Phil Hubbard and Rob Kitchin, eds, Key thinkers on space and place, 2nd ed. (London: Sage, 2011). In the field of medieval studies, foundational contributions include Barbara A. Hanawalt and Michal Kilbialka, eds, Medieval practices of space (Minneapolis: University of Minnesota Press, 2000); Mayke de Jong, Frans Theuws, and Carine van Rhijn, eds, Topographies of power in the Middle Ages (Leiden: Brill, 2001); Virginia Chieffo Raguin and Sarah Stanbury, eds, Women's space: patronage, place, and gender in the medieval church (Albany, NY: State University of New York Press, 2005), and Geraldine Heng, Empire of magic: medieval romance and the politics of cultural fantasy (New York: Columbia University Press, 2003).

25 Mark Girouard, Life in the English country house: a social and architectural history (New Haven: Yale University Press, 1994), 33. For the sacral borrowings of Westminster Hall, see Christopher Wilson, 'Rulers, artificers, and shoppers: Richard II's remodelling of Westminster Hall, 1393-99', in The regal image of Richard II and the Wilton Diptych, ed. Dillian Gordon, Lisa Monnas, and Caroline Elam (Coventry: Harvey Miller, 1997), 33-59. (In contrast, the now-destroyed Archbishop's Palace at Canterbury, itself the location of significant feasts, measured 126 by 42 feet - half the length of Westminster Hall [Girouard, 34].)

26 For discussion of the statues and their placement, and more broadly the decorative programme of the hall, see Wilson, 'Rulers, artificers, and shoppers', 41-2.

27 See Sponsler, The queen's dumbshows.

28 See Andrea R. Harbin, Space and movement on the medieval English religious stage ( $\mathrm{Ph} . \mathrm{D}$. dissertation, Washington D.C., The Catholic University of America, 2006), and Sarah Beckwith, 'Work, markets, and civic structure: organizing the York Corpus Christi plays', in Signifying God: social relation and symbolic act in the York Corpus Christi plays (Chicago: University of Chicago Press, 2001).

29 Roy Shipperbottom, 'Precious metals on food', in Look and feel: studies in texture, appearance and incidental characteristics of food: proceedings 
of the Oxford symposium on food and cookery 1993, ed. Harlan Walker (Devon, UK: Prospect Books, 1994), 211-14, at 212.

30 Although later architectural modifications to Westminster's Great Hall have a limited ability to comment upon the medieval fabric of the building, in Francis Sandford's 1687 work, The history of the coronation of the most high, most mighty, and most excellent monarch, Fames II, Sandford includes a diagram noting the layout of the Great Hall for the coronation feast, which depicts the placement of tables, tableware, and king's dais (108-9). This layout is consistent with that used for the coronation feast of Queen Katherine in 1421 (A chronicle of London, 162-3). In particular, the diagram for James II's banquet identifies the location of entrances added to the Great Hall after the fourteenth century and descriptively labels these entrances. At the north end of the Great Hall are the two doors, the first of which is described as, 'The door through which the Meat was brought in from the Chequer yard' and the second of which is, 'The Passage into the Hall from the Cellars'. The location of these entrances suggests a routine or ongoing plan for feast items, which included subtleties, to enter the Great Hall from close by its main north entrance. One effect of bringing the items in at this end of the Great Hall is that it affords those assembled the best and longest view possible as the items moved towards the king's seat.

31 Sydney J. Shep, 'Digital materiality', in A new companion to digital humanities, ed. Susan Schreibman and John Unsworth (Chichester, West Sussex: John Wiley \& Sons, Ltd., 2016).

32 Alfred Gell, Art and agency: an anthropological theory (Oxford: Oxford University Press, 1998).

33 The distinction between haptic and optical has been proposed by Gilles Deleuze as multiple functions of perception, rather than representing different senses. Building on this, Laurie Marks's work on haptic visuality in video images has been particularly influential. Marks argues that haptic visuality encourages a 'bodily relation' that relies on connections between the viewer's body, the object, and vision. See Touch, sensuous theory and multisensory media (Minneapolis, University of Minnesota Press, 2002), 17.

34 Susanne Akbari, Seeing through the veil: optical theory and medieval allegory (Toronto: University of Toronto Press, 2004), 24.

35 For further consideration of virtuality, see Órla Murphy, who addresses these blurred boundaries through the lens of intermediality in, 'Intermediality: experiencing the virtual text', in Readings on audience and textual materiality, ed. Graham Allen, Carrie Griffin, and Mary O'Connell (London and Brookfield, V'T: Pickering and Chatto, 2011), 155-62.

36 Drucker, 'Performative materiality', paragraph 17. 


\section{Reading architecturally: The wall texts of a Percy family manuscript and the Poulys Daunce of St Paul's Cathedral}

As discussed in the previous chapter, reading extracodexical texts materially requires attending to particular details such as space and place, and embodied experiences shaped by these materialities, such as movement. These three aspects of material reading converge in a striking way when considering the role of architecture in fashioning reading practices. Architecture may not seem an obvious direction in which to look when assessing the culture of reading in late-medieval England, but its neglect intersects with modern aesthetic judgments regarding the kinds of texts deemed sufficiently literary for study, a practice that has led to neglect of extracodexical texts more generally. In fact, civic and religious buildings throughout medieval Europe, and even the households of private individuals, could incorporate text in several ways and places, from the plates used at table to the hangings and paintings on their walls. The latter category of extracodexical texts offers a striking example of the intersection between reading and architecture. Wall texts typically accompanied imagistic paintings made on the walls, or on cloths or panels hung on the walls, of churches, private houses, and professional buildings. Although not completely unknown to modern audiences of medieval culture, they are uncommon in their survival. ${ }^{1}$ The most well-known wall texts of the fifteenth and early sixteenth centuries survive only through transcriptions of the texts recorded in manuscripts, where they may be supplemented only by brief descriptions of the images they once accompanied. Yet both in manuscript and in what can be reconstructed of their original locations, wall texts present another opportunity to examine how readers related to texts outside the bounds of manuscripts, and present instead in alternative material spaces. They also provide reminders of how richly textual were daily lives in late-medieval England, where texts might appear in cathedrals, guild houses, 
and well-to-do households not only in elaborately decorated manuscripts, but also on pottery vases, pitchers, rings, panel paintings, wall hangings, and wall paintings - to say nothing of the text in cathedral windows.

Confronting the practice of reading in architectural contexts requires further widening recognition of the spectrum of participatory reading experiences, particularly those shaped by materialities. In an architectural, extracodexical text, reading does not occur only when a reader holds or views a static, stationary book. It can also occur as readers moved throughout rooms, walking by or walking to or walking around textually contingent places and objects. Such places are socially constructed, and as such not only are shaped by the people who designed and used them, but shape those people in return. ${ }^{2}$ Such effects extend also to reading practice. In particular, movement in architectural space further emphasizes the social and physical role of the body in reading practice. Such considerations as these are not restricted, however, to medieval literary culture and architecture alone. Writing about such physical experiences in more modern contexts, digital media theorist Mark Hansen and others emphasize how bodily engagement with the world around a person can create marked effects. Acknowledging how various forms of media, and media located within particular places, promote specific types of relationships with readers today, it becomes particularly clear that understanding of medieval textual culture can be enriched by considering how texts, such as wall texts, might elicit or promote distinct types of interactions with readers. I contend that these modes of participation could, in turn, shape reading practices and reading experiences. Consequently, focusing on wall texts provides an opportunity to consider how architecturally inflected participation might arise, what its processes of apprehension might be, and how participation through architectural reading might shape interpretation. In particular, because wall texts can be located in spaces that people moved through, the reading experiences involving wall texts occasion the participation and shaping of the body as it negotiates the material, architectural space that also becomes readable space. Accordingly, in this chapter I will examine two sets of wall texts surviving in manuscripts that evidence details of their original architecture contexts, one secular and one religious, and will argue that the material environs effect alternative modes of reading experience shaped by both architectural space and the embodiment of readers. 
The Percy wall texts

The secular example with which I begin addresses a series of particularly noteworthy wall texts recorded in the mid-fifteenthcentury English manuscript MS Royal 18.D.ii at the British Library in London. The manuscript is best known as the sole illuminated copy of Lydgate's Siege of Thebes. The illuminations in the manuscript were added after the Percy family acquired the book in the early sixteenth century. These were not the only additions made to the text in the first quarter of the century, however. Initially the manuscript only included two texts, namely Lydgate's aforementioned Siege as well as his Troy Book. Sometime between 1516 and 1527, following its acquisition by the fourth Earl of Northumberland, Henry Percy, the manuscript was expanded. The new additions included a metrical chronicle of the Percy family as well as copies of additional verses painted on walls and ceilings of two of the family's Yorkshire estates. The latter form the particular interest of this chapter, notably for how they connect reading and architectural space, for the way these connections function to shape the authority of the Percy family, and for how they enable recognition of a late-medieval secular mode of contemplative, domestic pilgrimage enacted through embodied reading.

The Percy wall texts are significant both for the number that survive and for the manuscript's descriptions that locate them within specific rooms and buildings on two of the family estates, the manor houses of Leconfield and Wressle. These rooms include a library ceiling, the Earl's son's private closet, garden-houses, and a bath - spaces both private and semi-public within the estates. In their subject matter, consistently instructive, the Percy family wall texts touch upon proverbial advice regarding sin, the vanity of human delights, a moralization of musical instruments, a dialogue about youth, and Aristotelian advice to princes. Together, they create a series of didactic works that, as one of the verses painted on the Earl's son's closet proclaims, 'made this hous for contemplacioun'. ${ }^{3}$

In effect, Royal 18.D.ii preserves a rare textual anthology of both the wall texts and the designations of the architectural spaces in which they were designed to be read. In this context, reading is not an experience bound solely between the covers of a book or kept within the temporal bounds of an individual, public, or private reading event, but figures as an intrinsic element of the household's architectural fabric and, indeed, that of the collective Percy estates. 
Similarly, architectural space figures as an essential constitutive frame for the reading experience, a subject lightly touched upon in the previous chapter, but deserving of extended attention.

The surviving wall texts thus represent the Percy estates as spaces that - through the verses' original collection on specific estates, and as unified again in manuscript - invite readers to traverse the Percy holdings and view the houses and estates as readable, textual, literary works. These verses manifest the estates in ways both virtual and physical, represented in the former through the manuscript, and in the latter through the original spaces they accompanied. As such, the verses invite readers to become virtual and physical tourists of the estate. They figure the Percy household as a space performed through embodied reading. In this reading experience, the reader's physical body assumes a significant role in the production of meaning that is, here, related to the spatialization of the Percy wall texts. Even as they figure the household in this way, they also contribute to the assessment of the varying materialities constituting late-medieval English literary culture, a culture that encompassed both embodied reading practice and large-scale spaces and places like the Percy estates. The Percy family wall texts demonstrate how, in and outside of books, a particular category of literary production invited readers to move through, use, and relate to space.

A review of the two manors mentioned in the manuscript anthologizing the wall texts, Leconfield and Wressle, will give context to the verses and their role in creating spaces for the transit of readers in the Royal manuscript and on the estates themselves.

Leconfield was located in the East Riding of Yorkshire, and functioned as the principal seat of the Percy family from the fourteenth through sixteenth centuries. Demolished in 1608-9, only earthwork remains today and these indicate the layout of what once was a fortified manor house surrounded by a moat. In the sixteenth century, however, a survey made in 1537 , an inventory of 1577 , and an estate plan of 1591 provide some details of the manor's layout around the time the verses were collected in the Royal manuscript. Leconfield was a quadrangular manor with three-storied towers at each corner. Residential wings flanked each side of the central courtyard, and the great hall was located opposite the entrance. The 1577 inventory noted a total of eighty-three chambers in the house; the earl and his family spread over twenty-three chambers in the south wing, which included a great chamber, a chapel, and a dining chamber, in addition to the closet of Lord Percy (the Earl's 
son, later the sixth Earl of Northumberland) and the library mentioned in the manuscript description of the verses. ${ }^{4} \mathrm{~A}$ deer park, 'very fair and large and meatley welle woddid', with a towered, brick house located a mile from the main house (referred to as the 'New Lodge') and garden (containing a multi-storied chamber) completed the grounds of the estate. ${ }^{5}$ The New Lodge was referred to in the household regulations of the fifth earl, compiled beginning in 1512, as the 'secrat houss' (secret house). In it, the earl annually broke up his household to retreat with select family and companions while taking the annual accounts. ${ }^{6}$ In addition, the household regulations record expenses for providing wood for fires in various rooms at Leconfield, including 'My Ladies Lybrary', 'My Lords Lybrary within the Mannor', and 'My Lords Lybrary over the Chapell Dour within the Mannour', and similarly record the expenses for a groom of the chamber whose duty involved 'kepynge of Fyre in the Jewell-Hous and Lyberary and Houses in the Garden and outher places where my Lorde shall syt aboute his Books' $(353,378)$. While this is the barest beginning of how the estate might be assessed, the repeated emphasis on the spaces the estate offered for reading situates its architectural fabric as part of the design that the wall texts themselves complemented and extended. ${ }^{7}$ Leconfield was made for reading.

Like Leconfield, Wressle Castle shared much in common with the layout of Leconfield. It too was structured as a quadrangular manor with multi-storied towers at each corner. Wressle survives today in the East Riding of Yorkshire only as ruins, three sides of this quadrangular castle having been demolished around 1650 or later. ${ }^{8}$ As with Leconfield, a garden inside the moat complimented the property, and the descriptions contextualizing the verses in Royal 18.D.ii indicate that Wressle included a house with an inner and outer chamber, its design perhaps inspired by the 'medieval love for the sequential planning of spaces'. 9 At Wressle, the castle similarly emphasizes the value and necessity of reading, as the sixteenth-century antiquarian and book collector John Leland delightedly indicates in his description of Wressle from his 1538-43 Itinerary:

One thing I likid exceedingly: yn one of the Toures ther was a study called Paradise, wher was a closet in the middle of eight squares latisd aboute, and at the top of every square was a desk legid to set bookes on booke on cofers within them; and this seemid as joined hard to the toppe of the closette, and yet by pulling one or al wolde 
cum downe briste highte in rabbettes [grooves] and serve for desks to lay bookes on. ${ }^{10}$

Here, Leland describes a study - significantly named Paradise that possessed a kind of Murphy-bed-style octagonal bookcase with pull-out shelves that converted into standing desks for the convenience of readers consulting multiple volumes. These descriptions of architecture, furnishings, and household maintenance practices at both Leconfield and Wressle clearly demonstrate the Percy family's deep interest in linking reading and architecture throughout two of their most significant properties.

Within these spaces can now be situated the specific locations of wall texts. MS Royal 18.D.ii records six different sets of verses in five different rooms at Leconfield. The rooms decorated with wall texts included the 'garett over the bayne', which provides a dialogue between the 'parte sensatyue' and the 'parte intellectyue' on the vanity of human delights; the garret could be either a room over the bath-chamber, or the ceiling of the bath-chamber. ${ }^{11}$ The 'garet at the New lodge in the parke' offers a poem on music as a metaphor for the well-ordered, virtuous life; this space might have served as a music room for the earl's pleasure during his annual retreat or during other times when he might wish to live separately from his household, as verses are composed on a variety of instruments. ${ }^{12}$ Between this set of verses and the next, the manuscript introduces a full-page illuminated Tudor-Percy emblem on f. 200r, the folio verso left blank. ${ }^{13}$ The emblem depicts a sun-in-splendour superimposed by a Tudor rose above a silver crescent that alludes to the Percy family, and includes additional imagery along with Latin and Middle English verses. ${ }^{14}$ Following the emblem, the provision of wall texts continues with proverbs on hope located on the 'rooffe of the hyest chawmbre in the gardinge', also on the walls of garret in the garden are verses relating the counsel of Aristotle to Alexander the Great; following these, 'in the rouf of my lorde percy closet', are proverbs about how, in youth, to become wise through study, which seem pointedly directed to the fifth Earl's son, Lord Percy, later the sixth Earl; lastly at Leconfield are proverbs on 'the roufe of my lordis library' that guide readers in their practice of daily virtues. ${ }^{15}$

At Wressle, three sets of verses decorated the walls of a single room of a house in the garden: first listed are those in the 'Innere chamber abouv of the house in the garding' that provide advice on a life of moderation, and which represent selections from Benedict 
Burgh's 'Cato major', a translation of the Distichs and the only set of wall texts in either household for which there are other witnesses. ${ }^{16}$ On the walls of the 'side of the vtter chamber aboue of the house' is more advice from Aristotle to Alexander; on the 'side of thutter chamber aboue of the house' are proverbs encouraging a virtuous life that twice refer to themselves as left to the reader 'for a memorial', one quatrain explaining further that this memorial is, 'Of loue and kyndnes and gode mynd special', suggesting a mnemonic function to the verses as well. ${ }^{17}$

In both their original locations and in the manuscript versions, the context provided for the wall texts indicates the extensive connection between the estates' architecture and the wall texts, and also indicates how this extensive textual architecture might have shaped readers' experiences. First, the texts in situ were not confined to a single room or even a single building at Leconfield, and even in Wressle occupied multiple rooms. Such a mode of organization would have required readers to move through multiple rooms and buildings in order to read them all at Leconfield, and multiple estates to read the entirety of them, an accomplishment most accessible to members of the family, their household, and frequent guests. Second, the manuscript version of the texts collects them all in a single, physical space, thus providing a more accessible source for those interested in reading the texts, but disinclined or unable to move between the estates and buildings. Third, the inclusion of the Percy emblem amid the manuscript presentation of the wall texts suggests that this unit in the manuscripts serves as more than a simple catalogue of texts that originated elsewhere. As such, the wall texts of the manuscript must be apprehended as part of a discrete work the emblem helps to create out of that section of the manuscript.

Recognizing these significant features of the wall texts suggests that, when considered for how they shape reading experiences, the reading experiences of the audiences engaged by each version of the wall texts must differ. This point may seem transparently obvious, but is worth stressing nevertheless for its ramifications. As audiences read the different versions of the wall texts, the spaces they traversed differ; readers of the texts originally located across the Percy estates were required to physically move among the buildings and estates (approximately twenty-five miles apart) in order to read the texts, while the readers of the manuscript version traversed the spaces virtually, and thus with greater ease. These dissimilar modes of access and reading impact how the Percy 
estates and MS Royal 18.D.ii contextualized the estate spaces and reading experiences, even though the modes of access - architecture, reading, and movement - seem initially points of commonality between the two.

Before pursuing this analysis of architectural reading further, discussion of the theoretical framework that underlies the consideration of the wall texts in their spatial settings will help evaluate the significance of the wall texts in their architectural settings, and the consequences their settings carry for our understanding of the embodied reading processes they provoke. This study emerges from intersecting focuses on bodies, architecture, and reading that are current interests in digital media and medieval studies. In particular, I employ the work of media theorist Mark Hansen, whose work has influenced the phenomenological approach to theorizing and analysing digital media. In 'Wearable space', an essay that became a chapter in Bodies in code, Hansen begins not phenomenologically, but with a nod to Gilles Deleuze's Cinema 1: the movement image. He first focuses on a concept introduced by Deleuze, that of the framing function performed by the technical image (a function that includes, for example, the technologies of the photograph, the film camera, and video camera). Deleuze identifies the frame as 'a relatively closed system which includes everything which is present in the image - sets, characters and props'. ${ }^{18}$ According to Deleuze, what makes the frame a closed system is its relation to what is out-of-frame and is, therefore, 'outof-field', which 'refers to what is neither seen nor understood, but is nevertheless perfectly present'. ${ }^{19}$ As Deleuze further explains in Cinema 1,

[T] he out-of-field already has two qualitatively different aspects: a relative aspect by means of which a closed system refers in space to a set which is not seen, and which in turn can be seen, even if it gives rise to a new unseen set, on to infinity; and an absolute aspect by which the closed system opens on to a duration which is immanent to the whole universe. ${ }^{20}$

This relative aspect of the frame creates space by its reference to what is not seen but, through the moving focus of the camera or through montage, relates one frame to the next. For Hansen, Deleuze's concept of the frame centres on bodily experience, for the 'the bottom line is we are able to perceive images only because we sense ourselves as form'. ${ }^{21}$ Hansen builds on this concept by arguing that our cultural shift to the digital 'has suspended the 
framing function' of the technical image, and 'has accordingly empowered the body, in a truly unprecedented way, as the framer of information'. ${ }^{22}$ Thinking of the shift away from the framing function of the technical image to the body as framer of information not only allows Hansen to move from ontological analysis to the phenomenological, but also carries ramifications for my argument and medieval studies more generally. That is, Hansen's shift is important for the way it suggests possible application of the analysis of modern digital culture to pre-print culture, where the body can also be similarly considered the framer of information or, more appropriately for medieval culture, knowledge. Accordingly, Hansen's relocation of spatial meaning from cinema technology to the embodied frame offers the grounds for applying digital media theory on space and architecture to medieval works.

Hansen connects his analysis of the frame to architecture, which works as a framing function and in relation to the body: 'architecture has, quite simply, displaced cinema as the quintessential art of framing for our time. ... [A] rchitectural framing necessarily involves a negotiation between formal manipulation, built space, and the life of the body'. ${ }^{23}$ For Hansen, to study the architectural is to consider how it relates to our embodied lives, how it is calibrated to them, and how it interacts with space. Considering space, in turn, involves the consideration of movement, that is, how one navigates bodily through space. Architecture, space, and embodiment are inextricably intertwined. For Hansen, these interactions create 'wearable space'. He explores the notion of wearable space through the Japanese-American artist Arakawa's concept of the 'architectural body': since the body, Hansen summarizes, is always a body in space, it thus becomes an architectural body. ${ }^{24}$ For Arakawa and his long-time collaborator Madeleine Gins, architecture contributes fundamentally to the fashioning of the self, acting as an 'outer skin' that dictates 'our behavior, beliefs, [and] perceptions, as well as our ways of living our lives'. ${ }^{25}$ Thinking of architecture as wearable space will impact our understanding of the wall texts in their architectural setting, as will be discussed further below.

In analysing how the architectural body spatially conditions human perception, Arakawa and Gins posit the notion of 'landing sites'. Landing sites describe how different forms of attention situate the body within an environment. As Arakawa and Gins explain, analysing landing sites enables one to 'gain perspective on human functioning and separate out its component factors ... 
kinaesthetically, tactilely, visually, orally, olfactorily, and gustatorily all at once'. ${ }^{26}$ Hansen adds that these landing sites 'occur as a perceiver's perception ... lands here and there', and compel 'the body to concentrate on recalibrating itself' in relation to space. ${ }^{27}$ In other words, landing sites implicate how the body participates with architectural space. Landing sites operate through three imbricated modes of attention: perceptual, imaging, and dimensionalizing. The perceptual landing site 'lands narrowly as an immediate and direct response to a probable existent, a bit of reporting on what presents itself'. ${ }^{28}$ Such a site might be the manuscript in front of a reader, a chair, a wall: whatever occurs in proximity to the body. In contrast, the imaging landing site 'lands widely and in an un-pinpointing way, dancing attendance on the perceptual landing site, responding indirectly and diffusedly to whatever the latter leaves unprocessed'. ${ }^{29}$ 'The imaging site shares some characteristics with Deleuze's notion of the out-of-field; it may be diffused, and perception might include what exists or happens around the corner, or will occur later in the day. Finally, the dimensionalizing landing site 'registers location and position relative to the body'; it creates the perception of depth and the effect of the siting environment. ${ }^{30}$ As Hansen summarizes, these sites 'are responsible for embodying space, for imbuing it with a sensory richness that yields bodily meaning'. ${ }^{31}$

In this approach to assessing how architecture participates with a person to affect apprehension and interpretation of space, we can already begin to see how analysis of the Percy wall texts, in their manuscript instantiation and in their original context, might be approached. Before offering such a reading, however, I want to emphasize how the practice of reading fits into this constellation of architectural, spatial embodiment. It has long been an understanding among medievalists that the body bears an important role in understanding medieval book culture, particularly through the influential book-as-body metaphor, and more lately in grappling with the recognition of the ways in which medieval manuscripts were based on the flesh of slaughtered animals; in recent years, scholars have acknowledged that reading, too, can involve the body, particularly through the mode of performance. ${ }^{32}$ Assessing the performative aspects of reading which contribute to the role of reading as an embodied experience, we should not only acknowledge performative and sensory modes of apprehension, such as the sensations of touching the flesh pages of a manuscript, but consider how other practices, such as materialities as discussed in the 
previous chapter, also contribute to embodiment. In this context, movement, which Hansen views as central to space-architecturebody negotiations, has a role in medieval sensory theory, which itself offers insight on a medieval theory of embodiment: it is through movement that the body visually, aurally, tactilely, spatially, and olfactorily apprehends its environment. This view of space-architecture-body negotiations provides a means for assessing the processes through which architectural reading relies on embodiment, and refines the role of medieval theories of the senses in the context of reading. Engaging embodiment and architecture in these ways points to the generalized nature of medieval reading as embodied experience, and to the specific functioning of architectural reading practice.

Consequently, in turning to architectural reading as the practice through which the wall texts of the Percy estates and MS Royal 18.D.ii can be apprehended, the body assumes a key role in constituting meaning through the experience of reading. As noted above, the meaning thus constituted will differ when considering the locations and reading experiences of the wall texts. First considering the texts as originally located on the Percy estate, as one of the verses notes, reading them casts the house - and the outlying buildings into which the wall texts extend - as an architecture of secular, household 'contemplacioun'. Although conventionally a devotional, immaterial practice, such contemplation relocates the readers' focus from the realm of the immaterial to the material. In Arakawa and Gins's terms, the readers' 'architectural body', their outer skin, incorporates all the information from the landing sites of each space in which they encounter the wall texts. Such incorporation does not simply insist on embodied reading, but also widens the readers' embodied perspectives, which become informed both by the didactic message of the texts, as well as by the servants that pass through or by the rooms, intent on their work; the other people using the spaces for edification, labour, or devotion; and those who are not present, but absent, intent on other activities. Consequently, the reader participates in the pageantry of life on the Percy estate, whether they read at Leconfield or Wressle.

To read on the estates, and to read these verses with the architectural body, encourages readers to recognize how the Percy family values proverbial advice, classical learning, and appreciation for the moral instruction of the musical arts, and to recognize how they decry vices: these are portrayed as essential not simply to the intellectual or moral life of readers, but also to the readers' 
conduct of themselves and their bodies. Indeed, this reading mode both emphasizes and models, through its embodied physicality, such a mode of living for the reader. Through the embodied role of reading and the architectural body, the reader, who becomes clothed in this educative space, both perceives and participates in the moral model household of the Percy family.

The localizability of the wall texts informs readers about virtues particular to the use of specific rooms in specific spaces. In Lord Percy's closet at Leconfield, for example, the wall texts inform the reader that the youth who 'thynkithe himself wyse / Shall know himself better by vertuus exercise' (202r / Flügel 482). These same verses, however, also comment on the mobility of information and learning: the youth who takes advantage of the opportunity to gain knowledge and skill in reasoning through study - perhaps even study in the library whose walls were decorated with proverbial advice - will be able to 'bere them away for his owne goode informacion' (ibid.). A later line additionally recommends moderation in education, as other verses recommend moderation more generally, advising readers that 'But allway to be in stody dryethe vp a mannes blode' (ibid.). 'The verses thus gesture to their location-specific function, suggest the transportability of the virtues gained in different spaces, and indicate that physical engagement with the texts read becomes part of the practice of these virtues. Furthermore, because the verses can be found in not just one room, but many, and not just one estate, but multiple estates, this moral mapping makes a statement that encompasses the Percy family lifestyle as a whole, and suggests the transferability of this lifestyle to readers outside the Percy family: it is both individuated to the family, but learnable by non-family readers. Even the recommendation to spend time on activities other than study encourages readers to move elsewhere and pursue other activities - into, for example, the park, where readers could enter the New Lodge at Leconfield for musical practice and encounter the verses there, or into the garden and the garden-houses possessed by both estates, and gain new opportunities to embody and be clothed in the moral architecture of the other verses.

Furthermore, the role of landing sites as applied to the Percy family wall texts suggests how the architectural environment of the texts would have engaged the readers' participation and thus their apprehension of the texts themselves. Royal 18.D.ii does not simply supply the name of the room or building in which wall texts are located, but also often identifies them spatially, as located in 
the 'rooffe' or the sides of chambers. It also identifies the rooms in relation to other rooms, emphasizing how the space of a particular wall text was meant to be understood. Wall texts are located in the 'hyest chawmbre', the 'vtter' (outer) chamber 'abouv of the house', in a 'closet', a 'garett over the bayne', the garret of the New Lodge, a mile distant from the manor itself. Spatially these rooms signify exclusivity of access, privacy, elevation. The work of accessing them at the estates themselves, and through the descriptions in the Royal manuscript, emphasizes that these architectural spaces convey meaning of which the reader of the wall texts is elicited to be aware.

As a result of such awareness provoked by landing sites, the reader engaged in apprehending the wall texts is made cognizant of reading as a bodily activity shaped by the architectural space of the texts. Places are not interchangeable; to read the music proverbs in a ground-level, great hall would produce a different interpretation and yield a different experience than would reading them in the garret in the New Lodge. In a great hall casually open to the public, the music proverbs would produce a reading experience shaped by the details of that landing site, attesting to a general valuation of musical instruction; in the garret above the New Lodge, they become woven into the apprehension of individual music education, eloquent of the personal value the earl places upon fluency in the art of musical practice. Further details of the spaces no longer recoverable would add to these readings in even more detailed ways: the nooks and crannies of the rooms, the presence or absence of windows and natural lighting, even the presence of servants or other people.

In contrast to the verses as they might have been read at Leconfield or Wressle, the manuscript version of the verses in Royal 18.D.ii provides an alternative perspective of the Percy estate. First, some description of the manuscript provides additional context for understanding the verses. The manuscript is a sizeable volume, measuring $395 \times 280 \mathrm{~mm}$ : a large book probably made for display and public reading, and less for individual reading experiences. Perhaps originally for presentation by its first owner, Sir William Herbert, the first Earl of Pembroke, it entered the Percy family when Henry Percy, the fourth Earl of Northumberland, married Maud Herbert, William's daughter. It then came into the ownership of Percy's son, Henry Algernon, for whom the manuscript was expanded to include material specific to the Percy family. The wall texts themselves are written in a 
gothic hand and decorated by large capitals with all the strapwork, flourishes, and decorative techniques of a display script. In its inclusion of the wall text verses, the manuscript seems to imply use elsewhere than Leconfield in particular, where manuscript access to the wall text verses might seem redundant, as so many of them focus on spaces on that estate; read in Wressle Castle, it could evoke the distant Leconfield while also providing the text of the verses in the Wressle garden-house; read elsewhere, it could evoke both absent estates.

While the reader of the wall texts in their original locations, who would pass amongst rooms with verses, would also be aware of rooms without verses, and thus tie the advice of the verses more strongly to specific types of activities available elsewhere on the estates, the manuscript version of the wall texts depicts the estates almost in the form of a summary, or synecdochally, in which the absence of rooms becomes less noticeable, and this 'highlights tour' of the estate represents the entirety of the estate. In Deleuze's terms, the other rooms of the estates are wholly 'out of frame' of the manuscript. Restricting the frame of the estates only to those rooms mentioned in Royal 18.D.ii consequently shapes the readers' focus exclusively on the work of this more limited collection of architectural frames. Yet the rest of the manuscript's contents might be viewed as standing in place of the absent rooms; it is to these works that the manuscript assemblage of the verses connect, rather than to other rooms at Leconfield and Wressle. These other texts include John Lydgate's 'Testament', 'Reignes of the Kinges of England', Siege of Thebes, and Troy Book; William Cornish's A Treatise between Information and Truth; John Skelton's 'On the Death of the Earl of Northumberland'; the anonymous Le assemble de dyeus; the anonymous 'The blsyoure of the arms of kyngis', which describes the arms of various kings; William Peeris's metrical chronicle of the Percy family; and, of course, the Tudor-Percy emblem placed between two sets of wall texts.

Overall, the manuscript includes works that provide advice on governance and moral authority, and others that speak to the history and might of England's secular rulers in general and the Percy family in particular. As Alexandra Gillespie characterizes the miscellany, it sustains 'traditional ideas about noble service to the monarch'. ${ }^{33}$ Viewed in a slightly different light, the texts move from a devotional exaltation of the virtues of Christ to several texts that engage, at a global-historical (Troy Book and Siege of Thebes), national (Lydgate's 'Reignes'), and local (Peeris's chronicle) level 
with the virtues, successes, failures, and necessary skills of secular rule, before ending with the wall texts. In consequence, the wall texts seem representative of the virtues and successes of private life that follow those of public service, and specifically testify to the private as well as public values and morals of the Percy family.

In the coupling of the verses with descriptions of architectural space, the wall texts of Royal 18.D.ii invite virtual movement through the estate. The role of movement indicates the significance of the embodied role of reading and the way that such a mode of reading can be enacted virtually. The way the manuscript wall texts invite movement into the virtual space of the estates' educational architecture intersects with recent scholarship on virtuality in medieval literary contexts. In particular, Seeta Chaganti has emphasized how multimedia combinations of, for example, 'murals, architecture, sculpture, poetic inscription and kinetic bodily participation' lead to the articulation of a virtual space for the viewer. ${ }^{34}$ The Royal manuscript, however, demonstrates how a single medium, poetic inscription, can create similar effects exclusively through its textual representation of architectural space. Architectural framing alone suffices to create virtual space through which readers can travel. Significantly, this suggests that focus on the role of 'multi-' in multimedia may not be a necessary condition for virtuality, particularly for medieval audiences conditioned to make connections across media instantiations of narratives - for example, hagiographic narratives in manuscripts and stained glass windows - on their own. Rather, the crucial determinant of virtual space is the role of embodied reading. When texts or other media works rely on, invite, or recommend experiences that situate reading as embodied experience, virtual movement and spatial negotiation commonly follow. For Hansen, to be embodied is to negotiate the relationship between the body and space. Furthermore, reading with the architectural body locates readers as central participants in the act of making meaning: such meaning exists not solely in the words of the texts themselves, but in the spaces and how the reader both perceives and relates to them.

\section{Lydgate's Daunce macabre}

The importance of space and place is particularly crucial to another set of wall texts, the danse macabre of the medieval St Paul's Cathedral in London. As such, the danse macabre demonstrates another example of architectural reading, showing how it emerged 
in contexts other than that of wall texts situated in the domestic household space. John Lydgate based his translated, revised and extended version of the danse macabre verses upon those painted on the outer walls of the charnel house (a building in which bones are piled) that bordered the cemetery of the Franciscan parish church Les Saints Innocents. The Parisian mural was created in the mid-1420s, and Lydgate likely saw it when living in the city from 1426 to $1429 .{ }^{35}$ Arranged in several sequential images, the mural depicted personifications of Death, represented as a decomposing corpse, leading away people who represented members of medieval society, such as kings, cardinals, merchants, and gentlewomen. Verses accompanied each pair of figures, one stanza in which Death addresses a person, commenting on the inevitability of death that the person's privileges cannot gainsay, and one stanza in which the person responds, first in protest and in contemplation of their sins, then in reluctant acceptance. Although not the first artistic depiction of the personification of death in medieval artistic culture, the Parisian danse macabre proved immediately influential; by the mid-fourteenth century churches across Europe had been adorned by the danse macabre. It was also quick to enter print circulation: by 1485 the Parisian danse entered print publication, and in 1538 Hans Holbein published a series of woodcuts of the danse likely based on the version at Basel. ${ }^{36}$ Its inclusion in $\mathrm{St}$ Paul's Cathedral in London represents the earliest adoption of the danse macabre outside Paris, fashioned about five years after the Parisian danse was created and Lydgate first saw and translated it. Lydgate's Daunce of Poulys, as a text and in its location in St Paul's Cathedral, has enjoyed greater attention in recent years in the wake of growing interest in both Lydgate's work in general and his engagement with materiality. ${ }^{37}$ Although the danse at St Paul's was destroyed in the mid-sixteenth century, and there are many questions about it that cannot be answered, documentary records, archaeological evidence, and manuscript witnesses to the London danse illustrate how it, as with the wall texts of the Percy estates, invited participation through space and place, visual apprehension, and mobility.

Place is particularly important to how the Daunce of Poulys invited participation, and what details can be identified about that place deserve consideration. Some of these details can be had from the surviving manuscripts that take care to indicate the place and space the poem inhabited. One of these manuscripts, Cambridge, Trinity College R.3.21, an important collection of 
Lydgatean verse, identifies the original location of the poem, later supplemented by further details in a second hand. ${ }^{38}$ The scribe provided his description of the poem's place in a rubricated headnote: 'hEre foloweth the Prologe of the / Daunce of Machabre translatyd by / Dan John lydgate monke of Bury out of / ffrensshe in to englyssh. whyche now ys / callyd the Daunce of Poulys'. Later, a second hand added more details around the headnote, noting below that ' $\&$ ther was pryntyd in pe cloystar at pe dispensys \& request of Jankyn Carpynter', while mentioning in the top margin above that 'this daunce of machabre is depeyntyd richly / at sent innocents closter in parys in fraunce'. ${ }^{39}$ Both the scribe and the writer of the later gloss emphasize the lineage and situation of the danse at St Paul's, with the scribe associating it more generally with St Paul's, and the second hand providing specific details of its place within St Paul's precinct: the Daunce of Poulys was located in the cloister.

Which cloister at St Paul's enclosed the Daunce of Poulys is made clear by the sixteenth-century historian and antiquarian John Stow, who comments upon it in his survey of London, stating that

There was also one great Cloyster on the north side of this church inuironing a plot of ground, of old time called Pardon church yard, wherof Thomas More, deane of Pauls, was either the first builder, or a most especiall benefactor, and was buried there. About this Cloyster, was artificially and richly painted the dance of Machabray, or dance of death. ${ }^{40}$

The scribe adds a few key details to the descriptions of Lydgate's poem in Trinity College R.3.21: the cloister enclosing the Daunce of Poulys framed a space referred to as the Pardon Churchyard, and had been built or rebuilt by Thomas More in the early fifteenth century. Pardon Churchyard was located on the north side of the cathedral, situated in a square framed on the south and east sides by the nave and north transept of St Paul's. The degree to which More intervened in the cloister's space remains as uncertain to audiences today as it did to Stow in the mid-sixteenth century, but evidence from archaeological research indicates that the space had been used for burials dating from the Anglo-Saxon era through the thirteenth century; by the fourteenth, it appears regularly as Pardonchirchhawe in the wills of citizens requesting burial there. ${ }^{41}$ Pardon Churchyard thus had functioned as a space important for several centuries to the citizens of the city who sought burial in its grounds. 
Whether More's contribution in the 1420 s was to arrange, as Stow notes uncertainly, for either the endowment or building of the cloister, it is clear that by the time Lydgate translates the verses, the space had become enclosed and thus less accessible to the general public. Amy Appleford views this enclosure and restricted access as one possible motivation for John Carpenter's contributions to having Lydgate's Daunce Macabre installed in the cloister at St Paul's. John Carpenter worked as the 'secretarius' for the city of London, its Common Clerk, from 1417 to 1438. He also compiled a manuscript documenting the practices of the city, a custumal called Liber Albus, and later became a member of Parliament. ${ }^{42}$ Carpenter was thus deeply engaged in the civic life of London, and his provision for the installation of the Daunce of Poulys, Appleford argues, represents the assertion and insertion of civic interests into the sacral space of St Paul's. ${ }^{43}$

Civic influence at St Paul's could also be expressed in more mundane and quotidian ways. Although the period in which the Daunce of Poulys was fashioned and installed in the Pardon Churchyard was yet a century from the notoriety of 'Paul's Walk', in which city fashionables and news hunters promenaded through the middle aisle of the cathedral nave to display their selves and discover news, St Paul's nonetheless contributed to and manifested the interests of citizens in many ways. Scribes assigned to serve the populace occupied designated places in the nave; its bells regulated the opening and closing of city markets; traffic between its north and south doors led to irritation and, by the mid-sixteenthcentury, a mayoral injunction against the carrying of ale, fish, and foods through the short cut. ${ }^{44}$ Boys gathered in the precinct grounds to play ball games until they were forbidden in 1385, and in 1400 a pretend battle among youths enacting disputes between the monarchies of Britain became an actual battle that ended with bloodshed and death. ${ }^{45}$ Some guilds also used the space for their own purposes; for example, the fullers assembled to attack one of their fellows there in $1365 .{ }^{46}$ More significant to civic welfare were the uses of the space around St Paul's Cross in the north-eastern yard as a site for folkmoots, where as early as 1263 the guilds 'won rights of self-determination for the first time in the city's history'. ${ }^{47}$ As David Lepine observes, the spaces and places of St Paul's served a variety of civic and secular social purposes. ${ }^{48}$

This use of St Paul's space particularly affected the locale of Poulys Daunce and, consequently, its reading. Its enclosure with the cloister built or endowed by More sought to effect a removal 
of the space from the city, and even a separation of the churchyard from the grounds of St Paul's itself. Such restrictions on access effected through the claustration of the Churchyard, however, may have had the counter-effect of making the space more desirable to the people of London. Over the course of the fifteenth century, Stow notes that Pardon Churchyard became a desirable space for burials of the city's elite: 'In this Cloyster were buryed many persons, some of worship, and others of honour. The Monuments of whome, in number and curious workemanship, passed all other that were in that Church'. ${ }^{49}$ The popularity of Pardon Churchyard as a desirable burying-ground for those of status in the city, 'in the years that Westminster Abbey was becoming the royal burial church and thus exclusive, ... gave tomb-makers more chances to innovate and establish fashionable designs'. ${ }^{50}$ Its restricted access and the innovative possibilities for its monuments made it a fashionable place to be seen in death.

It is within this space of the Pardon Churchyard and Cloister that Carpenter had caused the Daunce of Poulys to be installed on the inside wall of the cloister, 'curiously painted vpon boord', as Stow notes. ${ }^{51}$ It thus framed Pardon Churchyard with its tombs and monuments. The location of the danse macabre on the walls of the cloister itself furthered this connection to death and reading, for the architectural conventions of the monastic cloister upon which the cloister of St Paul's and other secular cloisters drew identify the space as one for reading. That is, cloisters by the end of the eleventh century 'had become the place for reading par excellence' ${ }^{52}$ In monastic cloisters, the cloister walks were often filled with book chests and cupboards; the arcade that let light and air into the cloister walk frequently included low benches at its base, so that monks might sit upon them to take advantage of better light for reading. ${ }^{53}$ While no archaeological evidence remains of the arcade at St Paul's to indicate whether it, too, included such a bench, the cloister participated in a long history associated with reading. This association was furthered in the 1440s, less than a quarter-century after the installation of Poulys Daunce, when Walter Sherrington, a canon of St Paul's from 1440 to 1449, established a library over the east walk of the cloister. ${ }^{54}$ Like the Percy family estates, the Pardon Cloister housing the Poulys Daunce was a space designed for reading. That Poulys Daunce inhabited a space designed for reading furthers understanding medieval perceptions of the range of experiences bound up in the act of reading, for Poulys Daunce, as a mural series, could be considered primarily a work of visual 
artistry, and could also be considered a performative text that leaned on the conventions of drama. ${ }^{55}$

These details of space and place further indicate how they, as landing sites, shaped the reading of Poulys Daunce in ways that, by design and by chance, could affect interpretation of the work. That is, following Appleford's argument, Carpenter's contribution of Poulys Daunce linked the city to the sacral space of the Pardon Churchyard. Pardon Churchyard itself linked to the city through the myriad ways that people of London made their presence felt in St Paul's. To read Poulys Daunce, then, was not simply to be educated in or reminded of the ever-present possibility of death and the need to prepare for it as individuals. To read Poulys Daunce was also to be invited through its architectural setting to consider the application of death to the community: to the dancers the work depicted, who included in their numbers not only the national and religious elites of king and pope, ladies and abbesses, but also the civic and familial members of society, from mayors to artificers and servants. ${ }^{56}$ The architecture of the space functions with the text to create a landing site that elicits such connections, even as the environment of St Paul's - audible to those in the Pardon Churchyard to view Poulys Daunce, and known to those familiar with the city - still furthered readers making such connections.

As readers confronted the Poulys Daunce, these details of the landing site of cloister and cathedral would have become incorporated into their apprehension as they read the work. In visuals and text, Poulys Daunce invites another form of identification and engagement from readers, that of embodied identification. Death, whose own embodiment is emphasized in the visual tradition of the danse macabre through its representation as a dessicated, animated corpse, is similarly shown reaching out to grasp the people it addresses, bridging the two bodies, and connecting them as a mirror reflecting present and future. A line from the 'verba auctoris', the author's words to the reader, makes the invitation to readers that they identify with the individuals death leads explicit: 'In this myrrour / euery man may fynde / That hym behouyth / to goon vpon this daunce'. ${ }^{57}$ The reader apprehending Poulys Daunce, in its images and texts, should apply it to themselves as if the work were a mirror that allowed them to see themselves and their end reflected in it. They are the bodies dancing with death; simultaneously, they are also the desiccated bodies of Death itself, a point made clear in one of the concluding stanzas of the danse: 
Ye folk that loken / vpon this scripture

Conceyveth heer / that al estatis daunce

Seth what ye be / \& what is your nature

Mete vnto wormys / nat ellis in substaunce

And have this myrrour / ay in remembraunce

Before your mynde / aboven al thyng

To all estatis / a trew resemblaunce

That wormes foode / is ende of your lyvyng. (Lansdowne MS 561-8)

Accordingly, Poulys Daunce invites readers to engage with the text in ways that cast light upon late-medieval views regarding how readers should participate with and interpret the work. The emphasis on the text as a mirror indicates that readers' participation with literary works was conceived through invitations to self-identify with the work, both in its representation of individuals and more generalized bodies. This invitation to identify further nuances another reading practice previously referred to that also involved identification, that of immersion. That is, texts represented as mirrors invite immersion through connecting the reader's self to the subjectivity represented in the text. The treatment of the subject in the work is, consequently, viewed as affecting readers' own subjectivities because of their identification with the subject or subjectivities of the work.

Furthermore, Lydgate's Daunce Macabre urges readers to participate by adopting multiple, overlapping subjectivities, in which they are both themselves, living and moving inexorably towards death, and themselves, in a sense already dead. In this way, readers apply the lessons of the danse to themselves in a visceral, immediate, and personal manner. ${ }^{58}$ In addition, as with other immersive texts, the multiplication of selfhood effected through participating in the mirroring of the text again suggests that medieval audiences engaged in their own practices for affecting and extending identity through accessories that, although not textual, represent another avenue for expressing the premodern posthuman.

Such application of text to self, leading to a distributed practice of subjectivities, is enhanced by the landing sites provided by $\mathrm{St}$ Paul's: standing in the cloister, they not only face the danse, but as they read it they move around the tombs and monuments of the churchyard circled by the cloister walk. These landing sites provoke readers to extend their awareness beyond themselves, participating in its multiplicity by means of the proliferation of deaths figured in the text and visuals of the mural, and through 
the monumental furnishings of the courtyard itself. The presence of the tombs and monuments consequently provide another set of landing sites available to readers, sites that provoke readers to participate in the message of Poulys Daunce by applying it to themselves, seeing all possible futures and professions that they might currently enjoy or to which they might have aspired, multiplying before them as bodies in death and in memory.

Although, again, none of these monuments survived Somerset's demolition of the Pardon Churchyard in 1549, the tombs favoured by the city elites who arranged for these tombs and monuments in the Pardon Churchyard certainly took advantage of the 'innovate[ive] and ... fashionable designs' offered by tomb-makers of the time. ${ }^{59}$ Among these designs would certainly have been included 'a new and strikingly different type of sepulchral monument' first built in England in 1424, a handful of years before the installation of Poulys Daunce: the transi-tomb, which depicted - like the danse macabre itself - a doubled mirror of the person buried, one image of them in life, and one of their decayed corpse reposing in death, skin stretched tight across a skeletal frame, often perforated by worms. ${ }^{60}$ The transi-tomb changed the traditional purpose of death monuments; rather than acting solely to represent the decayed body of the deceased, transi-tombs served a variety of purposes, one of which was to educate the living as a memento mori, reminding viewers of their own forthcoming deaths. ${ }^{61}$ In engaging with both tombs and text, readers of Poulys Daunce triangulate between three bodily landing sites: the bodies of the danse macabre, the bodies monumentalized on tombs, and the bodies of the readers themselves. The interrelationships between these three bodies effect architectural reading of Poulys Daunce as dependent upon both place and body. Reading Poulys Daunce in the Pardon Churchyard thus even more profoundly emphasizes the message of the work by the way the landing sites of the churchyard provided direct, immediate evidence of the readers' end, and of the bodies they inhabited that were simultaneously both living and dead, salvation their only hope of survival. In all these ways, the work of landing sites evoked through the location of Poulys Daunce thus invites readers to extend their situational awareness beyond the frame of those artfully crafted boards painted with the danse to consider the surrounding environment itself and its contributions to their apprehension of the work. They, too, may see their ends in the same churchyard whose transi-tombs, along with the danse, depict the finality of death along with an embodied force 
focused on the decaying corpse. This is the work of the posthuman, in which the sense of self becomes multiplied and externalized through the technology of the tomb, the art of the multimodal textand-image of the Poulys Daunce, the architecture of the churchyard and cloister walk, and the interactions among these landing sites and the reader.

Exclusive to the tradition of Lydgate's Daunce Macabre most associated with Poulys Daunce is acknowledgment of the emotional response such work might engender in the reader who participates by applying this visual, visceral, bodily lesson to themselves: 'Be nat afferd', Lydgate consoles (577). With that phrase he both acknowledges an anticipated response and then seeks to transform it: '[T] rust trewly / ye shal nevir the sonner deye', he adds; rather, the sight should cause the reader to 'dreede' sin 'And vse vertu / prayer \& almesse deede' to 'doon the bettir' (579, 580, 583-4). By acting on the dread stirred by the danse, readers so moved are invited to conclude their reading with action bent on improving their spiritual state.

This situated awareness and the emotional movement that Lydgate invites readers to transform through action correspond to a similar interest in movement throughout the danse macabre, which, after all, is conceived through the expression of movement in dance. The intersection between its choreographic mode of expression and its architectural inhabitance have received attention from both Elina Gertsman and Seeta Chaganti, who note how the vertical movement of the danse (framed by the verticality of the cloister arcade and from the verticality of the upright figures of Death and the people whom Death invites to dance, which most likely were placed above the verses of their dialogues) exists in tension with its lateral movement of the dance (its sequential progression along the walls from figure to figure). For Gertsman this movement, fused with artistic traditions including literary and visual, invites readers to perform a 'kinesthetic mode of looking' at the danse. ${ }^{62}$ For Chaganti, the tension between the vertical and lateral movement of the danse create the 'virtual churchyard that becomes an important part of the spectator's experience', and it is within this space that interchange between multiple forms - of bodies, of movement, of the temporalities of life and death - can occur. ${ }^{63} \mathrm{I}$ would argue that the movement extends beyond looking by contributing to the performance of participatory reading. Furthermore, the virtualizing effects of movement, although in need of further discussion here, are not 
the least effects that movement creates for the participatory reader of Poulys Daunce.

That is, while the placement of the dance along the four walls of the cloister walk not only effects virtual movement, it also effects literal, physical movement around the Pardon Churchyard that, nonetheless, does not end within the cloistered walk of the Pardon Churchyard itself: the Pardon Churchyard at St Paul's was not only an end point in one's travels, but was also a through-point, a space between spaces, through which readers passed as they entered and left the Pardon Churchyard. Reading concluded, business in the Pardon Churchyard concluded, readers had to move on, enter new landing sites, and that forward movement is further propelled and shaped by the invitation issued them in the final lines of the poem: readers should move themselves physically out of the space, mentally in their 'mynde / to revolve and rede' further (578) and, through these movements, engage in 'vertu / prayer $\&$ almesse deede' (583). The most logical place to begin the text of Poulys Daunce would have been on the wall adjacent to the door leading into and from the nave of St Paul's, which was located on the east wall in the southernmost corner of the cloister. ${ }^{64}$ Following the typical progression of laterally organized murals in the direction of reading, left to right, Poulys Daunce likely began by that door on the south wall, leading to the west wall, north wall, then east wall and back towards the door leading into the nave. This layout would position readers to re-enter the nave upon concluding their reading, where they would then be situated to act on Lydgate's advice to engage in prayer. Under such conditions, readers' mobility as elicited by Poulys Daunce would lead them into the space where they could further the instruction begun by the work. Re-entrance into the nave, then, functions as a transition to a final landing site, a conclusion that propels readers from self-scrutiny to spiritual action.

In these ways, Poulys Daunce and the Percy family wall texts, one a work situated in a religious space focused on inspiring the reader to pursue spiritual improvement, one a work situated in domestic spaces focused on inspiring the reader to moral improvement, are similarly shaped by their architectural environments and the landing sites these environments provide to provoke a reading practice that responds to the details of space and place. This architectural reading also, like the other reading practices focused on making readers work, invites readers' participation: not only the performance of visual apprehension, but the interactions 
of mobility conditioned by that architectural context. The details of these architectural situations share a similar difficulty in reconstructing their finer details, but that difficulty does not disguise the impact location had on the participatory work of reading. The particular influence of place on wall texts of the danse macabre and the Percy family estates would generate different interpretive responses among readers, and generate distinct practices of apprehension, if situated in distinct places with their own particular architectural demands. Even in their manuscript contexts, they provoke a different mode of participatory reading.

\section{Virtual tourism, mental pilgrimage and the wall texts}

Mobile participation with Lydgate's Daunce Macabre and the Percy estates does not end with the simple representation of text situated within architectural space across the Pardon Churchyard and the Percy estates. The manuscript versions of both works offer an alternative mode of participatory reading, in which movement aided by architectural references reconstructs what Chaganti refers to as a 'virtual churchyard' - and what might thus be termed in the context of the Percy wall texts the 'virtual estate'. The virtual spaces - virtual landing sites - created through the manuscript versions of these works, however, differ markedly from the physical spaces of their architectural installation. Manuscript versions of the two works treat the spaces as exemplary, from which noise, traffic, labourers, servants, and all the details of quotidian experience are elided. In these contexts, movement and place, and the interactions between them, become both sanitized and virtualized.

Such treatment of movement in the manuscripts evokes intriguing connections between the virtualized movement they offer and today's practice of virtual tourism. Such tourism - often by website, but also through videos and other media - selectively represents destinations in order to appeal to the desires of the target audiences. A basic example of virtual tourism is that provided by Google Earth, which a person can use to revisit sites from which they have been absent for years, or access panoramic imagery of a site to which they have never been. ${ }^{65}$ In particular, virtual tourism has been criticized for the way it lifts spaces 'out of their local contexts' for the purpose of providing luxury experiences to the 'mobile elites' ${ }^{66}$ Extending this reading to the manuscripts of Lydgate's Daunce Macabre and the wall texts in Royal 18.D.ii suggests that the manuscripts' versions of the works remove them 
from their local contexts in order to re-map them onto landing sites designed for the benefit of a reading elite. Reading the two wall texts through manuscripts encourages readers not only to absorb their moral lessons, but to participate in virtualized movement that offers insight on the locationally distinct authority of the works. For Lydgate's Daunce Macabre, the visceral instruction offered by the architectural surroundings of the Pardon Churchyard, with its tombs and monuments, is replaced by the guiding authority of the poet's voice, which comes to dominate in the absence of the architecture and, in the longest version of the work (the version of Lydgate's translation considered less connected to St Paul's), through the inclusion of verses in which the translator, Lydgate, addresses his readers. For the Percy wall texts, the sanitized landing sites of the manuscript that situates the wall texts among other works invites readers to understand the political, social, and moral authority enjoyed by the Percy family. The collection of other texts in the Percy family manuscript also suggests an investment in this message of power and authority. As readers encounter the wall texts in manuscript form, removed as the texts are from the daily life of the estates where they were originally located, readers encounter the Percy family estates as a fantasy of the idealized household, characterized by the moderate lifestyle of labour, education, and self-improvement of the family.

However, the didactic function of Poulys Daunce and the Percy wall texts in manuscript also shapes the expectation that touring virtual, didactic architecture will result in moral improvement for readers. This differs from, as is arguably its consequence in modern contexts of virtual tourism, an enhanced sense of self-importance. These differing attitudes that emerge from contemporary analysis of the function of virtual tourism, and how this enables analogous critiques of the way the wall texts facilitate experience of the danse and the Percy estates, create tension between two modes of virtual experience (and the didactic work of moral improvement clearly intended as a consequence of absorbing the moral lessons of the wall texts). This tension gestures to culturally distinct expectations and practices that surround both virtual experiences: one functions to enhance the individual's sense of specialness, and the other functions didactically to facilitate moral reflection and inculcate virtue.

These contrasts between the modern and late-medieval function of virtual tourism also evoke another experience more familiar to medieval audiences, the practice of mental pilgrimage. Medieval mental or 'imaginary' pilgrimage drew on pilgrimage literature in 
order to provide more accessible experiences to wider audiences. Rewards might even be considered greater for those who travelled mentally as opposed to physically, for the mental travellers received their rewards for this spiritual labour from God alone. ${ }^{67}$ Yet the continued popularity of pilgrimage in the later Middle Ages challenges the valuation thus placed upon mental pilgrimage. As Kathryne Beebe observes, 'Pilgrimage in spirit perhaps drew basic inspiration from a fundamental ambivalence within Christian thought about the merits of going elsewhere to seek the holy, as opposed to seeking inner sanctity'. ${ }^{68}$ When considering the manuscript versions of the texts of Lydgate's Daunce Macabre and the Percy family manuscript in this light, the dynamic between the problems of mental tourism and the benefits of mental pilgrimage suggests a complicated role for the works.

Indeed, with specific reference to the Percy wall texts, the life of one of the Royal manuscript's readers provides evidence to indicate that at least one person seems to have responded to the manuscript's representation of the Percy estates and their moral messages as a virtual tourist, rather than as a mental pilgrim: Henry Algernon Percy, the 'Lord percy' for whom wall texts were provided in his closet (f. 202r-204r / Flügel 482-5), later the sixth earl of Northumberland. Placed within the household of Cardinal Wolsey, where he was bullied for fiscal imprudence, the young Percy developed a romantic attachment to Anne Boleyn in the early 1520s. This incurred the wrath of Henry VIII, directed at both son and father, and led to a severe chastising of Percy from the fifth Earl, who came to the Cardinal's household to meet with his son. During this meeting the father condemned his son, saying, 'thou hast allwayes byn a prowde, presumpcious, disdaynfull, And a very onthryfte waster' ${ }^{69}$ Throughout his adulthood, the sixth earl furthered the familial tensions apparent in this episode. His comment in a letter to Thomas Cromwell on the 'debility and unnaturalness of those of my name' indicates his own contempt for his family. ${ }^{70}$ Childless and in the last years of his life, he seems to have sought to disperse the inheritance of his brothers by assigning grants of lands outside the family (ibid.). Finally, in the months before his death, he was unwillingly caught up in the Yorkshire rebellion known as the Pilgrimage of Grace and, while bedridden, said to be 'weeping, ever wishing himself out of the world', upon which occasion he handed over Wressle to Robert Aske, a leader of the uprising and a former servant of the Percys, and fled. ${ }^{71}$ He died not many months after, in June of 1537, having refused to make financial provisions 
for his widow. ${ }^{72}$ Such actions seem to be less the work of a magnate respectful of his inheritance and guided by the moral principles advocated in the wall texts, learning from them in the way that a 'mental pilgrim' might from a pilgrimage text, and more the responses of a member of the political and cultural elite of Tudor England, interested in securing his comfort and pleasures in ways analogous to those of the contemporary virtual tourist. ${ }^{73}$ Indeed, Henry Algernon Percy's father, when commenting on his son's pride, disdain, and wastrel ways, certainly seems to have expected that his son would have engaged with the wisdom of the wall texts on a much less superficial level.

Not only does this again broaden our understanding of interests that shape cultural production in later medieval England, but the connection also creates a parallel between religious sites and the way the wall texts of Royal 18.D.ii map the Percy estate, and the danse macabre evokes mental pilgrimage as its readers traverse the landing sites of the Pardon Cloister. Both the wall texts of the Royal manuscript and medieval pilgrimage activities focus on the spatialization of knowledge, in which particular modes of experience are tied to specific locations. As a pilgrim might travel to specific locations in Jerusalem, or within a cathedral marked by virtual pilgrimage stations, or through reading an itinerary or travel narrative to learn and refresh their knowledge of events in the life of Christ, so might the reader of the Royal manuscript traverse various sites of the Percy estates, gaining knowledge in each location. In effect, this parallel depicts a kind of nascent 'heritage tourism', in which the religious has been replaced by secular moral and ethical guides for living a virtuous life, and demonstrates how the texts serve as a 'memoriall' (210r / Flügel 495) to the family's past values.

Considering the connection between mental pilgrimage and the two wall texts also points to further connections to the work of mental pilgrimage. John Ganim and Shayne Legassie, introducing an essay collection focused on exploring the notion of cosmopolitanism in medieval culture, through examples including texts that allowed readers to travel virtually to other places through reading them, suggest that 'imaginative identifications' between and among places provided means by which medievals evaluated their own identities and senses of belonging. ${ }^{74}$ What this suggests is that wall texts like those of Poulys Daunce and those of the Percy estates may have, through their localized, architectural reading, engaged readers similarly in both reflection on their identities and senses 
of belonging. Readers of Poulys Daunce were reminded that they belonged to the Christian community of London, centred at $\mathrm{St}$ Paul's; through the connection of Poulys Daunce with installations of the danse macabre in other locations - connections that were (for example) made explicit in Shirley's and the second hand's additions to Lydgate's Daunce Macabre in the Trinity manuscript - readers were also invited to considered themselves part of a broader European community of readers drawn together by both their engagement with the danse and its universalizing subject matter. In a related vein, readers of the Percy wall texts in Royal 18.D.ii were invited to participate in a pilgrimage of the estates of this elite family in a way otherwise restricted to members of the household. Reading wall texts in manuscripts, then, in addition to reading them on site, could invite readers to perform fellowship across space, time, and place. As Ganim asserts of pilgrimage, wall texts could offer an 'epistemological metaphor' 75 focused on the performance of embodied, architectural reading that enabled readers to know themselves better, improve themselves, and join similarly minded communities of fellow readers. It is the virtual churchyard turned outward to encompass the whole of a shared culture.

\section{Conclusion}

Returning to the initial quote offered in Royal 18.D.ii regarding how the Percy wall texts present their architectural frame as a 'hous' that was 'made ... for contemplacioun', the mnemonic function of the wall texts evokes as well their apprehension through architectural reading. The presence of Poulys Daunce and the Percy family wall texts emphasizes how architecture, as well as books, could be designed for reading, for speaking to and with their readers. Furthermore, the interrelationship between place and text indicates that, just as the materiality of manuscripts produces different effects on readers, and invites distinct modes of reading practice, so too could architecture, through the local, immediate details of the landing sites created through the interaction of place, text, and reader. In considering the interrelationships effected through texts situated architecturally, Heather Meakin argues for the adoption of the term 'architext'. To analyse an architext is to recognize 'that the texts and the space they occupy are interdependent on one another for their meaning; text is not simply applied to a neutral surface' ${ }^{76}$ Not only is it that space and place are socially constructed, but how that space is designed and used 
- from its passers-by to its wall texts - reflects that construction and consequently invites readers to participate in particular ways conditioned by this social context. Furthermore, the wall texts, in both manuscripts, on the Percy estates and on the walls of Pardon Churchyard at medieval St Paul's, exemplify reading practices that cross the boundary of secular and religious reading. In this context, negotiating the architectural bodies of reader and text provides access to the shaping of the self, and reinvigorates the recurring late-medieval debate between active and devotional lives by blending the two into an experience that remains engaged with the world through domestic architecture, or through civic engagement, even as it leans on devotional practices. Such mobile reading through space echoes how, in the immersive reading practices of the previous chapter, movement in synthetic space provided a key means by which the agency of immersive readers could be enacted. Mobility, in physical architectural spaces, synthetic narrative spaces, and the virtual spaces provided through texts in manuscripts, fundamentally shapes the role of reading through its emphasis on the body as a conduit to interpretation. Reading is, in all these circumstances, an embodied experience, in which how the body moves and relates to space affects the interpretive work of readers.

This reliance on reading as an activity carried out through the ability to move through space also underscores how provision of the extracodexical wall texts throughout the estate at Leconfield, in particular, equates the house with reading and textuality, as if the estates were books themselves to be traversed by their embodied readers. Similarly, reading begun through participating in Poulys Daunce in the Pardon Churchyard could reinforce the social role of the cathedral in medieval culture as dedicated to reading, practised across the landing sites of the cathedral: in the churchyard in contemplation of death, and in the nave while gazing at stained glass windows that visually and textually related their own narratives, or in chapels at prayers. Not only does this allude to the culturally authoritative function of medieval literature, but the estates and cathedrals, like books, also become authoritative texts that invite people to read and learn from them, reinforcing their cultural authority. In creating textual, inhabitable space, extracodexical works such as the wall texts also suggest that reading evokes both learning and inhabitation, developing a resonance between immersion in the household or cathedral and immersion in a book. Such immersion entails identification of reader with the textual work and, in the case of the wall texts, the morals and values they 
express. Furthermore, the way that landing sites function to extend readers' bodily conceptions of themselves beyond their physical confines into the spaces in which they read highlights how reading functions as a technology of the self. To read, and particularly to read with the architectural body, engages the body and changes the body in relation to the space of reading. In this way, reading both enables readers of the extracodexical texts situated within architectural spaces to recognize the way that these spaces can inform, teach, and improve their inhabitants, and also invites readers to bring that architectural, textual, moral awareness with them as they move into new landing sites, religious and secular, public and private, embodied and virtual. Participatory reading involves bodies in action.

\section{Notes}

1 Wall texts have been little-studied before the recent material turn generated interest in these non-canonical, architecturally sited texts, which include not only works painted directly on the plaster of walls or ceilings, but on cloth hangings and tapestries. The past decade's re-evaluation of the work of John Lydgate has been especially prominent in assessing wall texts and verses on painted cloths, as the verses of several poems designed for walls or wall hangings survive. Most relevant for the present essay is Seeta Chaganti's work on the role of death in apprehending John Lydgate's verses on the danse macabre situated in medieval St Paul's Cathedral in London ('Danse macabre and the virtual churchyard'. postmedieval 3:1 [2012], 7-26). Claire Sponsler addresses the close relationship between such works and writing when assessing the etymological links between 'textile' and 'text' ('Text and textile: Lydgate's tapestry poems', in Medieval fabrications: dress, textiles, clothwork, and other cultural imaginings, ed. E. Jane Burns [New York: Palgrave Macmillan, 2004], 19-34). See also Jennifer Floyd's discussion of Lydgate's verses for the Amorours of London ('St. George and the "steyned Halle”: Lydgate's verse for the London Armourers', in Lydgate matters, ed. Cooper and DennyBrown, 139-64). Writing from the perspective of an art historian, rather than a literary critic, Linda Safran situates the wall texts of medieval Italy as a form of public discourse that functioned in conjunction with other spatial, textual, and decorative systems ('Public textual cultures: a case study in southern Italy', in Textual cultures of

medieval Italy, ed. William Robins [Toronto: University of Toronto Press, 2011], 115-44). For a general introduction to wall texts, see Roger Rosewell (Medieval wall paintings in English and Welsh churches [Woodbridge, UK: Boydell, 2011]). 
2 For an extended analysis on the social construction of space in a medieval literary context, see Valerie Johnson, 'A forest of her own: greenwood-space and the forgotten female characters of the Robin Hood tradition', in Robin Hood in outlaw(ed) spaces: media, performance, and other new directions, ed. Lesley Coote and Valerie B. Johnson (London and Burlington, VT: Ashgate Press, 2017), 21-39.

3 The wall texts from the Royal manuscript have been edited by Ewald Flügel, 'Kleinere Mitteilungen aus handschriften', Anglia 14 (1892), 463-97, and the manuscript is also available online in a digitized facsimile published by the British Library (at the time of this writing, accessible at www.bl.uk/manuscripts/FullDisplay. aspx?index=11\&ref=Royal_MS_18_D_II); see f. 202r (Flügel, 1892: 482 ) for this specific quote. All other quotations from the text will be transcribed from the manuscript, and their citations will also include the page numbers to the corresponding passage in Flügel's edition. Critical treatment of these verses has been of the passing sort; see, in addition to other sources cited above, A. S. G. Edwards ('Middle English inscriptional verse texts', in Texts and their contexts: papers from the Early Book Society, ed. John Scattergood and Julia Boffey [Dublin: Four Courts Press, 1997], 26-43, at 29-30), which situates the Leconfield and Wressle verses within the context of genre.

4 Anthony Emery, Greater medieval houses of England and Wales, 13001500: volume 1, northern England (Cambridge: Cambridge University Press, 1996), 262-3.

5 A petition of 1652-3 provides a twenty-one-year lease of 'the house called the New Lodge in the Park called the New Park of Leconfield' to Allan and Josselin Percy (Clay, 1896: 183). The description of the park is offered by John Leland in 1577; see the Itinerary of Fohn Leland the antiquary, Vol. 1. 3rd ed. Ed. Thomas Hearne (Oxford: James Fletcher, 1768), 47.

6 Henry Algernon Percy, The regulations and establishment of the household of Henry Algernon Percy, the fifth earl of Northumberland at his castles of Wressle and Leckonfield in Yorkshire, begun Anno Domini MDXII (London: William Pickering), 299, 303, 442. This work is also known as the Northumberland Household Book. On the tradition of the 'secret house', see Girouard, Life in the English country house, 76, 78.

7 For an extensive, detailed analysis of how the space of a Tudor estate might be explored and analysed, see James M. Sutton, Materializing space at an early modern prodigy house: the Cecils at Theobalds, 1564-1607 (Aldershot, UK and Burlington, VT: Ashgate, 2004).

8 Bernard Burke, The historic lands of England, vol. 2 (London: E. Churton, 1849), 55.

9 John A. Goodall, 'The great tower of Rochester Castle', in Medieval art, architecture, and archaeology at Rochester, ed. Tim Ayers and 
Tim Tatton-Brown (Leeds: British Archaeological Association, 2006), 265-99, at 288 .

10 Leland, The Itinerary of Fohn Leland the antiquary, Vol. 1, 55. At Leconfield, Leland had observed a related space, also called Paradise; at Leconfield, however, it is 'a litle studying Chaumber', which housed the genealogy of the Percy family (ibid., 47).

11 The latter is the more probable conclusion; although in the sixteenth century great houses began to include specialized spaces for books and reading, in earlier buildings, such as Caister Castle, constructed in the early fifteenth century at the behest of Sir John Fastolf, the bathing house formed part of the owner's suite of chambers; at Caister Castle, it held about two dozen books (see Chris M. Woolgar, The Great House in late medieval England [New Haven: Yale University Press, 1999], at $63)$.

12 For a discussion on the types of instruments and music lessons supported by these proverbs, see Rob C. Webman, The crisis of music in early modern Europe, 1470-1530 (New York and London: Routledge, 2005), at 155-6.

13 Fol. 200 is a singleton added into the quire, but Malcolm Parkes considers the scribal hand to be the same throughout these folios; see Malcolm B. Parkes, English cursive book hands 1250-1500 (Oxford: Clarendon Press, 1969), pl. 15.

14 The most extensive analysis to date of the emblem is that offered by Arthur. G. Dickens, 'The Tudor-Percy Emblem in Royal MS. 18 D ii'. The archaeological journal 112 (1956), 95-99. For a more recent analysis, see Alexandra Gillespie, “"These proverbes yet do last”: Lydgate, the fifth earl of Northumberland, and Tudor miscellanies from print to manuscript'. The yearbook of English studies 33, Medieval and Early Modern Miscellanies and Anthologies (2003), 215-32, at 230-2.

15 In this case, 'roufe' most probably means ceiling, a not uncommon location for wall texts. These library proverbs have been argued to represent a debate between two voices offering opposing comments on the value of study, although they are not formatted as a dialogue in the way that the verses in the 'garett over the bayne' are, where the speakers are labelled each time the voices shift. For more on this argument, see Fiona S. Dunlop, 'Mightier than the sword: reading, writing and noble masculinity in the early sixteenth century', in Representing medieval genders and sexualities in Europe: construction, transformation, and subversion, 600-1530 (Woodbridge, UK and Burlington, VT: Ashgate, 2011), 161-72, at 163-4. See Appendix C for an index of the wall texts' first and last lines.

16 For more details about the verses situated in each of these spaces, see Appendix C.

17 This passage's evocation of medieval mnemonic practices suggests a significant relationship between the wall texts and the embodied, 
mobile reading depicted here. For more on locationally situated medieval mnemonic practices, see Mary Carruthers, The craft of thought: meditation, rhetoric, and the making of images, 400-1200 (Cambridge: Cambridge University Press, 1998). The Royal manuscript's linking of wall text to sites within the Percy family estates, in particular, evokes the 'locational memory' of which Carruthers writes (10); by emphasizing mobility not solely in the manuscript alone, but also through the estates themselves, however, the function of the Percy wall texts extends beyond that of the mnemonic into the realm of embodied shaping of the self.

18 Gilles Deleuze, Cinema 1: The movement-image, trans. H. Tomlinson and B. Habberjam (Minneapolis: University of Minnesota Press, 1986), at 12 .

19 Ibid., 16.

20 Ibid., 17.

21 Mark Hansen, New philosophy for new media (Cambridge, MA: MIT Press, 2004), 176.

22 Mark Hansen, 'Wearable space'. Configurations 10:2 (2002), 321-70, at 322.

23 Hansen, 'Wearable space', 322, 323.

24 Ibid., 331.

25 Michel Deville, 'How not to die in Venice: The art of Arakawa and Madeline Gins', in Architectures of poetry, ed. María Eugenia Díaz Sánchez and Craig Douglas Dworkin (Amsterdam and New York: Rodopi, 2004), 77-91, at 80. Deville discusses Madeline Gins and Arakawa, Architectural Body ('Tuscaloosa: University of Alabama Press, 2002).

26 Gins and Arakawa, Architectural Body, 13.

27 Hansen, 'Wearable space', 331; New philosophy for new media, 186.

28 Gins and Arakawa, Architectural Body, 7.

29 Ibid., 8.

30 Ibid., 21.

31 Hansen, 'Wearable space', 322.

32 See, for example, Jessica Brantley's Reading in the wilderness.

33 Gillespie, 'These proverbes yet do last', 229.

34 Chaganti, 'Danse macabre and the virtual churchyard', 7.

35 For the creation date of the Parisian danse macabre, see Sophie Oosterwijk, 'Money, morality, mortality: the migration of the danse macabre from murals to misericords', in freedom of movement in the Middle Ages (2003 Harlaxton Symposium Proceedings), ed. Peregrine Horden, Harlaxton Medieval Studies 15 (Donington, UK: Shaun Tyas, 2007), 37-56. For Lydgate's residency in Paris, see Schirmer, Fohn Lydgate, 91-2.

36 A timeline of the spread of the danse is included as an appendix to the only critical version of Lydgate's version of the text, The Dance of 
Death, ed. Florence Warren and Beatrice White, EETS 181 (London: Oxford University Press, 1931), at 97-8; the 1485 edition printed by Guy de Marchaunt is reproduced in Der tanzende tod. Mittelalterliche totentänze, ed. Gert Kaiser (Frankfurt am Main: Insel, 1983), 70-107. For Holbein's version, see Peter Parshall, 'Hans Holbein's Pictures of death', in Hans Holbein: paintings, prints and reception, ed. Mark Roskill and John Oliver Hand (Washington: National Gallery of Art, 2001), 83-95, and Christian Müller, Hans holbein d.j. die druckgraphik im kupferstichkabinett Basel (Basel: Schwabe, 1997), 144-9, 278-85.

37 Influential studies of Lydgate's danse macabre include that of Amy Appleford, 'The dance of death in London: John Carpenter, John Lydgate, and the Daunce of Poulys', Fournal of medieval and early modern studies 38:2 (2008), 285-314; Chaganti, 'Danse macabre and the virtual churchyard'; and Sophie Oosterwijk, who has studied it as part of an extensive body of work focused on the danse macabre in medieval Europe. See especially, 'Death, memory and commemoration: John Lydgate and “Macabrees Daunce” at Old St Paul's Cathedral, London', in Memory and commemoration in medieval England (Proceedings of the 2008 Harlaxton Symposium), ed. Caroline M. Barron and Clive Burgess, Harlaxton Medieval Studies 20 (Donington, UK: Shaun Tyas, 2010), 185-201. For a more general, but comprehensive assessment of the danse macabre, see Elina Gertsman, The dance of death in the Middle Ages: image, text, performance (Turnhout: Brepols, 2010).

38 Trinity R.3.21 was compiled by two scribes, one known as the Hammond scribe and the other as the Trinity Anthologies scribe; it later belonged to the antiquarian John Stow. The portion of the manuscript containing the wall texts is attributed to the hand of the Trinity Anthologies scribe. For details on the work of these scribes in these and a related manuscript, see Linne R. Mooney, 'Scribes and booklets of Trinity College Cambridge, manuscripts R.3.19 and R.3.21', in Middle English poetry: texts and traditions; essays in honour of Derek Pearsall, ed. Alastair J. Minnis (Woodbridge, UK: Boydell, 2001), 241-66.

39 F. 278v, my transcription; a digitized facsimile of the manuscript is available online at http://trin-sites-pub.trin.cam.ac.uk/james/viewpage.php? index $=1374$. The miniscule initial ' $h$ ' above the first line of the scribe's headnote was clearly intended as a guide for the later illumination of a major capital, for which additional space was provided; this programme of decoration extends through the first twelve folios of the manuscript, but was never completed. It nevertheless indicates that both scribes involved in collaborating on the manuscript compiled it with attention to it as an important collection worth the additional time, effort, and expense to decorate.

40 John Stow, A Survey of London: reprinted from the text of 1603, vol. 1 (Oxford: Clarendon Press, 1908), at 327. 
41 John Schofield, St Paul's Cathedral before Wren (Swindon, UK: English Heritage, 2011), at 167.

42 Sheila Lindenbaum, 'London texts and literate practice', in The Cambridge history of medieval English literature, ed. David Wallace (Cambridge: Cambridge University Press, 1999), 284-309, at 294.

43 Appleford, 'The dance of death in London', 305.

44 Schofield, St Paul's Cathedral before Wren, 145, 185.

45 On the denunciation of ball games by the Bishop of London in 1385, see David Lepine, A brotherhood of canons serving God: English secular cathedrals in the later Middle Ages (Woodbridge, UK: Boydell, 1995), 13. On the battle play, see Samuel K. Cohn, Jr., Popular protest in late medieval English towns (Cambridge: Cambridge University Press, 2013), 71 .

46 Ibid., 50.

47 Ibid., 85.

48 Lepine, A brotherhood of canons, 13.

49 Stow, A Survey of London, vol. 1, 327-8.

50 Schofield, St Paul's Cathedral before Wren, 137.

51 Ibid., 109.

52 John McNeill, 'The continental context', Fournal of the British archaeological association 159 (2006), themed issue on The medieval cloister in England and Wales, ed. Martin Henig and John McNeill, 1-47, at 13.

53 Ibid., 12-13.

54 Caroline M. Barron and Marie-Hélène Rousseau, 'Cathedral, city and state, 1300-1540', in St Paul's: The cathedral church of London, 604-2004 (New Haven and London: Yale University Press, 2004), at 42.

55 For assessment of Poulys Daunce as dramatic performance, see Sponsler, The queen's dumbshows, 'Performing pictures', 67-96.

56 Two versions of Lydgate's poem exist, referred to as the A and B versions. Which figures are included in the danse differs between these (the A text, for example, includes passages on a lady of great estate, a monk, a usurer, a squire, a parson, a clerk, and a tregetour; the B text includes passages on a mayor, a canon regular, a doctor of law, a judge, a nun, an artificer, and a servant). Appleford argues that the B text is most likely the version that was installed at St Paul's, as the inclusion of major, judge, artificer, and servant made the text more localized to figures more characteristic of London (Learning to die in London, 1380-1540 [Philadelphia: University of Pennsylvania Press, 2015], 90-4).

57 The dance of death, ed. Warren and White, lines 9-10 from the B version represented by the London, British Library MS Landsdowne 699.

58 Chaganti, in 'Danse macabre and the virtual churchyard', notes that previous discussion of this phenomenon demonstrates a Derridean 
paradox, that identification is both individual and universal; for Chaganti, this emphasizes the focus on form in the danse macabre (11-12).

59 For the fashionableness of St Paul's tombs, see Schofield, St Paul's Cathedral before Wren, 137.

60 The best resource for the transi-tomb itself is Kathleen Cohen's Metamorphosis of a death symbol: the transi tomb in the late Middle Ages and the Renaissance (Berkeley: University of California Press, 1973), quoted here from p. 1. Schofield, in St Paul's Cathedral Before Wren, also discusses a transi-tomb originally located in the middle of the choir of St Paul's, the tomb of Dean Colet, which survives only in an engraving made by Wenceslaus Hollar from 1657, at 137-8; further study of the fragmentary survivals of other monuments at St Paul's is still wanting, until which the most comprehensive resource is the engravings by Hollar published in William Dugdale's History of St Paul's (London: Thomas Warren, 1658).

61 Cohen, Metamorphosis of a death symbol, introduction and chapter 1. The first English transi-tomb, that of Henry Chichele, the Archbishop of Canterbury, makes this educational role of the transi-tomb explicit in its inscription, which reads (in Cohen's translation from the original Latin): 'I was a pauper born, then to Primate raised / Now I am cut down and ready to be food for worms / Behold my grave, / Whoever you may be who passes by, I ask you to remember / You will be like me after you die; / All horrible, dust, worms, vile flesh' (16, n. 9).

62 Gertsman, The dance of death in the Middle Ages, 180.

63 Chaganti, 'Danse macabre and the virtual churchyard', 17 and 22.

64 This door has been omitted in the map of St Paul's that has seen the widest circulation, created by Tracey Wellman for Derek Keene, Arthur Burns, and Andrew Saint, eds, St Paul's: The cathedral church of London 604-2004, 42 (fig. 20), and reprinted in Appleford, 'The dance of death in London', 288; Appleford, Learning to die in London, 85 (fig. 3). This map shows only one exit in the centre of the north cloister wall, leading from the Pardon Churchyard into the grounds of the Minor Canon's residences, and omits any means for entering or exiting the cloister from the cathedral itself. Schofield, intimately familiar with the architectural evidence of the cathedral and its history, suggests that there 'was probably a public entrance to the cloister, perhaps near Sherrington's chapel' outside the northeast corner of the cloister and abutting the north entrance to the nave (St Paul's Cathedral before Wren, 172). A second door into Pardon Cloister, Schofield notes, was the one referred to in the arrangements for Prince Arthur's marriage to Catherine of Aragon as a 'little door against the Consistory that leadeth into the Palace', from the west wall of the north transept, shown in an undated sixteenth-century plan of the cathedral known as the 'Codrington plan', which 'led first to the 
Pardon Churchyard' (ibid., 145 and figs 4.4 [Codrington plan] and 4.108 [Museum of London Archaeology plan]).

65 Google's most well-known virtual tour explores Abbey Road, https:// insideabbeyroad.withgoogle.com/en. In a more serious example of the political and historical role virtual imagery like that provided by Google Earth can play: at the time of the writing of this chapter, satellite imagery was used by the UN to assess the state of the late antique ruins at Palmyra, much of which had been overtaken and demolished by the Islamic State (ISIS) in 2016.

66 Mimi Sheller, 'Virtual islands: mobilities, connectivity, and the new Caribbean spatialities'. Small Axe 11:3 (October 2007), 16-33, at 23, 26. Mobile elites are not only those who can choose to visit the sites, however remote, but also those who will never visit the sites, but possess technology, such as mobile smartphone technology, enabling them to access such tours.

67 Kathryne Beebe, 'Reading mental pilgrimage in context: the imaginary pilgrims and real travels of Felix Fabri's "Die Sionpilger." Essays in medieval studies 25 (2008), 39-70, at 43. See also Kathryn M. Rudy, Virtual pilgrimages in the convent: imagining Ferusalem in the late Middle Ages (Turnhout: Brepols, 2011).

68 Beebe, 'Reading mental pilgrimage in context', 58.

69 George Cavendish, The life and death of Cardinal Wolsey, ed. R. S. Sylvester, EETS 243 (London: Oxford University Press, 1959), 32.

70 Quoted in Richard W. Hoyle, 'Percy, Henry Algernon, sixth earl of Northumberland (c.1502-1537)'. Oxford dictionary of national biography (Oxford: Oxford University Press, 2004); online edn, Jan 2008.

71 Richard W. Hoyle, The Pilgrimage of Grace and the politics of the 1530s (Oxford: Oxford University Press, 2001), at 284.

72 Cf. Hoyle, 'Percy, Henry Algernon'.

73 During or after the sixth earl's lifetime, other readers of the manuscript left their marks between its pages: on $\mathrm{f}$. $1 \mathrm{r}$, the inscription 'Kateryne Eggcomb' may have been that of the sixth earl's wife; the sixth earl's nephew, Henry Fitzalan, twelfth earl of Arundel, inscribed his surname and motto on f. $212 \mathrm{vol}$. After that, according to the British Library description of the manuscript's provenance, it seems to have entered the hands of John Lumley, the first baron Lumley, who records it in a catalogue of his collection assembled in the year of his death, 1609.

74 John M. Ganim and Shayne Aaron Legassie, 'Introduction' to Cosmopolitanism and the Middle Ages (New York: Palgrave Macmillan, 2013), 1-20, at 3 and 6. See also Matthew Boyd Goldie, The idea of the antipodes: place, people, and voices (New York: Routledge, 2010), who argues that place-specific medieval practices, laws, and expression simultaneously produce a kind of 'flatness' through how they are shared across cultures (14). 
75 John M. Ganim, Chaucerian theatricality (Princeton: Princeton University Press, 1990), 63. Ganim also emphasizes the performativity of the pilgrimage narrative, which he relates to theatricality. Relatedly, Claire Sponsler argues that the theatrical performativity of many late-medieval texts represents a medieval engagement with collaboration through readers' and others' performances of texts that counters modern notions of the singular author (The queen's dumbshows, 1).

76 Heather Meakin, The painted closet of Lady Anne Bacon Drury (Farnham, UK and Burlington, VT: Ashgate, 2013), 3. 


\section{Reading temporally:}

Thomas of Erceldoune's prophecy, Eleanor Hull's Commentary on the penitential Psalms, and Thomas Norton's Ordinal of alchemy

Thomas Hoccleve's Dialogue with a friend, previously discussed in the Introduction as exemplifying a moment of participatory reading, incorporates several specific reading practices into the interaction described between Hoccleve and his friend. One of these participatory reading practices, which Hoccleve also represents in the poem, is the practice of reading temporally. Temporal reading emerges prominently in the poem when, in its prologue to 'Jereslaus' Wife', to which his interventionist friend and reader prodded him to add the final moralization, Hoccleve describes how the friend had previously visited him. After a discussion of Hoccleve's health, in which Hoccleve asserts he must return to study and writing to prove his recovered wits against the insults of a disbelieving public, the friend asks Hoccleve what the poet will write next. Hoccelve explains that he plans to take up the matter of a Latin treatise and translate it into English. The treatise 'lerne for to dye / I-callyd is', Hoccleve says, and explains that it might help others:

yf that hym lyke / rede and beholde, consyder and se well / that it is full hard delay accompts / tyll lyfe begyne to colde; short tyme is then / of his offencis olde to make a just and trewe rekenynge. ${ }^{1}$

The reader desirous of preparing well for death can, if he wishes, read Hoccleve's work. Reading about death and the necessity to prepare for it by addressing one's sins in advance helps prepare for the inevitability of the effects of time on human lives. Supporting this point Hoccleve explains that his own awareness of time presses upon him, for he has reached his mid-fifties and thinks often about how the sweetness of the world too easily turns to bitterness. In this passage Hoccleve illustrates several common notions of time 
that developed over the course of the Middle Ages. He describes the effects of experiencing time that he conceives of as possessing an inevitable, linear force; he also addresses the circularity of time, which can predictably turn from sweetness to bitterness, and back again to sweetness. These two notions of temporality, as linear and as circular, had long affected medieval understanding of the repeating patterns of human history and experience, as discussed previously in Chapter 2 when discussing the historical nonlinearity John Lydgate crafted into the Siege of Thebes.

Other concepts of time, such as agrarian and biblical, permeated the fabric of medieval culture. ${ }^{2}$ Contrasts between sacred and secular, monastic and mercantile notions of time, the temporality of the zodiac, of agriculture, of the church, and more, have received much attention. ${ }^{3}$ These multiplicities of temporality, of course, witness a medieval awareness of, and interest in, how different ways of attending to time shape perceptions of the world. Time did not simply affect human experience, however; it influenced life in ways that intersect with medieval literary culture. In literature, time could also be manipulated and trivialized. This treatment of time also emerges in Hoccleve's Dialogue, in which multiple social perceptions of temporality intersect and are represented as influencing both the writer's and, potentially, readers' experiences. Different ways of perceiving the value and practice of time also shape the treatment of multiple temporalities in the poem. Yet, despite the significance of time in late-medieval culture, and despite the attentiveness paid to different medieval schema for conceiving of time, and despite extensive study on the book of hours - as a text defined by time - and its role in constructing a popular understanding of sacred time in the late Middle Ages, little attention has been paid to how late-medieval perceptions of temporality intersect with reading experiences, and in particular how readers' engagements with time become reading practice. In this chapter, I draw on a range of texts across religious and secular genres to show how pervasively time becomes incorporated into reading experiences and participatory reading practice in late-medieval England. Different ways of engaging with and understanding time shape reading experiences and, consequently, textual interpretation, from the pace of reading to readers' creation of narrative sequence to the reader's personal orientation to historical time.

The workings of temporality have, as with the other reading practices discussed previously, also engaged the interest of critics, artists, and theorists working with digital media, alongside theo- 
retical ways of understanding time, from the work of Stephen Hawking to that of Giorgio Agamben. Among critics of digital media, how the experience of time in and in response to digital media have gained the most attention. Such critics, seeking to apply concepts drawn from narratology, have sought to explain and analyse temporal phenomenal present in works like video games. Analysing such, contrasts of duration and speed framed through the work of Gerard Genette and others have occupied the primary focus of scholars of digital media. ${ }^{4}$ Similarly to how digital media scholars study the processes of materiality, such critics' interest has focused on how digital media facilitate the manipulation of time through the properties of media. For example, 'system time' addresses how the permanency of the text can be affected by software and the formal materialities of a computer system, such as its processing speed. An example of 'system time' emerges through William Gibson's Agrippa (a book of the dead), which was stored on a floppy disk and famously programmed to erase itself. The act of auto-erasure imposes limits driven by the programming, the system, of the work. These limits affect the time within which the work is available for a reader's perusal. Accordingly, system time contrasts with and can affect 'reading time', which refers to the temporal availability of a text to readers. An illustrative example of constrained reading time is that exemplified in William Poundstone's 'Project for 'Tachitoscope [Bottomless Pit]', which flashes image and text that disappear and are replaced within fractions of seconds. ${ }^{5}$ Both system time and reading time intersect in Gibson's and Poundstone's works in ways that require readers to adjust the duration of their reading practice to respond to the limitations imposed by the reading and system times of these works.

Accordingly, digital media critics often view the treatment of reading time as an intrinsic property of types of media. This approach emphasizes fundamental differences between, for example, the experiences of reading time in digital and print media, since their formal materialities differ. As Markku Eskelinen explains, 'If system time and reading time were to be applied to print narratives, they would usually have both unlimited system time and unlimited reading time, because they are supposed to be permanent and there are no temporal limitations set to their reading'. ${ }^{6}$ Eskelinen's influential argument treats the media form of a work as inalterably affecting reading experiences. This view, however, overlooks how social use can affect reading time both in print, manuscript, and digital media. Consequently, while such 
criticism usefully directs attention to the qualities of a work that affect the reader's experience of and engagement with temporality, it also invites further scrutiny of time, particularly for how the cultural and historical contexts of media affect temporal experiences and engagements.

One example of how such issues may be considered involves returning briefly to examples of the reading practice attended to in Chapter 2, nonlinear reading. As previously discussed, when medieval writers and modern critics explicitly address how nonlinear reading functions, they often link it to the formal materialities and structural considerations of textual organization. The division of a work into lexia, such as chapters or parts, can facilitate nonlinear reading practices driven by the readers' association of passages of interest to themselves. Such associational reading has been related to time in the context of hypertext media, as critics suggest that nonlinear reading facilitates access to, and intake of, information in ways characterized as shallow and swift, as indicated by the dominance of the terminology used to describe hypermedia reading as 'browsing' and 'surfing'.7 The shallowness of engagement with information was compensated for by the speed that allowed readers to apprehend greater amounts of information; hypertext media enable speed through the division of text into lexia and the provision of means for easily connecting one lexia to another via hyperlinks. For medieval writers, similarly connecting time to nonlinear reading, swiftness and shallowness are the opposite of the results achieved by nonlinear reading. For example, considering the Orcherd of Syon, it is noteworthy that the translator links negotiation among textual nodes to the ability to spend 'o tyme in oon, anopir tyme in anopir' (1), which helps promote 'bisye \& ofte redyng' (421). To read nonlinearly offers readers the opportunity to choose how and where to spend their reading time, and increases the frequency of reading practice. In the perspective of medieval writers, nonlinear reading, when practised with temporal mindfulness, affects both reading frequency, reading pace, and textual navigation: one structural and two temporal aspects of reading that intersect to produce particular cognitive results. 'Bisye' reading can be developed through reading multiple passages in whatever sequence the reader finds useful, a change to reading pace reliant upon textual organization; 'ofte' reading develops more easily when the text can be dipped in and out of at will, when passages can be read independently and placed in associational context with each other. Yet rather than producing the shallow apprehension of 
'surfing', this temporal practice of nonlinear reading helps make the reading experience deeper and more productive for the individual. Participatory reading can thus involve readers manipulating their temporal practice in order to enhance a deeper, customized engagement with the text.

\section{Reading as temporal manipulation}

By moving from lexia to lexia often and busily, readers manipulate the temporality of their reading practice in order to effect change in apprehension of a text. In the Orcherd, this practice of temporal reading is represented as relying on adjustments to reading pace and textual sequence in order to customize the text to the individual reader's needs and interests. Yet temporal reading does not promote only the ability to customize reading pace and frequency in order to achieve 'bisye' reading. An interpretation of how temporal reading functions that contrasts with the view of the translator of the Orcherd emerges in the Middle English translation of the Pseudo-Augustinian soliloquies. In it, the translator notes instead that temporal reading offers an opportunity for refreshment of the reader. To this translator, the divisions of the text facilitate readers' negotiation among passages, so 'that where it lyketh hym he may begynne and also ende, ne lest often repeticion of one thing schulde make hevenesse'. 8 By moving among lexia according to preference and interest, readers may avoid the boredom of repetition. Changing one's reading pace, frequency, and sequence in order to dwell over a passage through its rereading, in this context, would be viewed as a problematic practice enhancing boredom, and thus counter-indicated by the need to keep the reader's attention engaged through encounters with fresh material. This perspective demonstrates how temporal reading could be viewed not only as a practice enhancing customization, but also as a practice of attentiveness. Temporal manipulation of reading pace and sequence could make apprehension of a text feel lighter or deeper. Neither the translator of the Orcherd nor that of the Soliloquies suggests a specific amount of time be spent on reading; rather, what they both emphasize is that readers' temporal manipulation of reading practice shapes the subjective and affective experiences of reading and, consequently, textual interpretation.

The differing approaches of these writers to temporal reading, and the way these approaches contrast with modern critics' views of the effects of reading on the temporal engagement with a text, 
suggests that temporal reading is also a culturally constructed practice whose effects may be bound to a particular place and time. That nonlinear reading is today viewed as 'swift' and 'shallow' may say more about what scholars and users alike expect from reading digital media, and how we choose to read digital media, than it says about any transhistorical continuity about practices of nonlinear reading. Treatment of the same reading practice in different cultural and historical contexts should not be viewed as consistently producing the same results, which is to view the effects of a reading practice as predictable and constant over time. Instead, the same practice may produce different results because reading develops through culturally contextualized training and practice.

Yet some aspects of reading practices can be identified as similar across time and cultural difference. Through temporal manipulation, medieval and modern readers gain another way to interact with their texts and exert agency over the reading experience. As medieval readers chose how to attend temporally to the text, how much time to spend on a passage, and whether to reread one or briskly move on to another passage, they exerted agency to determine what aspects of temporal reading would most benefit their apprehension of the work. At the same time, however, as with other practices of participatory reading, writers advocating temporal reading practice did not view such readers as setting the agenda for their reading experience. Instead, writers treat their stated goals for the text, or the text's aims as determined by its genre, as predetermining readers' agendas and circumscribing the use of their agency. Readers should exert choices insofar as their choices support the effective interpretation of the work as stated by the writer or translator, or as implied by the genre of the text. Temporal reading, in this light, serves to make achieving the agenda set by a text or writer more likely and more accessible. That temporal manipulation becomes part of the work of participatory reading demonstrates how writers viewed time as a significant aspect of reading experiences, and the ability to affect time as crucial to readers' participation, although reading temporally does not change readers' abilities to affect the agenda set by the text or writer. For medieval writers, to read is to comply with the aims of the text read.

For readers, temporal reading under the guidance of writers' proleptic instructions enabled a mode of reading that facilitated textual customization and enhanced attentiveness and engagement. While writers also seek to predetermine readers' responses by 
treating temporal reading as guiding affective responses to the text, temporal reading nonetheless requires the participation and compliance of readers, who can also choose to concentrate on whatever other aspect of interpretation suits them; furthermore, that writers represent the results of temporal reading as somewhat mutable may also indicate that its results might not be fixed, but could be adjusted to suit the goals of readers. That is, while texts like the Orcherd of Syon that are designed for nonlinear apprehension can facilitate temporal reading by making a text more accessible to reading characterized by dwelling either briefly or lingeringly over short passages, these texts cannot make other reading practices inapplicable. That medieval writers nevertheless chose to advocate for temporal reading demonstrates how they viewed it, in its multifaceted application, as significant to the work of understanding a text. It made a difference to them that readers should approach a work in a particular mindset, and with the expectation of achieving particular results from their reading; writers turned to temporal reading to create a practice that would help achieve those results.

Temporal manipulation in these ways is not exclusive to medieval reading practice alone. Temporality, for example, also emerges as an aspect of literary culture through the work of textual composition: to 'abbreviaten' or 'abreggen' was viewed as diminishing both length and time, as explained in the Middle English translation of De re militari: 'Pese bookes of werre craft ... ben breueliche y-gedered oper schortliche abreged out of auctors apreued'. ' Abridgement is an activity that can be both 'brief' and 'short', which unites perceptions of length and time. Linking length and time to textual composition further suggests that temporal manipulation functioned as a feature not of reading alone, but of both writing and reading. This view complicates Eskelinen's notion of 'system time' by demonstrating how temporal manipulation may not only emerge from the formal qualities of an object, or through the experiences of a reader, but also, in the context of medieval literary culture, through the processes that writers, scribes, and readers enact through the practices that define them. The temporal manipulation of the length of the text also impacts what Genette refers to as 'pseudo time', which is the amount of text used to describe an event. ${ }^{10}$ In other words, medieval writers and scribes who altered the length of a text engaged in a process of altering the temporality of a text, even as readers also manipulated temporal experience through the process by which they apprehended a text. Both writing and reading offered opportunities to 
practice temporal participation with a text, demonstrating that temporality in medieval literary culture extends past the simple notion of narrative temporality to a much more complex and multifaceted perception of time.

Considering that time is not simply an aspect of narrative craft, but of readers' experiences, and of scribes' and writers' material, formal engagement with and contributions to a text invites further consideration of how time might be manipulated with consequences for readers' apprehension of a work. Abridgement introduces an example of how scribal emendation of a text could affect reading time, but reading time could also be effected through occasion and performance. The example of John Lydgate's 'Soteltes' discussed in the previous chapter exemplifies a text whose reading time was limited to the duration the subtleties entered the hall at Westminster at the end of each course of the coronation feast, and concluded when they were consumed or taken away in order to introduce the next course or end the feast. Ephemeral works like the 'Soteltes' thus impose limitations on reading time that are not responsive to the desires of readers to linger or not, but are, rather, responsive to the materiality of the text and the conditions of the occasion. Ephemerality may affect temporal reading in ways not restricted by events. For example, in the Percy family wall texts, the natural rhythms of the household create effects that would shape the way readers assess the work's temporality. The verses providing proverbs on the subject of music located in the garret above the New Lodge would be apprehended differently if read just before a music lesson as opposed to after it, or would be read differently again during seasons or years without such lessons taking place. The use of space thus conveys its own temporal effects on a work, effects which can be ephemeral even when not tied to a specific event. Ephemerality constrains reading time in a way that, as Eskelinen observed, the printed (or manuscript) text may not - with some exceptions.

One exception to the constraints on temporal reading imposed by ephemerality emerges through a work's remediation into another format. Such affected the Percy family wall texts and Lydgate's 'Soteltes' when the verses were included and resituated for readers in manuscript contexts. There, the imposed, event- and spaceorchestrated temporal constraints disappear, in the sense that readers can choose to extend or shorten the experience of reading them according to their own wishes. Nevertheless, maintaining the 'Soteltes' verses within the framework of the banquet suggests that 
limits on reading time can be constructed virtually, if not materially. This virtual representation of temporal limits is evoked by the location of the verses within the framework of the banquet: there, they are represented as if still part of a temporally finite experience. Providing the framework of the occasion does not contextualize the content of the verses alone; it also evokes the temporalities, including the temporal limits, of the occasion in the act of conveying the verses to readers. Preserving the temporality of occasional verse, however, imposes changes upon it. Emphasizing the temporal limits to the verses in their occasional context can evoke a sense of urgency applied to subsequent readings of the work, even as it also emphasizes connections to the past event, thus imparting a gloss of continuity and stability to the work's message. ${ }^{11}$ Such treatment of time may be supportive of the message of the text in its original presentation. Yet this treatment of time does not belong to the original work, but emerges from its new context. Remediation of the text thus remediates its temporalities as well, even under the guise of maintaining the work's previous temporalities. Accordingly, reorganization of a text by the application of new schema, such as a work's re-organization into new chapters, can create new temporal effects. Consequently, examining a text for its engagement with time may require considering, for example, how manuscript witnesses represent various schema for dividing and organizing a text, as each schema may differently affect temporal manipulation.

\section{Reading as participatory temporality}

For medieval readers, temporal manipulation does not represent the only way time becomes intertwined with the work of reading. Indeed, temporal manipulation can be seen as contributing to a practice of reading that might more broadly be considered as 'participatory temporality'. This term draws on the critical framework of participatory materiality as discussed in Chapter 3, and also extends theorization of temporalities encountered in digital media. In digital media studies, Raine Koskimaa has elaborated on narratological understanding of temporality and contrasted it with assessments of temporality by scholars of digital media to distinguish four levels of temporality in narrative digital texts: user time (which is the time a person spends reading a text, and synonymous with reading time), discourse time (the time of the narrative discourse), story time (the time the narrative events take 
place within the synthetic space of the narrative), and system time. Koskimaa notes that multiple levels of temporality can be engaged simultaneously, for system time operates in the same moments as story time and discourse time; this convergence of temporalities 'merge together in a novel way' in digital media. ${ }^{12}$ Such merging of temporalities suggests a particularly interesting development, for it indicates that distinct modes of temporalities may, in intersecting, affect each other - and affect even the user or reader.

Although the convergence of multiple temporalities may take place differently according to particular types of media, such convergences are not unique to digital media. For example, consider the widespread and influential metaphor of the book as flesh of Christ, previously mentioned as an example of the intersection between materiality and embodiment in reading practice. The metaphor also possesses a temporal functionality. One of the more descriptive uses of the metaphor is provided by Richard Rolle in a passage on devotional reading. Rolle writes:

[S]wet Jhesu, py body is lyke a boke written al with rede ynke; so is by body al written with rede woundes. Now, swete Jhesu, graunt me to rede upon by boke, and somewhate to undrestond pe swetnes of pat writynge, and to have likynge in studious abydynge of pat redynge. ${ }^{13}$

While Rolle does not explicitly address time, the metaphor he deploys here nevertheless evokes several temporalities that converge through it. First, calling attention to the nature of the book as flesh and body invites readers to consider the formal, material temporalities of the manuscript, which was once a living animal possessed of its flesh, but has since become remediated into the book. Next, comparing that manuscript body to the wounded body of Christ evokes for readers the historical temporality of his life. Other temporalities that converge through this metaphor are discourse time and reading time. A final temporality is that of story time: while Rolle does not relate a fictive narrative, he nevertheless narrates a micro-event, that of the development of his devotional practice in response to the book as body metaphor, which begins with the explanation of the metaphor, transitions into the development of a meditative practice based upon it, and anticipates the enactment of that practice.

Only one of these temporal levels, user/reading time, specifically examines reading experiences, such as that of temporal manipulation. Yet the convergence of other temporalities intersects with 
reading time in ways that affect interpretation. This convergence marks the capacious medieval now, the all-encompassing sense of the present that asynchronously enfolds the past. ${ }^{14}$ This convergence also relies on the act of reading: to understand the book as body metaphor, readers recognize the convergence of temporalities as they consider their own relation not simply to their devotional practice alone, but also to the temporalities of that practice. To read the book as body metaphor, as described by Rolle, necessitates that readers recognize the various temporalities that converge in and through the metaphor, and interpret the metaphor through that understanding. The way the metaphor unites embodiment with temporality further suggests that embodied reading may always also be temporal reading, even when the temporality may not be emphasized in the text read. That is, embodiment is temporally contextualized as the body itself exists in and is subject to time. This engagement with time comes to the forefront of readers' attentions when, as Hoccleve illustrates above, a text connects awareness of time to its effects on the human body. To engage in embodied reading consequently also evokes the temporality of the body that characterizes medieval human experience.

Thus, as with materiality, and as with the temporal manipulation of writing discussed above, convergence of such temporalities requires readers to engage in temporally structured processes as they read. In effect, these processes contribute to how readers perform and thus understand temporality. Accordingly, participatory temporality offers a comprehensive term useful for considering both how temporalities converge as part of the reading experience, and also what the convergence of those temporalities achieves. Accordingly, considering participatory temporality involves assessing how temporalities function as processes with which the reader participates. The remainder of this chapter will discuss three fifteenth-century works, one a secular, prophetic poem; one a devotional work translated by Dame Eleanor Hull, a Commentary on the penitential Psalms; and the third marking a return to Thomas Norton's Chaucerian treatise on alchemy, the Ordinal of alchemy. Assessment of these works will demonstrate how participatory temporality functions across late Middle English literary genres as a widespread reading practice that shapes readers' work.

Prophecies cluster around the figure of Thomas of Erceldoune, a thirteenth-century Scots poet; many of these prophecies, few if any of which can be attributed to the historical figure of Thomas, were collected in Thomas of Erceldoune's prophecy following its initial 
romance-styled prologue that explains Thomas's rather fantastic experiences. This prologue and the prophecies form Thomas of Erceldoune's prophecy survive imperfectly in three fifteenth-century manuscripts and one from the sixteenth century, and in shortened fragments in several others. Two of these manuscripts include the text alongside other prognosticative or prophetic works, reflecting the compilers' strong interest in history and temporality. In Thomas of Erceldoune, the story of the prologue follows Thomas as he rests beneath a tree on a May morning. He then sees a richly dressed lady riding nearby, whom he initially takes to be Mary as Queen of Heaven despite the demurral of the lady, who says she comes from elsewhere. After Thomas pressures her into having sex, she takes him with her under the hill to her land, where Thomas spends what seem to be three days, only for the queen to explain that three years have passed. She then returns him to the tree where they first met, and at his importuning grants him a gift and shares five prophetic pronouncements. These five pronouncements include multiple prophecies, and form the subjects of the second and third parts of the poem. The work is thus deeply engaged with the multiplicity of time and temporalities people experience. ${ }^{15}$ Its prophecies, in particular, require readers' temporal participation in order to effect interpretation.

How the prophecies elicit readers' temporal participation begins with the narrating perspective of the poem. Identifying the speaker requires readers to immediately assess the chronology of the poem, work that the shifting identity of the speaker complicates. All witnesses to the prologue of Thomas of Erceldoune's prophecy begin in the first person, using 'I' to summarize the subject matter of the poem. From the mid-fifteenth-century Lincoln Cathedral Library MS 91, compiled by the Yorkshire gentleman Robert Thornton in his northern dialect of Middle English, the narrator explains, 'Lystyns, lordyngs, ... I sall 3ow tell al strew a tale / Als euer was herde by nyghte or daye', which shall include his telling of 'Batells donne sythene many a 3ere; / And of batells pat done sall bee'. ${ }^{16}$ Such a conventional opening invites identification of the narrator as a poet providing a traditional oral performance of the work, whose written form includes those legacies of the oral tradition. This first-person becomes attributed to Thomas explicitly not many lines later: 'Als I me went', and sat under the tree, 'I herde pe jaye ... als I laye'. ${ }^{17}$ Thus the initial 'I' of the poem becomes, for the reader of the text in manuscript, retroactively identified as that of Thomas. Thomas may occupy the role of the performing poet, 
which would represent the poem as not only about his experience, but also as relating his experience through his own authoritative voice. That identification thus requires readers to locate the poem and its speaker in time, requiring interpretation of the poem depending upon reading temporally.

As the speaker's perspective does not remain constant throughout the prologue, its inconsistency invites further temporal work on the part of readers. Only a few dozen lines after the first-person description of Thomas beneath the tree, the perspective shifts to third person as readers learn that 'Thomas laye' and 'He sayd' $(73,75)$. This shift may represent malleable, multiple narratorial identity, or it may represent the autographic textual voice. ${ }^{18}$ Regardless of the view of the narrator that one adopts, however, the narrating perspective represents two temporal moments. The third-person narrator relates Thomas's activities as if they occur in the present, creating a sense of proximity and immediacy; the first-person narrator depicts events viewed as past developments on which the first-person narrator reflects. This shifting perspective adds a degree of mobility to the temporalities of the poem. The temporal mobility implied by the shifting perspective of the narrating point of view thus challenges readers to orient the poem temporally in relation to themselves. Is the poem contemporary to a reader, or from the recent past, or from further back in history? As the subject matter of the poem focuses on prophecy, determining its temporal orientation relative to readers is a necessity.

Reading temporally may seem like a typical reading practice that all readers engage in while reading any text. Yet not all texts require this work. For example, those set in the present moment, such as the prologue to the Canterbury Tales, do not require readers' temporal orientation until factors external to the text, such as changing linguistic practice and religious culture, make the present-day setting of the poem a historical artefact to its readers. Thus, while reading temporally may be a necessity for any reader engaging with a text outside of its original historical context, temporal reading is only a necessity for some readers encountering the text as its initial and intended audience. In such cases, temporal reading can be - as Thomas of Erceldoune's prophecy demonstrates, along with the other texts to be discussed below - planned for and crafted as an aspect of the text designed to elicit readers' participation in order to promote particular ways of apprehending the text, interpreting it, or otherwise participating with it. 
In the case of Thomas of Erceldoune's prophecy, readers temporally orienting themselves to the poem engage in one mode of temporally interactive reading practice. Readers' different temporal orientations lead to different ways of interpreting the work and its topicality. In other words, viewing the poem as contemporary suggests that some prophecies are more likely to be as yet unfulfilled; a poem situated with greater temporal distance suggests that readers might expect some prophecies to have been fulfilled already, and some perhaps yet to be fulfilled. Readers' temporal participation thus shapes interpretation. Such reliance upon readers, as with other reading practices discussed previously, seems not to have suited all writers equally well. For example, a fifteenth-century prophecy attributed to Merlin in Trinity College Dublin MS 516 clearly indicates uncertainty about how readers will orient themselves temporally to the prophecy. This uncertainty perhaps arises because the character of Merlin would have been recognized as a character of the past, temporally distant, which could then have prompted readers to perceive the prophecy itself as applying to a temporally distant past. Yet attribution of the prophecy to Merlin clearly added to its authority, and provided a context and authority worth maintaining. Accordingly, to address this problem and still encourage readers to orient the prophecy to their present moment, the writer of the Merlin prophecy adds the year. The poem begins with phrasing echoed by other versions of the prophecy, 'When lordes wille is londes law', then concludes the stanza with, 'Then schal the lond of Albyon torne into confusioun! / A $M C C C C l x$ and on, few lordes or elles noone'. ${ }^{19}$ When the law of the land is the will of its lords, the land will fall into confusion; by 1461, few lords stand against such calamity. Adding the date diminishes the need to rely upon readers' ability to orient the poem temporally to themselves. Supplying the date explicitly encourages application of the prophecy to the readers' contemporary political situations. Consequently, the presence of the date in the Dublin MS 516 version of the prophecy indicates the significance of the absence of dates in other works. Undated prophesies rely on other cues to encourage readers to orient such writings temporally, and rely to a greater degree upon readers themselves.

How readers temporally orient the poem consequently shapes expectations regarding the focus and applicability of prophecies. As a result, by challenging readers' temporal orientation through its varying and multiple narratorial perspectives, Thomas of Erceldoune's prophecy begins to make readers work to locate 
it temporally in history. It also begins to develop expectations regarding the prophecies, even as this challenge of temporal orientation underscores the slippery multiplicity of time in the text. That such temporal orientation relies on readers' efforts underscores the participatory function of temporal reading. As previously discussed in the context of reading materially, what a reader does, and how a text proleptically invites the application of a reader's work, functions as part of the process that enacts the participatory nature of the reading practice. Temporal participation is cued by the text, but occurs through the actions of readers that affect interpretation.

This emphasis on temporal participation continues throughout the text in its provision of the prophecies themselves. Although many of the prophecies describe recognizable historical events, they do so - as is conventional for prophetic writings - allusively. These allusions require work on the part of the reader to sequence, thus situating further temporal participation as a prelude to understanding the subject matter and relevance of the prophecies. Furthermore, recognizing the events referred to in the prophecies as historical occasions that have already transpired again points to the processual function of temporality in the poem, as readers must distinguish them from forecasted events that have not yet occurred. Readers' understanding of these aspects of the poem becomes further complicated by the presentation of the prophecies in temporal clusters that, within each cluster, proceed chronologically, even as the clusters themselves are not presented in chronological order.

The first prophecy related by the queen to Thomas exemplifies how the presentation of the prophecies could influence readers' temporal performance. At the start of the second fytt, after the queen presents Thomas with the gift of truth-telling, she also provides him with a marvel, a prediction, at his request. At the conclusion of the prediction, she states,

Thomas, herkyne what I the saye:

Whene a tree rote es dede,

The leves fadis pane \& wytis awaye;

$\&$ froyte it beris nane pane, white ne rede.

Of be baylliolfe blod so sall it falle:

It sall be lyke a rotyne tree;

The comyns, \& pe Barlays alle,

The Russells, \& be ffresells free

All sall pay fade, and wyte awaye. ${ }^{20}$ 
The provision of family names make the historical allusion of the queen's prophecy readily identifiable to readers familiar with the Second War of Scottish Independence. The resolution to the First War (which lasted from 1296 to 1328) had left various families denied access to the lands in Scotland that they viewed as their own; through allegiance with England, they pursued their claims in what became the Second Scottish War of Independence, which began in 1332 and lasted until 1357. These families included that of Edward Balliol, who claimed right to the throne of Scotland, and led the families of his faction - which included the Comyns, Frasers, and Barclays and were known collectively as the Disinherited - in the first of several campaigns in Scotland. ${ }^{21}$ This exemplifies one of the more recognizable temporal allusions in the poem that readers have to decipher in order to understand the implications of the prophecies.

This prophecy centres on events from the first to second quarters of the fourteenth century, and focuses particularly on events that took place in 1333: the failure of Balliol's party when confronted with forces supporting David the Bruce's hold of the throne. ${ }^{22}$ Next, the queen's second prophecy discusses the Battle of Halidon Hill, also in 1333, a bloody defeat for the Scots. She then moves back temporally to reference the 1298 battle at Falkirk, in which Edward I of England defeated Scots led by William Wallace. After Thomas importunes her again, the queen moves forward temporally to the Battle of Bannockburn in 1314 during the First Scottish War of Independence, and after a few more events from the First War, on to the partial successes of Edward Balliol in 1332 during the Second War. The sequence of prophecies thus moves from events of the Second War to events of the First, after which follow earlier events from the Second War that precede the previously referenced Second War events. The poem concludes with prophecies about the future, extending even to an allusion that could be interpreted as referring to the return of King Arthur, unifying all Britain.

This organization of events within the prophecy clusters presents the past not as ordered, but as intersecting and branching in a rhizomatic network, and further represents the future as malleable and subject to interpretive ambiguity. ${ }^{23}$ No one prophecy is presented as providing a single key to unlocking the future; no single event dominates and imposes a linear narrative to history. The text thus invites readers' participation by providing them with the prophecies as temporal puzzles. In solving them, the 
reader orients the relation between past and future events, and further orients himself temporally: what is future for the poem's Thomas the Rhymer and the Fairy Queen becomes past for the knowledgeable, alert reader. Such work in reading emphasizes again how late-medieval writers anticipated readers on whose interpretive labour they could rely. Such work also suggests how the text might have interested its readers. Robert Thornton, gentry landowner and copyist of the Lincoln Cathedral manuscript copy of Thomas of Erceldoune's prophecy, may well have turned to the poem for reminders of the recent past that he could recognize and, in considering them alongside the future prophecies, assess how he might respond to developments in the tense political situation in Yorkshire and Scotland of the mid-fifteenth century. ${ }^{24}$

Furthermore, the presentation of the intermixed sequence of past events followed by predictions about the future creates an impression of social and political chaos. Identifying and contextualizing the past events referred to in the prophecies from events that had not yet occurred requires readers' temporal participation. In effect, readers of the prophecies have to assemble mental chronologies of the events in order to draw order and meaning from chaos. In doing so, they distinguish past events from future events, which they can then interpret in ways consonant with their individual political ideologies. Through temporal participation with Thomas of Erceldoune's prophecy, the reader emerges as a figure whose efforts bring order to history and clarity to time. Participation through temporal reading positions readers as both vehicles for and agents of temporality.

In these ways, reading temporally in late-medieval England involved temporal manipulation, the assemblage and orientation of the reader with regard to differing temporalities, and the convergence of multiple layers of time that readers engaged with and which shaped how readers interpret the work. Such aspects of temporal reading become explicit both in works that address time in relation to reading, and in works whose focus specifically involves time. Examples of these modes of temporal performativity can be identified in the descriptions of reading practice included in the Orcherd of Syon and the Pseudo-Augustinian soliloquies described above, and in more literary works such as Thomas of Erceldoune's prophecy. Aspects of temporal participation may also affect reading experiences in different ways, as temporal manipulation of the sort discussed in the Orcherd of Syon and the Pseudo-Augustinian soliloquies seeks to shape affective responses to the work read, 
while temporal orientation in Thomas of Erceldoune influences how readers orient themselves and the texts they read in relation to multiple conceptions of time. Such modes of temporal participation can also be identified in works less explicitly engaged with time or the practice of reading as these, and across the divide of devotional and secular literature. Examples of texts that demonstrate further engagement with temporal performativity these ways include Eleanor Hull's Commentary on the penitential Psalms and Thomas Norton's Ordinal of alchemy. A brief description of how each text represents temporal participation will contribute to a more nuanced picture of its workings as a reading practice, and demonstrate how temporal reading can intersect with other participatory reading practices previously described, such as nonlinear reading.

Eleanor Hull translated her Commentary on the penitential Psalms in the 1420s, when she, widowed, was living at least part of the time at Sopwell Priory, a house of nuns dependent upon the powerful and influential Abbey of St Albans. Her Commentary survives in a single manuscript collected and owned and partly copied by Richard Fox, the steward of St Albans. Following after the Commentary is Hull's translation of the Meditations on the days of the week. There, Hull demonstrates her interest in and sensitivity to temporal participation by addressing readers' temporal manipulation. Expanding on and altering the sense of her AngloNorman French source, Hull writes that it is unnecessary for readers to follow the linear arrangement of the text. Instead, they should negotiate the text according to their needs and interests: 'Nere it nedyth allweys to begyn at euery tyme at the begynnyng hereof but per as hym best lykyth and hath most devocyon to rede', and adds, 'by cause the redyng shold not turne hem to enoye for to long redyng'. ${ }^{25}$ That is, Hull suggests to readers that starting at the beginning is not an absolute necessity; starting where they most prefer helps produce a reading experience that is not overlong and therefore annoying. Hull thus indicates that devotion can be enhanced through readers' application of nonlinear apprehension of the text, and nonlinear reading shapes the affective consequences of reading pace. Nonlinear reading thus facilitates deeper understanding of a text by giving the reader a practice through which they can temporally manipulate their experience with the work by adjusting the length of the text and, with it, their reading time. In contrast to the shortness of temporal performance Hull advocates in the Meditations, however, her Commentary demonstrates an alternative approach focused on lengthening text and 
time. Hull achieves this by taking a single verse, and on occasion a single word of one of the penitential psalms, and expounding on it at length. Thus Hull's commentary on verse 1 of Psalm 6 extends from folio $7 \mathrm{r}$ of the manuscript to f. $8 \mathrm{r}$, from lines 275 to 314 of the commentary. ${ }^{26}$ Hull derives this practice from the source she translates; in making it accessible to the reader of Middle English, her text exemplifies and performs temporal manipulation for readers in ways that extend their engagement with the text of the psalms. Explication becomes a temporal practice that influences readers' devotional experiences.

Such temporal manipulation further converges for readers of the Commentary through their awareness of Christian history, brought forth into the present by the texts of the psalms. This convergence is enhanced not by the work of the reader alone, but also by textual references to such history, as when the commentary for Psalm 6 discusses how the psalm reflects events from the life of David. Hull also provides encouragement that heightens still further how other types of participation may contribute to readers' understanding of the psalms, as for example when she leads into a discussion of Psalm 6:1 with, 'Then lete ous al crye as he dyd, Domine ne in furore tuo' (275). Readers may join in with the text more profoundly if they vocalize their reading, joining in with David himself and a virtual community of other readers engaged in the same act. In this way, temporal participation converges with readers' temporal perception of history to affect the readers' awareness of the relationship between moments of Christian history. ${ }^{27}$ Hull shapes her text in such a way as to encourage readers' expression of agency through temporal participation, and shapes that agency to produce a particular devotional effect of affective response, for temporal reading becomes a means for furthering affective response to the text through the encouragement of vocal reactions to reading the text. In this way, the reader's time converges with David's time through the unifying medium of the voice.

One further detail related to the Commentary deserves note for how it implicates the afterlife of the reading practices enjoined upon readers through their temporal apprehension of the text. Eleanor Hull is atypical both in her role as a woman translator writing in late-medieval England, and also because a probate copy survives of her will. She wrote the original copy in 1458, as the will states, 'with myn owne hande'. ${ }^{28}$ It thus authoritatively speaks to what Hull thought important to bequeath to others without the intermediating influence of another writer's composition of 
the document. Most relevantly, her will refers to several books in Hull's ownership. She bequeaths all of them to her spiritual director, Robert Housewife, an ordained priest and long-term friend of Hull's who lived nearby the abbey at Sopwell manor. She writes, 'Also I bequethe to my fader Housewyf my greet portous and my litel portous and my sauter... Also I bequethe my fader Husewyf my blue bible of Latyn' (203-4). Hull directs that a large breviary, a small breviary, a psalter, and a Latin bible be given to Housewife. Striking in their absences are references to Hull's Commentary or Meditations. Hull mentions these four books alone, and no other books, papers, or written documents of any kind. The absence is telling particularly given her gifts to Housewife, who in his role as friend and priest might be most interested in possessing copies of Hull's works on spirituality. The absence of any reference to written texts further suggests that, at the time of her death, Hull may not have owned a copy of the works she had translated several decades before. This absence of reference to surviving copies of Hull's works in her own possession casts an interesting light on how medieval writers may have viewed their literary output. While it may comment on the expense of paper and parchment exceeding what a writer might wish to spend simply to retain a copy of their work, it also suggests that writers may have focused less on retention and ownership of what was only beginning to be thought of as their intellectual, creative property, and more on the value of its circulating in copies that could be read by others.

Yet in considering Hull not only as a writer, but also as a reader, the will provides further insight about the application of the reading practices discussed here. That is, three of the four books Hull mentions - the breviaries and the psalter - collected the psalms as their centrepieces. Hull clearly harboured an ongoing and intense interest in reading the psalms. That Hull maintained multiple manuscripts collecting the psalms, but may not have retained a copy of her own translation of commentary on the psalms, suggests that maintaining a copy of the Commentary may also have been unnecessary to her not only as a writer, but also as a reader. If Hull's practice may be indicative of other readers' practices, then learning the lessons provided by the Commentary rendered continued ownership of a copy less necessary. In this light, reading the Commentary effectively entailed learning its matter so thoroughly that subsequent reading of the psalms in other contexts could evoke the lessons and give application to the practices taught by the Commentary. This point is further supported by the text 
itself, which does not restrict its explicative work to the texts of the psalms themselves. Indeed, matters like how a title functions are also explained. Such treatment of the role of titles suggests that Hull anticipated the work would be accessed by unsophisticated readers for whom the explication of the paratextual function of a title was new information. It also suggests that Hull expected readers would need this explanation because they would encounter psalms in other places bearing titles unaccompanied by explanation. In other words, readers of the Commentary were expected to read psalms again in other contexts, bringing to those subsequent acts of reading the lessons and practices modelled and guided by the Commentary. These lessons and practices include both the substance of the commentary, and also its practice of temporal performativity. Readers apprehending the psalms in other contexts could thus focus on them in ways that involved their now-practised manipulation of time, dwelling over and lengthening the experience of a text, and considering how the convergence of the psalms' many temporalities reminded readers of their place in history. Such convergences would also serve to remind readers about their place in Christian temporalities. These Christian temporalities look in the present moment always to the past in order to anticipate the future, and perceive time as both circular and linear, repeating and simultaneously always on the cusp of rupture through the expectation of linear history brought about by the Second Coming and Apocalypse.

Another mode of temporal participation emerges in the act of rereading. In his Ordinal of alchemy, Thomas Norton depicts his interest in reading practices when he threatens his readers with alienation from God should they change even 'oone sillable' of his text. ${ }^{29}$ Instead of changing the text, he explains, they should reread it: 'Therfore trust not to oon reding or twine, / But xx. tymes it wolde be ouer-sayne' (176-7). Re-engaging a work through rereading it invests and engages readers in a process of temporal extension. This extension of duration is not meditative or affective in its practice as that afforded by temporally reading the psalms in the ways described above, but intellectual. Norton emphasizes this function of reading temporally when he explains that his work 'conteynyth ful ponderose sentence' best understood by reading 'many bokis, \& then this with-alle' $(178,181)$. While Hull and the translator of the Pseudo-Augustinian soliloquies seem to have found rereading conducive to experiences of boredom and annoyance, Norton is not alone in encouraging rereading and thus 
encouraging temporal participation through re-engagement with a text. Similarly, while the majority of emendation invitations are located in prologues or otherwise near the beginning of a text, some are located near the end, which provokes rereading as a strategy of corrective reading. Corrective and temporal reading intersect in the practice of rereading, further nuancing the work of readers' participation.

The temporal performance of rereading is multiple and varied; it affects and is effected by readers in many and different ways. For example, reading performs temporal convergence. By rereading, the reader moves forward in interpreting the text while looking backward to passages already encountered, recalling in the present the knowledge gained through past reading. Readers thus, through rereading, create a personalized temporal experience. Furthermore, considering rereading in terms of temporal structure points to how rereading is, in a way, a participatory temporality of productive disruption: rereading disrupts linear engagement with a text by introducing knowledge gained through previous acts of reading, and relies on that knowledge to transform the reader's present engagement with the text. Temporal participation applied to rereading thus applies a kind of palimpsest effect to reading the text, in which the recollection of previous readings layer over each other and the present text. ${ }^{30}$ This palimpsestic experience of reading is not exclusive to rereading, however; it collects with it, as Norton points out, not simply a rereading of a single text from a single moment, but the application to a text of the 'many bokis' a reader has apprehended over many occasions. Commentaries of the psalms overlay subsequent readings of the psalms, and readers bring to the twentieth reading of the Ordinal of alchemy every insight gained over the previous nineteen readings, layered over and under and overlapping with any other reading accomplished between and since previous rereading. Such reading is simultaneously focused on memory and temporality, using memory as the vehicle through which multiple times of reading and the multiplicity of things learned converge in the present moment of reading, applied to the present text. Consequently, the temporality of rereading emerges as a productive process, deepening readers' understanding of the text, and contributing to the readers' intensive engagement with it.

Finally, temporal participation in late-medieval England whether enacted through manipulation, orientation, or rereading - provides readers with strategies for shaping their affective and 
intellectual responses to texts. Furthermore, temporal participation also invites consideration of the processes of historicizing the self through reading, in which reading provokes confrontation of multiple temporalities, such as the grand historical narrative of Christianity, but also with more private, local temporalities like those developed and experienced by individuals recalling their own histories as readers. At the same time, writers sought to shape temporal reading toward particular ends, thus contributing to the effort to educate England's growing audience of readers. Yet, even as writers sought to shape such reading experiences, and with them develop particular reading practices that built towards intensive engagement with texts, readers could nevertheless exercise their agency to counter such practices, or engage with a text by not reading it at all.

\section{Notes}

1 From the Dialogue, in Hoccleve's works: the minor poems, 11. 530-1.

2 Aron Gurevich, 'What is time', in Categories of medieval culture, translated by G. L. Campbell (London: Routledge and Kegan Paul, 1985), 93-152, at 102.

3 See for example the seminal and still-influential Jacques Le Goff, Time, work and culture in the Middle Ages, trans. by Arthur Goldhammer (Chicago and London: University of Chicago Press, 1980); Roger S. Wieck, Time sanctified: the book of hours in medieval art and life (New York: George Braziller, 1988); Simona Cohen, Transformations of time and temporality in medieval and renaissance art (Leiden and Boston: Brill, 2014).

4 See Raine Koskimaa, whose influential work on digital temporalities includes, 'Playing with time in digital fiction', International journal of transmedia literacy 1:1 (2015), 19-33; and 'Approaches to digital literature: temporal dynamics and cyborg authors', in Reading moving letters: digital literature in research and teaching, ed. Roberto Simanowski, Jörgen Schäfer, and Peter Gendolla (Bielefeld: Verlag, 2010), 129-44. For Genette's work on time and reading, see Narrative discourse: an essay in method, trans. Jane E. Lewin (Ithaca: Cornell University Press, 1983), where Genette discusses the difficulty of measuring the " duration" of a narrative to that of a story', which is a difficult endeavour 'for the simple reason that no one can measure the duration of a narrative. What we spontaneously call such can be nothing more ... than the time needed for reading; but it is too obvious that reading time varies according to particular circumstances, and that ... nothing here allows us to determine a "normal" speed of execution' (86). However, the inability to determine a 'normal' speed of 
reading did not stop late-medieval writers from seeking to manipulate it nevertheless, as will be discussed here.

5 Published in Electronic literature collection, vol. 1 (2006), ed. N. Katherine Hayles et al. http://collection.eliterature.org. For discussions of system time and reading time, see Markku Eskelinen, Cybertext poetics: the critical landscape of new media literary theory (New York and London: Continuum, 2012), at 135-6.

6 Ibid., 136. Eskelinen's work has shaped discourse on temporality in new media for years, and still reflects the pervasive influence of secondwave digital media criticism, which sought to distinguish the practices of new media as a rupture from previous practices.

7 Gervais, 'Is there a text on this screen?'; Silvio Gaggi, From text to hypertext: decentering the subject in fiction, film, the visual arts, and electronic media (Philadelphia: University of Pennsylvania Press, 1997); Landow, Hypertext 3.0.

8 See Appendix B for the full quotation.

9 Middle English Dictionary, 'abreggen', 2, https://quod.lib.umich. $\mathrm{edu} / \mathrm{m} / \mathrm{med} /, 2017$. The phrase can be translated into modern English as, 'These books of war-craft have been briefly gathered or shortly abridged from authoritative sources'.

10 Ibid., 34-5.

11 See Karen Elaine Smyth, Imaginings of time in Lydgate and Hoccleve's verse (Farnham: Ashgate, 2011).

12 Ibid., 'Approaches to digital literature', 137.

13 Richard Rolle of Hampole, English writings of Richard Rolle. Ed. Hope Emily Allen (Oxford: Clarendon Press, 1931), at 36.

14 Carolyn Dinshaw, How soon is now? Medieval texts, amateur readers, and the queerness of time (Durham, NC and London: Duke University Press, 2012).

15 Roseanna Cross argues that the different way time flows for Thomas in the fairy world compared to the human world represent heterochronias, a feature Thomas of Erceldoune shares with other romances. For Cross, heterochronias represent to readers how the natural world can be regarded from multiple perspectives. This treatment of temporality in the contrasting places of the poem, although not directly bearing on reading temporally, nevertheless contributes to how the poem repeatedly marks and depicts different layers of temporality. See " "Heterochronia" in Thomas of Erceldoune, Guingamor, "The Tale of King Herla,” and the story of Meriadoc', Neophilologus 92:1 (2008), 163-75.

16 All quotations here and following come from The romances and prophecies of Thomas of Erceldoune, ed. J. A. H. Murray, Early English Text Society OS 61 (London: N. Trübner, 1875), lines 1-4 and 16-17. Murray provides the text of the Thornton MS in parallel with three other versions. For a description of the contents of the Thornton 
MS, see Robert Thornton and his books: essays on the Lincoln and London Thornton manuscripts, ed. Susanna Fein and Michael Johnston (Woodbridge, UK: University of York Press, 2014).

17 Lines 25, 33ff.; I have regularized 'I' for Thornton's ' $\mathrm{j}$ '.

18 A. C. Spearing, Medieval autographies: the ' $I$ ' of the text (South Bend, IN: University of Notre Dame Press, 2012).

19 From Medieval English political writings, ed. James M. Dean (Kalamazoo, MI: Medieval Institute Publications, 1996), 9, lines 1 and 5-6.

20 Ibid., lines 325-33. Modernized, these lines read: 'Thomas, hearken to what I tell you: / When a tree root is dead, / The leaves then fade and wither away; / And it bears no fruit then, neither white nor red. / Of the Balliols' blood so shall it fall: / It shall be like a rotten tree; / The Comyns and the Barclays all, / The Russells, and the Friseals [Frasers] free / They shall all fade, and wither away'.

21 For a general orientation to the background of the Scottish Wars of Independence that form the primary subject matter of the queen's prophecies, see Michael Brown, The wars of Scotland, 1214-1371 (Edinburgh: Edinburgh University Press, 2004); Andy King and Michael A. Penman, eds, England and Scotland in the fourteenth century: new perspectives (Woodbridge, UK: Boydell, 2007); and Andy King and Claire Etty, England and Scotland, 1286-1603 (London: Palgrave, 2016).

22 Thomas of Erceldoune's prophecy, xxvff.

23 My use of 'rhizomatic' here follows development of the term in Deleuze and Guattari's $A$ thousand plateaus, referring to a non-hierarchical assemblage. The term has also been usefully explored in medieval studies in relation to manuscript studies, as providing an alternative to the traditional stemmatic view of manuscript relations; see Michael G. Sargent, 'Organic and cybernetic metaphors for manuscript relations: stemma-cladogram-rhizome-cloud', in The Pseudo-Bonaventuran lives of Christ, ed. Johnson and Westphall, 197-263.

24 For further discussion of Robert Thornton's interest in Thomas of Erceldoune's prophecy, see Lesley Ann Coote, Prophecy and public affairs in later medieval England (York: University of York Press, 2000), 183-6.

25 Quoted in Alexandra Barratt, 'Dame Eleanor Hull: the translator at work', Medium AEvum 72:2 (2003), 277-96, at 284, from folio 148r of Cambridge University Library MS Kk.1.6.

26 From The seven Psalms: a commentary on the penitential Psalms translated from French into English by Dame Eleanor Hull, ed. Alexandra Barratt. Early English Text Society 307 (Oxford: Oxford University Press, 1995).

27 For a discussion of the performativity of the penitential Psalms in Hull's and other versions, see Anne Sutherland, 'Performing the 
penitential Psalms in the Middle Ages', in Aspects of the performative in medieval culture, ed. Manuele Gragnolati and Almut Suerbaum (Berlin and New York: Walter de Gruyter, 2010), 15-38.

28 Text of the will is included in Barratt's edition of The seven Psalms, 203-4, at 203.

29 Thomas Norton, Ordinal of alchemy, 174. See Appendix A for the full passage in which Norton discourages corrective reading.

30 'Palimpsestic reading' is a concept developed by Inge Boer, who argues that analysis of palimpsestic reading helps identify stereotypes in contemporary French culture; see Disorienting vision: rereading stereotypes in French orientalist texts and images (Amsterdam and New York: Rodopi, 2004), 18-19. Although anachronistic in its application to contemporary society, the palimpsest metaphor seems particularly apt as a way of describing the effects of reading temporally in latemedieval England. It is also worth noting that explicit instructions in any reading practice can reflect stereotypes about its audience, as I note in Chapter 2. 


\section{Conclusion \\ Nonreading in late-medieval England}

Through emendation, nonlinear apprehension, materiality, and temporality, late-medieval readers in England enjoyed access to a diverse number of reading practices that invited and positioned their participation as central to the making of meaning. Suffusing these practices, medieval understandings of the body, of architecture, of mobility, and of space indicate a recognition of reading as an intellectual activity intensely physical, embodied in its practice. The materiality not only of the textual medium itself, but also of readers and the spaces they inhabited while reading, impacted reading experiences in profound ways.

In explicitly inviting, modelling, or discouraging such practices, writers considered what it meant to be a reader even as their understanding of what it meant to be a writer underwent change influenced by altering notions of their own authority and, eventually, the printing press. They determined that readers could indeed participate in the creation of meaning, and guided their audiences towards the types of reading practices that did not require formal university education or universal literacy. To the writers who elicited and modelled interactive, participatory reading practice, reading and writing were not only viewed as complementary activities; they were also activities that could involve the same work, the same practices, although different in scale. Both writers and readers engaged in emendation; writers relied on nonlinear reading to construct the structure of their works; they inserted themselves into the narratives they composed even as they invited readers' own participatory contributions. To be a reader in England of the late fourteenth to early sixteenth centuries was to be understood as acting like a writer.

In this context, it can be useful to Hoccleve's friend who, as discussed in the Introduction, prompts the addition of a moral to Hoccleve's translation of 'Jereslaus' Wife'. The friend can be 
situated firmly within the category of participatory reader, even as he contributed in a writerly way the moral to Hoccleve's poem. His participation with Hoccleve's texts involved interactions that shaped the final form of the work, and even motivated an addition to the work - but did not demonstrate the authority that had begun to characterize the identity of the writer. His additions were presented to Hoccleve, suggested to him, and accepted or rejected by Hoccleve as author. Hoccleve's Dialogue offers a compelling portrait of a participatory reader. Hoccleve shares an interest in such with many other writers of the time. In the words of Thomas Usk, who, writing in the late fourteenth century, exclaimed that he desired not simply a good reader, but 'coveite[d] and pray[ed for] a good book-amender, in correccion of wordes and sentence', ${ }^{1}$ the participatory reader could offer much that writers viewed as beneficial. Nevertheless, that particularly desirable type of reader necessitated training and accommodation in order to engage most productively with the writer's work. This training could start with activities as straightforward as assessing the metre of a line to judge whether any words might have been altered and, in their alteration, complicate the metre. Such readers needed both the encouragement to recognize themselves as capable of contributing to texts in transmission and interpretation, and the training that could make those contributions most effective. Writers, including Usk, Lydgate, Caxton, Hull, Skelton, and others, turned to participatory reading practices to facilitate the encouragement of this thoughtful, contributory reader.

Participation thus develops through discourse and reading practices as a fundamental aspect of the work of ideal readers, whom writers sought to encourage, train, and constrain. Readers could participate through how they negotiated texts; how they responded to them physically, intellectually, and emotionally; how they identified with a narrative or a character; how they related to the text's material qualities or its material surroundings; and how they related to them temporally. Further forms of participatory reading, such as question poems and other ludic works, and immersion such as that promoted in medieval devotional reading and experienced today when playing most video games, could also invite participation. ${ }^{2}$ Participatory practices, accordingly, fostered a literary culture of exchange and community. By emphasizing participatory reading strategies, writers encouraged readers, or subsets of their readers, to practice or enact particular responses. Such writers' interest in and reliance upon readers' participation cannot be 
understated in its consequences: 'The elicitation of readers' participation represents the work of readers as mattering. Participatory readers mattered because their work made a difference - to the text, to its interpretation, and even, sometimes, to the writer.

That readers' work mattered points to a significant change from the older discourse of the 'learned' and the 'lewid', the Latinate, literate, highly educated writers confronted by readers characterized by their ignorance of Latin, which ignorance betokened their scant claims to literacy. In the culture of the learned and the lewid, readers were perceived as scarcely able to participate with writers, let alone contribute in ways that mattered. This change, from that of the lewid vernacular reader whose contributions engendered little consideration, anticipation, or accommodation, to the participatory vernacular reader, speaks to how writers perceived the possibilities of their growing vernacular audience whose literacy practices were at the same time increasing in sophistication. As Katharine Breen has argued, writers from the twelfth century onwards sought to shape lay readership. ${ }^{3}$ Writers focused on how to inculcate amongst this audience ethical self-ordering, a project Breen sees as demonstrated most spectacularly in Piers Plowman. Yet the inculcation of a self-regulating framework did not suffice to address all the needs that, by the fifteenth century, writers viewed readers as facing. Nor did it address how writers began to see readers as offering valuable work complementary to their own. In consequence, participation emerges to flourish in discourse and practice. Focusing on participation thus underscores a concept of readers and reading in late-medieval England that treats readers as partners in the making of meaning. Recognizing readers as participatory partners thus enriches the portrait of late-medieval literary culture with which we engage. Even as it has become a given that late-medieval writers explored notions of authorship and authority that move them closer to the modern (and Romanticized) notion of the author as the sole creative force for a work, exploring participatory reading acts as a counter, for participatory reading practices demonstrate a collaborative model of meaning-making in which both writers and readers contribute to the creation and interpretation of literary works.

Nevertheless, not all writers viewed readers as able to respond with such positive contributions, or viewed readers as useful or desirable for their potential to provide such. Chaucer - who restricts encouragement of his texts' emendation to a closed audience, who elsewhere seems particularly fixed on enlarging the 
authority of the writer - offers intriguing counter-portraits of a different type of reader and a different type of reading. His portraits, illustrated in Troilus and Criseyde and the Prologue to the Wife of Bath's Tale, is that of the nonreader. Considering nonreading alongside the reading practices previously discussed shows how late-medieval attempts to shape reading represent, in some ways, repeated attempts to avoid flirting with futility. No matter what writers recommended to readers, and no matter how strenuously they sought to safeguard against undesirable reading practices, readers could nevertheless choose to act on the very agency that many writers desired to harness to their own ends. Readers could even read by choosing not to.

Addressing what readers might do and how they might relate to texts, the book historian Leah Price asks, what 'would it mean to study books without privileging reading?' For Price, one way to answer this question lies in considering what she calls the 'nonreading' work of books. Considering 'nonreading' is to examine not only reading, but how books were handled (in which something is done to the book) and circulated (in which something is done to other persons by means of the book). ${ }^{4}$ Price's concept of nonreading adds another angle to studying the history of the book and reading. The concept of nonreading also invites analysis that attends to the arguments of object-oriented ontology and new materialisms. As studying nonreading involves attending to the material nature of books, moments of nonreading demonstrate how the book as matter performs its own reading and its own narratives even as it interacts with humans and nonhumans alike, affecting their reading of and participation with a text.

In this context, two moments of participation figured around textual objects in Chaucer's works call for particular attention. As one of the examples focuses on a letter rather than the book, expanding Price's focus from the book to textual objects considered more broadly not only encompasses the examples discussed below, but also emphasizes how often reading experiences in medieval culture can be identified outside the covers of manuscripts through other engagements with textuality, from wall texts and subtleties to documents.

The first example of nonreading to consider comes from Troilus and Criseyde. Pandarus and Troilus have begun to collaborate in their efforts to persuade Criseyde to acknowledge and respond to Troilus's professed love for her, although Criseyde proves hesitant. Abandoned by her father who has left Troy to join the 
Greeks encamped outside its walls, Criseyde lives isolated from the nominal power structures of the city even as she also enjoys a degree of independence. The moment of nonreading develops when Pandarus passes the first letter from Troilus to Criseyde in Book II. In Price's terms, this moment falls into the category of nonreading circulation, in which the text object acts on a person. The events leading up to the letter exchange are also significant for our understanding the letter's eventual nonreading moment. Pandarus has previously informed Criseyde of Troilus's love for her and encouraged her to love him in return. He has also coached Troilus in his letter-writing skills, instructing him to beblot the letter with his tears. Troilus, having followed these instructions, kisses the letter. At that moment he acknowledges the letter as an agential object, saying, 'Lettre, a blisful destine / The shapyn is'. That is, Troilus views the letter as possessing the ability and power to enact change in 'Troilus's destiny.

The letter's moment of nonreading occurs when Pandarus conveys the letter to Criseyde. It is at this point when he hands it over that the situation becomes a little strained: as Chaucer writes, Pandarus meets with Criseyde in a garden with other people about, and there he, 'hente hire faste, / And in hire bosom the lettre down he thraste' (II.1154-5). He seizes Criseyde and thrusts the letter down the front of her dress. The language here is striking in its connotations - through 'hente' and 'thraste' - of violence. What this moment of nonreading demonstrates is how the letter acts as a textual object that does not simply stand in for or communicate Troilus's desire to form a relationship with Criseyde. Instead, it disquietingly exceeds that meaning through the language of seizure, assault, and injury that echoes through the letter's movement. Facilitated by Pandarus, the letter here asserts a violent, sexualized authority over Criseyde's body, acting not only as a communicative object and love-token, but as assailant. This work of the letter thus queers Criseyde's body as the two intermingle, destabilizing Criseyde's bodily privacy and independence. In this way, analysing the work of nonreading in this scene shows how the letter compromises Criseyde's bodily autonomy, thus undermining her earlier claim that 'I am myn owene womman' (II.750). This loss of autonomy elicits Criseyde's compliance to the demand of Pandarus that she read and respond to the letter. It represents a loss of autonomy further emphasized and extended by later events in the poem. It also represents reading gone awry, in which the rejection of reading proves as problematic as reading could also 
be. Consequently, nonreading demonstrates the dangerous possibilities of participation. Both reading and nonreading can provoke destabilization, suggesting that engaging with texts cannot always be relied upon as a benefit to readers.

The second example of nonreading comes from the Wife of Bath's prologue: that moment in which Alison, realizing that her fifth husband, Jankyn, will never cease to read to her from his book of wicked wives. She grabs the manuscript and, as she explains, 'Al sodeynly thre leves have I plyght / Out of his book' (790-1). She abruptly wrenches three pages from Jankyn's anti-feminist anthology. This moment of nonreading not only represents what Tom Shippey has referred to as an example of bibliophobia, but further distinguishes additional perspectives regarding human relationships to books. ${ }^{6}$ In ripping apart the book, Alison uses it as an object whose state speaks to and fuels her disagreement with her husband. Strained and disrupted, the book's material state represents the emotional and intellectual state of their marriage. In addition, reframing this moment of nonreading to examine it not from a human perspective, but from the perspective of the book, shows how the book has become a victim of their marital disputes: in effect, readers witness the victimization of the book. The blame for disturbing misogyny falls upon it first, and Alison responds to harm and silence it. This example of nonreading also demonstrates how nonreading functions as an act of resistance to instruction. How writers - and even other readers - wish readers to participate may not necessarily suit the interests or welfare of those readers. Nonreading provides a participatory counter-practice to participatory reading. In the practice of nonreading, the reader exerts independent agency to oppose and even defend herself against the imposition of others' agendas.

Furthermore, the body of the book acts as a surrogate for and prologue to the violence Alison immediately perpetrates upon Jankyn's body: just after she rips out the pages, she explains that she, 'with my fest so took hym on the cheke / That in oure fyr he fil bakward adoun' (792-3). Violence to the book's body prefigures violence to Jankyn's body. In its surrogate representation of violence, and in the way that the book engenders Alison's violent response, the book in a moment of nonreading also becomes weaponized. From it springs forth further violence. Both Troilus's letter and Jankyn's book demonstrate how textual objects can function not as objects of reading, but through the hands of nonreaders as agents of victimization, ones that threaten the integrity 
of Criseyde's and Jankyn's bodies. Nonreading demonstrates how it, too, can be an embodied practice. Even as reading can evoke and require the embodied participation of readers, nonreading can reflect on the embodied possibilities of texts themselves in their material forms. The work of reading, in its nonreading practice, is thus not restricted to the cognitive, intellectual realm alone. Perhaps most importantly, Chaucer's depictions of nonreading remind audiences of writers and readers in the Middle Ages and today that, as much as medieval writers might have desired to prompt particular types of reading practice, they had to recognize the effects of the agency of readers that they sought to utilize for their own ends: possessed of independent agency, readers could always disregard whatever guidance writers sought to offer them in order to read and use texts for their own ends.

Included in the category of nonreading practice is a host of other acts. In particular, readers who wrote their names in their books mark moments of nonreading. Nonreading is also marked by doodles drawn by readers in the margins and flyleaves. Many such examples of nonreading can be seen in the margins of University of Chicago MS 564, a copy of the Canterbury Tales. It is liberally adorned with the names of several owners, primarily from the sixteenth century. Such inscriptions of identity have been adduced both as evidence of ownership, and also as evidence of particular attachment to the text. ${ }^{7}$ However, in the act of inscribing a name, the person writing it does not read, but is involved in an act of nonreading. The signature thus displays a conspicuous moment in which the writer did not pay attention to the text.

Doodles can operate similarly. In the margin of MS 564, f. 37r, someone penned a doodle of an inquisitive, bearded face. Above it has been written, perhaps by the same person, 'Ryght worshepfull', as if testing a possible letter salutation. Margins of manuscripts were often favoured for this purpose. In Oxford, Bodleian MS Selden supra 53, a collection of Hoccleve's poems and Lydgate's Danse macabre, the figure of a happy man, waving, has been drawn in dry point opposite a stanza from Hoccleve's 'Complaint' on $\mathrm{f}$. $78 \mathrm{r}$, and numerous other skeletal faces in dry point appear on folios $54 \mathrm{r}, 73 \mathrm{r}$, and $97 \mathrm{r} .{ }^{8}$ In a mid-fifteenth-century copy of Lydgate's Fall of Princes, a reader turned the manuscript sideways to explore a possible letter salutation in its left margin, 'to $\wedge$ my moste very frynde in Rygarde and to' on f. $22 \mathrm{v}$, and later, on f. $45 \mathrm{r}$, partway through a description of the rule of the Israelite king Rehoboam, a reader has added in the bottom margin 'forget nott' above a set 
of entwined initials, which treats the book as a long-lasting monument recording what was presumably an affectionate relationship. ${ }^{9}$ Although it is possible that a person, searching for a writing surface, simply picked the manuscript up, turned to a random page, and penned their name, initials, or a drawing, it seems more likely that examples like these readers' marks emerge in moments when the manuscript initially had been employed for reading. Readers read with dry point or pen in hand, or pen and ink nearby, perhaps intending annotation. Instead, they elected to do something other than attend to the text. Perhaps distracted, perhaps thinking of other matters, perhaps even bored, a reader stopped reading. Yet this reader continued to use the book. However, the reader's use of it reflects a purpose other than reading. Such signatures, doodles, and marginalia ostentatiously mark moments when readers exerted their agency to escape the guidance of writers and instead pursue their own interests, leaving behind their own nonreading commentary.

In the hands of those nonreaders writing their names, texts were not in that moment of inscription sources of instruction. Instead, the object of the text provided a material vehicle for memory and identity. In the hands of doodlers, margins and flyleaves become spaces for play. Additionally, these moments of nonreading indicate how easily readers could turn their pens to other ends, how easily they could move between the role of ephemeral reader and the role - however mildly expressed - of contributor. In this role, they provided something to be read by later audiences, something that would compete with an author's words, even Chaucer's words, for the attention of subsequent readers. Acts of reading could also prompt resistant marginal commentary, as when John Shirley comments on Lydgate's misogyny in the Mumming at Windsor to exclaim, 'A daun Iohan, est y vray?', and the scribe of Lydgate's Fall of Princes in Harley 2251 disgruntledly addresses Lydgate in the margins, 'Be pees I bidde yow', 'Ye wil be shent', 'Ye haue no cause to say so', 'Ye gete yow to thank', and 'Be pees or I wil rende this leef out of your book', and then comments on the reactions of future readers when adding, 'There is no good woman that wil be wroth ne take no quarrel agenst this booke as I suppose' ${ }^{10}$ The book whose materiality is so necessary for corrective reading, whose organization prompts emotional and intellectual responses to the tales, whose temporalities elicit readers to situate themselves in particular historical or fictive moments, becomes also a space for readers to assert themselves, their individuality, and their 
responses. Such moments of nonreading and resistant reading marked by marginal commentary further contribute to readers' avenues for self-assertion and resistance. Such responses demonstrate the degree to which writers' attempts to guide and influence readers could represent flirtations with futility.

These responses additionally highlight how much more strictly controlled the seeming liberatory digital media of today can be. A reader of a web page can only click on links provided, or abandon it altogether. They can only alter the text of pages, or leave comments or notes behind, when those pages provide an interface specially designed to accept, record, and publish such remarks. In other words, the materiality of the manuscript and print book enabled responses from readers to be noted regardless of writers', scribes', or printers' plans, whereas it takes specialized design or add-on applications to enable readers to comment similarly on digital material, making the affordance of such participation part of or absent from a digital work's planned design. Yet both medieval writers and readers and those of today's digital media engage in exploring ways to relate to each other across the divide of time and space and community occasioned by the dissemination of texts to and beyond the writer's initial audience. Finally, examining these long histories of the book, and the long histories of reading embedded within books and related textual media, demonstrates how complex and easily overlooked can be the practice of reading itself. In the academy today, reluctance and hesitance often emerge around the subject of critical reading as questions about its nature and function continue to arise: What is critical? What does it entail? What does it privilege, and what does it obscure? What are its benefits? While exploring ways of answering these questions, it can be useful to keep in mind that these questions have been asked for hundreds of years, in periods that witnessed greater challenges facing literary reading, and literary culture, than those we confront today. Not too many years ago, the National Educational Association in a series of studies first concluded that 'Reading [was] at Risk', then discovered that 'Reading [was] on the Rise', a determination that was subsequently determined to represent a 'New Chapter in American Literacy'. ${ }^{11}$ This arc, from the disappearance of reading to the realization that it had not failed nor disappeared, but simply been practised in application to unfamiliar media, in unfamiliar places, and in unexpected ways, is one worth remembering when evaluating reading not simply today alone, but also in the late Middle Ages. 


\section{Notes}

1 Thomas Usk, The testament of love. Ed. Gary W. Shawver (Toronto: University of Toronto Press, 2002), at III.9.146-51.

2 See, for example, Kimberly Bell's essay, "Rounes to rede”: ludic reading games in the alliterative wheel of fortune poem Somer Sonenday', in Games and gaming in medieval literature, ed. Serina Patterson (New York: Palgrave, 2015), 169-86. Bell usefully summarizes key contributors to the discussion on literary games in offering a definition of literary games as 'played by willing participants (the reading and listening audience members) who engage in a contest with the author (a game of interpretation) to achieve a certain outcome (discovering the message of the poem)' (174). Although the study of literary games exceeds the scope of this project, it is worth emphasizing that the literary game depends centrally upon readers' participation. A literary game without a participating reader is incomplete, existing as a game only in potential. As with the forms of participation discussed here, to achieve a successful game requires readers to be guided towards particular actions or interpretations. Thus literary games also give rise to dependency on readers' agency that is in some way controlled or limited. For another approach to literary games that bridges the digital-literary divide, see Anastasia Salter, What is your quest? From adventure games to interactive books (Iowa City: University of Iowa Press, 2014) and Marie-Laure Ryan, Narrative as virtual reality: immersion and interactivity in literature and electronic media (Baltimore: Johns Hopkins University Press, 2003). As Betsy McCormick puts it in the 'Afterword: medieval ludens' to Games and gaming, ludic work - whether that of the video games, or a medieval game of chess - 'both affect[s] and reveal[s] culture' (215). As I have argued above and throughout, participatory work such as the reading practices assessed herein also affect and reveal culture. On immersion as participation, see Ryan above and also Alison McMahan, 'Immersion, engagement, and presence: a method for analyzing 3-D video games', in The video game theory reader, ed. Mark J. P. Wolf and Bernard Perron (New York and London: Routledge, 2003), 67-86.

3 Breen, Imagining an English reading public, 1150-1400.

4 Price, How to do things with books in Victorian Britain, 5.

5 Riverside Chaucer, ed. Benson, II.1091-2. All quotations from Chaucer that follow are drawn from this edition.

6 Tom Shippey, 'Bibliophobia: hatred of the book in the Middle Ages'. The Matthews memorial lectures for 1999. London: Birkbeck College, forthcoming, and available online at www.bbk.ac.uk/english/about-us/ bibliophobia-hatred-of-the-book-in-the-middle-ages .

7 See, for example, the discussions in Robert Babock et al., A book of her own: an exhibition of manuscripts and printed books in the Yale 
University Library that were owned by women before 1700 (New Haven: Beinecke Rare Book \& Manuscript Library, Yale University, 2005).

8 My thanks to Elon Lang, in whose dissertation Hoccleve and the poetics of reading (diss., Washington University in St. Louis. 2010), 146, I first learned about this manuscript in time to arrange my own viewing of it.

9 Chicago, Newberry Library Case MS 33.3.

10 Eleanor Prescott Hammond, 'A reproof to Lydgate', in Modern language notes 26:3 (1911), 74-6, at 75 .

11 These quotations are taken from the title of NEA publications about their reading surveys, available online at www.neabigread.org/publications.php. 


\section{Appendix A \\ Emendation invitations}

\begin{tabular}{llll} 
Date & Author & Title & Quote \\
\hline $1384-5$ & Thomas Usk & Testament of Love & $\begin{array}{l}\text { I desyre not only a good reder, but also I coveite and pray a good book-amender, in } \\
\text { correccion of wordes and of sentence; and only this mede I coveite for my travayle, that } \\
\text { every inseer and here of this leude fantasye devoute horisons and prayers to god the greet } \\
\text { juge yelden; and prayen for me in that wyse. (III.9.146-51) }\end{array}$ \\
& $\begin{array}{ll}\text { Geoffrey } \\
\text { Chaucer }\end{array}$ & Troilus and Criseyde & $\begin{array}{l}\text { For myne wordes, here and every part, } \\
\text { I speke hem alle under correccioun } \\
\text { Of yow, that feling han in loves art, } \\
\text { And putte it al in your discrecioun } \\
\text { To encrese or maken diminucioun } \\
\text { Of my langage, and that I yow bi-seche. }(3.1331-6)^{2}\end{array}$
\end{tabular}




\begin{tabular}{|c|c|c|c|}
\hline Date & Author & Title & Quote \\
\hline $1386-1400$ & $\begin{array}{l}\text { Geoffrey } \\
\text { Chaucer }\end{array}$ & $\begin{array}{l}\text { Canterbury Tales, } \\
\text { Prologue to the } \\
\text { Pardoner's Tale }\end{array}$ & $\begin{array}{l}\text { But nathelees, this meditacioun } \\
\text { I putte it ay under correccioun } \\
\text { Of clerkes, for I am nat textueel. } \\
\text { I take but the sentence, trusteth weel. } \\
\text { Therfore I make protestacioun } \\
\text { That I wol stande to correccioun. (X.55-60) } \\
\text { Yet pray I you that reden that I write, } \\
\text { Foryeve me, that I doo no diligence } \\
\text { This ilke story subtilly to endite. } \\
\text { For both have I the wordes and sentence } \\
\text { Of him, that at the seintes reverence } \\
\text { The story wroot, and folwen hir legende, } \\
\text { And pray yow that ye wol my werke amende. }{ }^{3}\end{array}$ \\
\hline 1389-1402 & $\begin{array}{l}\text { Anonymous } \\
\text { translator }\end{array}$ & $\begin{array}{l}\text { Chastising of God's } \\
\text { Children }\end{array}$ & $\begin{array}{l}\text { Of pis pistle now I make an ende, wip pankynges to god; and if I haue errid in my symple } \\
\text { writyng for ignoraunce or for defaute of feelyng, I commende me to } 30 u r e \text { preiers, and } \\
\text { loweli I submitte me to oper mennys correccions. }\end{array}$ \\
\hline $1390-3$ & John Gower & Confessio Amantis & $\begin{array}{l}\text { This bok, upon amendement } \\
\text { To stoned at his commandement, } \\
\text { With whom myn herte is of accord. }(90-2)^{5}\end{array}$ \\
\hline $1395-6$ & $\begin{array}{l}\text { Usually } \\
\text { attributed to } \\
\text { John Purvey }\end{array}$ & Wycliffite Bible & $\begin{array}{l}\text { I preie, for charité and for comoun profyt of Cristene soulis, that if ony wiys man fynde } \\
\text { ony defaute of the truthe of translacioun, let him sette in the trewe sentence and opin of } \\
\text { Holi Writ, but loke that he examyne truli his Latyn Bible, for no doute he shal fynde ful } \\
\text { manye Biblis in Latyn ful false, if he loke manie, nameli newe. And the comune Latyn } \\
\text { Biblis han more nede to be correctid, as manie as I have seen in my lif, than hath the } \\
\text { English Bible late translatid. }\end{array}$ \\
\hline
\end{tabular}


Date

Author

1400

Anonymous

Title

Pricke of Conscience

Quote

Bot I pray yhou alle, par charité,

Pat pis tretice wil here or se

Yhe haf me excused at bis tyme,

If yhe fynde defaut in pe ryme,

For I rek nought, pogh pe ryme be rude,

If be maters par-of be gude.

And if any man pat es clerk,

Can fynde any errour in pis werk,

I pray hym he do me pat favour,

Pat he wille amende pat errour;

For if men may here any errour se,

Or if any defaut in pis tretice be,

I make here a protestacion,

Pat I wil stand til be correccion

Of ilka rightwyse lered man,

Pat my defaut here correcte can. (9581-96)

1400-50 Anonymous Treatise of Perfection

translator of the Sons of God

$\begin{array}{lll}\text { 1400-50 } & \begin{array}{l}\text { Anonymous } \\ \text { Wycliffite }\end{array} & \begin{array}{l}\text { Glossed Gospel of } \\ \text { Matthew, BL Add. } \\ \text { translator }\end{array} \\ \end{array}$

I intend to transpose for myne owne lernynge a trettesse frome latyn into englysche, compiled bi dan john rusbroke, the first prior of the chartyrhowse in valle viridi iuxta bruxellam, whiche tretysse is called the tretesse of perfeccioun of the sonnys of god, that es to saye the grownde and the ledere vnto the trew trayse of perfeccioun. Wherfore 3 if ony man happen to rede it, or zit here it redde, whiche approbately can defete it, mekely I beseche pame to withedrawe the defawte and gyffe stede to the trwothe. ${ }^{8}$

If any lerid man in holy writ se bis glose, dispise he not it wiboute good examynacioun of olde origynals of doctourus, for pis scribeler hadde trauel wip false bokes to se manye and chese be bat beeste and clereste sentence acordynge wip holy wryt and resoun. If ony lerid man in holy writ fynde only defaute in pis glose, sette he in pe treupe and cler sentence of holy docturis, for pis is pe greet desire of pis pore scribeler. ${ }^{9}$ 


\begin{tabular}{|c|c|c|c|}
\hline Date & Author & Title & Quote \\
\hline c. 1408 & John Lydgate & Reson and Sensuallyte & $\begin{array}{l}\text { But who that of good dilligence } \\
\text { Lyst bysye him to don his cure } \\
\text { To sen and rede thys scripture, } \\
\text { And feleth fully the sentence, } \\
\text { Yif hee therin kan fynde offence, } \\
\text { My wille is this, that he observe } \\
\text { Me to repreve, as y desserve, } \\
\text { Besechinge him for to directe } \\
\text { Al that ys mys, and to correcte. }(32-40)^{10}\end{array}$ \\
\hline 1410 & $\begin{array}{l}\text { Edward of } \\
\text { Norwich }\end{array}$ & Master of Game & $\begin{array}{l}\text { I, 3oure oune in euery humble wyse, am me auenturyd to make thys symple boke, of } \\
\text { which y recommende and submitte to zoure noble and wyse correccioun; the weche boke } \\
\text { shall, yf hit leke to zoure forsayd lordshippe, be callyd Maistere of Game. }{ }^{11}\end{array}$ \\
\hline \multirow[t]{2}{*}{$\begin{array}{l}1410- \\
\text { before }\end{array}$} & John Walton & $\begin{array}{l}\text { Consolation of } \\
\text { Philosophy: Prefacio } \\
\text { Translatoris }\end{array}$ & $\begin{array}{l}\text { Insuffishaunce of cunnyng and of wit } \\
\text { Defaute of langage and of eloquence } \\
\text { Dis work from me schuld haue withholdyn 3it } \\
\text { Bot pat 3oure heste hap done me violence, } \\
\text { Pat nedes most I do my diligence } \\
\text { In thyng pat passeth myn abilite } \\
\text { Besekyng to zoure noble excellence } \\
\text { Pat be 3oure help it may amended be. (1-8) }\end{array}$ \\
\hline & & & $\begin{array}{l}\text { And euery lord or lady what ze be, } \\
\text { Or clerk pat likep for to rede pis, } \\
\text { Besekyng lawly wip humylite } \\
\text { Supporte where I haue seyde amys; } \\
\text { Correctep only pere pat nedful is, } \\
\text { If word or sentence be noght as it scholde. } \\
\text { My-self I am vnsuffishaunt I-wys } \\
\text { For if I couthe have bettre done I wolde. }(241-8)^{12}\end{array}$ \\
\hline
\end{tabular}




\begin{tabular}{|c|c|c|c|}
\hline Date & Author & Title & Quote \\
\hline c. 1411 & $\begin{array}{l}\text { Thomas } \\
\text { Hoccleve }\end{array}$ & Regiment of Princes & $\begin{array}{l}\text { I dreede at my maistir Massy, } \\
\text { Pat is of fructuous intelligence, } \\
\text { Whan he beholdith how vnconnyngly } \\
\text { My book is metrid, how raw my sentence } \\
\text { How feeble eek been my colours, his prudence } \\
\text { Shal sore encombrid been of my folie; } \\
\text { But yit trust I, pat his beneuolence } \\
\text { Compleyne wol myn insipience } \\
\text { Secreetly, \& what is mis, rectifie. }(10-18)^{13}\end{array}$ \\
\hline 1412 & $\begin{array}{l}\text { Andrew of } \\
\text { Wyntoun }\end{array}$ & Original Chronicle & $\begin{array}{l}\text { And set to pis I gif my will, } \\
\text { My wit I ken sa skant partill } \\
\text { That I drede saire pame till offend } \\
\text { That can me and my work amend, } \\
\text { Gif I writ ouper maire or lese, } \\
\text { Bot as pe story beris witnes... } \\
\text { Bot, lordis, gif youre curtasy } \\
\text { Forbeire me in pis ieperdy, } \\
\text { And fra thare breth wald me defend, } \\
\text { That can repreve and will nocht mend. }(33-8,47-50)^{14}\end{array}$ \\
\hline
\end{tabular}




$\begin{array}{lll}\text { Date Author } & \text { Title } & \text { Quote }\end{array}$

$1420 \quad$ John Lydgate Troy Book

Preynge to alle pat schal it rede or se,

Wher as I erre for to amenden me,

Of humble herte and lowe entencioun

Commyttyng al to her correccioun,

And ther-of thanke; my wille is bat bei wynne,

For thoruz her support pus I wil begynne. (P.379-84)

Lowly beseching to zour gentilnes,

Of mercy only, bope neze and ferre,

Where ze fynde pat I fayle or erre,

For to correcte, or ze ferper flitte,

For to zour grace I holy al commytte. (I.4432-6)

And al bat shal pis noble story rede

I be-seche of support and of grace,

Per I offende in any maner place,

Or wher-so-euere bat bei fynde errour,

Of gentilnesse to shewe bis fauour:

Benygnely for to done her peyne

To correcte, raper ban disdeyne.

For wel wot I moche ping is wrong,

Falsly metrid, bope of short \& long (V.3476-84) 
For in metring bou3 ber be ignoraunce,

zet in pe story 3 e may fynde plesaunce

Touching substaunce of [bat] myn auctour wryt.

And pouze so be pat any word myssit,

Amendith it, with chere debonaire;

For an errour to hyndren \& appaire,

Dat is nat seide of purpos nor malys,

It is no worshippe to hym bat is wys (V.3491-8)

At V.3504-10, Lydgate says that no one is so bold as he who is 'vnkonnyng' (3505) and no one so ready to 'vndir-take' (3508) as he who 'can no skyl on prose nor on vers' (3510). Lydgate then adds:

For vn-to hem my boke is nat directe,

But to swiche has hauen, in effect,

On symple folke ful compassioun,

Dat goodly can by correccioun

Amende a ping, \& hindre neuere-adel' (V.3513-16)

And in pis lond zif per any be,

In borwe or toun, village or cite,

bat konnyng hap his [Chaucer's] tracis for to swe,

Wher he go brood or be shet in mwe -

To hym I make a direccioun

Of pis boke to han inspeccioun,

Besechyng hem, with her prude loke,

To race $\&$ skrape poru3-oute al my boke,

Voide $\&$ adde wher hem semeth nede. (V.3531-9) ${ }^{15}$

1420-40 Anonymous Orcherd of Syon

If ony fruyt or heerbe be here myssett or plauntid, I commytte alle defautis or errouris to pe correccioun of betir lettrid clerkis $\&$ of trewe feelynge fadris. ${ }^{16}$ 


$\begin{array}{lll}\text { Date Author } & \text { Title Quote }\end{array}$

1420-50 Anonymous

Mirour of Our Lady

But for that I knowe myne owne feoblenes, as well in connyng as in verteu; therefore I will neyther seke defaulte in other, ne maynteyne myne owne; but lowely I submyt me and all oure wrytynges, and other werkes to the correccyon of oure mother holy

chyrche, \& of the prelates and fathers therof, and of all that are wyser and can fele better. Besechynge you all way mooste dere and deuoute systres to praye that bothe thys, and all other dedes be euer rewlyd to oure lordes worshyp. ${ }^{17}$

1420 - but John Lydgate Temple of Glas uncertain

James I
Kingis Quair
No go pi wai, bou litel rude boke,

To hir presence, as I pe comaund,

And first of al bou me recomavnd

Vnto hir \& to hir excellence,

And prai to hir bat it be noon offence,

If eny woorde in pe be myssaide,

Biseching hir she be not euel apaied;

For as hir list, I wil be efte correcte,

When bat hir likep againward be directe:

I mene pat benygne $\&$ goodli of face.

Nou go bi way \& put pe in hir grace. $(1394-1403)^{18}$

Go litill tretis nakit of eloquence,

Causing simplese and povertee to wit,

And pray the reder to have pacience

Of thy defaute and to supporten it,

Of his gudnese thy brukilnese to knytt,

And his tong for to reule and to stere,

That thy defautis helit may ben here. $(1360-6)^{19}$ 
Date

Author

Title

1424-8 John Lydgate

Danse Macabre
Quote

$\mathrm{O}$ ze my lordes / and maisters all in fere,

Of auenture / pat shal pis daunce rede

Lowly I preie / with al myn herte entere

To correcte / where as ze se nede;

ffor nouzt ellis / I axe for my mede

But goodly support / of this translacioun

And with fauour / to sowponaile drede

Benignely / in zour correccioun. $(665-72)^{20}$

1425-75 M. N. Translator's prologue

to Marguerite

Porete's Mirror of

Simple Souls

$1426 \quad$ John Lydgate

Pedigree of Henry

Wherefore I wole folewe pe sentence acordynge to pe matere, as ny3 as God wole ziue me grace, obeiynge me euere to pe correccioun of hooli chirche, preiynge goostli lyuers and clerkis bat bei wole fowchesaaf to correcte and amende pere bat I do amys. ${ }^{21}$

Yit shal I folow my maistre douteles,

Calot, and be not recheles

Liche his writyng my stiel to direct;

Wher I dar pray hem to correct,

I mene tho pat shall hit sene or rede. $(67-71)^{22}$

1426-8 Anonymous The Pilgrimage of the Life of Man
I schal not faille teuchyng the substaunce,

Thogh on makyng I ha no suffysaunce;

ffor my wrytyng, in conclusion,

ys al yseyd vnder correcion. (Prologue, 147-50) ${ }^{23}$ 


$\begin{array}{lll}\text { Date } & \text { Tuthor } & \text { Quote }\end{array}$

1438-9 John Lydgate Fall of Princes

I shal procede in this translacioun,

Fro me auoidyng all presumpcioun,

Lowli submyttyng eueri hour \& space

Mi reud language to my lordis grace. (438-41)

Yiff ought be wryte or seid to your plesaunce,

The thank be yove to your royal noblesse;

And wher I faylle, atwyteth ygnoraunce,

$\mathrm{Al}$ the diffautys aret to my rudnesse,

With this annexyd, requeryng of humblesse,

That alle thoo which shal this makyng rede,

For to correcte wher-as they se nede. (3373-9)

To alle thoo that shal this book be-holde,

I them be-seke to haue compassyoun,

And ther-with-al I prey hem that they wolde

Favoure the metre and do correccyoun. $(3394-7)^{24}$

1440

Translator's epilogue Good hope is reste and al yit shal amende

to Palladius on

Theron y treste And al this longe yeer

Husbandry

Of husbondrie in hast y thynke anende

The forme book is doon and Ianyueer

And lo my lord in honde hath ffeueryeer

Wul he correcte by what have y to done

He wul doon as a lord Thenne aftir heer

Asfaste y thynke on sette At Marchis mone (bk III) ${ }^{25}$ 
Date

Author

John Capgrave

1440

Life of St Norbert

1440-60

\section{Richard Roos}

La Belle Dame Sans Merci

c. 1447 John Russell

Boke of Nurture

1448

Thomas

Hoccleve

of York'

\section{Quote}

3e noble men, if bat ze list to race

Or rende my leuys pat I to zou write

ze may weel doo it; I schal zou neuyr wite.

In zoure correcioun put I pis matere

For I wil sewe \& translate pis story,

And wele I wote zoure hertis be so clere,

So ful of charite withouten trechery,

3e wil not put on me no vyleny,

But I deserue it, and pat schal I nowt,

As I hope, neythir in speche ne bowt. (lines 19-28) ${ }^{26}$

And specially, let this be thy prayere

Un-to hem all that thee wil rede or here,

Where thou art wrong, after their help to cal

Thee to corecte in any part or al. $(832-5)^{27}$

Go forthe lytelle boke, and lowly pow me commende

vnto alle yonge gentilmen / bat lust to lerne or entende,

and specially to pem pat han exsperience, praynge pe[m] to amende and correct pat is amysse, pere as y fawte or offende. $(1235-8)^{28}$

'Balade to My Lord If pat I in my wrytynge foleye,
As I do ofte (I can it nat withseye,

Meetrynge amis / or speke vnfittyngly,

Or nat by iust peys / my sentences weye,

And nat to the ordre of endytyng obeye,

And my colours sette ofte sythe awry,

With al myn herte wole I buxumly,

It to amende and to correcte, him preye;

For vndir his correccioun stande y. $(46-54)^{29}$ 


\begin{tabular}{|c|c|c|}
\hline Date & Author & Title \\
\hline 1449 & John Metham & Amoryus and Cleopes \\
\hline $1450-75$ & Anonymous & Courte of Sapyence \\
\hline $\begin{array}{l}1456 \\
\text { before }\end{array}$ & John Shirley & $\begin{array}{l}\text { Verse prologue later } \\
\text { copied by John Stow } \\
\text { into BL Additional } \\
29729\end{array}$ \\
\hline c. 1460 & $\begin{array}{l}\text { Scribe of } \\
\text { British Library } \\
\text { Royal MS } 18 \\
\text { D.II }\end{array}$ & Siege of Thebes \\
\hline
\end{tabular}

\section{Quote}

And the sempyl wryter besechyth off supportacion

For the rude endytyng of this story,

But euery word ys wrytyn vndyr correccion

Off them that laboure in this syens contynwally;

For fulle herd yt ys, I knowe yt veryly,

To plese the pepyl: but the sqwete frute schewyth the gentil tre,

And the mowth the hert; yt wyl none odyr be. $(50-6)^{30}$

And to whos presence my book shal atteyne,

His hastyf dome I pray hym modefye,

And not detraye, ne have it in dysdayne,

For I purpoos no makyng to dystayne.

Meke herte, good tonge, and spyryte pacyent -

Who hath these thre, my bok I hym present,

And as hym lyst lete hym detray or adde. $(58-64)^{31}$

Whan yt ye rede ther on or se

ffor than my trauayle it welbe sett

I aske of you no other dett

bot wher defaute is or ye blame

yt nenpayr ye auctors name

as for fayllinge of ye scripture

of ye meter or ortografyure

wouch saue it to correcte

elles of ye defaute am I suspecte

yt thorugh your supportacion

yow list to make correccion

sith to such craffte I am not vsed (64-75) ${ }^{32}$

Here begynneth the Segge of Thebes ful lamentably tolde by Iohn lidgate Monke of Bury anneyynge it to pe talls of Canterbury. (f. 148r) ) $^{33}$ 
1449 - but John Lydgate undated

1449 - but John Lydgate undated
'A Prayer to St Thomas of Canterbury'

1449 - but John Lydgate undated
'An Exhortation to Priests'

'Exposition of the Pater Noster'
Quakynge for fere, goo forth, litle Table,

Be not to bolde for noo presumpcioun

Toffir this martre, glorious and notable,

To shew thy c[1]auses, sauf of Deuocioun,

I them present with humble affeccioun,

Praynge echoon that shal thes seen or rede

Nat to disdeigne but doo Correccioun,

In hoop this martre shal help vs in our nede. $(113-20)^{34}$

Go, lityll byll, with all humylite

Pray holy prestes that have devocion

To syng ther masse, of there benyngnite

Off this dyte to have inspeccion,

Mekely compylede vnder correccion,

Dyrecte of hert, both to more \& lasse,

Of humble wyll \& no presumpcion,

To prestes dysposyd ech day to syng per masse. (lines 49-56) ${ }^{35}$

To alle my maystris knelyng on my kne

That shall reede this Compylacyoun,

I pray them meekly of ther benyngnyte

First dewly doon Examynacyoun,

And folwyng affter Iust correccyoun

When they haue leyser and convenable space,

That I may ffynde Supportacyoun

By goodly ffavour to correcte of ther grace. $(329-36)^{36}$ 


\section{Date}

Author

1449 - but John Lydgate

undated

'The Churl and the

Bird'

1449 - but John Lydgate undated

1449 - but John Lydgate undated

1449 - but John Lydgate undated

Margarete'

'The legend of St

\section{Quote}

Go, litel quaier, \& recomaunde me

Vn-to my maistir with humble affeccioun;

Beseche hym lowly, of mercy \& pite,

Of thi rude makyng to have compassioun;

And as touchyng thi translacioun

Out of the Frenssh, how-euyr the Englysh be,

All thyng is seide vndir correccioun

With supportacioun of your benygnyte. $(379-86)^{37}$

'The fifteen joys and

Go litil tretys! and meekly me excuse,

To alle tho that shal the seen or reede;

Giff any man thy rudenesse list accuse

Make no diffence, but with lowlyheed

Pray hym refourme, wher as he seeth neede;

To that entent I do the forth directe

Wher thu faylest, that men shal the correcte. $(309-15)^{38}$

'The legend of Seynte That I shulde considre welle and see

In Frensshe and Latyne thyn holy passyoun,

Thi martirdam and thi virginite,

And thereof make a compilacyoun;

So, as I cowde, vnter correccioun,

And vnter supporte of alle that shal it rede,

Vpon this storye thus I wylle procede. $(71-7)^{39}$ Austin at Compton

Go litil tretys, void of presumpcioun!

Prese nat to ferre, nor be nat to bold;

This labour stant undir Correccioun,

Of this myracle remembryd many fold,

In many shire and many Cite toold,

To you echon to whom I it directe,

By-cause I am of wittis dul and old,

Doth your deveer this processe to corecte. $(401-8)^{40}$ 


\begin{tabular}{|c|c|c|c|}
\hline Date & Author & Title & Quote \\
\hline $\begin{array}{l}1449-\text { but } \\
\text { undated }\end{array}$ & John Lydgate & $\begin{array}{l}\text { 'The virtues of the } \\
\text { Mass' }\end{array}$ & $\begin{array}{l}\text { Go lytyll tretyse, requyre the folk of grace } \\
\text { That shall of the haue inspeccion, } \\
\text { Be nat to bolde to appere in no place } \\
\text { Of malapertnesse nor presumpcion, } \\
\text { Thyne Auctor sympyll, though of affeccion } \\
\text { He meneth well, pray hem that shall the rede } \\
\text { With goodly support to do correccion } \\
\text { Thee to reforme where as they se nede. (lines } 657\end{array}$ \\
\hline $\begin{array}{l}1449-\text { but } \\
\text { undated }\end{array}$ & John Lydgate & Isopes Fabules & $\begin{array}{l}\text { And, yef I fall bycause of ignoraunce, } \\
\text { That I erre in my translacion, } \\
\text { Lowly of hert \& feypfull obeysaunce, } \\
\text { I me submyt to beyr correccion, } \\
\text { Of hem, pat haue more clere inspeccion } \\
\text { In matyrs, pat touche poetry, } \\
\text { Me to reforme pat pey nat deny. }(43-9)^{42}\end{array}$ \\
\hline $\begin{array}{l}1449-\text { but } \\
\text { undated }\end{array}$ & John Lydgate & Stans puer ad mensam & $\begin{array}{l}\text { Go, litel bille, bareyn of eloquence, } \\
\text { Praye yonge children that the shal see or Reede, } \\
\text { Thoughe thow be compendious of sentence, } \\
\text { Of thi clauses for to taken heede, } \\
\text { Whiche to al vertu shal theyr yowthe leede. } \\
\text { Of the writyng, thoughe ther be no date, } \\
\text { If ought be mysse,--worde, sillable, or dede, - } \\
\text { Put al the defaute vpon Iohne Lydegate. }(92-9)^{43}\end{array}$ \\
\hline 1463 & George Ashby & $\begin{array}{l}\text { 'A prisoner's } \\
\text { reflections' }\end{array}$ & $\begin{array}{l}\text { Also vndyr protestacion } \\
\text { That I will nat kepe presumptuosly } \\
\text { Any errour or feynyd opinion, } \\
\text { But me to theym conforme graciously, } \\
\text { That of hygh connyng haue plenteuously, } \\
\text { Besechyng theym my defaut to correct, } \\
\text { Yef any be, and nat to me hyt to arect. }(323-9)^{44}\end{array}$ \\
\hline
\end{tabular}




\begin{tabular}{|c|c|c|c|}
\hline Date & Author & Title & Quote \\
\hline 1463 & John Capgrave & Life of St Katherine & $\begin{array}{l}\text { After him [the original translator] next I take upon me } \\
\text { To translate this story and set it more pleyne, } \\
\text { Trostyng on other men that her charyté } \\
\text { Schall help me in this caas to wryght and to seyne. }(232-5)^{45}\end{array}$ \\
\hline 1474 & $\begin{array}{l}\text { William } \\
\text { Caxton }\end{array}$ & $\begin{array}{l}\text { The game and playe of } \\
\text { the chesse }\end{array}$ & $\begin{array}{l}\text { besechyng al them that this litel werke shal see, here, or rede to have me for excused for } \\
\text { the rude and symple makyng and reducyn into our Englisshe. And where as is defaute to } \\
\text { correcte and amende, and in so doyng they shal deserve meryte and thanke. And I shal } \\
\text { pray for them that God of His grete mercy shal rewarde them in His everlastyng blisse in } \\
\text { heven, to the whiche He brynge us, that wyth His precious blood redemed us. Amen. }\end{array}$ \\
\hline 1475 & Anonymous & Babees book & $\begin{array}{l}\text { Therfore I pray that no man Reprehende } \\
\text { This lytyl Book, the whiche for yow I make; } \\
\text { But where defaute ys, latte ylke man amende [...] } \\
\text { But ouere I passe, prayyng withe spyrit gladde } \\
\text { Of this labour that no wihte me detray, } \\
\text { But where to lytyl ys, latte him more adde, } \\
\text { And whenne to myche ys, latte him take away; } \\
\text { For thouhe I wolde, tyme wole that I no more say; } \\
\text { I leve therfore, And this Book I directe } \\
\text { To euery wihte that lyste yt to correcte. }(29-31,204-10)^{47}\end{array}$ \\
\hline 1475 & $\begin{array}{l}\text { William } \\
\text { Caxton }\end{array}$ & $\begin{array}{l}\text { Recuyell of the } \\
\text { historyes of Troye }\end{array}$ & $\begin{array}{l}\&[\mathrm{I}] \text { praye alle them that shall rede this sayd werke to correcte hyt } \& \text { to hold me excusid } \\
\text { of the rude \& symple translacion. }{ }^{48}\end{array}$ \\
\hline 1477 & $\begin{array}{l}\text { William } \\
\text { Caxton }\end{array}$ & $\begin{array}{l}\text { Dictes and sayengis of } \\
\text { the philosophres }\end{array}$ & $\begin{array}{l}\text { And so afterward I cam vnto my sayd lord \& told him how I had red \& seen his book } \\
\text { / And that he had don a meritory dede in the labour of the translacion therof in to our } \\
\text { englissh tunge / wherin he had deseruid a singuler lawde } \& \text { thanke etc. Thenne my sayd } \\
\text { lord desired me to ouersee it and wher as I sholde fynde faute to correcte it / wherin I } \\
\text { answerd vnto his lordship / that I coude not amende it / But if I sholde so presume I } \\
\text { might apaire it [.... ] And thus obeying hys request and commaundement I haue put me } \\
\text { in deuoyr to ouersee this hys sayd book [.... Y Y my sayd lord or ony other persone what } \\
\text { someuer he or she be that shal rede or here it / that If they be not wel plesyd wyth all that } \\
\text { they wyth a penne race it out or ellys rente the leef out of the booke. }{ }^{49}\end{array}$ \\
\hline
\end{tabular}


Date

Author

Title

1477 William

Caxton

c. 1477 Thomas

Norton

1477-8

William

Caxton

1480

William

Caxton

1480-98
John Skelton
Historie of Fason

Ordinal of alchemy

Humblie besekyng. ... all other that luste to rede or here it / to correcte where as they shalle finde defaulte. ${ }^{50}$

And that no man for better ne for wors

Change my writing, for drede of Goddis curs;

For where quyck sentence shal seme not to be,

pere may wise men fynd selcouth privyte;

And changing of som oone sillable

May make this boke vnprofitable.

Therfore trust not to oon reding or twine,

But xx. tymes it wolde be ouer-sayne;

For it conteynyth ful ponderose sentence,

Al be it that it fawte forme of eloquence.

But the best thing that ye do shalle

Is to rede many bokis, \& then this with-alle. $(170-81)^{51}$

Go lytil quayer / submytte you euery where

Vnder correction of benyuolence

And where enuye is / loke ye come not there. ${ }^{52}$

Mirrour of the world

Humbly requyryng alle them that shal fynde faulte, to correcte and amende where as they shal ony fynde, and of suche so founden that they repute not the blame on me, but on my copie whiche $i$ am charged to folowe. ${ }^{53}$

Besechynge you that shall it see or rede,

In every poynte to be indyfferente,

Syth all in substaunce of slumbrynge doth procede.

I wyll not saye it is mater in dede,

But yet oftyme suche dremes be founde trewe.

Now constrewe ye what is the resydewe. $(534-9)^{54}$ 


\begin{tabular}{|c|c|c|}
\hline Date & Author & Title \\
\hline $\begin{array}{l}1480 \text { s, } \\
\text { late? }\end{array}$ & $\begin{array}{l}\text { Robert } \\
\text { Henryson }\end{array}$ & Morall fabillis \\
\hline 1481 & $\begin{array}{l}\text { William } \\
\text { Caxton }\end{array}$ & Reynart the fox \\
\hline 1481 & $\begin{array}{l}\text { William } \\
\text { Caxton }\end{array}$ & Tullius of olde age \\
\hline 1482 & $\begin{array}{l}\text { William } \\
\text { Caxton }\end{array}$ & Polychronicon \\
\hline 1483 & $\begin{array}{l}\text { William } \\
\text { Caxton }\end{array}$ & Caton \\
\hline 1483 & $\begin{array}{l}\text { William } \\
\text { Caxton }\end{array}$ & Golden Legend \\
\hline
\end{tabular}

In hamelie language and in termes rude

Me neidis wryte, for quhy of eloquence

Nor rethorike, I neuer vnderstude.

Thairfoir meiklie I pray zour reuerence,

Gif 3 e find ocht that throw my negligence

Be deminute, or 3 it superfluous,

Correct it at 3our willis gratious. $(36-42)^{55}$

And yf ony thyng be said or wreton herin / that may greue or dysplease ony man / blame not me / but the foxe / for they be his wordes \& not myne / Prayeng alle them that shal see this lytyl treatis / to correcte and amende / Where they shal fynde faute / For I haue not added ne mynusshed but haue folowed as nyghe as I can my copye whiche was in dutche. ${ }^{56}$

$\&$ submyttyng me to the amendyng \& correction of the reder and vnderstonder / that is disposed to rede or haue ony contemplacion in thystoryes of this book ${ }^{57}$

And where as ther is fawte / I beseche them that shal rede it to correcte it / For yf I coude haue founden moo storyes / I wold haue sette in hit moo / but the substaunce that I can fynde and knowe I haue shortly sette hem in this book. to thentente that such thynges as haue ben done syth the deth or ende of the sayd boke of polycronycon shold be had in remembraunce and not putte in oblyuyon ne forgetynge / prayenge all them that shall see this symple werke to pardone me of my symple / and rude wrytynge .... Fynysshed per Caxton $^{58}$

And J requyre and byseche alle suche that fynde faute or errour / that of theyr charyte they correcte and amende hit / And J shalle hertely praye for them to Almyghty god / that he rewarde them. ${ }^{59}$

Besechyng alle theym that shall see or here it redde to pardone me where I haue erryd / or made fawte / whyche yf ony be / is of ygnoraunce and ageyn my wylle / and submytte it hooly of suche as can \& may to correcte it / humbly besechyng them so to doo / and in so doyng / they shal deserue a synguler lawde and meryte / \& I shal pray for them vnto almyghty god that he of his begygne grace reward them. ${ }^{60}$ 


\section{Date} Author

1484

William

Caxton

Title

The book of the knight of the tower

$1484 \quad$ William

Lyf of our lady

\section{Quote}

And alle other that be vnderstandyng \& fyndyng ony defaute / I requyre \& pray them of theyre charyte to correcte and amende hit / and so doyng they shall deserue thanke and meryte of god / to whome I shalle pray for them. ${ }^{61}$

Goo lityl book and submytte the

Vnto al them / that the shal rede

Or here / prayeng hem for charite

To pardon me of the rudehede

Of myn enpryntyng / not takyng hede

And yf ought be doon to theyr plesyng

Say they thyse balades folowyng.

[There follow two pairs of a Latin prayer in prose and English prayer in rhyme royal]. ${ }^{62}$

Also by Caxton in this book:

Besechyng al to haue pyte $\&$ routh

That therof shal haue ony Inspeccion

Yf oughte be lefte of necligens and slouthe

Or sayd to moche of presumpsion

I put hit mekely to hir correccion

And axe mercy of my trespace

There as I erre $\&$ put me in her grace

Euery makyng with his light distayne

In sothfastnes who so takyth hede

Wherfore no wonder though myn herte playne

Vpon his deth and for sorow blede

For want of hym now in my grete nede

That shold allas conueye and dyrecte

And with his supporte amende and correcte

The wronge traces of my rude penne

There as I erre and goo not lyne right

But that for he ne may me not kenne

I can nomore but with al my myght

With al myn herte \& myn Inward sight

Prayeth for hym that now lyeth in cheste

To god aboue to geue his sowle good reste 


\begin{tabular}{lll} 
Date & Author & Title \\
\hline 1484 & $\begin{array}{l}\text { William } \\
\text { Caxton }\end{array}$ & The royal book
\end{tabular}

1485

William Charles the grete

Caxton

maners

Caxton

Fayttes of armes

Caxton

William Eneydos

Caxton

\section{Quote}

Thenne I exhorte \& desyre euery mā that entendeth to the prouffyt \& seluacyon of his soule / to ouer see this sayd book / in whiche he shal fynde good \& prouffytable doctryne by which he may the rather attayne to come to euerlastyng blysse $\&$ alwaye what that is wryton is vnder correctyon of lerned men / humbly besechyng them to correcte \& amende where as is ony defaute. \& so doyng they shal doo a merytory dede. For as nyghe as god hath gyuen me connyng I haue folowed the copye as nyghe as I can. ${ }^{63}$

From the prologue:

I haue emprysed and concluded in my self to reduce this sayd book in to our englysshe / as all alonge and playnely ye may rede / here / and see in thys book here folowyng / besechyng al them that shal fynde faute in the same to correcte and amende it / And also to pardone me of the rude \& symble reducyng

From the epilogue:

I haue put me in deuoyr to translate thys sayd book as ye heretofore may se al a longe and playn / prayeng alle them that shal rede / see or here it / to pardon me of thys symple \& rude translacyon and reducyng / besechyng theym that shal fynde faute to correcte it / \& in so doyng they shal deserue thankynges / \& I shal praye god for them. ${ }^{64}$

Prayeng al them that shal rede $\&$ here it to correcte where as they fynde faulte and to holde me excused of the rude \& vnparfyght englysh. ${ }^{65}$

And where as I haue erryd or made defaulte I beseche them that fynde such to correcte it $\&$ so dooyng I shal praye for them. ${ }^{66}$

And Souerane lord pis werk I haue studiit and maid with gret laubour and submittis it to pe correccioun of pe halykyrk and me alsua / and to pe correccioun of pe kyrk of rome and all vthir / bat the correccioun of fautis pertinis to / bot I traist and it be correk writtin par is na herrecy na errour in it bot pe haly doctrine of ihesu and verite. ${ }^{67}$ Oxenford to ouersee and correcte this sayde booke. And taddresse and expowne where as shalle be founde faulte to theym that shall requyre it. [...] Then I praye hym \& suche other to correcte adde or mynysshe where as he or they shall fynde faulte / For I haue but folowed my copye in frenshe as nygh as me is possyble / And yf ony worde be sayd therin well / I am glad. and yf otherwyse I submytte my sayde boke to theyr correctyon. ${ }^{6}{ }^{8}$ 


\begin{tabular}{|c|c|c|c|}
\hline Date & Author & Title & Quote \\
\hline $1490 \mathrm{~s}$ & Anonymous & $\begin{array}{l}\text { The Digby } \\
\text { 'Conversion of St } \\
\text { Paul' }\end{array}$ & $\begin{array}{l}\text { Thus we comyte yow all to the Trynyte, } \\
\text { Conkludyng thys stacion as we can or may, } \\
\text { Vnder the correccyon of them that letteryd be; } \\
\text { How-be-yt vnable, as I dare speke or say, } \\
\text { The compyler here-of shuld translat veray } \\
\text { So holy a story, but with fauorable correccyon } \\
\text { Of my fauorable masters of ther benygne supplexion (353-9). }{ }^{69}\end{array}$ \\
\hline 1495 & $\begin{array}{l}\text { Wynkyn de } \\
\text { Worde }\end{array}$ & $\begin{array}{l}\text { Printer's prologue to } \\
\text { Trevisa's Policronicon }\end{array}$ & $\begin{array}{l}\text { Redyng of bokes / slouthe wyll ay forbarre } \\
\text { An sondry wyse / whiche gyue Instuccion } \\
\text { As dothe this boke / of Polycronycon } \\
\text { Whiche Roger Thorney Mercer / hath exhorted } \\
\text { Wynken de worde / of vertuous entent } \\
\text { Well to correcte / and greatly hym comforted } \\
\text { This specyall boke / to make and sette in prent } \\
\text { This is the grounde / of all that he hath ment } \\
\text { Reders to glade / and voyde al ydelnesse } \\
\text { Trustynge to please / bothe god and man I gesse. }{ }^{70}\end{array}$ \\
\hline 1500-1 & Gavin Douglas & Palais of honoure & $\begin{array}{l}\text { Breif burall quair, of eloquence all quyte, } \\
\text { With russet weid and sentence imperfyte, } \\
\text { Til cum in plane, se thow thow not pretend tha. } \\
\text { Thy barrant termis and thy vyle endyte } \\
\text { Sall not be min; I wyll not have the wyte. } \\
\text { For, as for me, I quytcleme that I kend tha. } \\
\text { Thow art bot stouth. Thyft lovys lycht but lyte. } \\
\text { Not worth a myte, pray ilk man till amend tha. } \\
\text { Fare on with syte! and on this wyse I end tha. }(2160-8)^{71}\end{array}$ \\
\hline
\end{tabular}


Vnder obedyence and the correccyon

Of you my maysters experte in connynge

I me submytte now with hole affeccyon

Vnto your perfyte vnderstondynge

As euer more mekely to you inclynynge

With dylygent laboure now without doutaunce

To detray or adde all at your plesaunce. (2926-33)

Vnto all poetes I do me excuse

Yf that I offende for lacke of scyence

This lytell boke yet do ye not refuse

Though it be deuoyde of famous eloquence

Adde or detray by your hye sapyence

And pardon me of my hye enterpryse

Whiche of late this fable dyde fayne and deuyse. $(5796-5802)^{72}$

1510-20 John Bourchier Arthur of Little (Lord Berners) Britain

$1513 \quad \begin{aligned} & \text { Henry } \\ & \text { Bradshaw }\end{aligned} \quad$ Life of St Radegund

I truste my symple reason hath ledde to the understandynge of the true sentence of the mater, accordinge to the whiche I have followed as nere as I coude, desyrynge all the reders and herers therof to take this my rude translacion in gre, and yf any faute be, to laye it to myn unconnynge and derke ignoraunce, and to mynysshe, adde or augment as they shall fynde cause requysyte. And in theyr so doynge I shall praye to God that after this vayne and transytory lyfe he may brynge them unto the perdurable joye of heven. ${ }^{73}$

Therfore I require / and pray you euerychone

That this litell treatyse shall reed or se

To accept my mynde with your discrecion

And it to correct after your charite

Amende the mater / where is necessite

For syth it is knowen / that I am no clarke. (64-9) $)^{74}$ 


\begin{tabular}{|c|c|c|c|}
\hline Date & Author & Title & Quote \\
\hline 1513 & $\begin{array}{l}\text { Henry } \\
\text { Bradshaw }\end{array}$ & Life of St Werburge & $\begin{array}{l}\text { With tremblynge penne / and hand full of drede } \\
\text { In termes rude translate nowe haue we } \\
\text { The noble historye of saynt Werburge in-dede, } \\
\text { Besekyng all them for their good humanite } \\
\text { Whiche this litel proces shall beholde and se, } \\
\text { For to adde and minisshe and cause reformacion } \\
\text { Where nede requireth after your discrecion. }(1978-84)^{75}\end{array}$ \\
\hline 1513 & $\begin{array}{l}\text { Richard } \\
\text { Fabyan }\end{array}$ & Chronicle & $\begin{array}{l}\text { Besechynge hym / that wyll so take the payne } \\
\text { Or any other / that lyste on this boke } \\
\text { Where any Errour / in this by hym is sayne } \\
\text { It to correct / and mende this rude boke } \\
\text { For by hym / that neuer yet / any ordre toke } \\
\text { Or gre of Scole / or sought for great cunnynyge } \\
\text { This werke is gaderyd / with small understandynge. }\end{array}$ \\
\hline 1518 & $\begin{array}{l}\text { Alexander } \\
\text { Barclay }\end{array}$ & Eclogues & $\begin{array}{l}\text { As I late turned olde bookes to and fro, } \\
\text { One litle treatise I founde among the mo: } \\
\text { Because that in youth I did compile the same, } \\
\text { Egloges of youth I did call it by name. } \\
\text { And seing some men haue in the same delite, } \\
\text { At their great instance I made the same perfite. } \\
\text { Adding and bating where I perceyued neede, } \\
\text { All them desiring which shall this treatise rede, } \\
\text { Not to be grieued with any playne sentence } \\
\text { Rudely conuayed for lacke of eloquence. }(73-82)^{77}\end{array}$ \\
\hline 1521 & Henry Pepwell & $\begin{array}{l}\text { Printer's verses on } \\
\text { the translation of } \\
\text { Christine de Pizan's } \\
\text { Book of the city of } \\
\text { ladies by Brian Anslay }\end{array}$ & $\begin{array}{l}\text { Prayenge his lordshyp / with others pat shall chaunce, } \\
\text { On it to rede / the fautes for to amende, } \\
\text { If ony be / for I do fayne intende, } \\
\text { Gladly to please, and wylfully remytte } \\
\text { This ordre rude / to them that have fresshe wytte. }(24-8)^{78}\end{array}$ \\
\hline
\end{tabular}




\section{Notes}

1 Usk, The testament of love.

2 Riverside Chaucer.

3 Riverside Chaucer. The first quote is from the Parson's Tale and the second from the Second Nun's Tale.

4 The chastising of God's children and the Treatise of perfection of the sons of god, ed. Joyce Bazire and Eric Colledge (Oxford: Basil Blackwell, 1957), p. 227, lines 24-7.

5 From The complete works of Fohn Gower, ed. G. C. Macaulay (Oxford: Clarendon Press, 1899-1902).

6 Josiah Forshall and Frederic Madden, eds, The Holy Bible, containing the Old and New Testaments, with the apocryphal books, in the earliest English versions made from the Latin Vulgate by Fohn Wycliffe and his followers, vol. 1 (Oxford: Oxford University Press, 1850), 13:277-83.

7 From The pricke of conscience (stimulus conscientiae), ed. Morris. Editors now consider the former attribution of The pricke of conscience to Richard Rolle to be mistaken.

8 The chastising of God's children, ed. Bazire and Colledge p. 229, lines 2-10.

9 Deansely, The Lollard Bible, 457.

10 Ernst Sieper, ed. Lydgate's Reason and sensuality. Early English Text Society (EETS) extra series (e. s.) 84 (London: Oxford University Press, 1901).

11 James I. McNelis, ed., The uncollated manuscripts of The Master of Game (Dissertation, University of Washington, 1996), 138.

12 Mark Science, ed. EETS original series (o. s.) 170 (London: Milford, 1927).

13 Regiment of Princes, ed. Furnivall.

14 The original chronicle of Andrew of Wyntoun, vol. 2: Wemyss MS. Ed. Frederick J. Amours. Scottish Text Series 1st ser. 53 (Edinburgh and London: Scottish Text Series, 1903-14).

15 Troy Book, ed. Bergen.

16 Ed. Hodgson and Liegey, 1.

17 From The myroure of oure ladye, 8-9.

18 Temple of Glas, ed. Josef Schick. EETS e. s. 60 (London: Kegan Paul, Trench, Trübner \& Co., 1891).

19 James I of Scotland, Stuart, Fames I of Scotland: the Kingis quair, ed. John Norton-Smith (Oxford: Clarendon Press, 1971).

20 From the 'Lenvoye de Translatour', in Eleanor Hammond, ed., English verse between Chaucer and Surrey (New York: Octagon, 1965$)$, $124-42$.

21 Marion Doiron, ed., “The Mirror of simple souls”: a Middle English translation', in Archivo italiano per la storia della pietà 5, ed. Romana Guarnieri (Roma: Edizioni di storia e letteratura, 1968), 241-355, at 249. Nicholas Watson has ably summarized the various arguments regarding the difficulty of dating the Middle English translation and its glosses by M. N.; see 'Melting into God the English way: deification in the Middle English Version of Marguerite Porete's Mirouer des simples âmes anienties', Prophets abroad: the reception of continental holy women in late-medieval England. Ed. Rosalynn Voaden (Cambridge: D. S. Brewer, 1996), $19-49$, at 33-32. The date range most frequently given is mid-fourteenth century.

22 MacCracken, vol. 1, 613-22.

23 The pilgrimage of the life of man, ed. Frederick J. Furnivall and K. B. Locock. EETS e.s. 77, 83, 92 (London: Kegan Paul, Trench, Trübner \& Co., 1899, 1901, 1904, repr. in one vol., 1973). Previously ascribed to Lydgate, the text is now viewed as the work of an anonymous writer.

24 Fall of princes, ed. Bergen. 
25 From Hammond, English verse, 202-6, at 206 (stanza B).

26 From The Life of St Norbert by fohn Capgrave.

27 In Frederick J. Furnivall, ed., Political, religious, and love poems, EETS o. s. 15 (London: Kegan Paul, Trench and Trübner \& Co., 1866 ; revol. ed. 1903 ), 80-111.

28 In Early English meals and manners, ed. Frederick J. Furnivall, 1-123.

29 In Hoccleve's works: the minor poems, ed. Furnivall and Gollancz.

30 John Metham, The works of Fohn Metham, including the romance of Amoryus and Cleopes, ed. Hardin Craig. EETS o. s. 132 (London: K. Paul, Trench, Trübner \& Co., 1916), 1-81.

31 The court of sapience, ed. E. Ruth Harvey (Toronto: University of Toronto Press, 1984).

32 Transcribed by Connolly in fohn Shirley: book production, 208-11.

33 Axel Erdman and Eilert Ekwall, eds, Fohn Lydgate's Siege of Thebes, vol. 2. EETS e. s. 125 (London: Kegan Paul, Trench, Trübner \& Co., 1930 ), 52.

34 The minor poems of $\mathcal{F}$ ohn Lydgate: part II, secular poems, ed. MacCracken, 140-3.

35 Ibid., 84-86.

36 Ibid., 60-71.

37 The minor poems of Fohn Lydgate: part I, religious poems, ed. Henry MacCracken. EETS e. s. 107 (Oxford: Oxford University Press, 1911 ), $468-85$.

38 Minor poems of Fohn Lydgate: part II, ed. MacCracken, 268-79.

39 Ibid., 173-92.

40 Ibid., 193-206.

41 Ibid., 87-115.

42 Ibid., 566-99.

43 In Early English meals and manners, ed. Furnivall, 26-33, at 32.

44 George Ashby's poems edited from two 15 ${ }^{\text {th }}$ century mss. at Cambridge, ed. Mary Bateson. EETS e. s. 76 (London: Kegan Paul, 1899$)$, 1-12, at 11.

45 The life of Saint Katherine, ed. Karen A. Winstead (Kalamazoo, MI: Medieval Institute Publications, 1999).

46 Preface to The game and playe of the chesse, ed. Jenny Adams (Kalamazoo, MI: Medieval Institute Publications, 2009).

47 Early English meals and manners, 1-9, at 2 and 8.

48 The prologues and epilogues of William Caxton, ed. Crotch, 5.

49 Ibid., 18, 20, 30. From the first (1477) edition of the Dictes; the second and third editions include the same material with minor variations of phrasing.

50 Ibid., 34 .

51 Norton, Ordinal of alchemy, ed. Reidy.

52 Caxton's Book of curtesye, ed. Frederick J. Furnivall. EETS e. s. 3 (London: N. Trübner, 1868), 53.

53 Mirrour of the world, ed. Oliver H. Prior. EETS e. s. 110 (London: Kegan Paul, Trench, Trübner \& Co., 1913 ), 7.

54 The complete English poems, ed. John Scattergood (New Haven and London: Yale University Press, 1983).

55 From The poems of Robert Henryson, ed. Fox, 3-110, at 4.

56 The prologues and epilogues of William Caxton, ed. Crotch, 62.

57 Ibid., 42

58 Ranulf Higden, Prolicionycion, trans. William Caxton. STC 13438 (Westminster: William Caxton, 1482), colophon. 
59 The prologues and epilogues of William Caxton, ed. Crotch, 78.

60 Ibid., 73

61 The book of the knight of the tower, ed. Margaret Y. Offord. EETS special series (s.s.) 2 (Oxford: Oxford University Press, 1971), 4.

62 The prologues and epilogues of William Caxton, 85.

63 William Caxton, trans., This book was compyled [and] made atte requeste of kyng Phelyp of Fraunce ... whyche book is callyd in frensshe. le liure Royal, STC 21429 (Westminster: William Caxton, 1485 or 6), aii verso.

64 Ibid., 96, 98

65 Ibid., 100.

66 Ibid., 104.

67 Meroure of wyssdome, vol. 3, ed. Craig McDonald. Scottish Text Society, no. 19 (Aberdeen: Aberdeen University Press, 1990$), 165$.

68 The prologues and epilogues of William Caxton, 109-10.

69 The Digby plays, with an incomplete 'Morality' of Wisdom, who is Christ, ed. Frederick J. Furnivall. EETS e.s. 70 (London: Kegan Paul, Trench, Trübner \& Co., 1896).

70 John Trevisa, Polychronicon, ed. Wynkyn de Worde. STC 13439 (London: Wynkyn de Worde, 1495), f. A1v.

71 The shorter poems of Gavin Douglas, ed. Priscilla J. Bawcutt (Edinburgh: Scottish Text Society, 2003).

72 The pastime of pleasure, ed. William Edward Mead, EETS o. s. 173 (London: Oxford University Press, 1928).

73 Arthur of Brytayn. STC 807 (London: William Copland, 1560), f. ir. This is the second edition; the first, which does not survive, was published $c$. 1534

74 The lyfe of Saynt Radegunde, 2nd ed. STC 3507 (London: Richard Pynson, 1525), f. aiiiir.

75 The life of Saint Werburge of Chester by Henry Bradshaw, ed. Carl Horstman (London: Trübner \& Co., 1887).

76 Newe cronycles of Englande and of Fraunce, 2nd ed. STC 10659 (London: Richard Pynson, 1516). f. aiiv.

77 The Egloges of Alexander Barclay, ed. Beatrice White, EETS o. s. 175 (London: Early English Text Society, 1928).

78 Christine de Pizan, The boke of the cyte of ladyes. Trans. Brian Anslay. STC 7271. (London: Henry Pepwell, 1521)f. Aaiiij. 


\section{Appendix B \\ References to nonlinearity in Middle English literature}

\begin{tabular}{|c|c|c|c|}
\hline Date & Author & Title & Quote \\
\hline $1225-40$ & & Ancrene wisse & $\begin{array}{l}\text { Nu, mine leove sustren, this boc ich todeale on eahte destinctiuns thet ye cleopieth } \\
\text { 'dalen'. Ant euch withute monglunge speketh al bi him-seolf of sunderliche thinges, ant } \\
\text { thah euch-an riht falleth efter other, ant is the leatere eaver i-teiet to the earre. }(131-3)^{1}\end{array}$ \\
\hline $1370-89$ & & $\begin{array}{l}\text { The Cloud of } \\
\text { unknowing }\end{array}$ & $\begin{array}{l}\text { For parauenture per is som mater per-inne, in pe beginnyng or in pe middes, pe whiche } \\
\text { is hanging \& not fully declarid pere as it stondep. Bot } 3 \text { if it be not pere, it is sone after, } \\
\text { or elles in pe eende. \& pus } 3 \text { if a man sawe o partye } \& \text { not anoper, parauenture he schuld } \\
\text { liztly be led into errour. }(130)^{2}\end{array}$ \\
\hline $1386-99$ & $\begin{array}{l}\text { Geoffrey } \\
\text { Chaucer }\end{array}$ & $\begin{array}{l}\text { The Canterbury Tales, } \\
\text { Miller's Tale }\end{array}$ & Turne over the leef and chese another tale. (I.3177) ${ }^{3}$ \\
\hline $1390-1420$ & & $\begin{array}{l}\text { Pseudo-Augustinian } \\
\text { soliloquies }\end{array}$ & $\begin{array}{l}\text { Ne the schalle not entende that he rede eche of hem alle over, but as muche as he may } \\
\text { or kan goostly feele; or so muche that he may throughli Goddes grace and helpe avayle, } \\
\text { and inflawme his affeccions to prayer or to swete meditacions; or els as moche as for the } \\
\text { tyme may be delyte hym to stere his soule to the love of God. Ne allwey it is not nede to } \\
\text { begynne at the begynnyng, but where it plesith hym best. And therfor every chapeter is } \\
\text { distincte wyth paraphes, that where it lyketh hym he may begynne and also ende, ne lest } \\
\text { often repeticion of one thing schulde make hevenesse. }(62)^{4}\end{array}$ \\
\hline
\end{tabular}


1400-49 Wycliffite biblical concordance

Nicholas Love Mirror of the blessed life of Jesus Christ

Mirror to devout people
Speculum devotorum
If a man haue mynde oonly of oo word or two of sum long text of be newe lawe and hab forzetyn al pe remenaunt, or ellis if he can seie bi herte such an hool text but he hap forzeten in what stede it is writen, pis concordaunce wole lede him bi be fewe wordis pat ben confrid in his mynde vnto pe ful text, and shewe him in what book and in what chapitre he shal fynde po textis which him list to haue. $(234)^{5}$

And first we shole vndirstande $\&$ haue in mynde, pe processe of pe nekst chapitre before pis. $(128)^{6}$

And I haue sett pe tytles of [be chapeters] in a table eftre pis prefacioun of pe booke pat who so euer liketh to rede it may see shortly ther all be matier of be booke folowyng, and rede when him lyketh beste. And pat he maye pe sonner fynde pat he desireth moste and be better kepe hit in mynde and also be redyer fynde hit if him luste to see hit azen.

Noghtwythstondyng hit were be beste who so myght haue tyme and laysere to rede hit all as hit is sett. $(170)^{7}$

For I have dyvydyd the boke folowynge in thre and thyrthy chapetelys to the worschype of the thre and thryty yere that oure Savyoure lyvyde in erther; and I have sette the tytyllys of hem alle in a tabyl aftyr thys prefacyon afore the boke that hosoevere lykyth to rede hyt maye see schortly there alle the matere of the boke folowynge and rede where hym lykyth best, and that he mygthte the sonnyr fynde that he desyrth moste, and the bettyr kepe hyt in mynde, and also redylokyr fynde hyt yf hym lyste to see hyt agen; notwythstondyne hyt were best, hoso mygth have tyme and laysyr therto, to rede hyt alle as hyt ys sette. (Preface, lines $10-18)^{8}$ 
This orcherd by Goddis grace my wil is to deuyde into seuene parties and ech party into fyue chapitres, as 3 e mowe se and rede in pe kalender folowynge.

In pis orcherd, whanne ze wolen be comforted, ze mowe walke and se bope fruyt and herbis. And albeit pat sum fruyt or herbis seeme to summe scharpe, hard, or bitter, 3 it to purgynge of pe soule bei ben ful speedful and profitable, whanne bei ben discreetly take and resceyued by counceil. Therefore, religiouse sustren, in pis goostli orcherd at resonable tyme ordeyned, I wole bat 3 e disporte $3 o u$ and walke aboute where 3 e wolen wip zoure mynde \& resoun, in what aleye 3 ou lyke, [and] namely bere 3 e savouren best as ze ben disposid. 3 e mowe chese if 3 e wole of xxxv aleyes where 3 e wolen walke, bat is to seye of xxxv chapitres, o tyme in oon, anopir tyme in anopir. (1) ${ }^{9}$

1427-36 Eleanor Hull Meditations upon the seven days of the week

1430-56 John Shirley
Nere it nedyth allweys to begyn at euery tyme at the begynnyng hereof, but per as hym best lykyth and hath most devocyon

to rede. $(16-19)^{10}$

A verse prologue to a $\mathrm{O}$ ye my lordes whan ye be holde / this boke or list it to vnfould / or ye ze leues turne to manuscript anthology rede / looke this calender and than proced. $(208)^{11}$

copied by Shirley

\section{Notes}

1 Ancrene wisse, ed. Robert Hasenfratz (Kalamazoo, MI: Medieval Institute Publications, 2000). Recommends against nonlinear reading.

2 The cloud of unknowing and the book of privy counselling, ed. Phyllis Hodgson. Early English Text Series o.s. 218 (Oxford: Oxford University Press, 1944). Recommends against nonlinear reading.

3 Riverside Chaucer.

4 Quoted in Hirsch, The revelations of Margery Kempe.

5 Quoted in Anne Hudson, The premature Reformation: Wycliffite texts and Lollard history (Oxford and New York: Clarendon Press, 1988).

6 Nicholas Love's Mirror of the blessed life of Fesus Christ, ed. Michael G. Sargent. Garland Medieval Texts 18 (New York: Garland, 1992).

7 Quoted in Gillespie, 'The haunted text', 129-72, from University of Notre Dame MS 67, f. 1r.

8 Quoted in Browne et al., eds, The Idea of the Vernacular, 73-37, at 74.

9 The Orcherd of Syon, ed. Hodgson and Liegey.

10 Quoted in Sheila H. Conard, The first edition of the Middle English translation in Cambridge University Library MS. Kk.i.6 (Dissertation, University of Cincinnati. Ann Arbor: ProQuest/UMI, 1995).

11 Quoted in Connolly, Fohn Shirley: book production. 


\title{
Appendix C \\ Percy family wall texts: first lines and locations
}

\author{
ff. 195v-: Dialogue between the 'parte sensatyue' and the 'parte intellectyue' on the vanity \\ 197v of human delights: \\ First line: 'The sermountynge pleasure who can expresse'. \\ Last: 'When all other thynge is vanite / That is not vayne'. \\ This dialogue was located in 'the garett over the bayne at kekingfelde'.
}

ff. 198r- Verses treating musical instruments as metaphors for a well-ordered, virtuous life:

$199 \mathrm{v} \quad$ First line: 'When the philosophers putagoras and tuball'.

Last: 'In heuyn we shall synge Osanna in excelsis'.

These verses were located in the 'garet at the New lodge in the parke of lekinfelde'.

f. 200r Tudor-Percy emblem (verso left blank)

ff. $201 \mathrm{r}-$ Proverbs on hope:

202r First lines: 'ESperaunce en dyeu. [/] Trust hym he is moste trewe'.

Last: 'Be thou contente and thou art aboue fortunes fall'.

These proverbs were located 'in the rooffe of the hyest chawmbre in the gardinge at lekingfelde'.

ff. $202 \mathrm{r}-$ An address to youth on the necessity of learning:

204r First line: 'HE that made this hous for contemplacioun'

Last line: 'ffor his faithfull goode mynde towards youths goode gouernaunce'

This address was located 'in the rouf of my lorde Percy closett at Lekyngfelde'. 
ff. $204 \mathrm{v}-$ A form of living:

205v First line: 'DRede god. and fle from syn'.

Last line: 'Leve well \& fere not hardely'.

These verses were located 'in the roufe of my lordis library at Lekyngefelde'.

ff. $205 \mathrm{v}-$ Advice of Aristotle to Alexander: ${ }^{1}$

206v First line: 'APPly to the best gyftis geuen to the'.

Last line: 'Thy name shalbe Immortall vnto the worldes ende'.

This advice to princes was located 'in the syde of the garet of the gardynge in Lekyngfelde'.

ff. 207r- Selections from Benedict Burgh's 'Cato Major':

209r First line: 'When it is tyme of coste and greate expense'.

Last line: 'A swete carnell of wysdam and of goode sentens'.

This Middle English translation of the Distichs was located 'in the sydis of the Innere chamber abouen of the house in the garding at Wresill'.

ff. 209r- Additional counsel of Aristotle to Alexander:

209v First line: 'PVnyshe moderately and dyscretly correcte'

Last line: 'Then shall ye do right and not offende your conscience'.

These verses were located 'in the syde of the vtter chamber above of the house in the gardynge at Wresyll'.

ff. 210r- Proverbs advising how to live an upright life:

211v First line: 'REmorde thyne ey Inwordly'

Last line: 'They whiche be goode of reason will incline'.

These proverbs were located 'in the syde of thutter chamber aboue of the hous in the gardyng at Wresyll'.

\section{Notes}

1 The Secretum secretorum tradition preserved the legend of Aristotle's education of Alexander; see Lydgate and Burgh (1894), Cary (1956), and Bunt (1994). 


\section{Bibliography}

\section{Manuscripts}

Antwerp, Museé Plantin-Moretus MS 16. 14

Cambridge, Trinity College R. 3. 21

Chicago, University of Chicago MS 564

Chicago, Newberry Library Case MS 33. 3

Dublin, Trinity College MS 516

Lincoln, Lincoln Cathedral Library MS 91

London, British Library MS Add. 10036

London, British Library MS Add. 36523

London, British Library MS Royal 18.D.ii

Longleat, Warminster, Marquis of Bath MS 257

New York, Morgan Library and Museum MS M. 898

Oxford, Bodleian MS Selden Supra 53

\section{Primary sources}

Ancrene Wisse. Ed. Robert Hasenfratz. Kalamazoo, MI: Medieval Institute Publications, 2000.

Andrew of Wynton. The original chronicle of Andrew of Wyntoun. Vol 2: Wemyss MS. Ed. Frederick J. Amours. Scottish Text Series $1^{\text {st }}$ ser. 53. Edinburgh and London: Scottish Text Series, 1903-14.

Ashby, George. George Ashby's poems edited from two 15th century mss. at Cambridge. Ed. Mary Bateson. Early English Text Society (EETS) extra series (e. s.) 76. London: Kegan Paul, 1899.

Barclay, Alexander. The Egloges of Alexander Barclay. Ed. Beatrice White. EETS original series (o. s.) 175. London: Early English Text Society, 1928.

Bell, Kimberly. "'Rounes to rede": ludic reading games in the alliterative wheel of fortune poem Somer Sonenday'. Games and gaming in medieval literature. Ed. Serina Patterson. New York: Palgrave, 2015. 169-186.

Bourchier, John Lord Berners. Arthur of Brytayn. $2^{\text {nd }}$ ed. STC 807. London: William Copland, 1560.

Bradshaw, Henry. The life of Saint Werburge of Chester by Henry Bradshaw. Ed. Carl Horstman. EETS o. s. 88. London: Trübner \& Co., 1887. 
- The lyfe of Saynt Radegunde. $2^{\text {nd }}$ ed. STC 3507. London: Richard Pynson, 1525.

Capgrave, John. The life of Saint Katherine. Ed. Karen A. Winstead. Kalamazoo, MI: Medieval Institute Publications, 1999.

—. The life of St. Norbert by Fohn Capgrave, ed. by Cyril Lawrence Smetana. Toronto: Pontifical Institute of Mediaeval Studies, 1977.

Cavendish, George. The life and death of Cardinal Wolsey. Ed. R. S. Sylvester. EETS 243. London: Oxford University Press, 1959.

Caxton, William. The book of the knight of the tower. Ed. Margaret Y. Offord. EETS special series (s. s.) 2. Oxford: Oxford University Press, 1971.

—. Caxton's Book of curtesye. Ed. Frederick J. Furnivall. EETS e. s. 3. London: N. Trübner, 1868.

- The game and playe of the chesse. Ed. Jenny Adams. Kalamazoo, MI: Medieval Institute Publications, 2009.

- Mirrour of the world. Ed. Oliver H. Prior. EETS e. s. 110. London: Kegan Paul, Trench, Trübner \& Co., 1913.

—. The prologues and epilogues of William Caxton. EETS 176. Ed. W. J.

B. Crotch. London: Oxford University Press, 1928.

- This book was compyled [and] made atte requeste of kyng Phelyp of Fraunce ... whyche book is callyd in frensshe. le liure Royal. STC 21429. Westminster: William Caxton, 1485 or 1486.

The chastising of God's children and the treatise of perfection of the sons ofGod. Ed. Joyce Bazire and Eric Colledge. Oxford: Basil Blackwell, 1957.

Chaucer, Geoffrey. Riverside Chaucer. $3^{\text {rd }}$ edition. Ed. Larry Benson. New York: Houghton Mifflin, 1987.

A chronicle of London: from 1089 to 1483 . Ed. Nicholas Harris Nicolas and Edward Tyrrell. London: Longman, Rees, Orme, Brown, and Green, 1827.

Church of England. The boke of the common praier. STC 16271. Worcester: John Oswen, 1549.

Clay, John William, ed. Yorkshire Royalist Composition Papers: Or, the Proceedings of the Committee for Compounding with Delinquents During the Commonwealth, vol. 3. Cambridge: Cambridge University Library. 1893, repr. 2013.

The cloud of unknowing and the book of privy counselling. Ed. Phyllis Hodgson. EETS o. s. 218. Oxford: Oxford University Press, 1944.

The court of sapience. Ed. E. Ruth Harvey. Toronto: University of Toronto Press, 1984.

The dance of death. Ed. Florence Warren and Beatrice White. EETS 181. London: Oxford University Press, 1931.

The Digby plays, with an incomplete 'Morality' of Wisdom, who is Christ. Ed. Frederick J. Furnivall. EETS e. s. 70. London: Kegan Paul, Trench, Trübner \& Co., 1896. 
Douglas, Gavin. The shorter poems of Gavin Douglas. Ed. Priscilla J. Bawcutt. Edinburgh: Scottish Text Society, 2003.

Fabyan, Richard. Newe cronycles of Englande and of Fraunce. $2^{\text {nd }}$ ed. STC 10659. London: Richard Pynson, 1516.

Gower, John. The complete works of Fohn Gower. Ed. G. C. Macaulay. Oxford: Clarendon Press, 1899-1902.

Hawes, Stephen. The pastime of pleasure. Ed. William Edward Mead. EETS o. s. 173. London: Oxford University Press, 1928.

Henryson, Robert. The poems of Robert Henryson. Ed. Denton Fox. Oxford: Clarendon Press, 1981.

Higden, Ranulf. Prolicionycion. Trans. William Caxton. STC 13438. Westminster: William Caxton, 1482.

Hoccleve, Thomas. Hoccleve's works: the minor poems. Ed. Frederick Furnivall and I. Gollancz. EETS e. s. 61, 73. Revised by Jerome Mitchell and A. I Doyle. London and New York: Oxford University Press, 1970.

—. Regiment of Princes. Ed. Frederick J. Furnivall. EETS e. s. 72. London: K. Paul, Trench, Trübner \& Co., 1897.

The Holy Bible, containing the Old and New Testaments, with the apocryphal books, in the earliest English versions made from the Latin Vulgate by Fohn Wycliffe and his followers. Vol 1. Ed. Josiah Forshall and Frederic Madden. Oxford: Oxford University Press, 1850.

Hull, Eleanor. The seven Psalms: a commentary on the penitential Psalms translated from French into English by Dame Eleanor Hull. Ed. Alexandra Barratt. EETS 307. Oxford: Oxford University Press, 1995.

Ireland, John. Meroure of wyssdome, vol. 3. Ed. Craig McDonald. Scottish Text Society, no. 19. Aberdeen: Aberdeen University Press, 1990.

Leland, John. Itinerary of Fohn Leland the antiquary, vol. 1. $3^{\text {rd }}$ ed. Ed. Thomas Hearne. Oxford: James Fletcher, 1768.

Love, Nicholas. Nicholas Love's Mirror of the blessed life of Fesus Christ. Ed. Michael G. Sargent. Garland Medieval Texts 18. New York: Garland, 1992.

Lydgate, John. Fall of princes. Ed. Henry Bergen. EETS e. s. 121-4. London: Oxford University Press, 1924-7.

—. Lydgate's Reason and sensuality. Ed. Ernst Sieper. EETS e. s. 84. London: Oxford University Press, 1901.

- Lydgate's Siege of Thebes part II. Ed. Axel Erdmann and Eilert Ekwall. EETS e. s. 125. London: Kegan Paul, Trench, Trübner \& Co., 1930 .

—. The minor poems of Fohn Lydgate: part I, religious poems. Ed. Henry MacCracken. EETS o. s. 107. Oxford: Oxford University Press, 1911.

—. The minor poems of Fohn Lydgate: part II, secular poems. Ed. Henry MacCracken. EETS o. s. 192. Oxford: Oxford University Press, 1934. - The pilgrimage of the life of man. Ed. Frederick J. Furnivall and K. B. Locock. EETS e. s. 77, 83, 92. London: Kegan Paul, Trench, Trübner \& Co., 1899, 1901, 1904, repr. in one vol., 1973. 
—. Temple of glas. Ed. Josef Schick. EETS e. s. 60. London: Kegan Paul, Trench, Trübner \& Co., 1891.

—. Troy Book. Ed. Henry Bergen. EETS e. s. 97, 103, 106, 126. London: Kegan Paul, Trench and Trübner \& Co., 1906-35.

Lydgate, John, and Benedict Burgh. Lydgate and Burgh's Secrees of Philisoffres: A Version of the 'Secreta Secretorum'. Edited by Robert Steele. EETS e. s. 66. London: Kegan Paul, Trench, Trübner \& Co., 1894.

Metham, John. The works of Fohn Metham, including the romance of Amoryus and Cleopes. Ed. Hardin Craig. EETS o. s. 132. London: K. Paul, Trench, Trübner \& Co., 1916, 1-81.

The myroure of oure ladye. Ed. John Henry Blunt. EETS e. s. 19. London: N. Trübner \& Co., 1873, repr. 1998.

Norton, Thomas. Ordinal of alchemy. Ed. John Reidy. EETS o. s. 272. London: Oxford University Press, 1975.

The Orcherd of Syon. Ed. Phyllis Hodgson and Gabriel M. Liegey. EETS o. s. 258. London: Oxford University Press, 1966.

Percy, Henry Algernon. The regulations and establishment of the household of Henry Algernon Percy, the fifth earl of Northumberland at his castles of Wresill and Lekinfield in Yorkshire, begun Anno Domini MDXII. London: William Pickering, 1827.

Pizan, Christine de. The boke of the cyte of ladyes. Trans. Brian Anslay. STC 7271. London: Henry Pepwell, 1521.

Porete, Marguerite. “"The mirror of simple souls”: a Middle English Translation'. Ed. Marion Doiron. Archivo italiano per la storia della pietà 5. Ed. Romana Guarnieri. Roma: Edizioni di storia e letteratura, 1968. 241-355.

The pricke of conscience (stimulus conscientiae): a Northumbrian poem by Richard Rolle de Hampole. Ed. Richard Morris. Berlin: A. Asher, 1863.

Richard Rolle of Hampole. English writings of Richard Rolle. Ed. Hope Emily Allen. Oxford: Clarendon Press, 1931.

The romances and prophecies of Thomas of Erceldoune. Ed. J. A. H. Murray, EETS o. s. 61. London: N. Trübner, 1875.

Roos, Richard. 'La Belle Dame Sans Merci'. Political, religious, and love poems. Ed. Frederick J. Furnivall. EETS o. s. 15. London: Kegan Paul, Trench and Trübner \& Co., 1866; rev. ed. 1903. 80-111.

Russell, John. 'Boke of nuture'. Early English meals and manners. Ed. Frederick J. Furnivall. E. E. T. S. o. s. 32. London: N. Trübner, 1931. $1-123$.

Sandford, Francis. The history of the coronation of the most high, most mighty, and most excellent monarch, Fames II. Wing S652. London: 1687.

Skelton, John. The complete English poems. Ed. John Scattergood. New Haven and London: Yale University Press, 1983.

Stuart, James I of Scotland. Fames I of Scotland: the Kingis quair. Ed. John Norton-Smith. Oxford: Clarendon Press, 1971. 
Thomas of Kent. The Anglo-Norman 'Alexander' ('Le Roman de toute chevalerie') by Thomas of Kent. Ed. Brian Foster, with the assistance of Ian Short. 2 vols, Anglo-Norman Text Society 29-33. London: AngloNorman Text Society, 1976-7.

Titus and Vespasian or, the destruction of Ferusalem. Ed. J. A. Herbert. London: Roxburghe Club, 1905.

Trevisa, John. Polychronicon. Ed. Wynkyn de Worde. STC 13439. London: Wynkyn de Worde, 1495.

Usk, Thomas. The testament of love. Ed. Gary W. Shawver. Toronto: University of Toronto Press, 2002.

Walter of Chatillon. The Alexandreis. Trans. David Townsend. Toronto: Broadview Editions, 2007.

Walton, John. Consolation of Philosophy. Ed. Mark Science. EETS o. s. 170. London: Milford, 1927.

'Wisdom'. Early English drama: an anthology. Ed. John C. Codewey. New York and London: Garland Publishing, 1993.

\section{Secondary sources}

Aarseth, Espin. Cybertext: perspectives on ergodic literature. Baltimore: Johns Hopkins University Press, 1997.

—. 'Nonlinearity and literary theory'. Hyper/text/theory. Ed. George Landow. Baltimore: Johns Hopkins University Press, 1994. $51-86$.

Adamson, Melitta Weiss. Food in medieval times. Westport, CT: Greenwood Press, 2004.

Akbari, Susanne. Seeing through the veil: optical theory and medieval allegory. Toronto: University of Toronto Press, 2004.

Alpers, Paul. 'Mode in narrative poetry'. To tell a story: narrative theory and practice. Ed. Robert M. Adams. Los Angeles: William Andrews Clark Library, 1973. 25-56.

Amsler, Mark. Affective literacies: writing and multilingualism in the late Middle Ages. Turnhout: Brepols, 2011.

—. 'Affective literacy: gestures of reading in the later Middle Ages'. Essays in Medieval Studies 18 (2001). 83-110.

Appleford, Amy. 'The dance of death in London: John Carpenter, John Lydgate, and the Daunce of Poulys'. Fournal of Medieval and Early Modern Studies 38:2 (2008). 285-314.

- Learning to die in London, 1380-1540. Philadelphia: University of Pennsylvania Press, 2015.

Arnold, Ellen F. Negotiating the landscape: environment and monastic identity in the medieval Ardennes. Philadelphia: University of Pennsylvania Press, 2011.

Babock, Robert et al., A Book of her own: an exhibition of manuscripts and printed books in the Yale University Library that were owned by women 
before 1700. New Haven: Beinecke Rare Book \& Manuscript Library, Yale University, 2005.

Barratt, Alexandra. 'Dame Eleanor Hull: the translator at work'. Medium AEvum 72:2 (2003). 277-96.

Barron, Caroline M., and Marie-Hélène Rousseau, 'Cathedral, city and state, 1300-1540'. St Paul's: the cathedral church of London, 604-2004. New Haven and London: Yale University Press, 2004.

Beckwith, Sarah. Signifying God: social relation and symbolic act in the York Corpus Christi plays. Chicago: University of Chicago Press, 2001.

Beebe, Kathryne. 'Reading mental pilgrimage in context: the imaginary pilgrims and real travels of Felix Fabri's "Die Sionpilger." Essays in Medieval Studies 25 (2008). 39-70.

Benson, C. David, and Barry A. Windeatt. 'The manuscript glosses to Chaucer's Troilus and Criseyde'. Chaucer Review 25.1 (1990). 33-53.

Birenbaum, Maija. 'Affective vengeance in Titus and Vespasian'. Chaucer Review 43:3 (2009). 330-44.

Boer, Inge. Disorienting vision: rereading stereotypes in French orientalist texts and images. Amsterdam and New York: Rodopi, 2004.

Boffey, Julia. 'Annotation in some manuscripts of Troilus and Criseyde'. English manuscript Studies 5 (1995). 1-17.

- 'From manuscript to print: continuity and change'. A companion to the early printed book in Britain, 1476-1558. Ed. Vincent Gillespie and Susan Powell. Woodbridge, UK, and Rochester: Boydell and Brewer, 2014. 13-26.

Bowers, John M. Chaucer and Langland: the antagonizing tradition. South Bend, IN: University of Notre Dame Press, 2007.

—. 'The tale of Beryn and The siege of Thebes: alternative ideas of The Canterbury Tales'. Writing after Chaucer: Essential readings in Chaucer and the fifteenth century. Ed. Daniel Pinti. New York: Garland, 1998. 201-25.

Brantley, Jessica. Reading in the wilderness: private devotion and public performance in late medieval England. Chicago: University of Chicago Press, 2007.

Breen, Katharine. Imagining an English reading public, 1150-1400. Cambridge: Cambridge University Press, 2013.

Brown, Matthew P. The Pilgrim and the bee: reading rituals and book culture in early New England. Philadelphia: University of Pennsylvania Press, 2007.

—. 'The thick style: steady sellers, textual aesthetics, and early modern devotional reading'. PMLA 121:1 (2006). 67-86.

—. 'Undisciplined reading'. Common-Place 8:1 (October 2007). Online at http://common-place.org/vol-08/no-01/reading/. Accessed 29 Oct. 2017.

Brown, Michael. The wars of Scotland, 1214-1371. Edinburgh: Edinburgh University Press, 2004. 
Bryan, Jennifer. Looking inward: devotional reading and the private self in late medieval England. Philadelphia: University of Pennsylvania Press, 2007.

Bühler, Carl F. 'The new Morgan manuscript of Titus and Vespasian'. PMLA 76:1 (1961). 20-4.

Bunt, Gerrit H. V. Alexander the Great in the Literature of Medieval Britain. Groningen: Egbert Forsten, 1994.

Burke, Bernard. The historic lands of England, vol. 2. London: E. Churton, 1849.

Byeong-Young Cho, and Lindsay Woodward. 'New demands of reading in the mobile Internet Age'. Mobile pedagogy and perspectives on teaching and learning. Ed. Douglas McConatha et al. Hershey, PA: IGI Global, 2014.

Bynum, Carolyn Walker. Christian materiality: an essay on religion in late medieval Europe. New York: Zone Books, 2011.

Camille, Michael. 'Sensations of the page: imaging technologies and medieval illuminated manuscripts'. The iconic page in manuscript, print, and digital culture. Ed. George Bornstein and Theresa Tinkle. Ann Arbor: University of Michigan Press, 1998. 33-53.

Carr, Nicholas. The shallows: what the internet is doing to our brains. New York: W. W. Norton, 2011.

Carruthers, Mary. The book of memory: memory in medieval culture. $2^{\text {nd }} \mathrm{ed}$. Cambridge: Cambridge University Press, 2008.

- The craft of thought: meditation, rhetoric, and the making of images, 400-1200. Cambridge: Cambridge University Press, 1998.

Cary, George. The Medieval Alexander. Cambridge: Cambridge University Press, 1956.

Chaganti, Seeta. 'Danse macabre and the virtual churchyard'. postmedieval 3:1 (2012): 7-26.

Charney, Davida. 'The effect of hypertext on processes of reading and writing'. Literacy and computers: the complications of teaching and learning with technology. Ed. Cynthia L. Selfe and Susan Hilligoss. New York: Modern Language Association of America, 1994. 238-63.

Chun, Wendy Hui Kyong. Control and freedom: power and paranoia in the age of fiber optics. Cambridge, MA: MIT Press, 2005.

Clark, Andy. Natural-born cyborgs: minds, technologies, and the future of human intelligence. New York: Oxford University Press, 2003.

Clark, Robert L. A., and Pamela Sheingorn. 'Performative reading: experiencing through the poet's body in Guillaume de Digulleville's Pelerinage de Jhesucrist'. Cultural performances in medieval France: essays in honor of Nancy Freeman Regalado. Ed. Eglal Doss-Quinby, Roberta L. Krueger, and E. Jane Burns. Rochester: Brewer, 2007. 135-51.

—. 'Performative reading: the illustrated manuscripts of Arnoul Greban's Mystere de la Passion'. European Medieval Drama 6 (2002): 129-54. 
"Visible words": gesture and performance in the miniatures of BNF, MS FR. 819-20'. Parisian confraternity drama of the fourteenth century: the Miracles de Nostre Dame par personages. Ed. Donald Maddox and Sara Sturm-Maddox. Medieval texts and cultures of northern Europe 22. Turnhout: Brepols, 2008. 193-217.

Cohen, Dan. 'The social contract of scholarly publishing'. Debates in the digital humanities. Ed. Matthew K. Gold. Minneapolis and London: University of Minnesota Press, 2012, 319-21.

Cohen, Jeffrey Jerome. Medieval identity machines. Minneapolis: University of Minnesota Press, 2003.

- Stone: An ecology of the inhuman. Minneapolis: University of Minnesota Press, 2015.

Cohen, Jeffrey Jerome, and Lowell Duckert, eds. Ecomaterialism. Special issue of postmedieval 4:1 (March 2013).

Cohen, Kathleen. Metamorphosis of a death symbol: the transi tomb in the late Middle Ages and the Renaissance. Berkeley: University of California Press, 1973.

Cohen, Sande. 'Publication, knowledge, merit: on some politics of editing'. Cultural critique 75 (Spring 2010). 114-47.

Cohen, Simona. Transformations of time and temporality in medieval and renaissance art. Leiden and Boston: Brill, 2014.

Cohn, Samuel K., Jr. Popular protest in late medieval English towns. Cambridge: Cambridge University Press, 2013.

Conard, Sheila H. The first edition of the Middle English translation in Cambridge University Library MS. Kk. i. 6. Dissertation, University of Cincinnati. Ann Arbor: ProQuest/UMI, 1995.

Connolly, Margaret. Fohn Shirley: book production in the noble household in fifteenth-century England. Aldershot, UK and Brookfield, VT: Ashgate, 1998.

Cooper, Lisa H., and Andrea Denny-Brown, eds. Lydgate matters: poetry and material culture in the fifteenth century. New York and London: Palgrave, 2008.

Coote, Lesley Ann. Prophecy and public affairs in later medieval England. York: University of York Press, 2000.

Coover, Robert. 'The End of Books'. The New York Times Book Review (June 21, 1992). 11, 23-25.

—. 'Literary hypertext: the passing of the Golden Age'. Keynote Address. Digital Arts and Culture. Atlanta, GA. October 29, 1999. Online at http://nickm. com/vox/golden_age.html. Accessed 29 Oct. 2017.

Cover, Rob. 'Audience inter/active: interactive media, narrative control and reconceiving audience history'. New media $\xi^{\circ}$ society 8.1 (2006): 139-58.

Crane, Susan. 'The writing lesson of 1381'. Chaucer's England: literature in historical context. Ed. Barbara A. Hanawalt. Minneapolis: University of Minnesota Press, 1992. 201-23. 
Crocker, Holly. 'Introduction: how open, or, can vulnerability go digital?' Online at https://postmedieval-forum.com/forums/forum-v-publicmiddle-ages/introduction-the-public-middle-age/ Accessed 29 Oct. 2017.

Cross, Roseanna. "'Heterochronia” in Thomas of Erceldoune, Guingamor, "The Tale of King Herla," and the story of Meriadoc'. Neophilologus 92:1 (2008). 163-75.

Curtius, Ernst Robert. European literature and the Latin Middle Ages. Transl. Willard R. Trask. Princeton: Princeton University Press, 1990.

Dagenais, John. Ethics of reading in manuscript culture: glossing the Libro de Buen Amor. Princeton: Princeton University Press, 1994.

Dean, James M., ed. Medieval English political writings. Kalamazoo, MI: Medieval Institute Publications, 1996.

Deansely, Margaret. The Lollard Bible and other medieval biblical versions. Cambridge: Cambridge University Press, 1920.

Delany, Paul. 'Hypertext, hypermedia and literary studies: the state of the art'. Hypermedia and literary studies. Ed. Paul Delany and George P. Landow. Cambridge, MA: MIT Press, 1991 (repr. 1994).

Deleuze, Gilles. Cinema 1: the movement-image. Trans. H. Tomlinson and B. Habberjam. Minneapolis: University of Minnesota Press, 1986.

Deleuze, Gilles, and Felix Guattari. A thousand plateaus: capitalism and schizophrenia. Trans. Brian Massumi. Minneapolis and London: University of Minnesota, 1987.

Despres, Denise. 'Ecstatic reading and missionary mysticism: the Orcherd of Syon'. Prophets abroad: the reception of continental holy women in latemedieval England. Ed. Rosalynn Voaden. Cambridge: D. S. Brewer, 1996. 141-60.

Deville, Michel. 'How not to die in Venice: the art of Arakawa and Madeline Gins'. Architectures of poetry. Ed. María Eugenia Díaz Sánchez and Craig Douglas Dworkin. Amsterdam and New York: Rodopi, 2004.

Dewdney, Andrew and Peter Ride. The digital media handbook. $2^{\text {nd }}$ ed. New York: Routledge, 2014.

de Jong, Mayke, Frans Theuws, and Carine van Rhijn, eds. Topographies of power in the Middle Ages. Leiden: Brill, 2001.

Dickens, Arthur G. 'The Tudor-Percy emblem in Royal MS. 18 D ii'. The Archaeological Fournal 112 (1956): 95-9.

Dinshaw, Carolyn. How soon is now? Medieval texts, amateur readers, and the queerness of time. Durham, NC and London: Duke University Press, 2012.

Drucker, Joanna. 'Performative materiality and theoretical approaches to interface'. Digital Humanities quarterly 7:1 (2013). Online at www. digitalhumanities.org/dhq/vol/7/1/000143/000143.html. Accessed 29 Oct. 2017. 
Dugdale, William. History of St Paul's. London: Thomas Warren, 1658.

Dunlop, Fiona S. 'Mightier than the sword: reading, writing and noble masculinity in the early sixteenth century'. Representing medieval genders and sexualities in Europe: construction, transformation, and subversion, 600-1530. Woodbridge, UK and Burlington, VT: Ashgate, 2011. $161-72$.

Ebin, Lois. Fohn Lydgate. Boston: Twayne, 1985.

Edwards, A. S. G. 'Middle English inscriptional verse texts'. Texts and their contexts: papers from the Early Book Society. Ed. John Scattergood and Julia Boffey. Dublin: Four Courts Press, 1997. 26-43.

Eisenstein, Elizabeth. The printing press as an agent of change: communications and cultural transformations in early-modern Europe. 2 vols. Cambridge: Cambridge University Press, 1979.

Emery, Anthony. Greater medieval houses of England and Wales, 13001500: volume 1, northern England. Cambridge: Cambridge University Press, 1996.

Engelsing, Rolf. 'Die perioden der lesergeschicte in der neuzeit'. Zur sozialgeschicte deutscher mittel-und untershicten. Gottingen: Vandenhoeck und Ruprecht, 1973. 112-54.

Ensslin, Astrid, and Alice Bell. 'New perspectives on digital literature: criticism and analysis'. dichtung-digital 37 (2007). Online at http:// dichtung-digital.de/editorial/2007.htm. Accessed 29 Oct. 2017.

Epstein, Robert. 'Eating their words: food and text in the coronation banquet of Henry VI'. Fournal of medieval and early modern studies 36:2 (Spring 2006). 355-77.

Eskelinen, Markku. Cybertext poetics: the critical landscape of new media literary theory. New York and London: Continuum, 2012.

Eve, Martin Paul. Open access and the humanities: contexts, controversies, and the future. Cambridge: Cambridge University Press, 2014.

Fein, Susanna, and Michael Johnston, eds. Robert Thornton and his books: essays on the Lincoln and London Thornton manuscripts. Woodbridge, UK: University of York Press, 2014.

Fisher, Matthew. Scribal authorship and the writing of history in medieval England. Columbus, OH: Ohio State University Press, 2012.

Fitzpatrick, Kathleen. Planned obsolescence: publishing, technology, and the future of the academy. New York: NYU Press, 2011.

Flannery, Mary C. Fohn Lydgate and the poetics of fame. Cambridge: Cambridge University Press, 2012.

Floyd, Jennifer. “'St. George and the 'steyned Halle”': Lydgate's Verse for the London Armourers'. Lydgate matters: poetry and material culture in the fifteenth century. Ed. Lisa H. Cooper and Andrea Denny-Brown. New York and London: Palgrave, 2008. 139-64.

Flügel, Ewald. 'Kleinere mitteilungen aus handschriften'. Anglia 14 (1892). 463-97. 
Ford, Judy Ann. Fohn Mirk's Festial: orthodoxy, Lollardy and the common people in fourteenth-century England. Cambridge: D. S. Brewer, 2006.

Foys, Martin. Virtually Anglo-Saxon: old media, new media, and early medieval studies in the late age of print. Gainesville: University Press of Florida, 2007.

Gaggi, Silvio. From text to hypertext: decentering the subject in fiction, film, the visual arts, and electronic media. Philadelphia: University of Pennsylvania Press, 1997.

Ganim, John M. Chaucerian theatricality. Princeton: Princeton University Press, 1990.

Ganim, John M., and Shayne Aaron Legassie. 'Introduction'. Cosmopolitanism and the Middle Ages. Ed. John M. Ganim and Shayne Aaron Legassie. New York: Palgrave Macmillan, 2013. 1-20.

Gell, Alfred. Art and agency: an anthropological theory. Oxford: Oxford University Press, 1998.

Genette, Gerard. Narrative discourse: an essay in method. Trans. Jane E. Lewin. Ithaca: Cornell University Press, 1983.

Gertsman, Elina. The dance of death in the Middle Ages: image, text, performance. Turnhout: Brepols, 2010.

Gervais, Bertrand. 'Is there a text on this screen? Reading in an era of hypertextuality'. A companion to digital literary studies. Ed. Susan Schreibman and Ray Siemens. Oxford: Blackwell, 2013. 183-202.

Gillespie, Alexandra. "“These proverbes yet do last”: Lydgate, the fifth earl of Northumberland, and Tudor miscellanies from print to manuscript'. The yearbook of English studies 33, Medieval and early modern miscellanies and anthologies (2003). 215-32.

Gillespie, Vincent. 'Anonymous devotional writings'. A companion to Middle English prose. Ed. A. S. G. Edwards. Cambridge: D. S. Brewer, 2004. 127-49.

—. 'The haunted text: reflections in A mirror to devout people'. The text in the community: essays on medieval works, manuscripts, authors, and readers. Ed. Jill Mann and Maura Nolan. South Bend, IN: University of Notre Dame Press, 2006. 129-72.

—_. 'Lukynge in haly bukes: lectio in some late medieval spiritual miscellanies'. Spätmittelalterliche geistliche literature in der nationalsprache, Band 2, Analecta Cartusiana 106. Ed. James Hogg. Salzburg: Institut für Anglistik und Amerikanistik, 1984. 1-27.

—. 'Vernacular books of religion'. Book production and publishing in Britain 1375-1475. Ed. Jeremy Griffiths and Derek Pearsall. Cambridge: Cambridge University Press, 1989. 317-44.

Gins, Madeline, and Arakawa. Architectural body. Tuscaloosa: University of Alabama Press, 2002.

Girouard, Mark. Life in the English country house: a social and architectural history. New Haven: Yale University Press, 1994. 
Goldie, Matthew Boyd. The idea of the Antipodes: place, people, and voices. New York: Routledge, 2010.

Goodall, John A. 'The great tower of Rochester Castle'. Medieval art, architecture, and archaeology at Rochester. Ed. Tim Ayers and Tim Tatton-Brown. Leeds: British Archaeological Association, 2006. 265-99. Green, Joshua, and Henry Jenkins. 'The moral economy of Web 2.0: audience research and convergence culture'. Media industries: history, theory, and method. Ed. Jennifer Holt and Alisa Perren. Malden, MA: Wiley-Blackwell, 2009. 213-25.

Griffiths, Jane. Diverting authorities: experimental glossing in manuscript and print. Oxford: Oxford University Press, 2014.

Grise, C. Annette. "In the blessed vyne[y]erd of oure holy saueour”: female religious readers and textual reception in the Myroure of oure ladye and the Orcherd of Syon'. The medieval mystical tradition: England, Ireland, and Wales. Ed. Marion Glasscoe. Cambridge: D. S. Brewer, 1999. 93-211.

—. 'Prayer, meditation, and women readers in late medieval England: teaching and sharing through books'. Texts and traditions of medieval pastoral care: essays in honour of Bella Millet. Ed. Cate Gunn and Catherine Innes-Parker. Woodbridge, UK: York Medieval Press, 2009. 178-92.

Gurevich, Aron. 'What is time'. Categories of medieval culture. Trans. G. L. Campbell. London: Routledge and Kegan Paul, 1985. 93-152.

Hall, David. Cultures of print: essays in the history of the book. Amherst: University of Massachusetts Press, 1996.

Hammond, Eleanor, ed., English verse between Chaucer and Surrey. New York: Octagon, 1965.

—. 'A reproof to Lydgate'. Modern language notes 26:3 (1911). 74-6.

Hanawalt, Barbara A., and Michal Kilbialka, eds. Medieval practices of space. Minneapolis: University of Minnesota Press, 2000.

Hanna, Ralph III. Pursuing history: Middle English manuscripts and their texts. Stanford: Stanford University Press, 1996.

Hanna, Ralph III, and A. S. G. Edwards, 'Rotheley, the De Vere circle, and the Ellesmere Chaucer'. Reading from the margins. Ed. Seth Lerer. San Marino: Huntington Library, 1996. 11-35.

Hansen, Mark. New philosophy for new media. Cambridge, MA: MIT Press, 2004.

—. 'Wearable space'. Configurations 10:2 (2002). 321-70.

Haraway, Donna. Simians, cyborgs, and women: the reinvention of nature. New York: Routledge, 1991.

Harbin, Andrea R. Space and movement on the medieval English religious stage. Dissertation, The Catholic University of America. 2006.

Hayles, N. Katherine. How we became posthuman: virtual bodies in cybernetics, literature, and informatics. Chicago and London: University of Chicago Press, 1999. 
- Writing machines. Cambridge, MA: MIT Press, 2002.

Hayles, N. Katherine et al., eds. Electronic literature collection, vol. 1 (2006), http://collection.eliterature.org. Accessed 29 Oct. 2017.

Hellinga, Lotte. Caxton in focus: the beginning of printing in England. London: British Library, 1982.

Heng, Geraldine. Empire of magic: medieval romance and the politics of cultural fantasy. New York: Columbia University Press, 2003.

Henisch, Bridget. Fast and feast: food in medieval society. University Park: Pennsylvania State University Press, 1976.

Higl, Andrew. Playing the Canterbury Tales: the continuations and additions. Farnham, UK and Burlington, VT: Ashgate, 2010.

Hirsch, John C. The revelations of Margery Kempe: paramystical practices in late medieval England. Leiden: E. J. Brill, 1989.

Holsinger, Bruce, and Elizabeth Robertson, eds. 'Vernacular theology and medieval studies: literary history and the religious turn'. English language notes 44:1 (2006). 77-137.

Hoyle, Richard W. 'Percy, Henry Algernon, sixth earl of Northumberland (c. 1502-1537)'. Oxford dictionary of national biography. Oxford University Press, 2004. Online edn, Jan 2008.

- The Pilgrimage of Grace and the politics of the 1530s. Oxford: Oxford University Press, 2001.

Hubbard, Phil, and Rob Kitchin, eds. Key thinkers on space and place. $2^{\text {nd }}$ ed. London: Sage, 2011.

Hudson, Anne. The premature Reformation: Wycliffite texts and Lollard history. Oxford and New York: Clarendon Press, 1988.

Hughes, Jonathan. 'Politics and the occult at the court of Edward IV'. Princes and princely culture: 1450-1650, vol. 2. Ed. Martin Grosman, Alasdair MacDonald, and Arie Vanderjagt. Leiden: Brill, 2005, 97-128.

Ingold, Tim. 'Materials against materiality'. Archaeological dialogues 14:1 (2007). 1-16.

Jenkins, Henry. Convergence culture. New York: New York University Press, 2008.

—. 'What happened before YouTube'. YouTube. Ed. Jean Burgess and Joshua Green. Cambridge: Polity Press, 2009. 109-25.

Jenkins, Henry, Sam Ford, and Joshua Green. Spreadable media: creating value and meaning in a networked culture. New York: New York University Press, 2013.

John, Nicholas A. 'Sharing and Web 2.0: the emergence of a keyword'. New media and society 15:2 (2012), 167-82.

Johns, Adrian. The nature of the book: print and knowledge in the making. Chicago: University of Chicago Press, 1998.

Johnson, Ian, and Allan F. Westphall. The Pseudo-Bonaventural lives of Christ: exploring the Middle English tradition. Turnhout, Belgium: Brepols, 2013. 
Johnson, Valerie. 'A forest of her own: greenwood-space and the forgotten female characters of the Robin Hood tradition'. Robin Hood in outlaw(ed) spaces: media, performance, and other new directions. Ed. Lesley Coote and Valerie B. Johnson. London and Burlington, VT: Ashgate Press, 2017. 21-39.

Jones, Rodney H., and Christoph A. Hafner, Understanding digital literacies: a practical introduction. London and New York: Routledge, 2012.

Joy, Eileen A., and Craig Dionne, eds. When did we become post/human? Special issue of postmedieval 1:1-2 (2010).

Joy, Eileen A., and Myra J. Seaman. 'Through a glass, darkly: medieval cultural studies at the end of history'. Cultural studies of the modern Middle Ages. Ed. Eileen A. Joy, Myra J. Seaman, Kimberly K. Bell, and Mary K. Ramsey. New York: Palgrave, 2007. 1-22.

Kaiser, Gert. Der tanzende tod. Mittelalterliche totentänze. Frankfurt am Main: Insel, 1983.

Keene, Derek, Arthur Burns, and Andrew Saint, eds. St Paul's: the cathedral church of London 604-2004. New Haven and London: Yale University Press, 2004.

Kerby-Fulton, Katherine. Books under suspicion: censorship and tolerance of revelatory writing in late medieval England. Notre Dame, IN: Notre Dame University Press, 2006.

Kerby-Fulton, Katherine, and Denise Despres. Iconography and the professional reader: the politics of book production in the Douce Piers Plowman. Minneapolis: University of Minnesota Press, 1999.

King, Andy, and Claire Etty. England and Scotland, 1286-1603. London: Palgrave, 2016.

King, Andy, and Michael A. Penman, eds. England and Scotland in the fourteenth century: new perspectives. Woodbridge, UK: Boydell, 2007.

Kirschenbaum, Matthew. Mechanisms: new media and the forensic imagination. Cambridge, MA: MIT University Press, 2008.

Kline, Daniel T. 'Father Chaucer and the Siege of Thebes: literary paternity, aggressive defense, and the prologue to Lydgate's Oedipal Canterbury Tale'. The Chaucer review 34 (1999). 217-35.

Knight, Jeffrey. Bound to read: compilations, collections, and the making of Renaissance literature. Philadelphia: University of Pennsylvania Press, 2013.

Koskimaa, Raine. 'Approaches to digital literature: temporal dynamics and cyborg authors'. Reading moving letters: digital literature in research and teaching. Ed. Roberto Simanowski, Jörgen Schäfer, and Peter Gendolla. Bielefeld: Verlag, 2010. 129-44.

_. 'Playing with time in digital fiction'. International journal of transmedia literacy 1:1 (2015). 19-33.

Kiousis, Spiro. 'Interactivity: a concept explication'. New media and society 4:3 (2002): 355-83. 
Krug, Rebecca. Reading families: women's literate practice in late medieval England. Ithaca: Cornell University Press, 2006.

Kurzweil, Ray. 'The future of libraries, part 2: the end of books'. Library journal (15 February 1992). 140-1.

LaFarge, Paul. 'Why the book's future never happened'. Salon.com. 4 October 2011. Online at www.salon.com/2011/10/04/return_of_hypertext/. Accessed 29 Oct. 2017.

Lancashire, Anne. London civic theatre: city drama and pageantry from Roman times to 1558. Cambridge: Cambridge University Press, 2002.

Landow, George P. Hypertext 3.0: critical theory and digital media in an era of globalization. Baltimore: Johns Hopkins University Press, 2006.

Lang, Elon. Hoccleve and the poetics of reading. Dissertation, Washington University in St Louis. 2010.

Le Goff, Jacques. Time, work and culture in the Middle Ages. Trans. A. Goldhammer. Chicago and London: University of Chicago Press, 1980.

Lepine, David. A brotherhood of canons serving God: English Secular cathedrals in the later Middle Ages. Woodbridge, UK: Boydell, 1995.

Lerer, Seth. Chaucer and his readers: imagining the author in late-medieval England. Princeton: Princeton University Press, 1993.

Limbu, Marohang. 'Digital and global literacies in networked communities: epistemic shifts and communications in the cloud era'. Digital rhetoric and global literacies: communication modes and digital practices in the networked world. Ed. Gustav Verhulsdonck and Marohang Limbu. Hershey, PA: IGI Global, 2014. 131-53.

Lindenbaum, Sheila. 'London texts and literate practice'. The Cambridge history of medieval English literature. Ed. David Wallace. Cambridge: Cambridge University Press, 1999. 284-309.

Lister, Martin et al., eds. Digital media: a critical introduction. New York: Routledge, 2003.

Liu, Ziming. Paper to digital: documents in the Information Age. Westport, CT: Greenwood Publishing, 2008.

Marks, Laurie. Touch, sensuous theory and multisensory media. Minneapolis: University of Minnesota Press, 2002.

Masson, Cynthea. 'Poetry and pedagogy in Norton's Ordinal of alchemy'. Florilegium 17 2000. 45-58.

Masten, Jeffrey, Peter Stallybrass, and Nancy Vickers. 'Introduction: language machines'. Language machines: technologies of literary and cultural production. Ed. Jeffrey Masten, Peter Stallybrass, and Nancy J. Vickers. London and New York: Routledge, 1997. 1-16.

Mazzoni, Cristina. The women in God's kitchen: cooking, eating, and spiritual writing. New York and London: Continuum, 2005.

McCormick, Betsy. 'Afterword: medieval ludens'. Games and gaming in medieval literature. Ed. Serina Patterson. New York: Palgrave, 2015. 209-22. 
McGrady, Deborah. Controlling readers: Guillaume de Machaut and his late medieval audience. Toronto: University of Toronto Press, 2006.

McKitterick, David. Print, manuscript and the search for order, 1450-1830. Cambridge: Cambridge University Press, 2003.

McMahan, Alison. 'Immersion, engagement, and presence: a method for analyzing 3-D video games'. The video game theory reader. Ed. Mark J. P. Wolf and Bernard Perron. New York and London: Routledge, 2003. 67-86.

McNamer, Sarah. Affective meditation and the invention of medieval compassion. Philadelphia: University of Pennsylvania Press, 2009.

McNeill, John. 'The continental context'. Fournal of the British Archaeological Association 159 (2006). Special issue on The medieval cloister in England and Wales. Ed. Martin Henig and John McNeill. $1-47$.

McNelis, James I. The uncollated manuscripts of The Master of Game. Dissertation, University of Washington, 1996.

Meakin, Heather L. The painted closet of Lady Anne Bacon Drury. Farnham, UK and Burlington, VT: Ashgate, 2013.

Meale, Carol M. "“oft sipis with grete devotion I thought what I might do pleysyng to god”: The early ownership and readership of Love's Mirror, with special reference to its female audience'. Nicholas Love at Waseda: proceedings of the international conference 20-22 Fuly 1995. Ed. Shoichi Oguro, Richard Beadle, and Michael Sargent. Cambridge: D. S. Brewer, 1997. 19-46.

Meyer-Lee, John. 'Lydgate's laureate pose'. Fohn Lydgate: poetry, culture, and Lancastrian England. Ed. Larry Scanlon and James Simpson. South Bend, IN: University of Notre Dame Press, 2006. 36-60.

- Poets and power from Chaucer to Wyatt. Cambridge: Cambridge University Press, 2007.

Michalove, Sharon D. 'The education of aristocratic women in fifteenthcentury England'. Estrangement, enterprise and education in fifteenthcentury England. Ed. Sharon D. Michalove and A. Compton Reeves. Stroud: Sutton, 1998. 117-39.

Middle English Dictionary (MED). https:/quod.lib.umich.edu/m/med/, 2017. Accessed 29 Oct. 2017.

Millar, Bonnie. The Siege of Ferusalem in its physical, literary and historical contexts. Dublin and Portland, OR: Four Courts Press, 2000.

Miller, Hills J. Ariadne's thread: story lines. New Haven and London: Yale University Press, 1992.

Minnis, Alastair. Medieval theory of authorship: scholastic literary attitudes in the later Middle Ages. $2^{\text {nd }}$ ed. Philadelphia: University of Pennsylvania Press, 2010.

Mintz, Sidney. 'Color, taste, and purity: some speculations on the meanings of marzipan’. Etnofoor 4:1 (1991). 103-8. 
Mooney, Linne R. 'Scribes and booklets of Trinity College Cambridge, Manuscripts R.3.19 and R.3.21'. Middle English poetry: texts and traditions; essays in honour of Derek Pearsall. Ed. Alastair J. Minnis. Woodbridge, UK: Boydell, 2001. 241-66.

Mosser, Daniel W. 'The two scribes of the Cardigan Manuscript and the "evidence" of scribal supervision and shop production'. Studies in bibliography 39 (1986). 112-25.

Moulthrop, Stuart. 'For thee: a response to Alice Bell'. Electronic Book Review. 21 January 2011. Online at http://electronicbookreview.com/ thread/electropoetics/networked. Accessed 29 Oct. 2017.

—. 'You say you want a revolution? Hypertext and the laws of media'. The new media reader. Ed. Noah Wardrip - Fruin and Nick Montfort. Cambridge, MA: MIT Press, 2003. 691-704.

Müller, Christian. Hans Holbein d. F. die druckgraphik im kupferstichkabinett Basel. Basel: Schwabe, 1997.

Murphy, Órla. 'Intermediality: experiencing the virtual text'. Readings on audience and textual materiality. Ed. Graham Allen, Carrie Griffin, and Mary O'Connell. London and Brookfield, VT: Pickering and Chatto, 2011. 155-62.

Murphy, Priscilla Coit. 'Books are dead, long live books'. Rethinking Media change: the aesthetics of transition. Ed. David Thorburn and Henry Jenkins. Cambridge, MA: MIT Press, 2004. 81-94.

Murray, Janet. Hamlet on the holodeck: the future of narrative in cyberspace. New York: Free Press, 1997.

Newman, Barbara. Sister of wisdom: St. Hildegarde's theology of the feminine. Berkeley: University of California Press, 1987.

Nichols, Stephen G. 'Introduction: philology in a manuscript culture'. Speculum 65:1 (Jan. 1990). 1-10.

Noonan, Sarah. "Bycause the redyng shold not turne hem to enoye": reading, selectivity, and pietatis affectum in late medieval England'. New medieval literatures 15 (2013). 225-54.

Obermeier, Anita. The history and anatomy of auctorial self-criticism in the European Middle Ages. Amsterdam: Rodopi, 1999.

Oosterwijk, Sophie. 'Death, memory and commemoration: John Lydgate and "Macabrees Daunce” at Old St Paul's Cathedral, London'. Memory and commemoration in Medieval England. Proceedings of the 2008 Harlaxton Symposium. Ed. Caroline M. Barron and Clive Burgess, Harlaxton Medieval Studies 20. Donington, UK: Shaun Tyas, 2010. 185-201.

—. 'Money, morality, mortality: the migration of the danse macabre from murals to misericords'. Freedom of movement in the Middle Ages. 2003 Harlaxton Symposium Proceedings. Ed. Peregrine Horden. Harlaxton Medieval Studies 15. Donington, UK: Shaun Tyas, 2007. 37-56.

Paloff, Benjamin. 'Digital Orpheus: The hypertext poem in time'. Fournal of Electronic Publishing 14:2 (Fall 2011). Online at http://dx.doi. org/10.3998/3336451.0014.211. Accessed 29 Oct. 2017. 
Parkes, Malcolm B. English cursive book hands 1250-1500. Oxford: Clarendon Press, 1969.

- 'The influence of the concepts of ordinatio and compilatio on the development of the book'. Scribes, scripts and readers. London: Hambledon Press, 1991.

Parshall, Peter. 'Hans Holbein's Pictures of death'. Hans Holbein: paintings, prints and reception. Ed. Mark Roskill and John Oliver Hand. Washington: National Gallery of Art, 2001. 83-95.

Partridge, Stephen. 'Designing the page'. The production of books in England 1350-1500. Ed. Alexandra Gillespie and Daniel Wakelin. Cambridge: Cambridge University Press, 2011. 79-103.

Partridge, Stephen, and Erik Kwakkel, eds. Author, reader, book: medieval authorship in theory and practice. Toronto: University of Toronto Press, 2012.

Patterson, Lee. 'Making identities in fifteenth-century England: Henry V and John Lydgate'. New historical literary study: essays on reproducing texts. Ed. Jeffrey N. Cox and Larry J. Reynolds. Princeton: Princeton University Press, 1993. 69-107.

Patterson, Serina, ed. Games and gaming in medieval literature. New York: Palgrave, 2015.

Payne, Robert. The promiscuity of network culture: queer theory and digital media. New York: Routledge, 2015.

Perry, Ryan. “some sprytuall matter of gostly edyfycacion”: readers and readings of Nicholas Love's "Mirror of the blessed life of Jesus Christ". The Pseudo-Bonaventuran lives of Christ. Ed. Ian Johnson and Allan F. Westphall. Turnhout: Brepols, 2013. 79-126.

Pope, James. 'A future for hypertext fiction'. Convergence: the international journal of research into digital media technologies 12:4 (2006). 447-65.

Prendergast, Thomas Augustine. Chaucer's dead body: from corpse to corpus. New York: Routledge, 2004.

Price, Leah. How to do things with books in Victorian Britain. New Haven: Princeton University Press, 2012.

Raguin, Virginia Chieffo, and Sarah Stanbury, eds. Women's space: patronage, place, and gender in the medieval church. Albany, NY: State University of New York Press, 2005.

Rettberg, Jill Walker. 'Feral hypertext: when hypertext literature escapes control'. The international handbook of internet research. Ed. Jeremy Hunsinger, Lisbeth Klastrup, and Matthew Allen. Dordrecht and London: Springer Verlag, 2010. 477-93.

Robertson, Kellie. 'Medieval materialism: a manifesto'. Exemplaria 22:2 (Summer 2010). 99-118.

Rosenzwieg, Roy, and Steve Brier. 'Historians and hypertext: is it more than hype?' Clio wired: the future of the past in the digital age. Ed. Roy Rosenzwieg. New York: Columbia University Press, 2011. 85-91. 
Rosewell, Roger. Medieval wall paintings in English and Welsh Churches. Woodbridge, UK: Boydell, 2011.

Rouse, Richard H., and Mary A. Rouse. Authentic witnesses: approaches to medieval texts and manuscripts. South Bend, IN: University of Notre Dame Press, 1991.

— - 'Statim invenire: schools, preachers and new attitudes to the page'. Renaissance and renewal in the twelfth century. Ed. Robert L. Benson and Giles Constable. Cambridge, MA: Harvard University Press, 1982. 191-335.

Rudy, Kathryn M. Virtual pilgrimages in the convent: imagining Ferusalem in the late Middle Ages. Turnhout: Brepols, 2011.

Rust, Martha, ed. Imaginary worlds in medieval books: exploring the manuscript matrix. New York: Palgrave, 2007.

Ryan, Marie-Laure. Narrative as virtual reality: immersion and interactivity in literature and electronic media. Baltimore: Johns Hopkins University Press, 2003.

Saenger, Paul. 'Books of hours and the reading habits of the later Middle Ages'. The culture of print: power and the uses of print in early modern Europe. Princeton: Princeton University Press, 1989. 141-73.

- Space between words: the origins of silent reading. Stanford: Stanford University Press, 1997.

Safran, Linda. 'Public textual cultures: a case study in southern Italy'. Textual cultures of medieval Italy. Ed. William Robins. Toronto: University of Toronto Press, 2011. 115-44.

Salter, Anastasia. What is your quest? From adventure games to interactive books. Iowa City: University of Iowa Press, 2014.

Salter, Elisabeth, and Helen Wicker. Vernacularity in England and Wales, c. 1300-1500. Turnhout, Belgium: Brepols, 2011.

Sánchez Martí, Jordi. 'Longleat House MS 257: a description'. Atlantis 27:1 (June 2005). 79-89.

Sargent, Michael G. 'Organic and cybernetic metaphors for manuscript relations: stemma-cladogram-rhizome-cloud'. The PseudoBonaventuran lives of Christ. Ed. Ian Johnson and Allan F. Westphall. Turnhout: Brepols, 2013. 197-263.

Schirmer, Elizabeth. 'Reading lessons at Syon Abbey: the Myroure of oure ladye and the mandates of vernacular theology'. Voices in dialogue: reading women in the Middle Ages. Ed. Linda Olson and Katherine Kerby-Fulton. South Bend, IN: University of Notre Dame Press, 2005. 345-76.

Schirmer, Walter. Fohn Lydgate: a study in the culture of the fifteenth century. London: Methuen, 1961.

Schofield, John. St Paul's Cathedral before Wren. Swindon, UK: English Heritage, 2011.

Sheller, Mimi. 'Virtual islands: mobilities, connectivity, and the new Caribbean spatialities'. Small Axe 11:3 (October 2007). 16-33. 
Shep, Sydney J. 'Digital materiality'. A new companion to digital humanities. Ed. Susan Schreibman and John Unsworth. Chichester, West Sussex: John Wiley \& Sons, Ltd, 2016.

Sherman, William H. Used books: marking readers in renaissance England. Philadelphia: University of Pennsylvania Press, 2007.

Shipperbottom, Roy. 'Precious metals on food'. Look and feel: studies in texture, appearance and incidential characteristics of food: proceedings of the Oxford symposium on food and cookery 1993. Ed. Harlan Walker. Devon, UK: Prospect Books, 1994. 211-14.

Shippey, Tom. 'Bibliophobia: hatred of the book in the Middle Ages'. The Matthews memorial lectures for 1999. London: Birkbeck College, forthcoming. Online at http://bbk.ac.uk/english/about-us/bibliophobiahatred-of-the-book-in-the-middle-ages. Accessed 29 Oct. 2017.

Siemens, Ray et al. 'Human-computer interface/interaction and the book: a consultation-derived perspective on foundational e-book research'. Collaborative research in the digital humanities. Ed. Marilyn Deegan and Willard McCarty. Farnham, Surrey: Ashgate, 2012. 163-90.

Simpson, James. "'Dysemol daies and fatal houres”: Lydgate's Destruction of Thebes and Chaucer's Knight's Tale'. The long fifteenth century. Ed. Douglas Gray, Helen Cooper, and Sally Mapstone. Oxford: Clarendon Press, 1997. 15-34.

Simpson, Percy. Proof-reading in the sixteenth, seventeenth, and eighteenth centuries. Oxford: Oxford University Press, 1935, repr. 1970.

Smyth, Karen Elaine. Imaginings of time in Lydgate and Hoccleve's verse. Farnham: Ashgate, 2011.

Somerset, Fiona, and Nicholas Watson, eds. Truth and tales: cultural mobility and medieval media. Columbus, OH: Ohio State University Press, 2015.

- The vulgar tongue: medieval and postmedieval vernacularity. University Park, PA: Pennsylvania State University Press, 2003.

Spearing, Anthony C. Medieval autographies: the ' $I$ ' of the text. South Bend, IN: University of Notre Dame Press, 2012.

Sponsler, Claire. The queen's dumbshows: Fohn Lydgate and the making of early theater. Philadelphia: University of Pennsylvania Press, 2014.

- ' 'Text and textile: Lydgate's tapestry poems'. Medieval fabrications: dress, textiles, clothwork, and other cultural imaginings. Ed. E. Jane Burns. New York: Palgrave Macmillan, 2004. 19-34.

Stow, John. A Survey of London: reprinted from the text of 1603, vol. 1. Oxford: Clarendon Press, 1908.

Strohm, Paul. 'Chaucer's fifteenth-century audience and the narrowing of the "Chaucer Tradition"”. Writing after Chaucer: essential readings in Chaucer and the fifteenth century. Ed. Daniel J. Pinti. New York and London: Garland Publishing, 1998, 107-8.

Suber, Peter. Open access. Cambridge, MA: MIT Press, 2012.

Sutherland, Anne. 'Performing the penitential Psalms in the Middle 
Ages'. Aspects of the performative in medieval culture. Ed. Manuele Gragnolati and Almut Suerbaum. Berlin and New York: Walter de Gruyter, 2010. 15-38.

Sutton, James. Materializing space at an early modern prodigy house: the Cecils at Theobalds, 1564-1607. Aldershot, UK and Burlington, VT: Ashgate, 2004.

Thérien, Gilles. Sémiologies. Montreal: Université du Québec à Montréal, 1985.

Trigg, Stephanie. Congenial souls: reading Chaucer from medieval to postmodern. Minneapolis: University of Minnesota Press, 2002.

Wakelin, Daniel. 'Instructing readers in fifteenth-century poetic manuscripts'. Huntington Library quarterly 73:3 (September 2010). 433-52.

- Scribal correction and literary craft: English manuscripts 1375-1510. Cambridge: Cambridge University Press, 2014.

Wardrip-Fruin, Noah. 'Blog-based peer review: four surprises'. Grand text auto, 12 May 2009. Online at https://grandtextauto.soe.ucsc. edu/2009/05/12/blog-based-peer-review-four-surprises/. Accessed 29 Oct. 2017.

Watson, Nicholas. 'Censorship and cultural change: vernacular theology, the Oxford translation debate, and Arundel's Constitutions of 1407'. Speculum 70:4 (1995). 822-64.

—_. 'Melting into God the English way: deification in the Middle English version of Marguerite Porete's Mirouer des simples âmes anienties'. Prophets abroad: the reception of continental holy women in late-medieval England. Ed. Rosalynn Voaden. Cambridge: D. S. Brewer, 1996. 19-49

Webman, Rob C. The crisis of music in early modern Europe, 1470-1530. New York and London: Routledge, 2005.

Wieck, Roger S. Time sanctified: the book of hours in medieval art and life. New York: George Braziller, 1988.

Wilson, Christopher. 'Rulers, artificers, and shoppers: Richard II's remodelling of Westminster Hall, 1393-99'. The regal image of Richard II and the Wilton Diptych. Ed. Dillian Gordon, Lisa Monnas, and Caroline Elam. Coventry: Harvey Miller, 1997. 33-59.

Windeatt, 'The scribes as Chaucer's early critics'. Writing after Chaucer: essential readings in Chaucer and the fifteenth century. Ed. Daniel Pinti. New York: Routledge, 1998. 27-44.

Wogan-Browne, Jocelyn et al. Idea of the vernacular: an anthology of Middle English literary theory, 1280-1520. Philadelphia: University of Pennsylvania Press, 1999.

Woolgar, Chris M. The Great House in late medieval England. New Haven: Yale University Press, 1999.

Ziegler, Henning. 'When hypertext became uncool: notes on power, politics, and the interface'. dichtung-digital 27 (2003). n.p. Web. Online at www.dichtung-digital.de/2003/issue/1/ziegler/index.htm. Accessed 29 Oct. 2017. 


\section{Index}

agency $3-5,14,17,34,47,49,50$, $67,69,71-4,78,82,87-8$, 91-4, 107, 117, 119, 121, $122,157,172,183,185,189$, 196-200

Alexander the Great 133, 134 Anglo-Norman see French of England

annotations see marginalia

Anselm 63, 65

Orationes sive meditationes 63

Arakawa and Madeline Gins 136-8 architectural bodies 136-7, 138-9, 142,158

architecture see reading and architecture

architext 156-7

Aristotle 130, 133, 134

Arundel's Constitutions 48, 50

Aske, Robert 154

assemblages see networks

assemble de dyeus, Le 141

Augustine 17

authority

and architecture 116, 157

of the king 111, 116

of the Percy family 130, 153

of place 153

of print 52

of prophecy 180

of readers $1-2,9-10,13,19,39$, $45,47-50,64,68,71,74,83$, $85,88,91-4,194-5$ of scribes 53-4, 94

in Troilus and Criseyde 197

of writers 1-2, 9-10, 18, 27-30, $39,45,47-50,52-4,64,67$, $71,74,77,83,88,91,93$, 193-6

authorship 18, 29, 38, 49, 51, 195

'Blsyoure of the arms of kyngis, The' 141

bodies see reading and bodies

Bodleian MS selden supra 53 199-200

Boleyn, Anne 154

Bonaventure, St 53-4

book as body 137, 176-7

Book of common prayer, The 62-3, 95

books of hours 9, 16, 17, 62, 65, 69, 168

Burgh, Benedict 133-4

Capgrave, John 50

Carpenter, John 144, 145

Catherine of Siena 64, 66, 93

Catherine of Valois 112, 113

Caxton, William 8, 27, 40-1, 43-5, $51,53-5,194$

Chaucer, Geoffrey 8, 11, 13, 27, 29-39, 45-6, 48, 51, 54, 70, 80-1, 83, 85-91, 93, 195-7, 199-200 
'Adam Scriveyn' 30, 36

Canterbury Tales 6, 14, 18, 35, $45,70-1,76,80-3,86-8,90-1$, 93, 179, 198-9

Troilus and Criseyde 13, 29-34, 45, 48, 196-7, 198-9

Wife of Bath 18, 196, 198-9

closed access see editing, closedaccess

collaboration $33,38-41,45,53$, 94, 195

collective writing and reading see compilation

compilation (also collective writing and reading) 50, 62-4, 70, 77, 80, 91, 134

consumption $37,66,68,95$,

$$
112-15,117
$$

control 5, 10, 14-15, 30, 35-7, 49, $52-3,67,69,72-4,77,80$, 92-4, 201

convergence (of media) 3, 41, 72, 109, 114, 121, 176-7, 185, 187-8

copyright 38-9

Cornish, William 141

Cotton Julius B.i 111-12

Cromwell, Thomas 154

dance 150

danse macabre 6, 16, 142-58, 199

Deleuze, Gilles 30, 51, 135-7, 141

De re militari 173

digital media 2-19, 28, 38-9, 42, $47,49,62-3,71-3,82,87$, 94-5, 107-9, 121, 129, 135-6, 168-9, 172, 175-6, 201

Distichs of Cato 133-4

division of texts see textual organization

doodles see marginalia

Drucker, Joanna 107, 109, 123

editing, closed-access 13, 28, 40, $43,47,88$ editing, crowd-sourced see editing, open access

editing, open access (also crowdsourced) $13,28,35,37-8$, 40-2, 44, 46-8, 51, 54-5

embodiment see reading, and embodiment

emendation see reading, corrective

emendation invitation 12,13 , 27-56, 63, 188

ephemerality see reading and ephemerality

Eskelinen, Markku 169, 173, 174

extracodexical texts $5,15,106-7$, 110-13, 115, 117, 119, 122, 128-9, 157-8

Fox, Richard 184

frame (and framing function) 135-6, 137

French of England 27, 28, 52, 184

Genette, Gerard 169, 173

gesture 73, 110, 119-20

Gibson, William 169

Gins, Madeleine and Arakawa 136-8

glosses see marginalia

Google Earth 152

Gower, John 13, 29-32, 35, 39, 45-6,

Gutenberg parenthesis 7-8

hagiographies 27,142

haptic visuality 121

Hansen, Mark 129, 135-8, 142

Harley 342374

Hayles, N. Katherine 107, 109

Henry V 111, 113

Henry VI coronation banquet 15, 110-20

Henry VIII 154 
Henryson, Robert 105, 106-7, 110, 122-3

'Abbey Walk' 105-7, 110, 112-13, 122-3

Herbert, Maud 140

Herbert, Sir William, first Earl of Pembroke 140

Hoccleve, Thomas 1-2, 167-8, 177, 193-4, 199

'Complaint' 199

Dialogue with a friend 167-8, 194

'Jereslaus' Wife' 1, 167, 193-4

Holbein, Hans 143

Housewife, Robert 186

Hull, Eleanor 17, 177, 184-7

Commentary on the penitential Psalms 17, 177, 184-7

Meditations on the days of the week 184, 186

humility topos 12, 27-8, 30, 41

hybrid reading practices see reading, hybrid

hypertext 4, 14, 63, 72, 82, 170, 171

interaction 1-19, 32, 38, 40-3, 49-51, 54, 106, 110, 117, 119, $122,129,136,150-2,156$, 167, 180, 193-4

Itinerary of Fohn Leland 132-3

Jerome, St 114

Kirschenbaum, Matthew 107, 108

Koskimaa, Raine 175-6

landing sites 136-40, 147-53, 155, $156-8$

layout of texts see textual organization

Leconfield, Percy family estate 16 , 130-4, 138-41, 157, 174

Leland, John 132, 133

Les Saints Innocents, Paris 143

lexia (and nodes) 14, 62, 63, 72, 73, $75,77,78,82,170,171$
Liber Albus 145

Lincoln Cathedral Library MS 91 178, 183

links (in media) 3, 4, 14, 63, 72, 77, 80-2, 170, 201

literacy

American 201

medieval 1, 7, 9, 16, 40, 42, 52, 54, 95, 108, 193, 195

literary foundations 83-8, 114

Longleat House MS 257 90-1

Lydgate, John 13-15, 16, 27, 29, $32-5,37,39-46,48,50,53$, 54, 71, 78, 80-94, 110-13, 120, 122-3, 130, 141, 142-5, 148, 150-4, 156, 168, 174, 194, 199, 200

Daunce of Poulys 16, 142

Fall of princes 27, 46, 199-200

Mumming at Windsor 200

'Reignes of the Kinges of England' 141

Siege of Thebes 14-15, 71, 78, 80-8, 90-4, 130, 141, 168

'Soteltes for the coronation banquet of Henry VI' 15, 110-15, 119, 122-3, 174

Stans puer ad mensam 50

'Testament' 141

Troy book 13, 32-4, 41-2, 45-6, $48,52,130,141$

Machaut, Guillaume 53

manuscript culture $3,5-6,8,12$, $13,15-16,18,28,31,32$, 41, 43, 51-6, 73, 88-92, 95, 106-10, 174-5, 201

manuscript matrix 108, 111, 115 marginalia 10, 12-13, 18, 31-2, 46, $74,79,144$

materiality forensic 108-9, 113-14, 117, 123

participatory $111,117-23,175$ performative $15,109,116-17$ 
formal 108-9, 111, 113-17, 121, 122, 123, 169-70, 176

see also reading and materiality meditatio 114

Merleau-Ponty, Maurice 108

Mirror of our lady 48

mise-en-page see textual

organization

More, Thomas 144, 145

movement see reading and mobility

MS Add. 1003690

MS Add. 3652390

multimedia 12,142

multimodality 150

M.898 89-90

networks (also assemblages) 14 ,

$18,51,77,80,82,94-5,141$, 182,183

new media see digital media

New Philology 108

nodes see lexia

nonreading see reading, and nonreading

Norton, Thomas 17, 29, 35-40, 48, $53,54,177,184,187-8$

Ordinal of alchemy 17, 35-6, 48, $52,177,184,187-8$

object-oriented ontology (OOO) 18, 107, 196

open-access see editing, openaccess

Orcherd of Syon 14, 64-74, 77-8, $81,88,92-4,96,170,171$, 173,183

organization of texts see textual organization

participation 1-19, 27-55, 64-72,

$74-5,79,80,88-9,93,105-7$, 109-11, 114-19, 121-3, 129, 137-9, 142-3, 148-53, 156, 157-8, 167-8, 171-5, 177-85, 187-8, 193-201
Peasants Revolt of 1381 see

Uprising of 1381

peer-review process 38-9, 46

Peeris, William 141

Percy family 16, 130-42, 146, 151-4, 156, 174

Percy, Henry, fourth Earl of Northumberland 130, 154

Percy, Henry Algernon, fifth Earl of Northumberland 130, 132, 154-5

Percy, Henry, sixth Earl of Northumberland 131-2

performance see reading and performance

phenomenology 107-8, 135, 136

Piers Plowman 53, 195

pilgrimage 16, 130, 152-6

Pilgrimage of Grace 154 place see reading and space

Poundstone, William 169 posthuman 16, 148, 150

Pricke of conscience 50

print culture $3-8,13,19,27-8$, 38-9, 43-5, 47, 51-2, 54-6, 94, 106, 136, 169, 193, 201

Prose siege of Ferusalem, the 89

Pseudo-Augustinian soliloquies 171, 183,187

readers

amateur see readers, nonprofessional devotional 62-95 passim and gender 13, 28, 44, 48-9, 51, $65,70,88$ nonprofessional 10, 34, 39, 41, 45,46

professional 10, 31, 32, 34, 41, $45,46,53,89,90$

Tudor 70

women $10,48-50,65,69-70$, 88 
reading

American 201

and architecture 16, 111, 115,

128-58, 193

associative $72,75,78,80,81$, $83-4,88,95,170$

collative $62,74,80$

corrective (and emendation)

7, 12-13, 27-56, 63, 64, 65, 69-70, 88, 91, 106, 109, 174,

$188,193,195,200$

devotional 10, 14, 62-95 passim,

110, 138, 176-7, 185, 194

and embodiment 12, 14, 16,

68-9, 95, 110, 114, 117, 120-3,

128-31, 135-9, 142, 147, 149,

156-8, 176-7, 193, 197-9

and emendation see reading, corrective

and ephemerality 49, 88, 174, 200

and genre 10-11, 29, 35, 36, 44, 70, 71, 110, 168, 172, 177

hybrid $14,30,35,38,44,48,71$, 80-8

and immersion $7,12,80,148$, 157, 194

Latinate 9, 10, 27, 47, 50, 63-4, $133,167,186,195$

and materiality $3,12,15-16,18$, $31,34,35-7,41,49,51-2,54$, $55,63,73,95,105-23,128-9$, 131, 137-8, 143, 156, 169-70, 174-7, 181, 193, 194, 196, 198-201

and mobility 12, 14-16, 65-9,

73, 105, 106, 110-11, 118-23, 128-9, 135-6, 138, 142, 143, 150-8, 193

model of 7

modes of 2, 5-7, 11, 13-18, 27-56, 62-95, 105-23, 128-58, 167-89

and movement see mobility and nonlinearity $7,12,13-15$, 17, 62-95, 106-7, 109, 168, 170-3, 184, 193

and nonreading 17-18, 193-201 as performance $137-8$ and place see reading and space proleptic $3,31,67,74,172,181$ retrospective 31 and space $12,15-16,19,66,69$, $85,105,110,115-16,118-19$, 122-3, 128-47, 149-52, 155-8, 172, 174, 193, 200, 201 and temporality (also time) 14, 16-17, 36, 53, 66, 68-9, 77, $82,83,150,156,167-89,193$, 194, 200, 201

Rolle, Richard 176-7

Roman de toute chevalrie 28

Royal 18.D.ii 16, 130, 132-3, 135, 138-42, 152, 155-6

Russell, John 50-1

R.3.21 (Trinity College, Cambridge MS) 16, 143-4

St Paul's Cathedral 16, 142-8, 151, 153, 156-7

Scotland 182, 183

Scottish Wars of Independence 182 scribes 10, 30, 32, 41, 45-6, 53-4, 72, 88, 89-92, 94-5, 144, 145, $173,174,200,201$

Sherrington, Walter 146

Shirley, John 156, 200

Siege of Ferusalem 75

Skelton, John 141, 194

Sopwell Priory 184, 186

space

virtual 16, 142, 150, 152

wearable 135-6

see also reading, and space

status

of objects 121

of readers $10,57,117$

of scribes 92

of writers $10,54,57,88$ 
stone $105,107,109-10,122$

Stowe, John 16, 144, 146

Strode (Ralph?) 13, 29-32, 35, 39, 45,46

Subtleties 111-23, 174, 196

Syon Abbey 48, 65, 69, 92, 94

technology

of the book $3,5,13,44,51-2$, 54,55 ,

of cinema and film 135-6

of the self 158

of reading 158

textual organization $10,15,62-7$, 69-70, 72-5, 77, 81-3, 88-90, $92,95,170,171,175$

time see reading, and temporality

Thomas of Erceldoune's prophecy $17,177-84$

Thomas of Kent 28

Thornton, Robert 178, 183

Titus and Vespasian 14-15, 71, 74-80, 81, 87-94

tourism, virtual 16, 152-6

transi-tombs 149

Trinity College Dublin MS 516

180
University of Chicago MS 564 199

Uprising of 1381, the 42

Usk, Thomas 194

video games 17, 80, 169, 194

virtual tourism see tourism, virtual

walking see reading, and mobility

wall texts $16,128-43,151-7,174$, 196 ,

Walter of Chatillon 63-4, 65

Wardrip-Fruin, Noah 38, 42, 46, 47

Grand text auto 38, 42

Westminster Abbey 146, 174

Westminster Great Hall 115-16, 118-21

Wikipedia 12, 38, 41

Wressel, Percy family estate 16 , $133-4$

Wycliffites 48,50

Yorkshire 130, 131, 132, 154, 178, 183 